UNIVERSIDADE DE SÃo PAULO

INSTITUTO DE FÍSICA E QUÍMICA DE SÃO CARLOS

DEPARTAMENTO DE FÍSICA E CIÊNCIA DOS MATERIAIS

\title{
MISTURA DE ONDAS EM MEIO KEŖR E BI-ESTABILIDADE ÓPTICA EM FILMES
}

EVANDRO JOSÉ TAVARES DE ARAUJO GOUVEIA

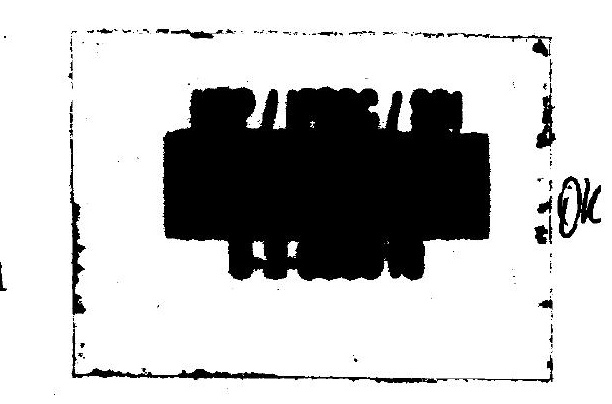

Tese apresentada ao Instituto de

Física e Química de São Carlos,

Universidade de São Paulo, para

obtenção do título de Doutor

em Ciências - "Física Aplicada".

Orientador: Prof. Dr. Jarbas Caiado de Castro Neto

São Carlos - SP

1992 
Av. Dr. Carlos Botelho, 1465 Caixa Postal 369

CEP 13560 - São Carlos - SP

Brasil

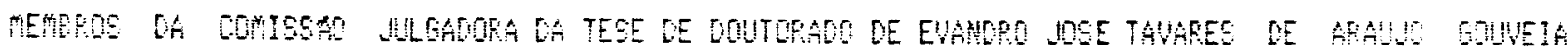

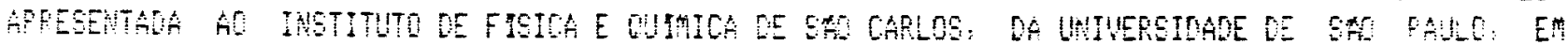
¿5. $3.19 \mathrm{~g}$

COEST MLGPAP:

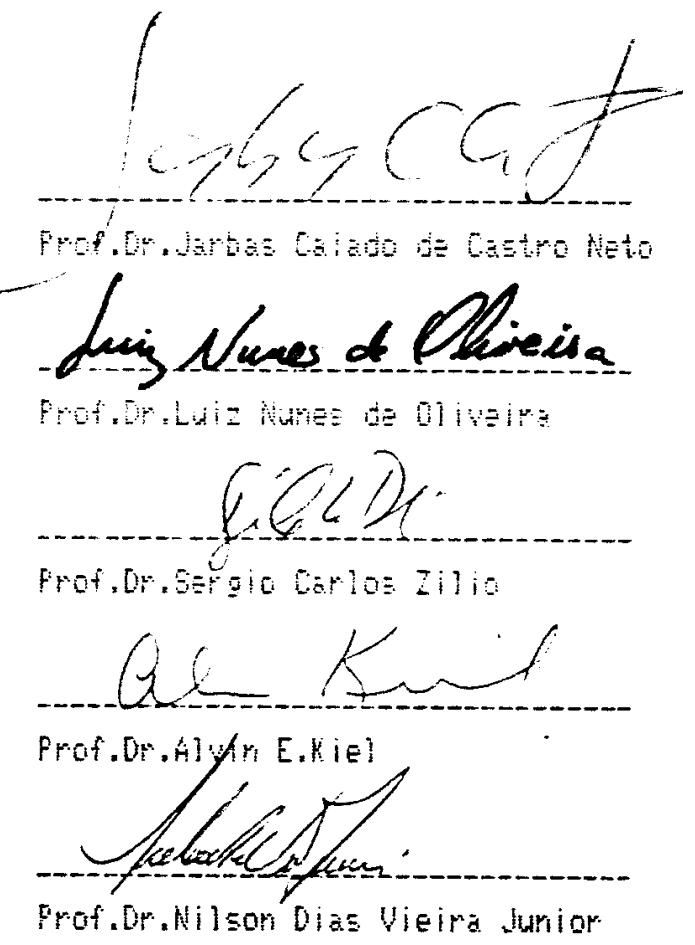


aos meus filhos

Marina e Hugo

aos meus pais

Edman $e$ Berenice

a minha irmã

Silvana

e à querida

Eneida 


\section{AGRADECIMENTOS}

- a Jarbas Caiado de Castro Neto pela sua orientação, dedicação e amizade.

- a Isabel Sertori pelo excelente trabalho de datilografia e apoio administrativo.

- a J.P. Andreeta por nos ceder as amostras de $\mathrm{GdAlO}_{3}: \mathrm{Cr}^{3+}$.

- a T. Catunda, A. Cansian, J.C. Penaforte, I. Guedes, L.A.O. Nunes e S.C. Zilio por participarem diretamente neste trabalho.

- a V.S. Bagnato por ceder seu laboratório para que parte do trabalho fosse concluída.

- a M. Siu Li pelo empréstimo de equipamentos.

- ao pessoal da oficina de óptica: Edivaldo, Marcos, Jonas, Fernando, os Robertos, Luiz, Romeu e Jae, pela presteza e dedicação quando da confeç̧ão dos diversos componentes ópticos que nós utilizamos.

- a todos da oficina mecânica pelo desenvolvimento das peças utilizadas neste trabalho.

- a S.A. Tonissi Jr. por seu indispensável apoio na parte eletrônica e computacional.

- a F.M.M. Yasuoka pelo "software" de impressão.

- aos demais da oficina eletrônica: Ricardo, Rui, Cesar, etc.

- aos técnicos do laboratório de óptica: Domingos, Paulinho e Gilberto.

- ao Ítalo e Edu pelo apoio gráfico.

- a dona Ivone pelos seus deliciosos sucos.

- ao pessoal da biblioteca pela dedicação. 
- ao pessoal da seção de alunos pela atenção.

- ao pessoal da limpeza por manterem um ambiente limpo e aconchegante.

- aos demais professores, alunos e funcionários pela amizade.

- a CAPES / PICD pela concessão de bolsa de estudos.

- aos demais órgãos financeiros: FAPESP, CNPq, FINEP e USP. 


\section{RESUMO}

Desenvolvemos um modelo teórico para tratar a mistura de várias ondas em meios absorvedores saturáveis, considerando a auto-difração de duas ondas incidentes numa grade de população, a qual é induzida no meio não-linear. O modelo foi investigado através de resultados experimentais observados em rubi $\left(\mathrm{Al}_{2} \mathrm{O}_{3}: \mathrm{Cr}^{3+}\right)$, alexandrita $\left(\mathrm{BeAl}_{2} \mathrm{O}_{4}: \mathrm{Cr}^{3+}\right)$ e $\mathrm{GdAlO}_{3}: \mathrm{Cr}^{3+}$. Demonstramos, pela primeira vez, transferência de energia por mistura não degenerada de duas ondas (NDTWM) em alexandrita e $\mathrm{GdAlO}_{3}: \mathrm{Cr}^{3+}$. Neste último, também observamos a difração de primeira ordem do feixe forte e medimos a variação de sua intensidade com relação a velocidade de deslocamento da grade. No $\mathrm{GdAlO}_{3}: \mathrm{Cr}^{3+}$, medimos o espectro de absorção do estado excitado e o espectro da parte real do índice de refração não-linear em quatro linhas do laser de argônio e na região de 560-620 nm de um laser de corante operando com rodamina $6 \mathrm{G}$. Os resultados indicam uma interação entre pares de cromo no estado excitado, seguida da absorção de um fóton, a qual pode explicar a variação da parte imaginária $n_{2}^{\prime \prime}$ com a intensidade, conforme observado experimentalmente.

Nós tentamos observar bi-estabilidade óptica em $\mathrm{GdAlO}_{3}: \mathrm{Cr}^{3+}$ mas não tivemos êxito, provavelmente por causa de efeitos transversais e também pelo aumento da absorção com a intensidade. Por outro lado, observamos um regime multi-estável numa cavidade FabryPerot vazia, onde o meio não-linear é o material usado na fabricação dos espelhos, que no caso foi $\circ \mathrm{ZrO}_{2}$. Também observamos comportamento multi-estável em filtros de inconel, causado pelo acoplamento termáóptico entre o filtro e a radiação laser. 


\section{ABSTRACT}

We have developed a new approach to deal with multi-wave mixing in saturable absorbing media, by considering the self difraction of two incident waves in a population grating which is created by them in the nonlinear medium. We have also made experimental work on ruby $\left(\mathrm{Al}_{2} \mathrm{O}_{3}: \mathrm{Cr}^{3+}\right)$, alexandrite $\left(\mathrm{BeAl}_{2} \mathrm{O}_{4}: \mathrm{Cr}^{3+}\right)$ and $\mathrm{GdAlO}_{3}: \mathrm{Cr}^{3+}$ in order to compare with our theoretical model. We have demonstrated energy transfer by nearly degenerated two wave mixing (NDTWM) in alexandrite and $\mathrm{GdAlO}_{3}: \mathrm{Cr}^{3+}$ for the first time. We measured the intensity of the first order difracted intense beam as a function of the frequency shift between the incident beams in $\mathrm{GdAlO}_{3}: \mathrm{Cr}^{3+}$. For this crystal, we have obtained the spectra of the excited state absorption and the real part of the nonlinear index at four wavelengths of an argon laser and in the range 560-620 $\mathrm{nm}$ of a rodamine 6G dye laser. These kind of spectra had never been reported before in that material. The results seems to support our proposal of an excited chromium pair interaction with an additional photon absorption which can explain the observed variation of the imaginary part of the nonlinear Kerr index with the intensity.

We tried to observe optical bistability in $\mathrm{GdAlO}_{3}: \mathrm{Cr}^{3+}$ but we were unsuccessful, probably due to strong transverse effects and increasing absorption with the intensity. However we observed multistable regime in empty Fabry-Perot cavities in which the mirrors were made of thin films of $\mathrm{ZrO}_{2}$ deposition. A multistable thermo-optical behaviour in inconel filters were also observed. 


\section{ÍNDICE}

1. INTRODUÇÃO

2. CONCEITOS DA ÓPTICA NÃO-LINEAR

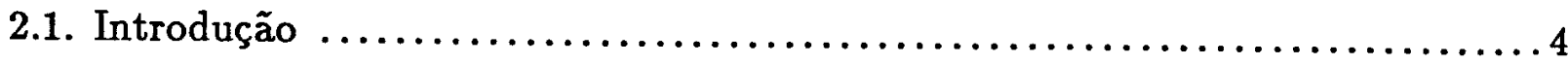

2.2. Propagação de Ondas Num Meio Não-Linear $\ldots \ldots \ldots \ldots \ldots \ldots \ldots \ldots \ldots \ldots \ldots$

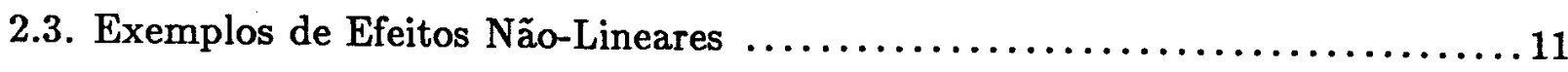

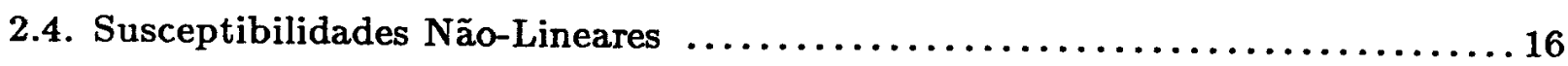

2.5. Mecanismos de Não-Linearidade e Índice de Refração ................... 19

2.5-1. Reorientação e Redistribuição Molecular .......................22

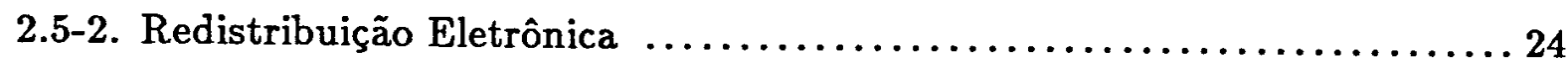

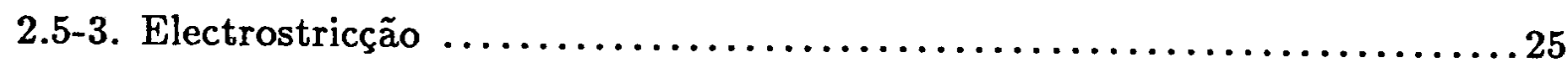

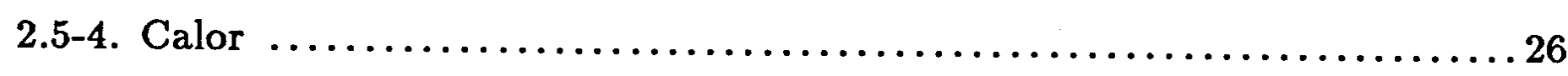

3. PROCESSOS ÓPTICOS NÃO-LINEARES E SUAS APLICAÇÕES

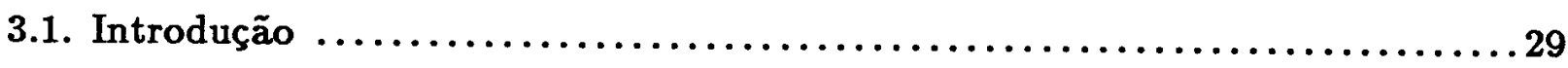

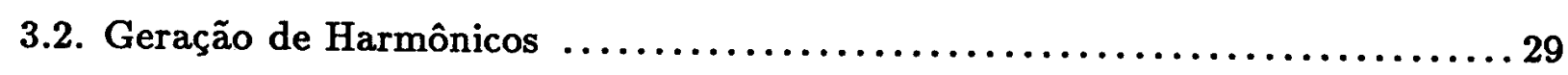

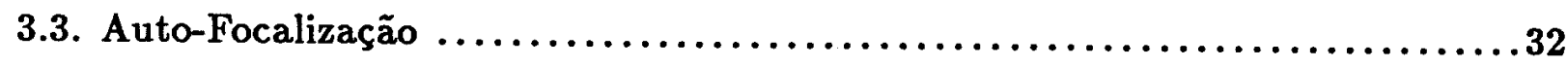

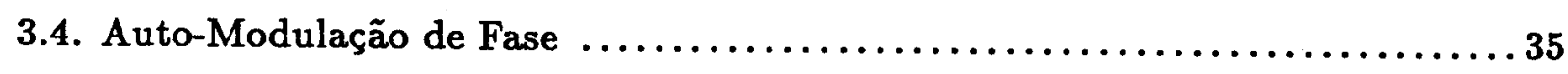

3.5. Auto-Difração em Redes Induzidas por Lasers $\ldots \ldots \ldots \ldots \ldots \ldots \ldots \ldots \ldots \ldots$

3.5-1. Superposição de Duas Ondas Planas ......................... 42

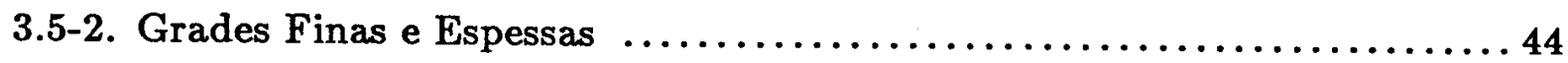

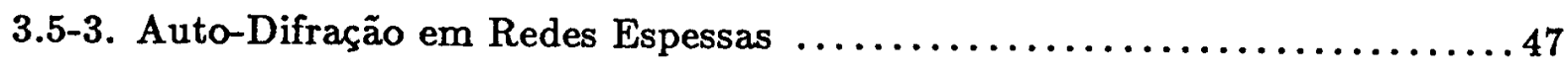




\section{MISTURA DE ONDAS EM MEIO KERR SATURÁVEL}

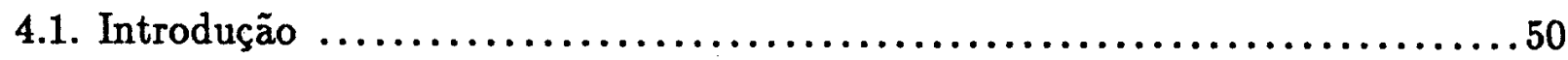

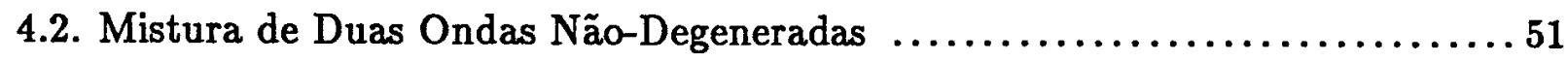

4.2-1. Cálculo das Susceptibilidades .............................. 52

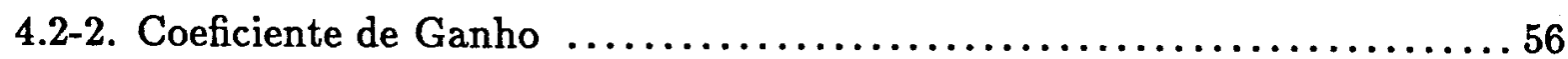

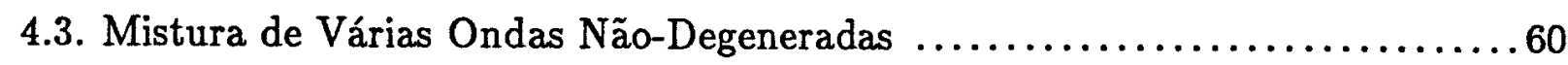

4.3-1. Descrição do Modelo ..................................... 61

4.3-2. Aplicação do Modelo à Mistura de Duas Ondas ....................66

5. RESULTADOS EXPERIMENTAIS EM $\mathrm{Al}_{2} \mathrm{O}_{3}, \mathrm{BeAl}_{2} \mathrm{O}_{4} \mathrm{E} \mathrm{GdAlO}_{3}$ DOPADOS COM $\mathrm{Cr}^{3+}$

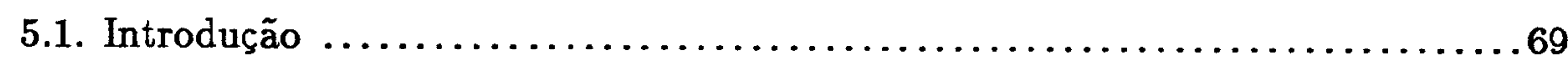

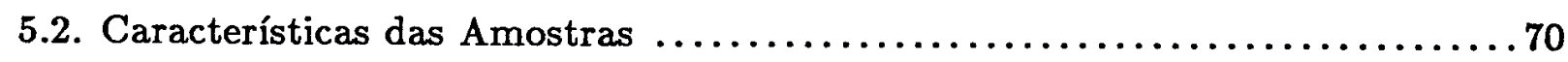

5.3. Descrição do Experimento de Mistura de Ondas .................... 74

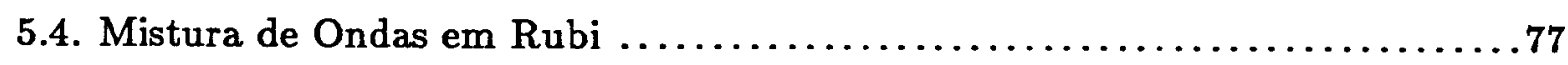

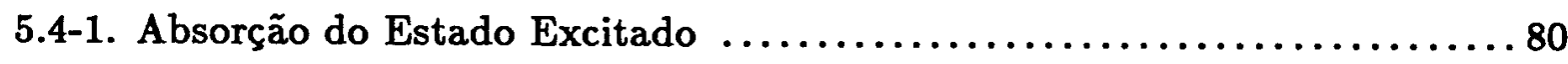

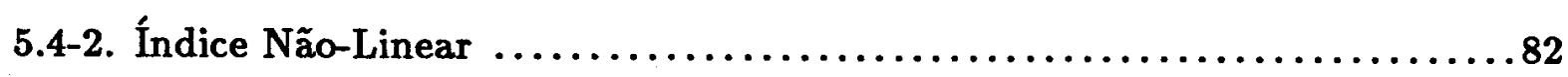

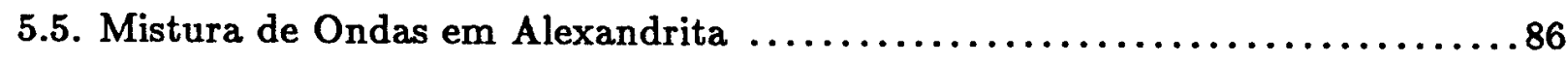

5.5-1. Curva de Ganho .................................... 88

5.5-2. Outras Ordens de Difração e Índice Não-Linear . ..................90

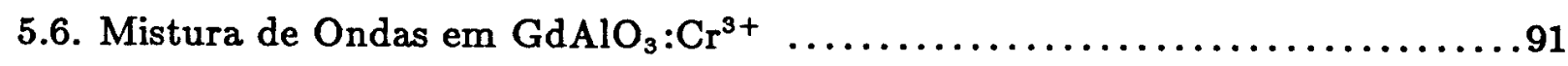

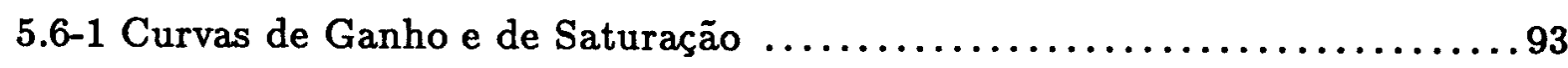

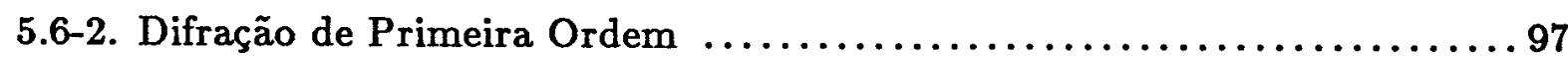

5.6-3. Parte Real do Índice Não-Linear $\ldots \ldots \ldots \ldots \ldots \ldots \ldots \ldots . \ldots . \ldots 9 . \ldots . \ldots . \ldots$

5.6-4. Parte Imaginária $n_{2}^{\prime \prime}$ e Absorção do Estado Excitado ................... 103 
6. BI-ESTABILIDADE ÓPTICA EM FILMES DE $\mathrm{ZrO}_{2}$ E INCONEL

6.1. Introdução .................................................

6.2. O Que é Bi-Estabilidade Óptica? ..............................114

6.3. Materiais e Mecanismos de Realimentação em Sistemas

Passivos Puramente Ópticos (SPPO) ...........................115

6.4. Bi-Estabilidade Óptica numa Cavidade Fabry-Perot .................117

6.4-1. Teoria ........................................... 117

6.4-2. Experimentos em $\mathrm{ZrO}_{2}$ e Inconel ..........................120

6.5. Tentativas de observar Bi-Estabilidade Óptica em $\mathrm{GdAlO}_{3}: \mathrm{Cr}^{3+} \ldots \ldots \ldots . .130$

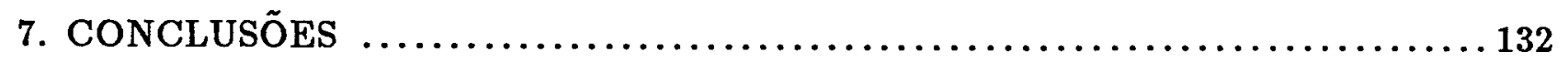

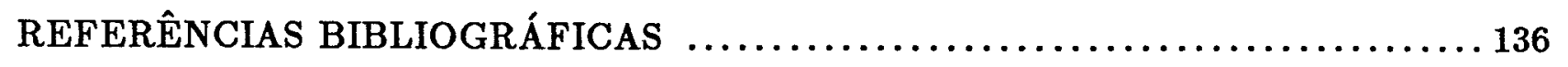

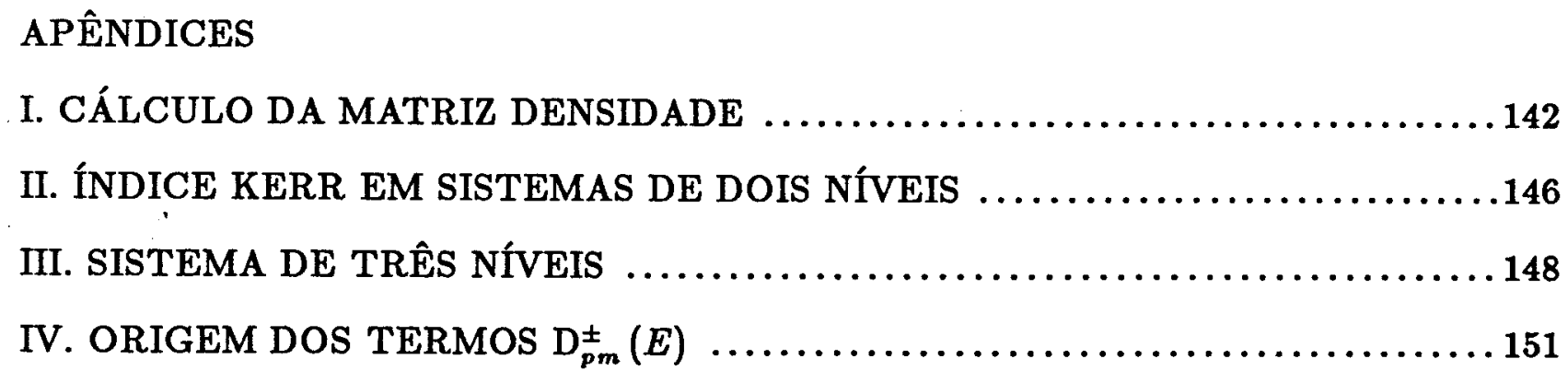




\section{INTRODUÇÃO}

Óptica não-linear envolve uma classe de interações entre radiação óptica e matéria, na qual a resposta do meio, manifestada pela polarização induzida pelos campos incidentes, depende do produto das amplitudes desses campos. As interações mais familiares, tais como a absorção linear e a refração, têm em comum a propriedade de que elas surgem de polarizações oscilantes no meio, as quais são proporcionais à primeira ordem do campo elétrico. Alguns dos processo ópticos não-lineares são extensões de processos ópticos lineares, por exemplo a absorção não-linear e o índice de refração não-linear. Mas, de modo geral, as interações não-lineares entre campos ópticos resultam em efeitos que diferem qualitativamente daqueles originados na óptica linear.

Neste trabalho investigamos alguns efeitos ópticos não-lineares associados ao índice de refração não-linear $n_{2}$ (ou à susceptibilidade de terceira ordem) em cristais dopados com cromo. Nosso maior interesse foi o cristal de $\mathrm{GdAlO}_{3}: \mathrm{Cr}^{3+}$, aluminato de gadolíneo dopado com $\mathrm{Cr}^{3+}$, onde pretendíamos observar um provável comportamento bi-estável em cavidades Fabry-Perot (FP) contendo este material em seu interior. Entretanto, efeitos não-lineares originados nos filmes depositados para formar os espelhos da cavidade, criaram dificuldades no desenvolvimento de uma cavidade isenta de não-linearidade, condição necessária para que pudéssemos isolar os efeitos oriundos do cristal.

Enquanto procurávamos sanar estas dificuldades, pesquisando diferentes filmes, vimos a possibilidade de aplicar a técnica da mistura quase degenerada de duas ondas (NDTWM), para observar a transferência de energia entre um feixe forte e outro fraco, na alexandrita $\left(\mathrm{BeAl}_{2} \mathrm{O}_{4}: \mathrm{Cr}^{3+}\right)$ e também no $\mathrm{GdAlO}_{3}: \mathrm{Cr}^{3+}$. Isto já havia sido feito no rubi $\left(\mathrm{Al}_{2} \mathrm{O}_{3}: \mathrm{Cr}^{3+}\right)$ e nós utilizamos este cristal como referência para verificação do desempenho do nosso sistema experimental. Nós fomos os primeiros a utilizar esta técnica nos dois materiais 
acima referidos [36]. Durante nossas observações constatamos que a máxima transferência de energia, a qual é consequência da formação de uma grade não-estacionária no meio, não ocorria numa diferença de frequência constante (o contrário do que estava estabelecido no tratamento convencional da NDTWM [30]), mas que esta última dependia da intensidade do feixe mais intenso.

Uma outra importante observação no $\mathrm{GdAlO}_{3}: \mathrm{Cr}^{3+}$ foi a dependência, com a intensidade do feixe forte, da razão $r$ entre as partes imaginária e real do índice Kerr $n_{2}[36]$. Além disso verificamos a inexistência de uma teoria que considerasse os efeitos de saturação em NDTWM. Esses efeitos haviam sido observados no rubi, mas foram tratados empiricamente [30]. Tudo isso nos motivou a desenvolver um tratamento teórico para a mistura de ondas em absorvedores saturáveis [25], a partir do qual a NDTWM é obtida como um caso particular e considerada como a auto-difração de ordem zero dos feixes que induzem a grade de população no meio não-linear. Quase ao mesmo tempo surgiram dois outros tratamentos similares $[37,42]$ no caso específico da NDTWM que, como dissemos acima, é um caso particular do nosso modelo.

Embora o nosso modelo descreva muito bem os efeitos de saturação observados experimentalmente, ele não prevê a dependência da razão $r$ com a intensidade. Isto instigou-nos a procurar outras explicações fora do modelo teórico e sim pensando no sistema físico (o $\mathrm{GdAlO}_{3}: \mathrm{Cr}^{3+}$ ) como responsável por tal dependência de $\mathrm{r}$, uma vez que tanto no rubi quanto na alexandrita tal efeito não fora observado. No Capítulo 5 deste trabalho proporemos e discutiremos o provável mecanismo reponsável pela variação de r observada no $\mathrm{GdAlO}_{9}: \mathrm{Cr}^{3+}$.

A apresentação do nosso trabalho terá a seguinte distribuição:

- No Capítulo 2 procuramos introduzir os conceitos da óptica não-linear, descrevendo 
o formalismo básico para propagação de ondas num meio não-linear e discutindo alguns mecanismos que originam efeitos ópticos não-lineares.

- No Capítulo 3 abordamos alguns processos ópticos não-lineares (ex. geração de harmônicos) e fazemos uma breve introdução do fenômeno da auto-difração em redes induzidas por lasers.

- No Capítulo 4 descrevemos a teoria da mistura não-degenerada de duas ondas segundo o modelo de dois níveis, que é o mesmo tratamento feito por Zhou et al [37] mas nós incluímos um termo adicional, o qual origina a razão $r$, que foi desprezado por eles. Apresentamos também o nosso modelo teórico, ligeiramente modificado da concepção original [25], com a inclusão de alguns termos que foram previamente ignorados.

- No Capítulo 5 apresentamos e discutimos os resultados experimentais obtidos nos três cristais dopados com cromo. Além da NDTWM, mostramos absorção do estado excitado e o espectro do índice não-linear (parte real) no $\mathrm{GdAlO}_{3}: \mathrm{Cr}^{3+}$.

- No Capítulo 6 faremos um tratamento a respeito do fenômeno da bi-estabilidade óptica, onde veremos a ocorrência de multi-estabilidade óptica em filmes de $\mathrm{ZrO}_{2}$ e Inconel, mas nenhuma observação de $\mathrm{BO}$ no $\mathrm{GdAlO}_{3}: \mathrm{Cr}^{3+}$.

- No Capítulo 7 faremos um resumo das principais conclusões a respeito do estudo aqui apresentado. 


\section{CONCEITOS DA ÓPTICA NÃO-LINEAR}

\subsection{INTRODUÇÃO}

O campo da óptica não-linear tem se expandido muito nessas três décadas desde a invenção do laser em 1960 [1]. Embora efeitos não-lineđres devidos à campos elétricos estáticos (efeito Kerr [2]) tenham sido observados já em 1875 e, também, o próprio conceito de óptica não-linear seja mais antigo do que o laser (ex. teoria da absorção de 2 fótons [3]), as primeiras demonstrações da resposta não-linear da matéria, à uma onda óptica intensa, só surgiram em $1961[4,5]$.

A razão para isto é que a interação da luz com a matéria se dá através da polarização induzida pelo campo incidente, o qual deve ser comparável ao campo inter-atômico que atua num elétron (cerca de $3 \times 10^{8} \mathrm{~V} / \mathrm{cm}$ ) e como as fontes de luz, até então, produziam campos pouco intensos (menor do que $10^{3} \mathrm{~V} / \mathrm{cm}$ ) era de se esperar que a resposta do meio, quando expressa numa série de potências do campo incidente:

$$
P=\epsilon_{o}\left[\chi^{(1)} E+\chi^{(2)} E^{2}+\chi^{(3)} E^{3}+\ldots\right]
$$

fosse adequadamente representada pelo primeiro termo desta expansão, isto é, fosse linear. Nesta expressão $\epsilon_{o}$ é a permissividade do vácuo, $P$ é a polarização e $\chi^{(i)}$ é a i-ésima ordem da susceptibilidade atômica. $O$ primeiro termo descreve a conhecida propriedade da óptica linear que é o índice de refração.

Já um pulso de laser com, por exemplo, $100 \mathrm{MW}$ de potência de pico e focalizado num diâmetro de $100 \mu \mathrm{m}$ produz um campo elétrico $E$ (no vácuo) de $3 \times 10^{7} \mathrm{~V} \mathrm{~cm}^{-1}$, obtido pelas expressões: 


$$
\begin{gathered}
E=27,45\left(\frac{\bar{I}}{n}\right)^{\frac{1}{2}} \\
\bar{I}=\frac{n}{2} c \epsilon_{o} E^{2}=\frac{P}{\pi w^{2}}
\end{gathered}
$$

$\bar{I}$ é a intensidade média do pulso em $\mathrm{Wm}^{-2}, P$ é a potência de pico, $n$ é o índice de refração linear, c é a velocidade da luz no vácuo e w é o raio do feixe.

Então, com o laser pode-se obter campos tão intensos quanto o campo inter-atômico, o que torna os outros termos da polarização tão importantes quanto o primeiro.

O experimento de Franken et al [4] justamente confirmou a existência do segundo termo $\left(\chi^{(2)}\right)$ pela observação de radiação ultra-violeta (UV) em $3471 \AA$ de um cristal de quartzo iluminado pela luz de um laser de rubi operando em $6943 \AA$, ou seja: geração de segundo harmônico. Já o trabalho de Kaiser e Garrett [5], que observaram a absorção de dois fótons, mostra o efeito oriundo do terceiro termo $\left(\chi^{(3)}\right)$.

A partir destes trabalhos aumentou o interesse na pesquisa em óptica não-linear, inicialmente em meios cristalinos e mais recentemente em líquidos e gases. A preferência por meios cristalinos devia-se principalmente ao fato de que $\chi^{(2)}$ é identicamente nulo num meio centro-simétrico tais como: vapor atômico, líquidos e gases moleculares não ativos opticamente. Sendo assim, os efeitos não-lineares nesses últimos originam-se de $\chi^{(3)}, \chi^{(5)}$, $\chi^{(7)}$, etc.

Outro fator importante que direcionou as pesquisas em cristais é que a bi-refringência pode ser usada para fazer casamento das velocidades de fase entre as radiações incidente e harmônica, através da dispersão do material [6]. Isto aumenta o comprimento de coerência, possibilitando maior eficiência na conversão harmônica. Entretanto, para que possam ser 
usados na geração de harmônicos, os materiais precisam:
a) ter grande $\chi^{(2)}$;
b) apresentar alta bi-refringência;
c) ter boa qualidade óptica;
d) suportar altas intensidades;
e) ser transparentes às radiações incidente e gerada.

- que, na prática, apenas poucos cristais produzidos conseguiram satisfazer estas exigências, sendo que a absorção no UV e no infra-vermelho (IR) são as maiores limitações.

Isto fez crescer o interesse em gases e líquidos que, apesar dos efeitos não-lineares mais importantes serem devidos a $\chi^{(3)}$, apresentam as seguintes vantagens:

1) podem ser preparados com boa qualidade óptica e em grandes dimensões;

2) não sofrem danos irreversíveis em altas intensidades ópticas;

3) apresentam boa transparência no UV e IR.

Outra característica importante é que o poder da interação não-linear $\left(\chi^{(3)}\right)$ pode ser aumentado enormemente se a radiação incidente for ressonante com um apropriado nível de energia do meio, especialmente em gases atômicos, os quais possuem linhas de absorção muito estreitas. Como exemplo desta característica citamos a conversão ascendente ("up conversion") do IR para o UV em vapor de sódio com eficiência de $50 \%$, obtida por Bloom et al [7].

Contudo, o interesse em cristais centro-simétricos dopados com $\mathrm{Cr}^{3+}$ também tem crescido (ou pelo menos se mantido), principalmente porque nesses materiais (particularmente o rubi, $\mathrm{GdAlO}_{3}: \mathrm{Cr}^{3+}$ e alexandrita) os efeitos não-lineares devido à susceptibilidade $\chi^{(3)}$ são relativamente intensos e a origem desta susceptibilidade ainda 
não está completamente compreendida, como será discutido mais adiante.

\subsection{PROPAGAÇÃO DE ONDAS NUM MEIO NÃO-LINEAR}

A partir das equações de Maxwell [2]:

$$
\begin{gathered}
\nabla \cdot \mathbf{D}=\rho \\
\nabla \cdot \mathbf{B}=0 \\
\nabla \times \mathbf{H}=\mathbf{J}+\frac{\partial}{\partial t} \mathbf{D} \\
\nabla \times \mathbf{E}=-\frac{\partial}{\partial t} \mathbf{B}
\end{gathered}
$$

e das relações

$$
\begin{gathered}
\mathbf{D}=\epsilon_{o} \mathbf{E}+\mathbf{P} \\
\mathbf{B}=\mu_{o}(\mathbf{H}+\mathbf{M})
\end{gathered}
$$

vamos obter a equação de propagação para um conjunto de $\mathrm{N}$ ondas que se deslocam como onda plana, mas permitindo uma variação transversal no perfil de amplitude $\mathbf{A}$ do campo elétrico total E. Assim escrevemos:

$$
\mathbf{E}(\mathbf{r}, t)=\left[\frac{1}{2} \sum_{j} \mathbf{A}_{j}(\mathbf{r}, t) e^{i\left(\omega_{j} t-\mathbf{k}_{\jmath} \cdot \mathbf{r}\right)}\right]+c . c .
$$




$$
=\operatorname{Re}\left[\sum_{j} \mathbf{A}_{j}(\mathbf{r}, t) e^{i\left(\omega_{j} t-k_{j} \cdot r\right)}\right]
$$

onde c.c. é o complexo conjugado e Re é a parte real dos termos em colchetes, em (2.3a) e $(2.3 b)$, respectivamente. Lembramos que, quando a forma (2.3b) é usada, normalmente é omitido o Re.

Através das equações (2.1) e (2.2), no caso de um meio homogêneo, não-magnético, não-condutor e sem cargas livres, chega-se a [8]

$$
\nabla^{2} \mathbf{E}-c^{-2} \frac{\partial^{2}}{\partial t^{2}} \mathbf{E}=\mu_{o} \frac{\partial^{2}}{\partial t^{2}} \mathbf{P}
$$

Se pudermos separar a polarização numa parte linear $\mathbf{P}_{\mathrm{L}}$ e noutra não-linear $\mathbf{P}_{\mathbf{N} \mathrm{L}} \mathbf{e}$ considerar que a parte linear é proporcional ao campo elétrico (resposta local), ou seja,

$$
\begin{gathered}
\mathbf{P}=\mathbf{P}_{\mathrm{L}}+\mathbf{P}_{\mathrm{NI}} \\
\mathbf{P}_{\mathrm{L}}(\mathbf{r}, t)=\epsilon_{o} \chi^{(1)} \mathbf{E}(\mathbf{r}, t)
\end{gathered}
$$

com

$$
\mathbf{P}_{\mathrm{NL}}(\mathbf{r}, t)=\frac{1}{2} \sum_{j} \mathrm{P}_{j}(\mathbf{r}, t) e^{i\left(\omega_{j} t-k_{j p} \cdot r\right)}+c . c .
$$

então, após usarmos a aproximação adiabática (aproximação de Born ou "Slow Varying Envelope Aproximation"-SVEA) obtém-se finalmente:

$$
\nabla_{t}^{2} \mathbf{A}_{\mathrm{j}}-2 i\left(\mathbf{k}_{\mathrm{j}} \cdot \nabla\right) \mathbf{A}_{\mathrm{j}}-\frac{2 i \omega_{j} n_{j}^{2}}{c^{2}} \frac{\partial}{\partial t} \mathbf{A}_{\mathrm{j}}=-\mu_{0} \omega_{j}^{2} \mathrm{P}_{\mathrm{J}}^{(n)} e^{i \Delta \mathbf{k}_{\mathrm{j}} \cdot \mathbf{r}}
$$




$$
\begin{gathered}
\Delta \mathrm{k}_{\mathrm{j}} \equiv k_{\mathrm{j}}-k_{\mathrm{jp}} \\
k_{j}^{2}=\frac{\omega_{j}^{2}}{c^{2}}\left(1+\chi_{j}^{(1)}\right)=\frac{\omega_{j}^{2}}{c^{2}} n_{j}^{2}
\end{gathered}
$$

$\nabla_{t}^{2}$ é o Laplaciano que atua nas coordenadas transversais e $n_{j}$ é o índice de refração linear na frequência $\omega_{j}$.

Este conjunto de equações acopladas $(j=1,2, \ldots, N)$ descreve a propagação das $\mathrm{N}$ ondas no meio não-linear. Devemos notar que a polarização não-linear atua como uma fonte de interação entre as diversas ondas pois, por (2.4) e (2.5), se $\mathbf{P}_{\mathrm{NL}_{\mathrm{L}}}$ fosse zero cada j-ésima onda propagar-se-ia independentemente com velocidade $c / n_{j}$.

Outro ponto importante é que o vetor de onda da polarização não-linear $\mathbf{k}_{\mathrm{jp}}$, em (2.6), pode ser diferente do vetor de onda de um campo óptico $\mathbf{k}_{\mathrm{j}}$ da mesma frequência. Isto acontece porque a diferença nas velocidades de fase entre a polarização induzida e o campo que a induziu pode mudar a direção do fluxo de energia distribuída entre as ondas [9].

Sobre a validade das aproximações expressas pelas equações (2.5) e implícitas na própria SVEA, vamos dispensar alguns comentários:

1) De modo geral a polarização do meio $\mathbf{P}_{\mathbf{T}}$ pode ser expandida numa série de momentos de distribuição de cargas no meio [10]:

$$
\mathbf{P}_{\mathbf{T}}(\mathbf{r}, t)=\mathbf{P}(\mathbf{r}, t)+\nabla L(\mathbf{r}, t)+\nabla: \nabla \mathbf{O}+\ldots
$$

O primeiro termo corresponde à polarização dipolar (usada em (2.4)), o segundo à quadripolar e assim por diante. Como os comprimentos de onda da radiação laser (cerca de 
$5 \times 10^{-5} \mathrm{~cm}$ ) são muito maiores do que as dimensões dos osciladores atômicos do meio ( $\left.10^{-8} \mathrm{~cm}\right)$ a convergência desta série é muito rápida e o termo de dipolo é dominante. Esta aproximação remove a não-localidade espacial, ou seja, a polarização depende do campo local.

2) A separação de $\mathbf{P}$ feita em (2.5a) é válida sempre que os campos incidentes no meio forem pouco intensos em comparação com aqueles que ligam os elétrons no meio. A aproximação falha, no entanto, quando os campos forem tal que possam saturar uma transição óptica, por exemplo.

3) A independência de $\chi^{(1)}$ (e também os $\chi^{(n)}$ de ordem superior) com o tempo é consequência da relação

$$
\left|\chi^{(n)^{-1}}\left(\frac{\partial \chi^{(n)}}{\partial \omega}\right) A^{-1} \frac{\partial A}{\partial t}\right| \sim \frac{\tau_{m}}{\tau_{c}}
$$

onde $\tau_{m}$ é o tempo de resposta da n-ésima ordem da polarização, $\tau_{c}^{-1}$ é a taxa característica de mudança da amplitude do campo e as barras significam o valor absoluto. Pode-se mostrar $[9,11]$ que quando a condição

$$
\tau_{m}<<\tau_{c}
$$

é satisfeita, então a susceptibilidade $\chi^{(n)}$ será independente do tempo (não-localidade temporal). Vê-se de (2.9) e (2.10) que a aproximação poderá não ser satisfeita se uma ou ambas das seguintes condições ocorrerem:

a) pulsos muitos curtos;

b) transições ressonantes.

Uma vez satisfeitas as exigências para a validade de (2.7), podemos usá-la na 
determinação das amplitudes $\mathbf{A}_{\mathfrak{J}}$, usando a apropriada componente de Fourier da polarização não-linear $\mathrm{P}_{\mathrm{j}}^{(\mathrm{n})}$, que pode escrever-se (em notação tensorial $\vdots$ ):

$$
\mathrm{P}_{j}^{(\mathrm{n})} \equiv \mathrm{P}^{(\mathrm{n})}\left(\omega_{j}\right)=\epsilon_{o}\left[\frac{n !}{p ! 2^{n-1}}\right] \chi^{(\mathbf{n})}\left(-\omega_{j} ; \omega_{1} \omega_{2} \ldots \omega_{n}\right) \vdots \mathbf{A}_{1} \mathbf{A}_{2} \ldots \mathbf{A}_{\mathbf{n}}
$$

onde $p$ é o número de frequências repetidas $(p=0,2,3, \ldots \mathrm{n})$. Por exemplo, se $\omega_{1}=\omega_{2}$ então $p=2$, mas uma frequência negativa é considerada diferente de sua correspondente $\left(-\omega_{1} \neq \omega_{1}\right)$. Na notação de $\chi^{(\mathbf{n})}$ está implícita a conservação de energia:

$$
-\omega_{j}+\omega_{1}+\omega_{2}+\ldots+\omega_{n}=0
$$

e o termo entre colchetes nos dá o fator correto, em sintonia com (2.3a), que representa o número de termos indistingüiveis sobre permutação dos índices.

No próximo capítulo veremos a aplicação da equação (2.11) e a solução de (2.7) para alguns fenômenos ópticos não-lineares.

\subsection{EXEMPLOS DE EFEITOS NÃO-LINEARES}

Note que na eq. (2.7a) está implícita uma soma na ordem da componente não-linear da polarização $\mathrm{P}_{\mathrm{j}}^{(\mathbf{n})}$. Na prática, entretanto, apenas uma certa ordem (a n-ésima) é necessária para que possamos descrever um determinado efeito óptico, uma vez que a polarização foi expandida em potências do campo elétrico e, então, os efeitos surgem na ordem crescente da amplitude do campo ou por razões de simetria. Como é o caso de materiais centrosimétricos (Seção 2.1), onde $\chi^{(2)}$ é nulo e os processos não-lineares surgem a partir de $\chi^{(3)}$, que pode existir em qualquer meio. 
0 termo linear, por exemplo, origina o índice de refração linear e a absorção linear (ou ganho) do meio, pois sendo $\chi_{j}^{(1)}$ complexo,

$$
\chi_{j}^{(1)}=\chi_{j}^{\prime}-i \chi_{j}^{\prime \prime}
$$

então, por (2.7c)

$$
\begin{gathered}
n_{L}^{2}\left(\omega_{j}\right)=1+\chi_{j}^{\prime} \\
\alpha_{j} \equiv \frac{\omega_{j}}{n_{L} c} \chi_{j}^{\prime \prime}
\end{gathered}
$$

Aqui $\alpha_{j}$ é o coeficiente de absorção da intensidade, $n_{L}$ é a parte real do índice de refração linear (a parte imaginária foi suposta muito menor do que a parte real).

O termo de segunda ordem origina frequências que são diferentes daquelas presentes nos campos incidentes. São os seguintes:

$$
\begin{gathered}
P_{i}^{(2)}\left(\omega_{3}=2 \omega_{1}\right)=\frac{\epsilon_{o}}{2} \chi_{i j k}^{(2)}\left(-\omega_{3} ; \omega_{1}, \omega_{1}\right) A_{1 j} A_{1 k} \\
P_{i}^{(2)}\left(\omega_{3}=\omega_{1}+\omega_{2}\right)=\epsilon_{o} \chi_{i j k}^{(2)}\left(-\omega_{3} ; \omega_{1}, \omega_{2}\right) A_{1 j} A_{2 k} \\
P_{i}^{(2)}\left(\omega_{3}=\omega_{1}-\omega_{2}\right)=\epsilon_{o} \chi_{i j k}^{(2)}\left(-\omega_{3} ; \omega_{1},-\omega_{2}\right) A_{1 j} A_{2 k}^{*} \\
P_{i}^{(2)}\left(\omega_{3}=0\right)=\epsilon_{o} \chi_{i j k}^{(2)}\left(0 ; \omega_{1},-\omega_{1}\right) A_{1 j} A_{1 k}^{*}
\end{gathered}
$$

onde a convenção de Einstein está implícita, e $i, j, k$ são as componentes cartesianas de cada vetor. A primeira expressão representa a geração de segundo harmônico, as duas 
seguintes a soma e a diferença de frequência e a última a retificação óptica, ou seja, uma polarização estática pode ser gerada no meio não-linear.

Uma análise semelhante se aplica ao termo de terceira ordem:

I) Geracão de Terceiro Harmônico

$$
P_{i}^{(3)}\left(\omega_{4}=3 \omega_{1}\right)=\frac{\epsilon_{0} \chi_{i j k \ell}^{(3)}}{4}\left(-\omega_{4} ; \omega_{1}, \omega_{1}, \omega_{1}\right) A_{1 j} A_{1 k} A_{1 \ell}
$$

II) Soma e Diferença de Frequências

$$
\begin{gathered}
P_{i}^{(3)}\left(\omega_{4}=\omega_{1}+\omega_{2}+\omega_{3}\right)=\frac{3 \epsilon_{o}}{2} \chi_{i j k \ell}^{(3)}\left(-\omega_{4} ; \omega_{1}, \omega_{2}, \omega_{3}\right) A_{1 j} A_{2 k} A_{3 \ell} \\
P_{i}^{(3)}\left(\omega_{4}=\omega_{1}+\omega_{2}-\omega_{3}\right)=\frac{3 \epsilon_{o}}{2} \chi_{i j k \ell}^{(3)}\left(-\omega_{4} ; \omega_{1}, \omega_{2},-\omega_{3}\right) A_{1 j} A_{2 k} A_{3 \ell}^{*} \\
P_{i}^{(3)}\left(\omega_{4}=\omega_{1}-\omega_{2}-\omega_{3}\right)=\frac{3 \epsilon_{o}}{2} \chi_{i j k \ell}^{(3)}\left(-\omega_{4} ; \omega_{1},-\omega_{2},-\omega_{3}\right) A_{1 j} A_{2 k}^{*} A_{3 \ell}^{*} \\
\text { com expressões similares (a menos do fator) para } \omega_{1}=\omega_{2} .
\end{gathered}
$$

III) Efeitos de Acãa Própria ("self action")

a) Auto-focalização ou Auto-desfocalização

$$
P_{i}^{(3)}(\omega)=\frac{3 \epsilon_{o}}{4} \operatorname{Re}\left[\chi_{i i k k}^{(3)}(-\omega ; \omega, \omega,-\omega)\right] A_{1 i}\left|A_{1 k}\right|^{2}
$$




\section{b) Absorção de 2 fótons}

$$
P_{i}^{(3)}(\omega)=\frac{3 \epsilon_{o}}{4} \operatorname{Im}\left[\chi_{i i k k}^{(3)}(-\omega ; \omega, \omega,-\omega)\right] A_{1 i}\left|A_{1 k}\right|^{2}
$$

IV) Mistura Degenerada de Quatro Ondas (DFWM)

$$
P_{i}^{(3)}(\omega)=\frac{3 \epsilon_{o}}{4} \chi_{i j k \ell}^{(3)}(-\omega ; \omega, \omega,-\omega) A_{1 j} A_{2 k} A_{3 \ell}^{*}
$$

V) Efeitos Raman

a) Efeito Kerr Induzido por Raman

$$
P_{i}^{(3)}\left(\omega_{1}\right)=\frac{3 \epsilon_{o}}{2} \operatorname{Re}\left[\chi_{i i k k}^{(3)}\left(-\omega_{1} ; \omega_{1}, \omega_{2},-\omega_{2}\right)\right] A_{1 i}\left|A_{2 k}\right|^{2}
$$

b) Espalhamento Raman Stokes (S) e Anti-Stokes (AS)

$$
\begin{gathered}
P_{i}^{(3)}\left(\omega_{S}\right)=\frac{3 \epsilon_{o}}{2} \operatorname{Im}\left[\chi_{i i k k}^{(3)}\left(-\omega_{S} ; \omega_{S}, \omega,-\omega\right)\right] A_{1 i}\left|A_{2 k}\right|^{2} \\
P_{i}^{(3)}\left(\omega_{A S}\right)=\frac{3 \epsilon_{o}}{4} \operatorname{Im}\left[\chi_{i j k \ell}^{(3)}\left(-\omega_{A} S ; \omega, \omega,-\omega_{S}\right)\right] A_{1 j} A_{1 k} A_{2 \ell}^{*}
\end{gathered}
$$

Um grande número de outros processos, além dos aqui citados, são descritos em detalhes em vários textos (e alguns no Capítulo 3 ), dentre os quais as referências $[8,9,11,12]$ são particularmente interessantes. 
É comum classificar os diversos processos ópticos como: paramétricos e não-paramétricos. Historicamente o termo paramétrico tem sido usado com referência àqueles processos que não envolvem transferência de energia para o meio (ex. geração de terceiro harmônico não-ressonante) e o não-paramétrico está associado ao processo que envolve essa transferência (ex. absorção ressonante de 2 fótons).

Como características dessa classificação tem-se, após o processo, o seguinte:
a) nos processos paramétricos
i - os átomos do meio não-linear permanecem em seu estado inicial
ii - a eficiência do processo depende do descasamento de fase $\Delta \mathbf{k}_{\mathbf{j p}}$

b) nos processos não-paramétricos

i - o estado final dos átomos é diferente do estado inicial

ii - o processo não depende de $\Delta \mathbf{k}_{\mathrm{jp}}$, pois o casamento de fase é automaticamente satisfeito.

No entanto, é preciso ter em mente que esta classificação dos processos ópticos não é rígida pois, por exemplo, a geração de terceiro harmônico (THG), mesmo sendo $\chi^{(3)}$ complexo (significando absorção do meio), é considerado um processo paramétrico.

Por último, os processos ópticos não-lineares podem ser representados através de diagramas onde a série de frequências, no argumento de $\chi^{(n)}$ em (2.11), são desenhadas como flexas ascendentes ou descendentes, se o sinal for positivo ou negativo, respectivamente. Os níveis que participam da interação não-linear são representados por linhas cheias (se níveis reais) ou pontilhadas (se níveis virtuais, sendo às vezes omitidas). 
Por tais diagramas não é possível determinar-se o fluxo de energia entre as ondas, o que só é feito através da solução da equação de propagação (2.7). A figura 2.1 exemplifica o uso desses diagramas para alguns dos processos citados nesta seção.

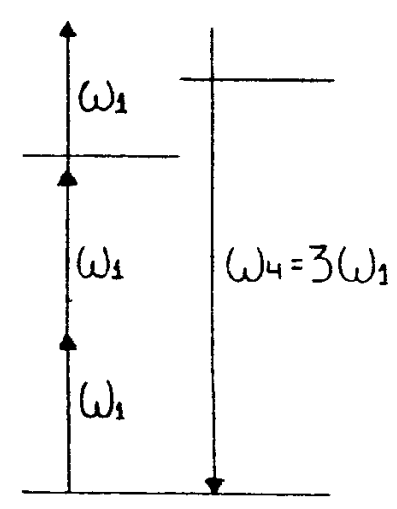

(a)

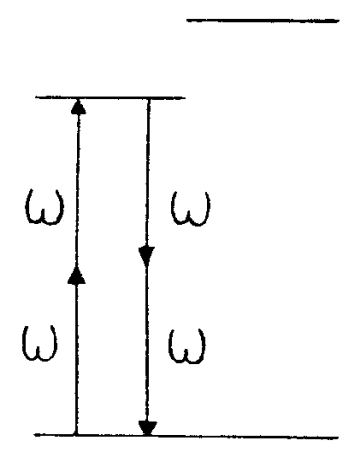

(b)

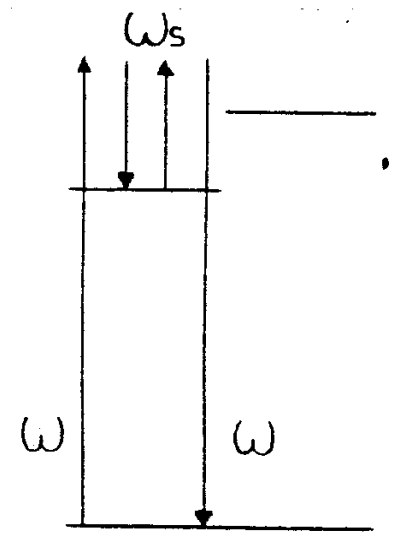

(c)

Fig. 2.1 Diagramas de processos não-lineares de terceira ordem.

a) geração de terceiro harmônico; b) absorção de dois fótons;

c) espalhamento Raman Stokes.

\subsection{SUSCEPTIBILIDADES NÃO-LINEARES}

É, certamente, de grande interesse a determinação das susceptibilidades ópticas nãolineares, tanto do ponto de vista experimental quanto do teórico. As susceptibilidades ópticas são propriedades características de um meio e, consequentemente, dependem da estrutura detalhada (atômica e molecular) desse meio. Por esta razão, não é possível obter-se uma teoria geral que possa aplicar-se à qualquer meio.

O primeiro tratamento geral sobre óptica não-linear foi feito por Armstrong et al [13], usando teoria de perturbação dependente do tempo. Eles calcularam as primeiras 


$$
\begin{array}{r}
\bar{\mu}=\sum_{m n} \mu_{m n} \rho_{n m} \\
=\operatorname{Tr}(\rho \mu)
\end{array}
$$

Tr significa o traço da matriz produto $\rho \mu$. A evolução do operador $\rho$ é descrita pela equação de Liouville determinada através da introdução de (2.16) na equação de Scrōdinger dependente do tempo, que é:

$$
i \hbar \frac{\partial}{\partial t} \rho=[\mathbf{H}, \rho]+i \hbar\left(\frac{\partial \rho}{\partial t}\right)_{\text {rel }}
$$

onde $\mathbf{H}$ é o Hamiltoniano total do sistema, formado pelo Hamiltoniano não perturbado $\mathbf{H}_{\mathbf{o}}$ e a perturbação de dipolo elétrico $-\mu . \mathbf{E}$, ou seja:

$$
\mathbf{H}=\mathbf{H}_{\mathbf{o}}-\boldsymbol{\mu} . \mathbf{E}
$$

$$
\mu=e r
$$

E é o campo elétrico total atuando no sistema quântico, $r$ o vetor posição do elétron, $e$ é o valor absoluto da carga do elétron.

O segundo termo de (2.18) representa as relaxações do operador $\rho$. Os auto-estados de $H_{0}$ possuem energias $E_{m}$ tais que

$$
H_{o}^{m n}=<\mathbf{m}\left|\mathbf{H}_{\circ}\right| \mathbf{n}>=E_{m} \delta_{n m}
$$

$\delta_{n m}$ é o delta de Kronecker.

Para resolver a equação de Liouville, supõe-se que a matriz densidade possa ser expandida numa série de potências da forma: 


$$
\rho=\rho^{(0)}+\rho^{(1)}+\rho^{(2)}+\ldots+\rho^{(\mathbf{n})}+\ldots
$$

que após substituição em (2.18) gera um conjunto de equações em ordem crescente da perturbação. A n-ésima ordem é

$$
i \hbar \frac{\partial}{\partial t} \rho^{(\mathbf{n})}=\left[\mathbf{H}_{\mathbf{o}}, \rho^{(\mathbf{n})}\right]+\left[-\mu . \mathbf{E}, \rho^{(\mathbf{n}-1)}\right]+i \hbar\left(\frac{\partial}{\partial t} \rho^{(\mathbf{n})}\right)_{r e l}
$$

e as condições iniciais ( $\mathbf{E}=0$, sistema em equilíbrio térmico) são:

$$
\begin{array}{r}
\rho_{11}^{(0)}=1 \\
\rho_{m \ell}^{(0)}=0, \quad \ell, m \neq 1
\end{array}
$$

Após determinação de $\rho^{(\mathbf{n})}$, a n-ésima ordem da susceptibilidade é obtida a partir de $(2.11),(2.17)$ e (2.19b). Embora seja apenas algébrico, o trabalho envolvido neste cálculo é muito intenso mas pode ser diminuído se começado pelo fim. Quer dizer, calculase inicialmente a ordem mais alta desejada, pois assim termos desnecessários são logo descartados.

\subsection{MECANISMOS DE NÃO-LINEARIDADE E ÍNDICE DE REFRAÇÃO}

Nesta seção faremos uma breve descrição de alguns mecanismos responsáveis pela mudança do índice de refração do meio, devida a intensidade de radiação óptica. Nosso interesse é apenas dar uma visão geral de como a interação da luz com o material pode gerar tal mudança.

A variação do índice de refração está associada à susceptibilidade $\chi^{(3)}(-\omega ; \omega, \omega,-\omega)$. Por isso, só estamos interessados em materiais onde $\chi^{(3)}$ seja a susceptibilidade não-linear 
de ordem mais baixa. Os efeitos não-lineares decorrentes desta e que, por sua vez, afetam a propagação (ou outras propriedades) de um mesmo feixe são denominados de Efeitos de Ação Própria ("Self Action Effects"). Nesta categoria estão: Auto-focalização (Autodesfocalização), Auto-Modulação de fase e Absorção de dois Fótons. Mistura Degenerada de Quatro Ondas (DFWM) não está incluída nesta classe porque, embora os feixes sejam todos de mesma frequência, eles são distinguíveis por: polarização ou direção de propagação (veja a diferença entre os ítens III e IV da seção 2.3).

Antes de iniciarmos a discussão dos mecanismos é preciso que estabeleçamos uma relação entre a variação do índice de refração $\Delta n$ e a resposta do meio $\chi^{(3)}$. Usaremos o sistema CGS com a finalidade de facilitar comparações com os diversos textos existentes. Então:

$$
\begin{aligned}
n^{2}=\left(n_{o}+\Delta n\right)^{2} & =1+4 \pi\left(\chi^{(1)}+\chi^{(3)}<E^{2}>\right) \\
& \simeq n_{o}^{2}+2 n_{o} \Delta n \\
\Delta n & \left.\simeq \frac{2 \pi}{n_{o}} \chi^{(3)}<E^{2}\right\rangle
\end{aligned}
$$

$n_{0}$ é o índice de refração linear e <> representa a média temporal. O índice não-linear $n_{2}$, ou índice Kerr do meio, é definido por

$$
\Delta n \equiv n_{2}<E^{2}>
$$

ou

$$
n_{2}(e s u)=\frac{2 \pi}{n_{o}} \chi^{(3)}(e s u)
$$


Porém é comum definir $n_{2}$ como coeficiente de intensidade $I\left(\Delta n=n_{2} I\right)$, expressa em $\mathrm{W} \mathrm{cm}^{-2}$, o que estabelece a seguinte relação:

$$
n_{2}\left(\mathrm{~W}^{-1} \mathrm{~cm}^{2}\right)=\left(\frac{4 \pi}{3 n_{o}}\right) 10^{-3} n_{2}(e s u)
$$

Ao longo deste capítulo, sempre que fizermos comparações entre valores de $n_{2}$, usaremos um ou outro tipo de unidade, de acordo com o que for mais utilizado na literatura para os materiais específicos em discussão.

Outro ponto que merece comentário é o caráter de resposta instantânea do meio nãolinear, implícita na eq. (2.25). Ou seja, uma vez que o campo elétrico está presente, há uma variação imediata no índice de refração. Na verdade é de se esperar que haja algum tempo necessário para que o meio possa responder à excitação. Esse tempo de resposta $\tau$ é introduzido fenomenologicamente através da equação de Debye [16]:

$$
\tau \frac{\partial}{\partial t} \Delta n+\Delta n=n_{2}<E^{2}>
$$

e cada mecanismo terá um tempo característico próprio. Passemos à discussão dos mecanismos.

De acordo com a relação de Lorenz-Lorentz:

$$
\frac{n^{2}-1}{n^{2}+2}=\frac{4 \pi}{3} N p
$$

onde $N$ é a densidade de átomos (moléculas) e $p$ é a polarizabilidade de um átomo (molécula). Vê-se que a variação de índice de refração deve estar, em princípio, associada à mudança dessas duas grandezas. Os principais mecanismos responsáveis pela variação da polarizabilidade são devidos à: 
- reorientação e redistribuição molecular

- redistribuição eletrônica.

E os associados à densidade são:

- electrostricção

- calor

\section{5 - 1. Reorientação e Redistribuição Molecular}

Este mecanismo é dominante em líquidos porque, nestes, as moléculas estão livres para girar e se mover, o que não acontece nos sólidos, em geral. O efeito só é possível em moléculas anisotrópicas, onde a presença de um campo óptico tende a alinhá-las através de sua interação com os dipolos induzidos nas mesmas. Uma vez estabelecidos esses dipolos, eles podem interagir entre si, de modo que as moléculas se redistribuem na busca de minimizar a energia livre do sistema.

A redistribuição molecular não é simples de ser formulada. Já a reorientação molecular pode ser compreendida da seguinte maneira: uma molécula alongada, com simetria cilíndrica, possui polarizabilidades $p_{\|}$e $p_{\perp}$ ao longo e na direção perpendicular ao seu eixo de simetria, respectivamente. Se o campo elétrico $\mathbf{E}$ faz um ângulo $\theta$ com esse eixo, então a polarizabilidade induzida $p$ será:

$$
\begin{aligned}
& p=p_{\|} \cos ^{2} \theta+p_{\perp} \operatorname{sen}^{2} \theta \\
& =p_{o}+\Delta p\left(\cos ^{2} \theta-\frac{1}{3}\right)
\end{aligned}
$$

onde $p_{o}=\frac{1}{3}\left(p_{\|}+2 p_{\perp}\right)$ é a polarizabilidade a campo nulo e $\Delta p=p_{\|}-p_{\perp}$. Portanto, a 
presença do campo provoca uma distribuição estatística $f(\theta, T)$ dada por:

$$
\begin{gathered}
f(\theta, T)=\frac{\exp \left[-\Delta U(\theta) / k_{B} T\right]}{\int_{o}^{\pi} \exp \left[-\Delta U(\theta) / k_{B} T\right] \operatorname{sen} \theta d \theta} \\
\left.\Delta U(\theta)=\frac{\Delta p}{2}\left(\cos ^{2} \theta-\frac{1}{3}\right)<E_{\ell}^{2}\right\rangle
\end{gathered}
$$

onde $T$ é a temperatura do sistema, $k_{B}$ é a constante de Boltzman e $E_{\ell}$ é o campo elétrico local.

O valor médio $\bar{p}$ da polarizabilidade (em todas as orientações possíveis) será:

$$
\begin{gathered}
\bar{p}=p_{o}+\Delta p\left(\overline{\cos ^{2} \theta}-\frac{1}{3}\right) \\
\overline{\cos ^{2} \theta}=\int_{0}^{\pi} f(\theta, T) \cos ^{2} \theta \operatorname{sen} \theta d \theta \\
\simeq \frac{1}{3}+\frac{2}{45} \frac{\Delta p}{k_{B} T}<E_{l}^{2}>
\end{gathered}
$$

e por (2.29) tem-se:

$$
\Delta n=\frac{2 \pi}{n_{o}}\left(\frac{n_{o}^{2}+2}{3}\right)^{2}\left[N_{o}\left(\bar{p}-p_{o}\right)+\left(\bar{N}-N_{o}\right) p_{o}\right]
$$

onde $\bar{N}-N_{o}$ é a variação da densidade molecular com a aplicação do campo elétrico (neste caso igual a zero). Então, de (2.25), (2.32) e (2.33) obtém-se a seguinte expressão para o índice Kerr de reorientação:

$$
n_{2}=\left(\frac{n_{o}^{2}+2}{3}\right)^{4}\left(\frac{4 \pi N_{o}}{45 n_{o}}\right) \frac{(\Delta p)^{2}}{k_{B} T}
$$


Devemos frisar que (2.34) representa o índice Kerr na direção do campo aplicado. Um cálculo semelhante pode ser feito para a direção perpendicular ao campo, que dá [16]:

$$
\Delta n_{\perp}=-\frac{\Delta n_{\|}}{2}
$$

caracterizando uma birrefringência induzida no meio pela reorientação molecular.

\section{5 - 2. Redistribuição Eletrônica}

A aplicação de um campo elétrico pode distorcer a distribuição eletrônica do meio. Essa distorção está associada à susceptibilidade de terceira ordem, que pode ser calculada pelo método da Seção (2.4). Este cálculo mostra que $\chi^{(3)} \sim 10^{-13}-10^{-15} e s u$, para um líquido ou sólido típico (fora da ressonância). Entretanto, $\chi^{(3)}$ pode ser aumentada muitas ordens de grandeza quando a frequência da radiação incidente está próxima de uma banda de absorção do meio.

O aumento em $\chi^{(3)}$ está relacionado à redistribuição de população dos níveis que é induzida pela excitação ressonante. Isto pode ser visto claramente no caso de um sistema de dois níveis (Seção 4.2). Tal mecanismo é particularmente importante em vapores atômicos, onde $\chi^{(3)} \sim 10^{-3} e s u$ pode ser encontrada.

Em semicondutores o processo de redistribuição também está presente. Neste caso a susceptibilidade $\chi^{(3)}$ está associada (como no sistema de dois níveis) à saturação da absorção dos excitons, e valores tão altos quanto $10^{-1}-1$ esu podem ser obtidos [17].

Embora a redistribuição eletrônica seja a contribuição dominante para $\chi^{(3)}$ quando a radiação está próxima da ressonância, existem materiais onde a contribuição não ressonante 
pode ser mais importante por causa de elevadíssimos momentos de dipolo de transição. Este é o caso, por exemplo, de alguns cristais dopados com cromo (como será discutido no Capítulo 5), onde o estado de transferência de carga é o responsável pelo valor de $\chi^{(3)}$ observado na região do visível $\left(\sim 10^{-5} e s u\right)$.

Um outro tipo de redistribuição eletrônica é a que ocorre em materiais fotorefrativos. Nesses materiais há uma migração de elétrons, quando da incidência de uma radiação óptica, que se redistribuem em novos sítios. Isto cria campos elétricos internos muito intensos, os quais mudam o índice de refração através do efeito eletro-óptico. $\chi^{(3)} \sim 1$ esu são obtidos nestes cristais.

\section{5-3. Electrostriç̧ão}

Electrostricção é a deformação do meio dielétrico sob a influência de um campo elétrico. Esta deformação cria uma densidade de pressão p (não confundir com polarizabilidade) nas cargas elétricas que, por sua vez, originam mudanças $\Delta N$ na densidade de cargas $N$. A contribuição para $\Delta N$, devida a este fenômeno, pode ser obtida através da equação de onda acústica com um termo de fonte, devido à força (por unidade de volume) $f$ originada pela variação de pressão. Tem-se $[12,16,18]$ :

$$
\begin{gathered}
\left(-\nabla^{2}+\frac{1}{v^{2}} \frac{\partial^{2}}{\partial t^{2}}-\frac{2 \Gamma}{v^{2}} \frac{\partial}{\partial t}\right) \Delta N=-\frac{1}{v^{2}} \nabla \cdot \mathbf{f} \\
\mathbf{f}=\nabla \mathrm{p}=\nabla\left(\frac{\gamma}{8 \pi}|A|^{2}\right) \\
\gamma=N_{o} \frac{\partial \epsilon}{\partial N} \simeq 2 n_{o} N_{o} \frac{\Delta n}{\Delta N}
\end{gathered}
$$




$$
v=\frac{1}{\sqrt{N \beta}}
$$

Aqui $\beta$ é a compressibilidade do meio, $v$ é a velocidade da onda acústica, $\epsilon$ é a constante dielétrica, $\Gamma$ é o coeficiente de amortecimento da onda (perdas no meio), $\gamma$ é a constante electrostrictiva e $A$ é a amplitude do campo elétrico.

A solução de (2.36a) no estado estacionário, para o caso de uma onda plana, é

$$
\Delta N=\frac{\gamma}{8 \pi v^{2}}|A|^{2}
$$

que por intermédio de (2.33) e (2.25) nos dá

$$
n_{2}=\frac{\gamma^{2} \beta}{8 \pi n_{o}}
$$

Uma característica deste mecanismo é que a mudança de índice de refração $\Delta n$ não depende da polarização do campo elétrico e, em razão disto, não ocorre rotação da elipse de polarização (presente nos mecanismos anteriores).

Em meio transparente a contribuição electrostrictiva é muito maior do que a contribuição eletrônica e é, muitas vezes, predominante nos sólidos. Valores típicos de $n_{2} \sim 10^{-11}$ esu e tempos de resposta de alguns nanosegundos são outras características deste mecanismo.

\section{5 - 4. Calor}

Absorção óptica pelo meio resulta em aquecimento na região onde a radiação incide. Em geral, isto causa uma diminuição na densidade de massa $\rho$, o que acarreta uma 
contribuição negativa para o índice de refração (ver (2.33)). Podemos expressar a mudança de índice como:

$$
\Delta n=\left(\frac{\partial n}{\partial T}\right) \Delta T
$$

onde a variação de temperatura $\Delta T$ satisfaz a equação de difusão de calor no meio.

Em cristais cúbicos e meios desordenados, onde a difusividade e condutividade térmicas, $D_{t}$ e $k$, respectivamente, são escalares e desde que a temperatura do material esteja longe de uma transição de fase $\left(D_{t}\right.$ independente de $\left.T\right)$, a equação de difusão reduz-se a [19]:

$$
\begin{gathered}
\frac{\partial \Delta T}{\partial t}=D_{t} \nabla^{2}(\Delta T)+\frac{Q}{\rho c_{p}} \\
D_{t}=\frac{k}{\rho c_{p}} \\
Q=\alpha I=\alpha \frac{n_{o}}{8 \pi} c|A|^{2}
\end{gathered}
$$

onde $c_{p}$ é o calor específico à pressão constante, $\alpha$ é o coeficiente de absorção do meio e $Q$ é a taxa de absorção de calor por unidade de volume.

Também neste caso, como no da electrostriç̧ão, a resposta do meio tem um caráter não-local descrito por (2.40a) (ou (2.36a)). O tempo de resposta do meio está associado ao tempo de difusão térmica $\tau_{d}$ que é dado por:

$$
\tau_{d}=\frac{\mathrm{w}^{2}}{8 D_{t}}
$$


onde w é o raio do feixe. No caso de pulsos curtos, ou seja, tempo de duração do pulso $t_{p}<<\tau_{d}$, o termo da difusividade pode ser desprezado em (2.40a) e, então, $\Delta T \simeq \frac{Q}{\rho c_{p}} t$ o que dá:

$$
n_{2} \simeq\left(\frac{n_{o} \alpha c w^{2}}{32 \pi k}\right) \frac{\partial n}{\partial T} \frac{t}{\tau_{d}}
$$

e em sólidos $\left(\tau_{d} \sim 0,1 s\right)$ para $\mathrm{w} \sim 1 \mathrm{~mm}$, tem-se:

$$
n_{2} \sim 10^{-5}\left(\frac{t}{\tau_{d}}\right) e s u
$$

Pode-se mostrar que (2.42) é uma boa aproximação válida também para tempos muito maiores do que $\tau_{d} \operatorname{com} t$ substituido por $\tau_{d}$ [16]. Portanto, este mecanismo é muito importante nos sólidos, com uso de lasers contínuos, pois $n_{2} \sim 10^{-5}$ esu. 


\section{PROCESSOS ÓPTICOS NÃO-LINEARES E SUAS APLICAÇÕES}

\subsection{INTRODUÇÃO}

Neste capítulo faremos um tratamento geral de alguns processos ópticos não-lineares já observados em diversos materiais. Entretanto, nosso interesse maior está nos cristais dopados com $\mathrm{Cr}^{3+}$ e em filmes, ambos objetos de estudo deste trabalho. Os efeitos abordados ao longo das seções 3.2 - 3.4 serão descritos de maneira um tanto superficial porque, nesses materiais, tais efeitos já foram bem discutidos noutros trabalhos (ex. referência [20]). Com relação à auto-difração em redes induzidas por lasers (Seção 3.5), faremos uma abordagem mais ampla porque o caso particular da mistura de ondas em absorvedores saturáveis (ex. $\mathrm{GdAlO}_{3}: \mathrm{Cr}^{+3}$ ) é um dos objetivos deste trabalho e será discutido no capítulo seguinte.

\subsection{GERAÇÃO DE HARMÔNICOS}

A geração de harmônicos é um dos mais antigos, e até hoje estudados, dentre os efeitos ópticos não-lineares. Como dissemos anteriormente, geração de segundo harmônico (SHG) em sólidos foi realizada pela primeira vez em 1961, no quartzo, com a duplicação da frequência de um laser de rubi [4]. Pesquisas posteriores permitiram a utilização de outros materiais, tais como o $\mathrm{KDP}\left(\mathrm{KH}_{2} \mathrm{PO}_{4}\right)$ ou $\mathrm{LiNbO}_{3}$, bombeados por lasers de corantes, rubi ou Nd:YAG, como fontes de radiação no visível ou no ultravioleta, através da SHG ou da geração de terceiro harmônico (THG). 
Vamos descrever a formulação básica para a geração de harmônicos de $\ell$-ésima ordem, no caso de ondas planas e no limite em que o campo incidente não é muito intenso ("undepleted interaction"). Adiante discutiremos as limitações e as diferenças apresentadas se o tratamento não seguisse essas aproximações.

Então, para um campo incidente com frequência $\omega$ e amplitude $A_{1}(z)$ (linearmente polarizado com vetor de onda $\mathrm{k}_{1}=k_{1} \mathrm{z}$ ), na aproximação adiabática, haverá o campo gerado com frequência $\omega_{\ell}=\ell \omega$ e amplitude $A_{\ell}(z)$ de modo que o campo total no meio, por (2.3a), será:

$$
E(z, t)=\frac{1}{2}\left[A_{1}(z) e^{i\left(\omega t-k_{1} z\right)}+A_{\ell}(z) e^{i\left(\omega_{\ell} t-k_{\ell} z\right)}\right]+c . c .
$$

e por (2.11), a $\ell$-ésima componente da polarização não-linear nas frequências $\omega_{\ell}$ e $\omega$ são respectivamente:

$$
\begin{gathered}
\mathrm{P}^{(\ell)}\left(\omega_{\ell}\right)=\epsilon_{o} \chi^{(\ell)}\left(-\omega_{\ell} ; \omega, \omega, \ldots \omega\right) A_{1}^{\ell} 2^{1-\ell} \\
\mathrm{P}^{(\ell)}(\omega)=\ell \epsilon_{o} \chi^{(\ell)}\left(-\omega ; \omega_{\ell},-\omega, \ldots-\omega\right) A_{\ell}\left(A_{1}^{*}\right)^{\ell-1} 2^{1-\ell}
\end{gathered}
$$

e substituindo estas expressões nas eqs. (2.7) tem-se:

$$
\begin{gathered}
\frac{d}{d z} A_{1}=-\left(\frac{i \ell \omega}{2^{\ell} c n_{1}}\right) \chi^{(\ell)}(-\omega ; \ell \omega,-\omega, \ldots-\omega) A_{\ell}\left(A_{1}^{*}\right)^{\ell-1} e^{-i \Delta k z} \\
\frac{d}{d z} A_{\ell}=-\left(\frac{i \ell \omega}{2^{\ell} c n_{\ell}}\right) \chi^{(\ell)}(-\ell \omega ; \omega, \omega, \ldots \omega) A_{1}^{\ell} e^{i \Delta k z} \\
\Delta k=k_{\ell}-\ell k_{1}=\frac{\ell \omega}{c}\left(n_{\ell}-n_{1}\right)
\end{gathered}
$$


aqui $n_{i} \equiv n\left(\omega_{i}\right)$ é o índice de refração. Assumindo $A_{1}$ aproximadamente constante e um meio não-linear de comprimento $L$ chega-se finalmente a:

$$
A_{\ell}(L)=\left(\frac{\ell \omega}{2^{\ell} c n_{\ell}}\right) \chi^{(\ell)} A_{1}^{\ell}\left(\frac{1-e^{i \Delta k L}}{\Delta k}\right)
$$

para a amplitude do campo e

$$
I_{\ell}(L)=\frac{\ell^{2} \pi^{2} L^{2}\left|\chi^{(\ell)}\right|^{2}}{\left(2 c \epsilon_{0}\right)^{\ell-1} n_{\ell} \lambda_{1}^{2}}\left(I_{1} / n_{1}\right)^{\ell} \frac{\operatorname{sen}^{2}(\Delta k L / 2)}{(\Delta k L / 2)^{2}}
$$

para a intensidade do feixe gerado, onde $\lambda_{1}$ e $I_{1}$ são o comprimento de onda no vácuo e a intensidade do feixe incidente, respectivamente.

Por (3.3) e pela expressão do campo $E(z, t)$ concluímos que a onda harmônica possui duas componentes: uma com velocidade de fase na frequência do $\ell$-ésimo harmônico e outra com velocidade de fase na frequência fundamental. Isto é consequência da dispersão do índice de refração (eq. 3.2c) e, por isso, essas duas ondas irão interferir construtivamente ou destrutivamente (eq. 3.4) em diferentes regiões do meio não-linear. A onda harmônica resultante tem vetor de onda $k=k_{\ell}-\Delta k / 2$ e, assim, sua velocidade de fase só estará na frequência do $\ell$-ésimo harmônico se $\Delta k=0$, caso em que o processo é dito em combinação de fase ou "phase matched".

Por (3.4) notamos que a intensidade da onda harmônica é máxima na situação de combinação de fase e oscila amortecidamente para $\Delta k \neq 0$ (em função de $L$ ). Neste caso haverá máximos para múltiplos ímpares do comprimento

$$
L_{c}=\frac{\pi}{\Delta k}
$$

denominado de comprimento de coerência. Portanto, a eficiência na geração de harmônicos está limitada pela relação (3.5) pois quanto maior for $\Delta k$ menor deverá ser o comprimento 
da amostra e, por (3.4), menor a intensidade do harmônico gerado!

Em perfeito casamento de fase, vê-se que a intensidade do harmônico gerado cresce quadraticamente com o comprimento do meio não-linear. É claro que isto é uma consequência da aproximação de não-depreciação do feixe incidente. Caso esta aproximação não seja utilizada devemos esperar que a geração harmônica seja limitada pela intensidade da onda incidente, ou eficiência máxima de $100 \%$. Por último, se feixes focalizados forem utilizados, a condição de perfeito casamento de fase deixa de ser $\Delta k=$ 0 e passa a ser

$$
\Delta k \sim-\frac{1}{z_{o}}
$$

onde $2 z_{o}=\pi \mathrm{w}_{o}^{2} n_{1} / \lambda_{1}$ é o parâmetro confocal de um feixe gaussiano de raio $\mathrm{w}_{o}[21]$.

\subsection{AUTO-FOCALIZAÇÃO}

Auto-focalização e auto-desfocalização são efeitos associados com variações espaciais na intensidade de um feixe incidente num meio não-linear. A primeira ocorre em meios com índice não-linear positivo, enquanto a outra em meios com índice negativo. Nos referiremos apenas à auto-focalização, pois a extensão para o caso da auto-desfocalização é imediata.

Como vimos no Capítulo 2 (eq. 2.24a), o meio não-linear possui índice de refração

$$
n=n_{o}+n_{2} I
$$

e para um feixe com perfil gaussiano, a intensidade $I$ é dada por 


$$
I(r)=I_{o} e^{-\frac{2 r^{2}}{w^{2}}}
$$

portanto, na presença do campo óptico, o índice de refração segue o perfil do feixe incidente, o que corresponde a uma lente convergente $\left(n_{2}>0\right)$ que focaliza o feixe. Esta focalização inicial diminui o raio do feixe $w$ e consequentemente aumenta ainda mais o poder de focalização dessa lente não-linear efetiva, porque a distância focal $\left(\sim \mathrm{w}^{2} / I_{0}\right)$ também é diminuída, o que resulta num efeito auto-gerador de focalização.

Devemos esperar, contudo, que o comportamento qualitativo de um feixe autofocalizado dependa da competição entre a difração do feixe incidente e o efeito dessa lente não-linear. No caso estacionário, a equação (2.7) para um campo linearmente polarizado e com vetor de onda $\mathbf{k}$ ao longo da direção $z$, é (no CGS):

$$
\nabla_{\mathrm{t}}^{2} A-2 i k \frac{\partial A}{\partial z}=-k^{2} \frac{n_{2}|A|^{2}}{n_{\mathrm{o}}} A
$$

A solução desta equação para um feixe de perfil genérico só é possível numericamente. Para um perfil inicialmente Gaussiano a solução numérica prevê que o comportamento do feixe depende de duas potências críticas $P_{1}$ e $P_{2}$ [22], relacionadas ao índice Kerr $n_{2}$ e ao comprimento de onda no vácuo $\lambda_{o}$ através de:

$$
\begin{gathered}
P_{1}=0,273 P_{2} \\
P_{2}=\frac{\left(1,22 \lambda_{o}\right)^{2} c}{128 n_{2}}
\end{gathered}
$$

De maneira que o feixe se auto-focaliza a uma distância $z_{f}$ dada por:

$$
z_{f}=\frac{0,185 k \mathrm{w}_{o}^{2}}{\sqrt{P / P_{2}}-0,858}
$$


se a potência incidente $P$ for maior do que $P_{2}$. Para potências entre $P_{1}$ e $P_{2}$ a intensidade próxima do eixo $z$ inicialmente aumenta (fraca auto-focalização) e depois diminui porque o efeito da difração supera o da auto-focalização. Também é previsto a existência de múltiplos pontos focais e a formação de anéis quando $P>2 P_{2}$.

Recentemente um tratamento teórico aproximado foi aplicado ao $\mathrm{GdAlO}_{3}: \mathrm{Cr}^{3+}$ e rubi [20] usando-se a integral de difração de Kirchoff, onde obteve-se excelente acordo com os resultados experimentais. Nesse trabalho foi considerado também os efeitos de saturação do feixe incidente e a estrutura anular, facilmente observada no $\mathrm{GdAlO}_{3}: \mathrm{Cr}^{3+}$, pôde ser explicada.

Uma solução aproximada para a eq. (3.9) pode ser obtida partindo-se da solução de um feixe Gaussiano num meio linear homogêneo $[16,18]$ :

$$
\begin{gathered}
A=|A| e^{-i k} \\
s(r, z)=\Phi(z)+\frac{r^{2}}{2} \beta(z) \\
|A(r, z)|^{2}=\left(\frac{A_{o}}{f(z)}\right)^{2} \exp \left[-\left(\frac{r}{\mathrm{w}_{o} f(z)}\right)^{2}\right]
\end{gathered}
$$

com as condições de contorno $(z=0)$

$$
\begin{gathered}
f=1 \\
\beta=\frac{1}{R} \\
\Phi=\Phi_{0}=\text { constante }
\end{gathered}
$$


Estas equações, no caso de um feixe incidente tipo onda plana (raio de curvatura $R=\infty$ ), prevêem uma auto-focalização para potências $P$ superiores à $P_{c}$, numa distância $z_{f}$ que é:

$$
z_{f}=\frac{0,5 k \mathrm{w}_{o}^{2}}{\sqrt{P / P_{c}-1}}
$$

e

$$
P_{c}=\frac{\lambda_{o}^{2} c}{16 \pi^{2} n_{2}}
$$

Comparando a solução numérica, eqs. (3.10) e (3.11), vemos que a solução acima apenas dá uma informação qualitativa muito grosseira sobre o efeito da auto-focalização.

Em resumo, deve-se notar que o parâmetro importante para que se tenha autofocalização é a potência do feixe incidente e não a sua intensidade, e que o comportamento detalhado desse feixe depende do seu perfil inicial. Em geral a forma assintóptica de (3.11), $P>P_{2}$, é válida mas as constantes são diferentes para cada tipo de feixe [22].

\subsection{AUTO-MODULAÇÃO DE FASE}

A auto-modulação de fase é um efeito semelhante à auto-focalização. É o resultado de uma combinação do índice não-linear e uma variação temporal da intensidade do feixe de luz que incide no meio. É claro que um pulso de luz focalizado apresenta um índice de refração não-linear que varia espacialmente (transversalmente) e também temporalmente. Por isso algumas vezes o efeito da auto-focalização é chamado de automodulação transversal (ex. Cap. VII da ref. [20]), mas de fato o nome auto-modulação de fase é reservado apenas às mudanças na fase da onda com a variação temporal da intensidade. 
No tratamento da auto-focalização fizemos $A(r, z, t)$ independente do tempo (caso estacionário) e agora só consideraremos a variação do campo com as variáveis $z$ e $t$ (desprezando a parte transversal), ou seja, estamos na aproximação de onda plana. Portanto, as equações pertinentes são (2.7) e a equação de relaxação de Debye (2.28) que no CGS ficam:

$$
\begin{gathered}
\left(\frac{\partial}{\partial z}+\frac{n_{o}}{c} \frac{\partial}{\partial t}\right) A(z, t)=-i \frac{\omega}{c} \Delta n A(z, t) \\
\tau \frac{\partial}{\partial t} \Delta n+\Delta n=\frac{1}{2} n_{2}|A(z, t)|^{2}
\end{gathered}
$$

Note que as eqs. (3.16) se reduzem à eq. (3.9) no caso estacionário $\left(\frac{\partial}{\partial t} \rightarrow 0\right)$, sem a parte transversal. Podemos simplificar estas equações mudando as coordenadas $z$ e $t$ para um sistema de referência que se move junto com o pulso:

$$
\begin{gathered}
z^{\prime}=z \\
t^{\prime}=t-\frac{n_{o} z}{c}
\end{gathered}
$$

e supondo que $\Delta n$ é real e que

$$
A\left(z^{\prime}, t^{\prime}\right)=A_{\mathrm{o}} e^{i \phi}
$$

onde $A_{o}$ e $\phi$ são ambos reais e cada um função de $z^{\prime}$ e $t^{\prime}$, chega-se ao seguinte conjunto de equações:

$$
\frac{\partial A_{o}}{\partial z^{\prime}}=0
$$




$$
\begin{gathered}
\frac{\partial \phi}{\partial z^{\prime}}=-\frac{\omega}{c} \Delta n\left(t^{\prime}\right) \\
\tau \frac{\partial \Delta n}{\partial t^{\prime}}+\Delta n=\frac{1}{2} n_{2} A_{o}^{2}\left(t^{\prime}\right)
\end{gathered}
$$

Por (3.19a) tem-se que $A_{o}=A_{o}\left(t^{\prime}\right)$, ou seja, o pulso se propaga sem deformar-se. E, por (3.19c) e (3.19b), a fase após o pulso propagar-se numa distância $L$ será:

$$
\Phi\left(L, t^{\prime}\right)=-\frac{\omega n_{2} L}{2 c \tau} \int_{-\infty}^{t^{\prime}} A_{o}^{2}\left(t^{\prime \prime}\right) e^{\left(t^{\prime \prime}-t^{\prime}\right) / \tau} d t^{\prime \prime}
$$

e se o tempo de duração do pulso for muito maior do que o tempo de resposta do meio, a equação (3.20) se reduz a:

$$
\Phi\left(L, t^{\prime}\right) \cong-\frac{\omega L n_{2}}{2 c} A_{o}^{2}\left(t^{\prime}\right)
$$

que é uma solução válida também para resposta instantânea do meio.

Na figura 3.1 ilustramos a solução (3.21) no caso de uma excitação Gaussiana com tempo de duração 2T. Na parte (a) mostramos a fase da amplitude do campo $\Phi(L, t)$ normalizada ao seu valor absoluto máximo:

$$
\left|\Phi_{\max }\right|=\frac{\omega L\left|n_{2}\right|}{2 c} A_{p}^{2}
$$

onde $A_{p}$ é a amplitude máxima do campo elétrico e consideramos $n_{2}$ positivo. Enquanto que na parte (b) está representado o deslocamento de frequência $\Delta \omega=\frac{\partial \phi}{\partial t}$, em relação à frequência incidente, também normalizado ao seu valor máximo:

$$
\left|\Delta \omega_{\max }\right|=\frac{1,7\left|\phi_{\max }\right|}{2 T}
$$




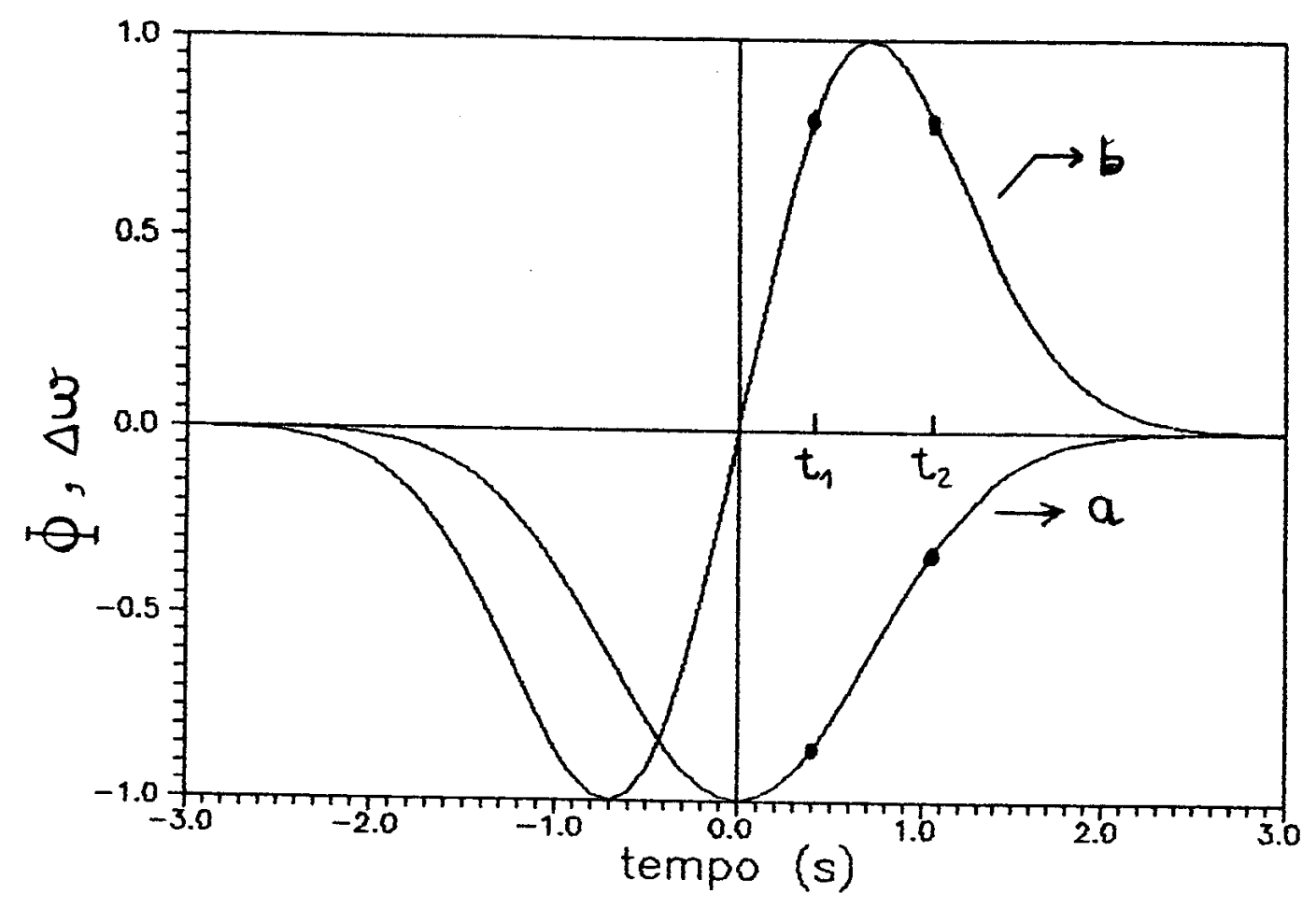

Figura 3.1 Fase (a) e Diferenca de Frequencia (b) normalizados em funcõo do tempo. $T=1,0$ s e $n_{2}$ real e positivo.

Os instantes assinalados nessa figura $\left(t_{1}\right.$ e $\left.t_{2}\right)$ correspondem a um mesmo valor de frequência mas fases diferentes. Consequentemente essas duas componentes do pulso interferem entre si, originando um máximo ou mínimo de interferência no espectro de frequência da intensidade

$$
I\left(\omega^{\prime}\right)=\frac{n_{o} c}{8 \pi}\left|\int_{-\infty}^{\infty} e^{-i \omega^{\prime} t} A_{o}(t) e^{i(\omega t+\Phi(t))} d t\right|^{2}
$$

e o mesmo ocorrerá para quaisquer par de pontos com as mesmas características daqueles indicados, ou seja, mesma frequência. O número de picos de interferência $N_{p}$, em cada lado do espectro de $I\left(\omega^{\prime}\right)$, é igual ao máximo deslocamento de fase $\left|\Phi_{\max }\right|$ dividido por $2 \pi$ : 


$$
N_{p}=\frac{\left|\Phi_{\max }\right|}{2 \pi}=\frac{\omega L\left|n_{2}\right|}{4 \pi c} A_{p}^{2}
$$

Portanto, através de (3.22) - (3.25), vemos que numa experiência de auto-modulação de fase pode-se determinar o índice Kerr contando-se o número de picos no espectro de frequência (ou medindo-se o máximo deslocamento de fase). Outra característica observada na figura 3.1 é que as frequências superiores do espectro $(\Delta \omega>0)$ são determinadas pela parte posterior do pulso $(t>0)$ enquanto que as inferiores $(\Delta \omega<0)$ se devem à parte anterior $(t<0)$.

A simetria (ou não) do espectro de frequências depende basicamente de dois fatores: simetria (ou não) do pulso da luz incidente e do tempo de resposta do índice de refração não-linear. Se o pulso do laser for assimétrico, então o espectro não só será assimétrico em extensão, mas também no espaçamento entre os máximos de interferência e ainda no conteúdo de energia (maior distribuição da energia num dos lados do espectro de frequências). Contudo o número de máximos de interferência permanece o mesmo em cada lado do espectro.

Quanto ao tempo de resposta do meio, se este for da ordem ou maior do que o tempo de duração do pulso, haverá um atraso na mudança de fase com relação ao pulso da luz incidente. Qualitativamente, o gráfico de $\phi(L, t)$ é semelhante ao da figura 3.1-a, mas será deslocado no sentido positivo de $t$. Já o deslocamento em frequência pode ser obtido (de forma aproximada) desprezando-se o segundo termo na equação (3.19c), porque a variação do índice de refração não atingiu o estado estacionário, o que dá

$$
\Delta \omega \cong-\frac{\omega L n_{2} A_{o}^{2}\left(t^{\prime}\right)}{2 c \tau}
$$

ou seja, $\Delta \omega$ tem a forma da figura 3.1-a (compare (3.26) com (3.21)). Daqui se conclui 
que as frequências inferiores $(\Delta \omega<0)$ dominam completamente o espectro, de maneira que este é assimétrico e a parte de frequências superiores possui menos energia e menor número de picos de interferência.

Recordamos que todas as considerações feitas acima tiveram como base um índice nãolinear positivo. É claro que num meio com $n_{2}$ negativo tais considerações permanecem válidas desde que observada uma inversão do eixo vertical na figura 3.1. Neste caso as interpretações são as seguintes:

a) num meio com resposta instantânea, as frequências superiores/inferiores são determinadas pela parte anterior/posterior do pulso.

b) num meio com relaxação, as frequências superiores $(\Delta \omega>0)$ dominam o espectro.

Em vista de tudo que foi abordado, podemos concluir que o grau de simetria do espectro alargado, bem como sua extensão, e o número dos máximos de interferência (e seu espaçamento) fornecem informações importantes sobre as características não-lineares do meio, principalmente sobre seu comportamento dinâmico $\left(\tau\right.$ e $\left.n_{2}\right)$, e ainda permite que se faça uma descrição da propagação temporal do feixe incidente através da equação (3.19c).

\subsection{AUTO-DIFRAÇÃO EM REDES INDUZIDAS POR LASERS}

Quando duas ondas intensas interferem num meio não-linear, os máximos/mínimos de intensidade provocam variações máximas/mínimas no índice de refração. Isto é, aparece uma modulação espacial no índice de refração, e/ou coeficiente de absorção, na região de interferência. Este princípio tem sido usado ao longo dos anos na produção de grades 
permanentes, através de processos fotográficos, em diversos materiais [23].

Aqui discutiremos apenas os tipos de grades dinâmicas ou transitórias, assim denominadas porque desaparecem logo que cessa a interferência entre os feixes de luz. A formação dessas grades está associada à alguma excitação do material, como por exemplo o desvio do equilíbrio térmico, a qual se relaciona ao índice de refração e/ou coeficiente de absorção.

Várias grades diferentes podem ser criadas, em tempos também diferentes, na interferência de apenas dois feixes de luz. Por exemplo, a absorção de luz faz com que surjam estados excitados, ou não, na região de interferência, originando uma grade de densidade de população. Por sua vez, a população desses estados pode decair para outros estados de energia mais baixa (ex. vibracionais) formando grades secundárias (um processo semelhante ocorre na formação de grades de cargas espaciais em materiais foto-refrativos). Em último lugar ocorre o equilíbrio térmico dessas excitações, o que produz uma grade térmica, a qual é sempre acompanhada por compressão ("stress"), tensão ("strain") e variações de densidade. É possível ainda, associada à grade térmica, uma grade de concentracão numa mistura de constituintes diferentes. Mas, seja qual for o tipo da excitação (população, temperatura, etc.) ela está ligada ao conjunto: índice de refração e/ou coeficiente de absorção, e nestes casos originam grades ópticas.

Nas sub-seções a seguir será feita uma discussão sobre os conceitos básicos de formação e deteç̧ão das grades ópticas, com maior ênfase na parte de auto-difração. O material apresentado aqui é um sumário das referências [19] e [24]. No Capítulo 4 apresentaremos um modelo mais completo sobre auto-difração, o qual inclui efeitos de saturação, desenvolvido recentemente por nosso grupo de Óptica [25]. 


\section{5-1. Superposição de Duas Ondas Planas}

Quando duas ondas planas de mesma frequência $\omega$, amplitudes de campo elétrico $A_{p}$ e $A_{B}$, vetores de onda $k_{p}$ e $k_{B}$ formando ângulo $\theta$ entre si, interferem, a onda resultante possui uma intensidade $I$ modulada espacialmente a qual denomina-se de grade de interferência. Isto está representado na figura 3.2. O vetor da grade q é

$$
\mathbf{q}= \pm\left(\mathbf{k}_{\mathbf{p}}-\mathbf{k}_{\mathbf{B}}\right)
$$

(a)

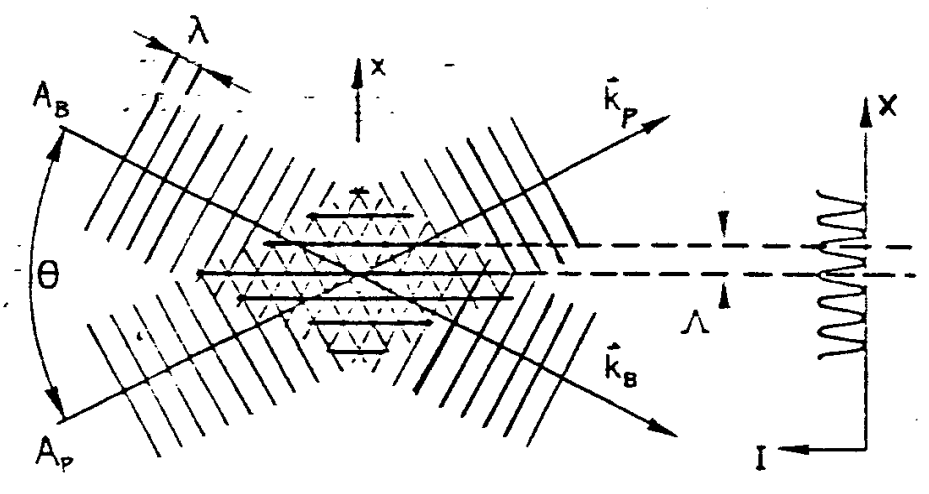

(b)

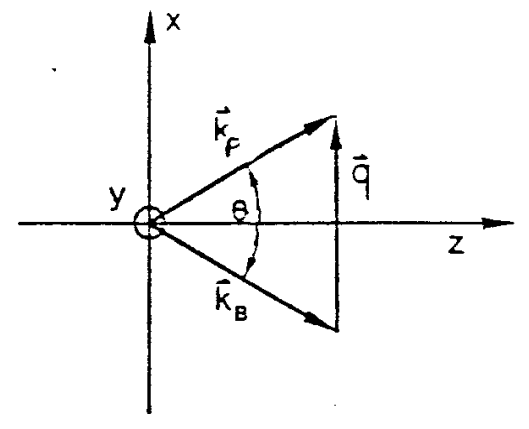

Fig. 3.2. a) Modulação espacial de uma grade de interferência;

b) representação gráfica dos vetores de onda e do vetor da grade q.

e o período espacial $\Lambda$ se relaciona à $q$ e ao comprimento de onda $\lambda$ por

$$
\Lambda=\frac{2 \pi}{q}=\frac{\lambda}{2 \operatorname{sen}(\theta / 2)}
$$

O campo elétrico total $\mathbf{E}(\mathbf{r}, t)$ e a intensidade (MKS), na região de interferência, serão:

$$
\mathbf{E}(\mathbf{r}, t)=\frac{\mathbf{A}}{2}(x, z, t) e^{i\left(\omega t-k_{z} z\right)}+c . c .
$$




$$
\begin{aligned}
I & =\frac{n_{o} c}{2} \epsilon_{o}\left(\mathbf{A} \cdot \mathbf{A}^{*}\right) \\
& =I_{p}+I_{B}+n_{o} c \epsilon_{o}\left(\mathbf{A}_{\mathbf{p}} \cdot \mathbf{A}_{\mathbf{B}}^{*}\right) \cos (\mathbf{q} \cdot \mathbf{r})
\end{aligned}
$$

onde

$$
\mathbf{A}(x, z, t)=\mathbf{A}_{\mathrm{p}} e^{-i k_{z} x}+\mathbf{A}_{\mathrm{B}} e^{i k_{z} x}
$$

À primeira vista a eq. (3.29b) nos diz que não há formação de grade se as duas ondas tiverem polarizações perpendiculares entre si. Isto é devido ao fato de que a expressão da intensidade acima só é válida para meios isotrópicos. Em meios anisotrópicos, a parte que representa a interação entre os campos, $\mathbf{A}_{\mathbf{p}} \cdot \mathbf{A}_{\mathbf{B}}^{*}$, deve ser substituída por um produto tensorial. Desse modo vê-se que é possível a formação de grades com $A_{p} \perp A_{B}$ [19].

Se os feixes interagentes forem pulsados, normalmente originados de lasers com modo travado, a interferência entre eles dependerá do atraso temporal $\tau$ que é decorrente de diferentes caminhos percorridos por ambos. Nesses casos a forma do pulso é do tipo Gaussiana e a interação também seguirá a mesma dependência temporal mas sua amplitude decrescerá com $\tau$ na forma:

$$
\mathbf{A}_{\mathrm{p}} \cdot \mathbf{A}_{\mathrm{B}}^{*} \sim e^{-\left(\frac{r}{2 x}\right)^{2}} e^{-\left(\frac{t}{x}\right)^{2}}
$$

onde $2 T$ é a largura do pulso.

Por outro lado, considerando-se que as fontes de luz reais não são ondas planas e sim, com boa aproximação na maioria dos casos práticos, do tipo Gaussiano (modo TEM ), isto causa uma limitação lateral da região de interferência. Contudo a interferência entre 
esses feixes produzirão grades próximas daquelas formadas por ondas planas se as seguintes condições forem satisfeitas [26]:

1) Mínima largura da zona de interação muito maior do que o período da grade ou, equivalentemente,

$$
q \mathrm{w}>>1
$$

2) Comprimento de superposição, na direção $z$, grande em comparação com a espessura do material.

3) Pouca atenuação dos feixes no material.

A primeira condição impõe um limite na focalização dos feixes (w é o raio do feixe). A segunda limita o ângulo entre os feixes e a última proibe a depreciação da grade pela absorção do meio.

\section{5-2. Grades Finas e Espessas}

A grade óptica, uma vez formada, poderá ser detectada observando-se a difração de uma terceira onda incidente $\mathbf{A}_{c}$. Esta onda pode ser também qualquer uma das duas que formaram a grade, e neste caso tem-se a auto-difração. Seja $\mathbf{k}_{\mathrm{c}}$ o vetor da onda incidente na grade de espessura $d$, formando um ângulo $\alpha$ com o eixo $z$. A m-ésima ordem de difração possui vetor de onda $k_{m}$ e forma um ângulo $\left(\phi_{m}-\alpha\right)$ com o respectivo eixo (veja a figura 3.3). 


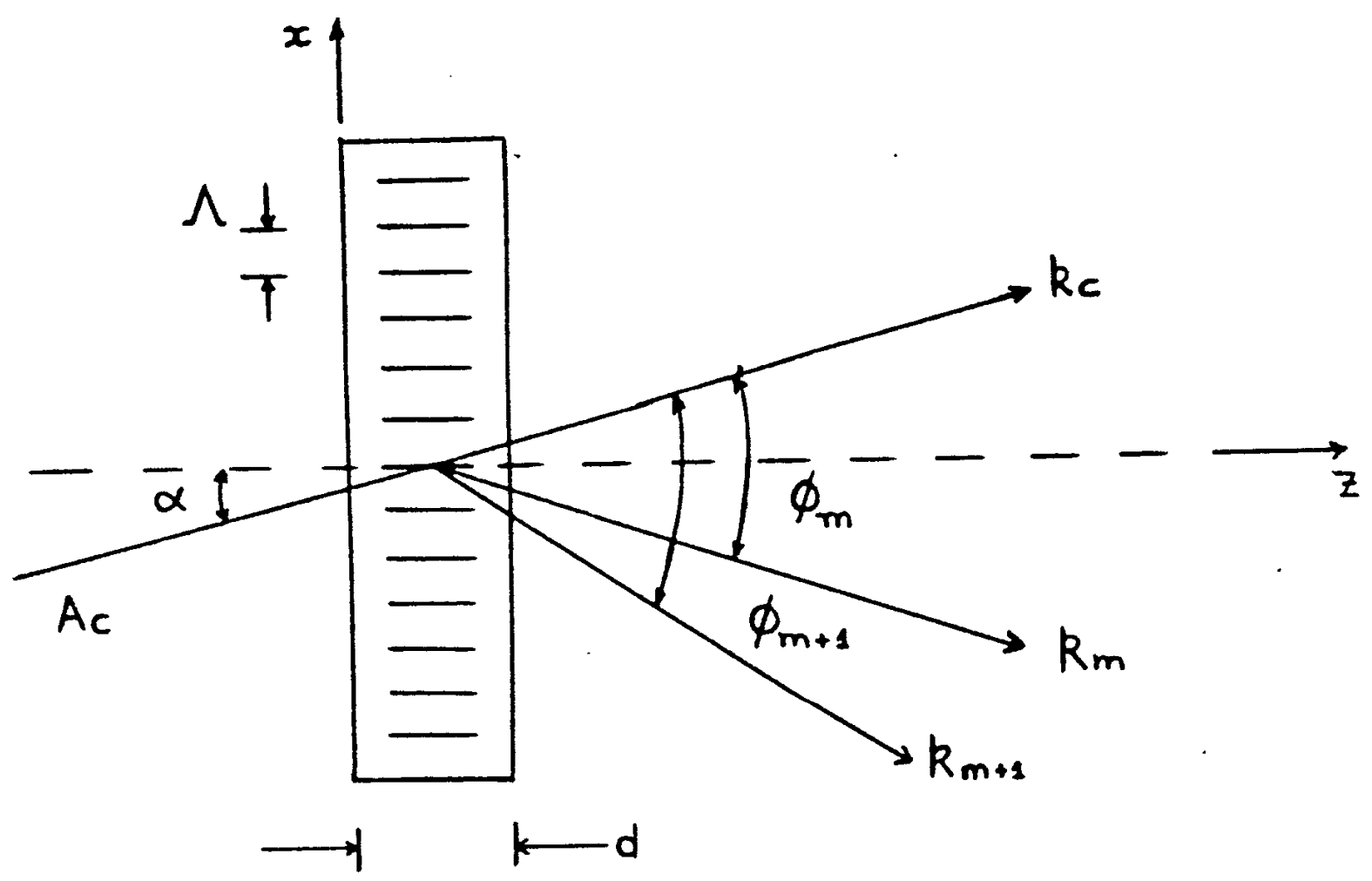

Fig. 3.3. Difração numa grade de espessura d e período $\Lambda$.

A grade é considerada fina se sua espessura é tal que a diferença de fase, experimentada pela onda que a atravessa, for desprezível. Na prática isto equivale à condição

$$
d<<\boldsymbol{\Lambda}
$$

e a grade pode ser representada por uma função periódica $t(x)$, com período $\Lambda$, de modo que a amplitude do campo elétrico após a grade (que é a superposição das ondas difratadas) seja o produto dessa função pela amplitude do campo incidente na grade, a saber:

$$
t(x) A_{c} e^{-i k_{c \varepsilon} x}=\sum_{m} A_{m} e^{-i k_{m x} x}
$$

o que nos dá a seguinte condição 


$$
k_{m x}=k_{c x}+m \frac{2 \pi}{\Lambda}
$$

ou

$$
\operatorname{sen}\left(\phi_{m}-\alpha\right)+\operatorname{sen} \alpha=m \frac{\lambda_{c}}{\Lambda}
$$

onde $m$ é um inteiro representando a ordem de difração. A condição (3.35b) nos diz que, em princípio, é possível a observação de diversas ordens difratadas para direções arbitrárias do feixe incidente!

Por outro lado, se (3.33) não é satisfeita a grade é dita espessa. Podemos dividir uma grade espessa em várias grades finas. Um feixe difratado pela primeira dessas grades apresentará uma diferença de fase $\Delta \phi$ relativa àquele difratado pela última, que é dada por

$$
\begin{aligned}
\Delta \phi & =\left(k_{m z}-k_{c z}\right) d \\
& =2 \pi\left[\cos \left(\phi_{m}-\alpha\right)-\cos \alpha\right] \frac{d}{\lambda_{c}}
\end{aligned}
$$

Esta diferença de fase poderá ser grande e isto causará interferência destrutiva, originando uma intensidade muito fraca da onda difratada. Note que, se o ângulo da onda $\mathbf{A}_{c}$ for escolhido de forma a satisfazer a condição $\phi_{m}=2 \alpha$, nenhuma diferença de fase existirá e, então, todas as ondas difratadas nas grades finas interferirão construtivamente, o que originará uma onda difratada intensa. Esta situação é derivada da condição de Bragg para difração

$$
\mathbf{k}_{\mathbf{m}}=\mathbf{k}_{\mathrm{c}}+\mathbf{m q}
$$

ou 


$$
\operatorname{sen} \alpha=\operatorname{sen}\left(\phi_{m} / 2\right)=m \frac{\lambda_{c}}{2 \Lambda}
$$

o que restringe a direção do vetor $\mathbf{k}_{\mathbf{e}}$.

É importante observarmos que se o feixe difratado pela grade for um dos próprios que a criou, ou seja $\alpha=\theta / 2$ (fig. 3.2), automaticamente a condição de Bragg é satisfeita para $m=1$ e, portanto, a primeira ordem difratada do feixe $A_{B}$ coincide com a ordem zero do feixe $\mathbf{A}_{\mathbf{p}}$ e vice-versa. $O$ caso em questão, denominado de auto-difração, será descrito a seguir.

\section{5-3. Auto-Difração em Redes Espessas}

Do que foi descrito acima, podemos entender que a observação de várias ordens autodifratadas será mais facilmente alcançada se tivermos uma grade fina, pois neste caso não há a limitação imposta pela lei de Bragg. Entretanto, por $(3.28)$ e as condições $(3.32,33)$, vê-se que este tipo de grade precisa ser formada em filmes. Com efeito, para comprimentos de onda no visível e ângulos $\theta$ tão pequenos quanto 1 minuto, a espessura do material deve ser de cerca de $100 \mu \mathrm{m}$.

Já a auto-difração numa rede espessa, mais apropriada em cristais, fica reduzida à existência de praticamente dois feixes, o de ordem zero e o de primeira ordem, por causa da condição de Bragg, a qual implica numa drástica diminuição da eficiência de difração das outras ordens. Sendo este o caso, o processo é denominado de mistura de duas ondas ou TWM ("Two Wave Mixing"). Identificando $A_{p}$ como $A_{o}$ e $A_{B}$ como $A_{1}$, e usando as equações $(3.29,30)$, verifica-se que a amplitude do campo resultante $A$ e a modulação do índice de refração $\Delta n$ (proporcional à intensidade total) serão: 


$$
\begin{gathered}
A=A_{\mathrm{o}}+A_{1} \mathrm{e}^{i(\mathbf{q} \cdot \mathbf{r})} \\
\Delta n=\frac{n_{2}}{2}\left[A_{o} A_{1}^{*} e^{-i(\mathbf{q} \cdot \mathbf{r}+\gamma)}+A_{1} A_{o}^{*} e^{i(\mathbf{q} \cdot \mathbf{r}+\gamma)}\right]
\end{gathered}
$$

onde introduzimos $\gamma$ para representar uma possível diferença de fase entre a grade de intensidade, criada pelos feixes incidentes, e a grade de índice de refração. Esta diferença de fase $\gamma$ pode ser causada, por exemplo, se o meio não responder instantâneamente ou for de resposta não-local.

Por (3.16a) e re-escrevendo a j-ésima amplitude como

$$
A_{j}(z)=\left|A_{j}(z)\right| e^{i \phi_{j}(z)}
$$

onde $\phi_{j}(z)$ é real, chega-se às seguintes expressões:

$$
\begin{aligned}
\frac{d\left|A_{o}\right|}{d z} & =-\left(\frac{\omega n_{2}}{2 c}\right)\left|A_{1}\right|^{2}\left|A_{o}\right| \operatorname{sen} \gamma \\
\frac{d\left|A_{1}\right|}{d z} & =+\left(\frac{\omega n_{2}}{2 c}\right)\left|A_{o}\right|^{2}\left|A_{1}\right| \operatorname{sen} \gamma \\
\frac{d \phi_{o}}{d z} & =-\left(\frac{\omega n_{2}}{2 c}\right)\left|A_{1}\right|^{2} \cos \gamma \\
\frac{d \phi_{1}}{d z} & =-\left(\frac{\omega n_{2}}{2 c}\right)\left|A_{o}\right|^{2} \cos \gamma
\end{aligned}
$$

com $n_{2}$ considerado real e desprezando-se a absorção do meio, por simplicidade.

A solução de (3.41), na forma de intensidades $I_{j}(z)$, em função da intensidade total incidente no meio $I_{T}=I_{o}(0)+I_{1}(0)$, é: 


$$
\begin{aligned}
& I_{o}(z)=I_{T}\left[1+I_{1}(0) I_{o}(0)^{-1} \exp \left(\frac{2 \omega n_{2}}{c} I_{T} \operatorname{sen} \gamma z\right)\right]^{-1} \\
& I_{1}(z)=I_{T}\left[1+I_{o}(0) I_{1}(0)^{-1} \exp \left(-\frac{2 \omega n_{2}}{c} I_{T} \operatorname{sen} \gamma z\right)\right]^{-1}
\end{aligned}
$$

que juntamente com as equações (3.42) nos leva às seguintes conclusões (se $n_{2}>0$ ):

1) Se $\gamma=0$, as duas ondas se propagam independentemente e sem sofrer qualquer modificação em suas intensidades (desprezamos a absorção). No entanto poderá haver uma inclinação na grade de índice, caso as intensidades sejam diferentes, causada pela diferença de fase $\phi_{0}-\phi_{1}$ que surgirá no meio.

2) Se $\gamma \neq 0$, as ondas trocam energia entre si e, se o meio for suficientemente extenso, toda a intensidade $I_{T}$ poderá ser totalmente transferida para o feixe $I_{1}$. E no caso especial $\gamma=\pi / 2$, que ocorre em meios foto-refrativos por exemplo [19], as fases das ondas permanecem inalteradas e, por isso, não ocorre qualquer inclinação da grade de índice.

É importante ressaltar que se o meio não-linear tiver resposta local, nenhuma transferência de energia ocorre pois, neste caso, $\gamma=0$. Isto é decorrente do fato de que o nosso tratamento tem sido feito considerando que a grade é estacionária. Veremos no próximo capítulo que mesmo nesse tipo de meio é possível criar uma grade não-estacionária fazendo-se as frequências ligeiramente diferentes, e que, devido ao tempo de resposta finito, haverá troca de energia. 


\section{MISTURA DE ONDAS EM MEIO KERR SATURÁVEL}

\subsection{INTRODUÇÃo}

No Capítulo anterior vimos que pode-se usar a mistura de duas ondas para transferir energia entre dois feixes de laser. A origem desta troca de energia é uma diferença de fase entre a grade de índice de refração, formada no meio não-linear, e o padrão de interferência dos feixes incidentes. Em meios foto-refrativos a diferença de fase é causada pela própria natureza do efeito foto-refrativo [27], no caso de frequências iguais. Num meio tipo Kerr, entretanto, a mudança de fase é normalmente produzida usando-se frequências diferentes (feixes não-degenerados), o que origina uma grade movendo-se e com uma defasagem proporcional ao tempo de resposta do meio [28].

O meio tipo Kerr é muito estudado principalmente porque é simples de ser tratado tanto analiticamente quanto numericamente. Tal meio é caracterizado por apenas dois parâmetros:

i) índice de refração não-linear $n_{2}$

ii) tempo de resposta $r$

e pode ser usado como modelo para o sistema de dois níveis saturáveis.

A mistura de ondas não-degeneradas em meio Kerr tem sido observada, e tratada teoricamente, em diversos materiais absorvedores ao longo desta última década [29-36]. No entanto, os efeitos de saturação no processo de auto-difração em meios absorvedores saturáveis de dois níveis, só há pouco foram discutidos teoricamente. Primeiro no caso 
particular da mistura de duas ondas não-degeneradas (NDTWM) [37] e recentemente para o processo de mistura de n-ondas por auto-difração [25].

Neste capítulo descreveremos os dois tratamentos, onde mostraremos que os resultados de Zhou et al [37] (seção 4.2) são obtidos como caso particular do nosso modelo [25] (seção $4.3)$.

\subsection{MISTURA DE DUAS ONDAS NÃO DEGENERADAS}

Consideremos duas ondas planas de frequências diferentes, incidindo num meio absorvedor saturável, com campos elétricos linearmente polarizados ao longo do eixo y e vetores de onda no plano x-z, tal como na figura 3.2b. Escrevendo a polarização do meio como:

$$
\mathbf{P}=\frac{\epsilon_{o}}{2} \sum_{j=1}^{2} \chi_{j} \mathbf{A}_{j}(z, t) e^{i\left(\omega_{j} t-k_{j} \cdot r\right)}+c . c .
$$

onde $\chi_{j} \equiv \chi\left(\omega_{j}\right)$ é a susceptibilidade complexa na frequência $\omega_{j}$, substituindo $\mathbf{P}$ e o campo elétrico $\mathbf{E}$ (eq. (2.3a)) na equação de propagação (2.4), chega-se a seguinte expressão para a variação de intensidade $I_{j}$ no meio:

$$
\frac{d I_{j}}{d z}=-\frac{\omega_{j} \chi_{j}^{\prime \prime} I_{j}}{\cos (\theta / 2) n_{o}}
$$

considerando-se o caso estacionário e que é válida a aproximação SVEA. Nesta expressão, $\chi_{j}^{\prime \prime}$ é a parte imaginária da susceptibilidade obtida pela relação:

$$
\chi_{j} \equiv \chi_{j}^{\prime}-i \chi_{j}^{\prime \prime}
$$


A solução da equação (4.2) é imediata, a saber:

$$
\begin{aligned}
& I_{j}(z)=I_{j}(0) e^{-\alpha_{j} z} \\
& \alpha_{j} \equiv \frac{\omega_{j} \chi_{j}^{\prime \prime}}{\cos (\theta / 2) c n_{o}}
\end{aligned}
$$

onde identificamos $\alpha_{j}$ como a absorção do meio na frequência $\omega_{j}$. É preciso que conheçamos $\chi_{j}^{\prime \prime}$ para que possamos descrever o que ocorre com os feixes após atravessarem o meio.

Com esta finalidade, vamos considerar o meio absorvedor saturável como um sistema de dois níveis e que um dos campos, digamos $A_{2}$, seja muito menos intenso do que o outro. Nesta situação podemos usar o formalismo da matriz densidade descrito no capítulo 2, onde o cálculo é feito considerando-se todas as ordens no campo forte $A_{1}$ e apenas a primeira ordem no campo fraco $A_{2}$. Este procedimento é o mesmo que fora adotado por Pinard e Grynberg [38] (e utilizado por Zhou et al [37]) mas nós iremos um pouco mais além com a inclusão de um termo, desprezado no tratamento feito por esses. Os detalhes do desenvolvimento estão descritos no apéndice I e só apresentaremos aqui as linhas gerais.

\section{2.-1. Cálculo das Susceptibilidades}

Sejam $a$ e $b$ os níveis superior e inferior, respectivamente. O tempo de relaxação longitudinal é $T_{1}$ e o transversal é $T_{2}$. Denominando a ordem de perturbação com relação à presença do campo fraco $A_{2}$, tem-se a seguinte condição inicial:

$$
\rho_{a a}^{(o)}+\rho_{b b}^{(o)}=1
$$


ou seja, inicialmente $A_{2}=0$ mas a presença do campo forte $A_{1}$ distribui a população entre os dois níveis. Por (2.22), as equações até a primeira ordem no campo fraco são:

$$
\begin{gathered}
i \hbar \frac{\partial \rho^{(o)}}{\partial t}=\left[H_{o}-\mu E_{1}, \rho^{(o)}\right]+i \hbar\left(\frac{\partial \rho^{(o)}}{\partial t}\right)_{r e l} \\
i \hbar \frac{\partial \rho^{(1)}}{\partial t}=\left[\rho^{(o)}, \mu E_{2}\right]+\left[H_{o}-\mu E_{1}, \rho^{(1)}\right]+i \hbar\left(\frac{\partial \rho^{(1)}}{\partial t}\right)_{\text {rel }}
\end{gathered}
$$

onde $\mu$ é o operador de momento de dipolo elétrico, com elementos de matriz $\mu_{a b}$.

A solução de ordem zero é imediata e nos dá:

$$
\begin{aligned}
& \rho_{a b}^{(o)}=-i \frac{\Omega_{1}\left(\rho_{b b}^{(o)}-\rho_{a a}^{(o)}\right)}{2\left(\Gamma_{a b}-i \delta_{1}\right)} e^{i\left(\omega_{1} t-k_{1} \cdot r\right)} \\
& \rho_{b b}^{(o)}-\rho_{a a}^{(o)}=\left[1+\frac{\Gamma_{a b}\left|\Omega_{1}\right|^{2}}{\Gamma_{a} \delta_{1}^{2}\left(1+r^{2}\right)}\right]^{-1}
\end{aligned}
$$

onde $\Gamma_{a b} \equiv T_{2}^{-1}$ é a taxa de decaimento da coerência, $\delta_{j} \equiv \omega_{0}-\omega_{j}$ é a dessintonia ou "detuning" da frequência $\omega_{j}$ com relação à frequência central da transição $\omega_{o}, \Omega_{j}=$ $\mu_{a b} A_{j} / \hbar$ é a frequência de Rabi e $r$ é dado por

$$
r=-\frac{\Gamma_{a b}}{\delta_{1}}=-\left(\delta_{1} T_{2}\right)^{-1}
$$

que, no sistema de dois níveis, é igual à razão entre as partes imaginária e real da susceptibilidade, na presença de um único campo (ver pág. 153 da ref. [18]).

Para achar a solução na primeira ordem é preciso mais empenho algébrico, embora o cálculo não seja difícil. A maior dificuldade é, com certeza, determinar as combinações de frequências que são importantes em cada elemento da matriz densidade. São elas: 


$$
\begin{gathered}
\rho_{a a}^{(1)}=B e^{i\left(\omega_{2}-\omega_{1}\right) t}+c . c . \\
\rho_{a b}^{(1)}=C e^{i\left(2 \omega_{1}-\omega_{2}\right) t}+D e^{i \omega_{2} t}
\end{gathered}
$$

onde $B, C$ e $D$ são funções dos vetores de onda, mas independem do tempo (aproximação de onda girante).

Substituindo as equações (4.9) em (4.6b), determina-se $D$ e, juntamente com $\rho_{a b}^{(o)}$, obtém-se as susceptibilidades $\chi_{j}$ igualando-se (4.1) com a relação:

$$
\begin{aligned}
P & =N \operatorname{Tr}(\mu \rho) \\
& =N \mu_{b a}\left(\rho_{a b}^{(o)}+\rho_{a b}^{(1)}\right)+c . c .
\end{aligned}
$$

onde $N$ é a densidade de átomos (íons, moléculas, etc.). Finalmente, os coeficientes de absorção para os feixes forte e fraco são respectivamente:

$$
\begin{gathered}
\alpha_{1}=\frac{\alpha_{o}\left[1+\left(\delta T_{2}\right)^{2}\right]^{-1}}{\cos (\theta / 2)\left(1+I_{1} / I_{\delta}\right)} \\
\alpha_{2}=\alpha_{1}\left[1+\frac{\left(\delta T_{2}\right) I_{1} / I_{6}}{1+I_{1} / I_{6}}\left(\frac{\Omega^{\prime}+r}{1+\Omega^{\prime 2}}\right)\right]
\end{gathered}
$$

com $\alpha_{o}$ o coeficiente de absorção linear no centro da linha, $I_{\delta}$ é a intensidade de saturação na frequência $\omega_{j}$, e $\Omega^{\prime}$ é o produto da diferença de frequências pelo tempo de resposta do meio $\tau$. Vejamos:

$$
\alpha_{o}=\frac{N\left|\mu_{a b}\right|^{2} T_{2} \omega_{o}}{\epsilon_{o} \hbar c n_{o}}
$$




$$
\begin{gathered}
I_{\delta}=\frac{n_{o} c \epsilon_{o} \hbar^{2}}{2\left|\mu_{a b}\right|^{2} T_{1} T_{2}}\left[1+\left(\delta T_{2}\right)^{2}\right] \\
\tau=T_{1}\left(1+I_{1} / I_{\delta}\right)^{-1} \\
\Omega^{\prime}=\left(\omega_{1}-\omega_{2}\right) \tau
\end{gathered}
$$

$\mathrm{Na}$ determinação das equações (4.11) consideramos que as frequências são muito próximas e que o tempo de relaxação transversal é muito menor do que o tempo de vida do estado excitado.

No limite $\delta T_{2}>1$ nossa expressão (4.11b) leva ao mesmo resultado de Zhou et al para a intensidade do feixe fraco $I_{2}(z)$ (veja a eq. (10) da ref. [37] e note que falta $z$ multiplicando o termo dentro do parêntesis). Entretanto, no nosso caso é possível prever a diminuição na absorção do feixe fraco causada pela presença do feixe forte, que é originada pelo termo proporcional a $r$ em (4.11b), quando ambos possuem a mesma frequência. Isto é conhecido como branqueamento ou "bleaching".

Embora o referido termo só apareça quando há o feixe forte (ver eq. (I.16)) não devemos confundi-lo como um termo de ganho de energia pelo feixe fraco [31], pois na verdade o branqueamento é devido à diminuição da população do estado fundamental provocada pela presença de ambos os feixes e, como tal, cada um sente este efeito individualmente (ver Seção 4.3). Contudo o efeito não está explícito no feixe forte porque nós consideramos $I_{2} \ll I_{1}$ quando fizemos o cálculo das susceptibilidades, em outras palavras: quando o feixe fraco chega o meio já está sobre a influência do feixe forte e este não "vê" o primeiro. Isto está implícito na forma das equações (4.6). 


\section{2 - 2. Coeficiente de Ganho}

Como vimos acima a absorção do feixe fraco é uma função da diferença de frequência entre os campos (ou $\Omega^{\prime}$ ). Desse modo é possível aumentar (ou diminuir) o coeficiente de absorção $\alpha_{2}$ e, consequentemente, gerar perda (ou ganho) de energia no feixe $A_{2}$. Obviamente o contrário ocorre com o feixe $A_{1}$ porque o meio não é uma fonte de energia!

O parâmetro de ganho exponencial $\Gamma_{1}$ é definido como:

$$
\Gamma_{1}\left(\Omega^{\prime}\right)=\ln \frac{I_{2}\left(L, \Omega^{\prime}\right)}{I_{2}(L, 0)}
$$

$L$ é o comprimento do meio e se $\Gamma_{1}\left(\Omega^{\prime}\right)$ é positivo (negativo) o feixe $A_{2}$ ganha (perde) energia do feixe $A_{1}$. De acordo com (4.4a) e (4.11b) a forma de $\Gamma_{1}\left(\Omega^{\prime}\right)$ é:

$$
\begin{aligned}
\Gamma_{1}\left(\Omega^{\prime}\right)= & \frac{-\alpha_{o} L \delta T_{2}}{\left[1+\left(\delta T_{2}\right)^{2}\right] \cos (\theta / 2)} \frac{I_{1} / I_{\delta}}{\left(1+I_{1} / I_{\delta}\right)^{2}}\left(\frac{\Omega^{\prime}-r \Omega^{\prime 2}}{1+\Omega^{\prime 2}}\right) \\
& =\frac{4 \pi n_{2}^{\prime} L}{\lambda \cos (\theta / 2)} \frac{I_{1}}{\left(1+I_{1} / I_{\delta}\right)^{2}}\left(\frac{\Omega^{\prime}-r \Omega^{\prime 2}}{1+\Omega^{\prime 2}}\right)
\end{aligned}
$$

aqui $\lambda$ é o comprimento de onda (vácuo) da radiação incidente $\left(\lambda_{1} \approx \lambda_{2}\right)$ e $I_{1}$ é o valor médio da intensidade do feixe forte no meio, que é determinado pela relação

$$
I_{1} \equiv \frac{1}{L} \int_{0}^{L} I_{1}(z) d z=I_{1}(0) \frac{\left(1-e^{-\alpha_{1} L}\right)}{\alpha_{1} L}
$$

a qual mostra que a teoria discutida até agora funciona muito bem quando $\alpha_{1} L<<1$. Isto é, quando $I_{1}(z) \cong$ constante $=I_{1}(0)$ (meio opticamente fino) a solução (4.4a) está correta porque a susceptibilidade $\chi_{2}$ independe de $z$. 
A forma (4.15) (obtida por (II.5) do apêndice II) se reduz àquela de McMichael et al [30] quando os efeitos de saturação não são considerados $\left(I_{1} \ll I_{6}\right)[40]$. Vemos que só existe ganho (ou atenuação) se $n_{2}^{\prime}$ for diferente de zero, ou seja, quando a frequência do feixe forte estiver deslocada do centro da banda de absorção. Isto pode ser acompanhado pela figura 4.1 a qual mostra $n_{2}^{\prime}$ e $n_{2}^{\prime \prime}$ em função de $\left(\omega-\omega_{o}\right) T_{2}$, normalizados ao valor máximo do módulo de $n_{2}$ que é $c \alpha_{o} / 2 \omega_{o} I_{\delta}$.Lembramos que o sinal de $r$ é o mesmo de $n_{2}^{\prime}$, conforme a equação (II.6) do apêndice II.

Com a ajuda desta figura e separando o parâmetro de ganho em suas partes simétrica $\Gamma_{S}\left(\Omega^{\prime}\right)$ e anti-simétrica $\Gamma_{A}\left(\Omega^{\prime}\right)$, que são:

$$
\begin{gathered}
\Gamma_{S}\left(\Omega^{\prime}\right) \equiv \frac{1}{2}\left[\Gamma_{1}\left(\Omega^{\prime}\right)+\Gamma_{1}\left(-\Omega^{\prime}\right)\right]=-C\left(\lambda, L, I_{1}\right) n_{2}^{\prime \prime} \frac{\Omega^{\prime 2}}{1+\Omega^{\prime 2}} \\
\Gamma_{A}\left(\Omega^{\prime}\right) \equiv \frac{1}{2}\left[\Gamma_{1}\left(\Omega^{\prime}\right)-\Gamma_{1}\left(-\Omega^{\prime}\right)\right]=C\left(\lambda, L, I_{1}\right) n_{2}^{\prime} \frac{\Omega^{\prime}}{1+\Omega^{\prime 2}}
\end{gathered}
$$

com

$$
C\left(\lambda, L, I_{1}\right) \equiv \frac{4 \pi L}{\lambda \cos (\theta / 2)} I_{1}\left(1+I_{1} / I_{\delta}\right)^{-2}
$$

é fácil de ver que a parte simétrica nunca origina ganho, pelo contrário, a existência da parte imaginária do índice de refração não-linear causa uma diminuição no processo de transferência de energia entre os campos. Isto pode ser entendido do seguinte modo: quando as frequências são iguais há, como dissemos antes, o branqueamento e o feixe fraco sofre menos atenuação ao passar pelo meio, mas se as frequências forem diferentes o feixe fraco será mais absorvido porque, espectroscopicamente, ele não sentirá a presença do outro feixe de luz (o mesmo raciocínio vale para o feixe forte). É como se agora houvesse uma inibição do branqueamento. 


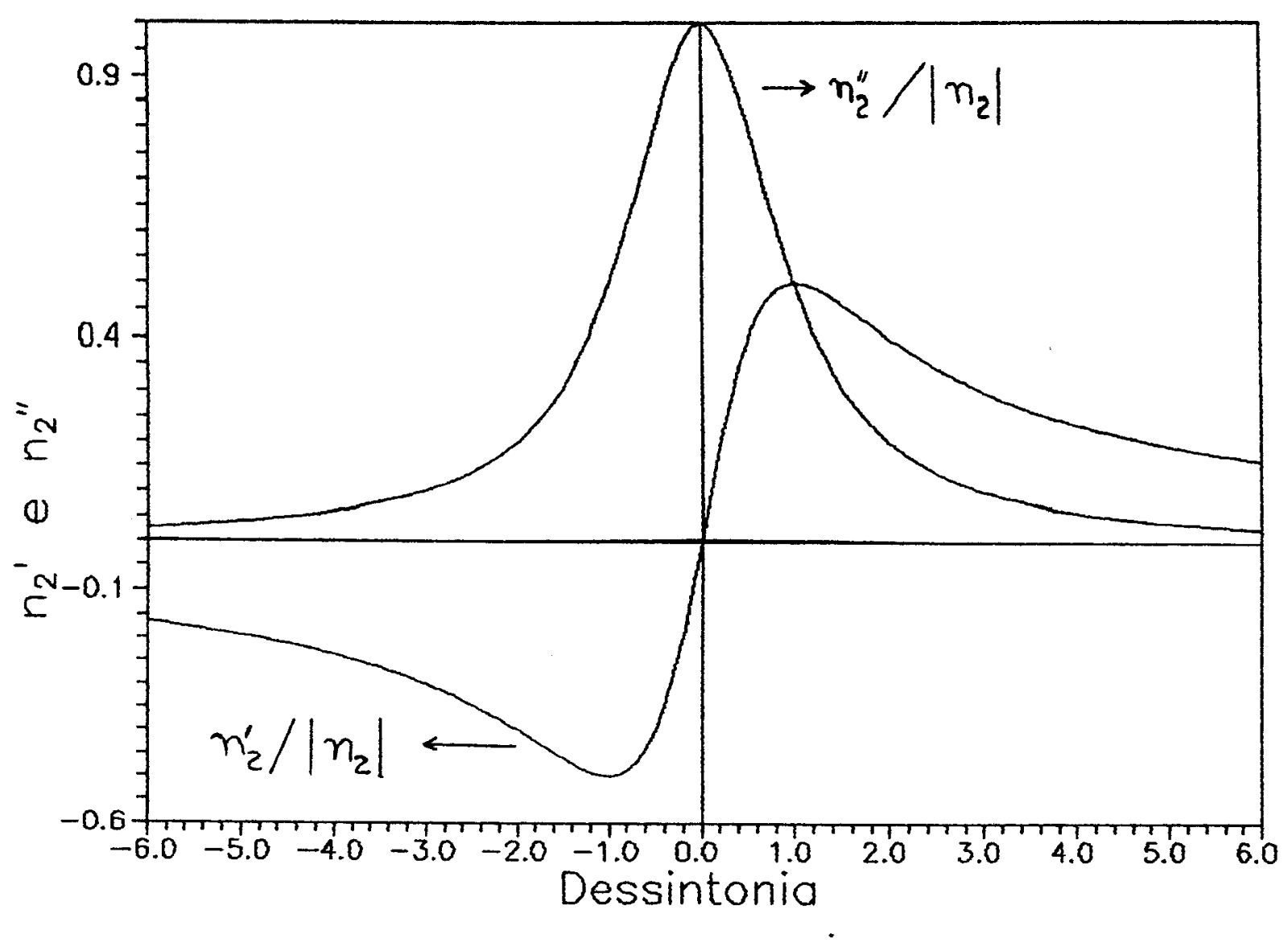

Figura 4.1 Partes Real e Imaginário do Índice Kerr $n_{2}$ versus Dessintonia.

O ganho (ou atenuação) está realmente ligado à parte anti-simétrica e depende exclusivamente de $n_{2}^{\prime}$ e no sinal do produto $n_{2}^{\prime} \Omega^{\prime}$. Por esta razão é que muitas vezes o parâmetro de ganho é definido como $[28,30,31,37]$ :

$$
\Gamma_{2}\left(\Omega^{\prime}\right) \equiv \ln \frac{I_{2}\left(L, \Omega^{\prime}\right)}{I_{2}\left(L,-\Omega^{\prime}\right)}=2 \Gamma_{A}\left(\Omega^{\prime}\right)
$$


e no caso de $n_{2}^{\prime}$ positivo, a curva $\Gamma_{2}\left(\Omega^{\prime}\right) \mathrm{x} \Omega^{\prime}$ é idêntica àquela de $n_{2}^{\prime} \mathrm{x}\left(\omega-\omega_{0}\right) T_{2}$ da figura 4.1. Portanto haverá ganho máximo se $\Omega^{\prime}=1$ e atenuação máxima (ganho do feixe forte) se $\Omega^{\prime}=-1$. O inverso é válido no caso $n_{2}^{\prime}$ negativo.

A medida da curva $\Gamma_{2}\left(\Omega^{\prime}\right)$ permite a determinação da parte real do índice de refração não-linear, o tempo de vida do estado excitado $T_{1}$, pela condição de máximo $\Gamma_{2}\left(\Omega^{\prime}\right)$ em $\Omega^{\prime}=\Omega_{\mu}^{\prime}$ que é

$$
\Omega_{\mu}^{\prime}=\frac{\left(\omega_{1}-\omega_{2}\right) T_{1}}{1+I_{1} / I_{\delta}}=1
$$

e ainda a intensidade de saturação $I_{\delta}$, fixando-se a diferença de frequências em $T_{1}^{-1}\left(I_{1}=\right.$ 0) e variando a intensidade do feixe forte $I_{1}$. Por outro lado, medindo-se $\Gamma_{1}\left(\Omega^{\prime}\right)$ pode-se determinar a parte imaginária $n_{2}^{\prime \prime}$ porque o máximo e mínimo ocorrem em $\Omega_{m a x}^{\prime}$ e $\Omega_{m i n}^{\prime}$, respectivamente que são:

a) $n_{2}^{\prime}>0 \Rightarrow \mathrm{r}>0$

$$
\begin{aligned}
& \Omega_{\max }^{\prime}=\sqrt{1+r^{2}}-\mathrm{r} \\
& \Omega_{\min }^{\prime}=-\sqrt{1+r^{2}}-\mathrm{r}
\end{aligned}
$$

b) $n_{2}^{\prime}<0 \Rightarrow r<0$

$$
\begin{aligned}
& \Omega_{\text {max }}^{\prime}=-\sqrt{1+r^{2}}+|r| \\
& \Omega_{\text {min }}^{\prime}=\sqrt{1+r^{2}}+|r|
\end{aligned}
$$

além disso o gráfico $\Gamma_{1}\left(\Omega^{\prime}\right) \times \Omega^{\prime}$ cruza o eixo $\Omega^{\prime}$ em $\Omega_{o}^{\prime} \neq 0\left(\Gamma_{1}\left(\Omega_{o}^{\prime}\right)=0\right)$ que é dado por:

$$
\Omega_{o}^{\prime}=\frac{1}{r}
$$

Esta condição (4.22) é uma consequência da presença do termo simétrico $\Gamma_{S}\left(\Omega^{\prime}\right)$ o 
qual desloca para baixo a curva anti-simétrica $\Gamma_{A}\left(\Omega^{\prime}\right)$. Daqui concluimos que um desvio da anti-simetria na curva $\Gamma_{1}\left(\Omega^{\prime}\right)$ indica de imediato um valor não nulo de $n_{2}^{\prime \prime}$.

Gostaríamos de enfatizar a contribuição deste modelo no que diz respeito à dependência da condição de máximo ganho com a intensidade, expressa em (4.19). 0 máximo de $\Gamma_{2}\left(\Omega^{\prime}\right)$ versus $I_{1} / I_{6}$ não ocorre em $I_{1}=I_{6}$ (caso em que $\Omega^{\prime}$ é independente de $I_{1}$ ) e sim em $I_{1} \simeq 0,68 I_{6}$ (fixado $\omega_{1}-\omega_{2}=T_{1}^{-1}$ ). Zhou et al [37] confirmaram experimentalmente a validade de (4.19) numa pastilha de vidro contendo corante e recentemente medidas feitas no rubi e $\mathrm{GdAlO}_{3}: \mathrm{Cr}^{3+}$ também mostraram o mesmo comportamento $[25,41]$. Nossa contribuição, com a extensão do tratamento de Zhou et al até o termo simétrico, também não é mínima por causa dos interessantes aspectos discutidos ao longo desta seção e que estão relacionados a presença deste termo.

\subsection{MISTURA DE VÁRIAS ONDAS NÃO DEGENERADAS}

Nesta seção descreveremos o modelo desenvolvido em nosso grupo para o tratamento do processo da mistura de muitas ondas, interpretadas como auto-difração numa grade de interferência não-estacionária que é formada por dois feixes, incidentes num meio absorvedor saturável, de frequências diferentes mas próximas uma da outra. A motivação deste trabalho [25] foi a observação dos efeitos da intensidade na condição de máximo ganho (equação (4.19)) além da necessidade de entender a curva de saturação e a variação da intensidade do feixe difratado em ordem superior, com o parâmetro de dessintonia $\Omega^{\prime}$, que havíamos detectado no $\mathrm{GdAlO}_{3}: \mathrm{Cr}^{3+}[36]$. Quando iniciamos o trabalho ainda não havia na literatura nada a respeito dos efeitos de saturação, embora tais efeitos já tinham sido observados na mistura de duas ondas [30], e o tratamento teórico de Zhou et al [37] foi publicado nesse meio tempo. 
Um outro tratamento a respeito da TWM foi publicado recentemente por Fujiwara et al [42] que, como veremos, está contido no nosso modelo como um caso particular.

\section{3-1. Descrição do Modelo}

Nosso modelo é uma extensão do tratamento de Fragnito et al [43] que investigaram o problema da auto-difração em grades de população estacionárias. Como já discutimos anteriormente, é a diferença de frequência entre os feixes que origina o ganho e por isso nós consideraremos o caso não-degenerado.

O meio absorvedor será representado por um sistema de três níveis, no qual o nível que é bombeado (i) decai muito rapidamente para o nível chamado de excitado (e). Esta situação corresponde ao caso $\gamma>>T_{i}^{-1}, T_{1}^{-1}$, que está mostrada no apêndice III. Então a equação que descreve a densidade de população $n_{e}$ do estado excitado é:

$$
T_{1} \frac{d n_{e}}{d t}+\left[1+S^{(o)}(x, z, t)\right] n_{e}=S^{(o)}(x, z, t)
$$

onde $S^{(o)}(x, z, t)$ é a intensidade total incidente no meio dividida pela intensidade de saturação $I_{6}$ e é denominado de parâmetro de saturação. Consideraremos apenas o caso de duas ondas planas, incidindo no meio com intensidades $I_{o}^{+}(z)$ e $I_{o}^{-}(z)$, o que leva à:

$$
\begin{gathered}
S^{(o)}(x, z, t)=S_{o}(z)+S_{1}(z) \cos (q x-\Delta \phi-\Omega t) \\
S_{o}(z) \equiv\left[I_{o}^{+}(z)+I_{o}^{-}(z)\right] / I_{\delta} \\
S_{1}(z) \equiv 2 \sqrt{I_{o}^{+}(z) I_{o}^{-}(z)} / I_{\delta}
\end{gathered}
$$


onde $q=2 \pi / \Lambda$ é o módulo do vetoí da grade (eq. (3.36)), $\Delta \phi=\phi_{o}^{+}-\phi_{o}^{-}$é a diferença de fase entre as duas ondas e $\Omega=\omega_{+}-\omega_{-}$é a respectiva diferença de frequências. Para resolver (4.23) vamos expandir em série de Fourier $\left(1+S^{(0)}\right)^{-1}$ e $n_{e}$ na forma:

$$
\begin{gathered}
\frac{1}{1+S^{(0)}}=\sum_{\ell=-\infty}^{\infty} B_{\ell}(z) e^{i \ell(q x-\Delta \phi-\Omega t)} \\
n_{e}=\sum_{\ell=-\infty}^{\infty} C_{\ell}(z) e^{i \ell(g x-\Delta \phi-\Omega t)}
\end{gathered}
$$

os coeficientes $B_{\ell}$ podem ser determinados diretamente de (4.24a) que dá:

$$
\begin{aligned}
B_{\ell} & =\frac{1}{\Lambda} \int_{o}^{\Delta} \frac{e^{-i \ell(q x-\Delta \phi-\Omega t)}}{1+S^{(o)}} d x \\
& =\left[\sqrt{\left(1+S_{o}\right)^{2}-S_{1}^{2}}-\left(1+S_{o}\right)\right]^{|\ell|}\left[\left(1+S_{o}\right)^{2}-S_{1}^{2}\right]^{-\frac{1}{2}} S_{1}^{-|\ell|}
\end{aligned}
$$

aqui não explicitamos a dependência em $z$ apenas para simplificar a notação.

A substituição das eqs. $(4.25,26)$ em $(4.23)$ nos leva à seguinte relação de recorrência:

$$
C_{p}\left(1-i \Omega T_{1} B_{o} p\right)-i \Omega T_{1} \sum_{m \neq 0}(p-m) C_{p-m} B_{m}=\delta_{p, o}-B_{p}
$$

Note que cada $B_{p}$ é sempre menor do que um e deverá decrescer com o aumento da ordem $p$, então podemos truncar a soma até $m=p$. Feito isto os coeficientes $C_{p}$ serão:

$$
\begin{gathered}
C_{o}=1-B_{o} \\
C_{p \neq o}=\frac{-B_{p}}{\Pi_{m=1}^{p}\left(1-i m \Omega T_{1} B_{o}\right)}
\end{gathered}
$$

e como $n_{e}$ é real tem-se $C_{-p}=C_{p}^{*}$. Essas expressões são válidas para qualquer intensidade dos feixes, entretanto experimentalmente o interesse é no caso em que um dos feixes possui 
intensidade muito menor do que a do outro e isto implica na condição $S_{1}<<S_{o}$ e simplifica sobre maneira os coeficientes $C_{p}$ que nesta situação serão:

$$
\begin{gathered}
C_{o}=S_{o}\left(1+S_{o}\right)^{-1} \\
C_{p \neq 0}=\frac{(-1)^{p+1}\left(1+S_{o}\right)^{-1}}{\Pi_{m=1}^{p}\left(1-i m \Omega^{\prime}\right)}\left[\frac{S_{1}}{2\left(1+S_{o}\right)}\right]^{|p|}
\end{gathered}
$$

$\operatorname{com} \Omega^{\prime}=\Omega T_{1}\left(1+S_{o}\right)^{-1}$ como em (4.12d).

Uma vez determinada a densidade de população do estado excitado é preciso resolver a equação de onda para o campo elétrico total $\mathbf{E}$ e, por simplicidade, vamos supor que as duas ondas incidentes são linearmente polarizadas. No estado estacionário e considerando $\Omega<<\omega_{+}, \omega_{-}$por (2.4) tem-se:

$$
\nabla^{2} E+\left(\frac{\omega}{c}\right)^{2}\left(\eta^{2}+\chi_{\sigma}+\frac{S}{1+S} \chi_{N L}\right) E=0
$$

$\eta$ é o índice de refração do material que hospeda o sistema absorvedor, $\chi_{N L}=\chi_{e}-\chi_{g}$ é a diferença entre as susceptibilidades do estado excitado e fundamental, respectivamente. Segundo as leis da difração em grades [19] e através da figura 4.2 tem-se:

$$
\eta \operatorname{sen} \theta_{p}=(2 p+1) \operatorname{sen}(\theta / 2)
$$




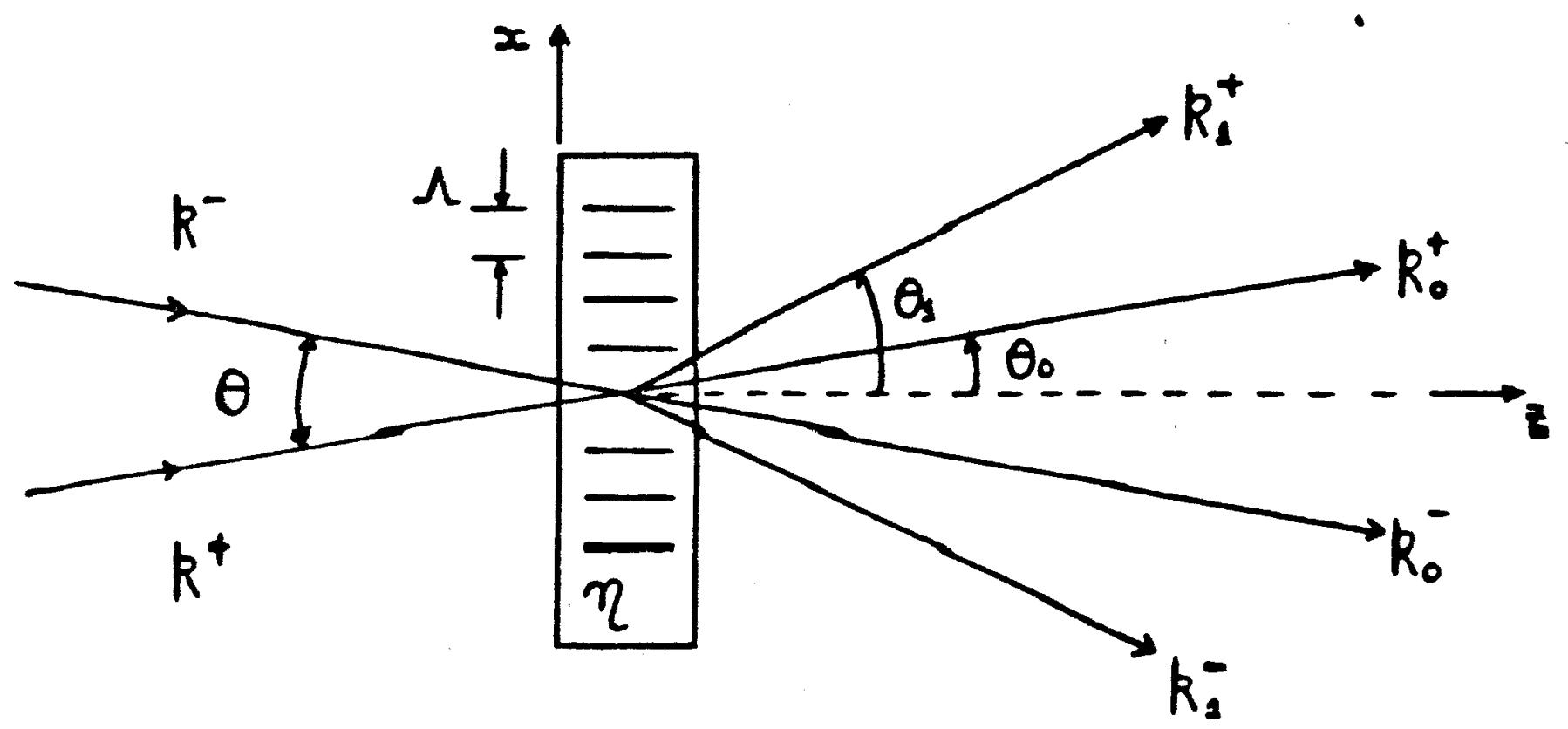

Fig. 4.2. Auto-difração numa grade de população.

e considerando pequenos ângulos podemos escrever:

$$
\begin{gathered}
\mathbf{k}_{\mathrm{p}}^{ \pm} \cdot \mathbf{r} \simeq \beta_{p} z \pm\left(p+\frac{1}{2}\right) q x \\
\omega_{+}^{p}=\omega+(p+1) \Omega \\
\omega_{-}^{p}=\omega-p \Omega
\end{gathered}
$$

$\operatorname{com} \beta_{p}=\frac{\omega \eta}{c} \cos \theta_{p}$ a componente $z$ do vetor de onda da p-ésima ordem difratada. Após essas considerações o campo elétrico se escreve: 


$$
\begin{aligned}
E(z, t) & =\frac{e^{i \omega t}}{2} \sum_{p=0}^{\infty}\left\{A_{p}^{+}(z) e^{i\left|(p+1) \Omega t-\left(p+\frac{1}{2}\right) q x\right|}+\right. \\
& \left.+A_{p}^{-}(z) e^{i\left|-p \Omega t+\left(p+\frac{1}{2}\right)\right| q x \mid}\right\} e^{-i \beta, z}+\text { c.c. }
\end{aligned}
$$

onde $A_{\mathrm{p}}^{ \pm}$são as amplitudes do campo elétrico de cada onda com componentes de $\mathbf{k}_{\mathbf{p}}$ na direção positiva $(t)$ ou negativa $(-)$ do eixo $x$. Após substituição de (4.35) em (4.31) chega-se finalmente a:

$$
\begin{aligned}
\frac{d A_{p}^{+}}{d z} & =-i \gamma_{p}\left\{\chi_{g} A_{p}^{+}+\chi_{N L} \sum_{m=o}^{\infty} e^{i\left(\beta_{p}-\beta_{m}\right) z}\left[C_{m-p} A_{m}^{+} e^{i(p-m) \Delta \phi}+\right.\right. \\
& \left.\left.+C_{p+m+1}^{*} A_{m}^{-} e^{i(p+m+1) \Delta \phi}+D_{p m}^{+}(E)\left(1-\delta_{o, m}\right)\right]\right\} \\
\frac{d A_{p}^{-}}{d z} & =-i \gamma_{p}\left\{\chi_{g} A_{p}^{-}+\chi_{N L} \sum_{m=o}^{\infty} e^{i\left(\beta_{p}-\beta_{m}\right) z}\left[C_{m-p}^{*} A_{m}^{-} e^{i(m-p) \Delta \phi}+\right.\right. \\
& \left.\left.+C_{p+m+1} A_{m}^{+} e^{-i(p+m+1) \Delta \phi}+D_{p m}^{-}(E)\left(1-\delta_{o, m}\right)\right]\right\}
\end{aligned}
$$

com

$$
\gamma_{p}=\omega^{2} / 2 c^{2} \beta_{p}
$$

Nessas equações os termos contendo os coeficientes $C$ 's representam o espalhamento na grade não-harmônica produzida apenas pelos feixes incidentes, enquanto os coeficientes $D$ 's descrevem a deformação dessa grade devida a interferência das ondas difratadas com as ondas de bombeamento [43] e a origem destes termos pode ser acompanhada no Apêndice IV. Em princípio a amplitude de qualquer ordem difratada pode ser determinada por (4.36) juntamente com os coeficientes $C$ 's de (4.29) e os $D$ 's determinados como no Apêndice IV, já incluídos os efeitos de saturação. A complexidade do problema depende do grau de aproximação desejada, entretanto quando $S_{1}<S_{o}$ poucos termos precisam 
ser considerados, o que leva a uma grande simplificação. Verificaremos agora a validade de nosso modelo no caso da mistura de duas ondas e no próximo capítulo compararemos com os resultados experimentais em Rubi, Alexandrita e $\mathrm{GdAlO}_{3}: \mathrm{Cr}^{3+}$.

\section{3-2. Aplicação do Modelo à Mistura de Duas Ondas}

Quando apenas duas ondas estão no meio isto significa que só a ordem zero deve ser considerada e por (4.36) tem-se imediatamente:

$$
\begin{aligned}
& \frac{d A_{o}^{+}}{d z}=-i \gamma_{o}\left[\left(\chi_{g}+\chi_{N L} C_{o}\right) A_{o}^{+}+\chi_{N L} C_{1}^{*} e^{i \Delta \phi} A_{\circ}^{-}\right] \\
& \frac{d A_{o}^{-}}{d z}=-i \gamma_{o}\left[\left(\chi_{o}+\chi_{N L} C_{o}\right) A_{o}^{-}+\chi_{N L} C_{1} e^{-i \Delta \phi} A_{o}^{+}\right]
\end{aligned}
$$

Se o meio for opticamente fino e $I_{o}^{-}<I_{o}^{+}$o coeficiente $C_{o}$ é aproximadamente constante pois a intensidade do feixe forte $I_{o}^{+}$não deve mudar muito ao longo do meio. Neste caso o termo entre parêntesis só contribui para a fase de cada onda (a parte real) e para o coeficiente de absorção (a parte imaginária), enquanto os outros termos são os responsáveis pela troca de energia entre as duas ondas. O coeficiente de absorção (intensidade) $\alpha$ será:

$$
\alpha \equiv 2 \gamma_{o}\left(\chi_{g}^{\prime \prime}+\chi_{N L}^{\prime \prime} C_{o}\right)=\frac{\alpha_{g}\left(1+S_{o}\right)^{-1}}{\cos \theta_{o}}
$$

onde $\alpha_{g}$ é o coeficiente de absorção do estado fundamental na frequência do laser e $\chi_{N L}^{\prime \prime}=-\chi_{g}^{\prime \prime}$ tanto no sistema de dois níveis ou no de três níveis que nós descrevemos no apêndice III. Substituindo $C_{1}$ e com $n_{2}=n_{2}^{\prime}+i n_{2}^{\prime \prime}$ e $r=n_{2}^{\prime \prime} / n_{2}^{\prime}$ (apêndice II), as equações para as intensidades são: 


$$
\begin{aligned}
& \frac{d I_{o}^{+}}{d z}=\left(\frac{4 \pi}{\lambda \cos \theta_{o}}\right) n_{2}^{\prime}\left(1+S_{o}\right)^{-2}\left(\frac{r-\Omega^{\prime}}{1+\Omega^{\prime 2}}\right) I_{o}^{-} I_{o}^{+}-\alpha I_{o}^{+} \\
& \frac{d I_{o}^{-}}{d z}=\left(\frac{4 \pi}{\lambda \cos \theta_{o}}\right) n_{2}^{\prime}\left(1+S_{o}\right)^{-2}\left(\frac{r+\Omega^{\prime}}{1+\Omega^{\prime 2}}\right) I_{o}^{-} I_{o}^{+}-\alpha I_{o}^{-}
\end{aligned}
$$

Estas expressões reduzem-se às de Fujiwara et al [42] se escrevemos as amplitudes dos campos e, como dissemos, é um caso particular do nosso modelo. Se os efeitos de saturação forem desconsiderados $\left(S_{o}<1\right)$ os resultados são os mesmos da mistura de duas ondas anteriormente conhecidos $[28,29,31]$.

Vê-se também que os termos que dependem de $r$ não provocam ganho e simplemente representam o branqueamento de um feixe pelo outro. E ainda se $I_{o}^{-}<<I_{o}^{+}$o primeiro termo em (4.39a) pode ser desprezado e a absorção do feixe forte satura com $\left(1+S_{o}\right)^{-1}$ enquanto a do feixe fraco satura com $\left(1+S_{o}\right)^{-2}$, no caso de $\Omega^{\prime}=0$ e lembrando que

$$
n_{2}^{\prime \prime}=\frac{\alpha_{g} \lambda}{4 \pi I_{\delta}}
$$

que é o mesmo resultado do tratamento de Zhou et al [37].

As equações (4.39) só admitem soluções analíticas exatas se $r=0$ e no limite $S_{o}<<1$. Estas soluções prevêem um aumento da intensidade $I_{o}^{-}(z)$ (e contínua diminuição de $I_{o}^{+}(z)$ ) com o comprimento do meio até um certo comprimento tal que o ganho iguala-se às perdas [29]. Se $r$ é diferente de zero só é possível obter soluções numéricas, contudo se a depreciação do feixe forte for desprezível pode-se chegar às seguintes soluções aproximadas:

$$
I_{o}^{+}(L)=I_{o}^{+}(0) e^{-\alpha L}
$$




$$
I_{o}^{-}(L)=I_{o}^{-}(0) \exp \left[\left(g \frac{r+\Omega^{\prime}}{1+\Omega^{\prime 2}}-\alpha\right) L\right]
$$

onde

$$
g=\frac{4 \pi}{\lambda \cos \theta_{0}} \frac{n_{2}^{\prime} I_{o}^{+}(0)}{\left(1+S_{0}\right)^{2}}\left(\frac{1-e^{-\alpha L}}{\alpha L}\right)
$$

e $L$ é o comprimento do meio não linear. A partir destas soluçōes chega-se às mesmas expressões para os ganhos $\Gamma_{1}\left(\Omega^{\prime}\right)$ e $\Gamma_{2}\left(\Omega^{\prime}\right)$ definidos na seção 4.2-2 (eqs. (4.15) e (4.18)) e, portanto, as demais conclusões contidas naquela seção continuam válidas. 


\section{RESULTADOS EXPERIMENTAIS EM $\mathrm{Al}_{2} \mathrm{O}_{8}$, $\mathrm{BeAl}_{2} \mathrm{O}_{4} \mathrm{E} \mathrm{GdAlO}$. DOPADOS COM Cr ${ }^{3+}$}

\subsection{INTRODUÇÃO}

Neste capítulo faremos um resumo das características dos cristais utilizados (seção 5.2), descreveremos em detalhes a mistura de duas ondas (seção 5.3) e discutiremos os nossos resultados experimentais obtidos nesses cristais (seções 5.4 a 5.6). Antes, porém, precisamos fazer algumas observações com relação aos valores aqui apresentados e que diferem daqueles previamente publicados [36]. Isto é devido ao seguinte:

i - Os coeficientes de absorção foram medidos naquela ocasião num instrumento recémadquirido (Cary 2315) que estava com defeito, causando um achatamento na escala de absorbância. Refizemos as medidas num espectrômetro Cary-17 com luz não-polarizada e também polarizada. Medimos ainda com laser de argônio na linha $5145 \AA$ com polarização vertical. A diferença entre essas medidas foram menores do que $5 \%$.

ii - Como foi discutido na seção 4.2-2, a intensidade de saturação não ocorre em $I_{o}^{+}(0)=I_{\delta}$ (o resultado conhecido naquela ocasião). Mas pode-se mostrar que quando fixamos a frequência da rampa num valor que corresponde ao máximo $\Gamma_{2}\left(\Omega^{\prime}\right)$ numa certa intensidade $i$ (o que foi feito) e a seguir aumentamos a intensidade do feixe forte, o máximo ocorre numa intensidade $I_{\max }$ dada por:

$$
I_{\max }=0,68 I_{\delta}+0,29 i
$$

desde que $i$ seja menor do que $I_{\delta} / 3$. Nossas medidas da saturação foram feitas com a rampa fixa quando a intensidade do feixe forte era $i=0,1 \mathrm{~kW} / \mathrm{cm}^{2}$. Portanto, as intensidades de 
saturação atuais relacionam-se às anteriormente determinadas $I_{\delta}^{\prime}$ por:

$$
I_{\delta}=\frac{\left(I_{\delta}^{\prime}-0,29 i\right)}{0,68} \frac{\left(1-e^{-\alpha L}\right)}{\alpha L}
$$

onde incluimos aqui o fator discutido em (4.16).

iii - As diferenças nos valores de $n_{2}^{\prime}$ são consequências dessas correções nos coeficientes de absorção, intensidades de saturação e da inclusão da intensidade média (4.16) no parâmetro de saturação $S_{o}$.

\subsection{CARACTERÍSTICAS DAS AMOSTRAS}

Cristais dopados com $\mathrm{Cr}^{3+}$ são bastante estudados principalmente porque oferecem grande potencialidade para ação laser. Os lasers de rubi $\left(\mathrm{Al}_{2} \mathrm{O}_{3}: \mathrm{Cr}^{3+}\right)[1]$ e o de alexandrita $\left(\mathrm{BeAl}_{2} \mathrm{O}_{4}: \mathrm{Cr}^{3+}\right)[44]$ são exemplos. De maneira geral os materiais dopados com $\mathrm{Cr}^{3+}$ apresentam duas bandas largas de absorção na região do visível, centradas em $400 \mathrm{~nm}$ $\left({ }^{4} \mathrm{~T}_{1 a}\right)$ e $550 \mathrm{~nm}\left({ }^{4} \mathrm{~T}_{2}\right)$. O bombeamento numa dessas bandas é seguido por decaimento não radiativo muito rápido $\left(\sim 10^{-9} \mathrm{~s}\right)$ para um terceiro nível $\left({ }^{2} \mathrm{E}\right)$ o qual possui tempo de decaimento relativamente longo $\left(\sim 10^{-3} \mathrm{~s}\right)$ e praticamente não há depopulação direta da banda excitada para o estado fundamental, ou seja, a eficiência quântica é próxima da unidade [50]. Portanto, tais materiais podem ser modelados por um sistema de três níveis sendo o nível excitado ${ }^{2} \mathrm{E}$ denominado de meta-estável e o seu longo tempo de vida se deve a regra de seleção de spin que proibe a transição por dipolo elétrico para o estado fundamental ${ }^{4} A_{2}$. Em consequência destas características consegue-se inverter a população com intensidades relativamente baixas (alguns $\mathrm{kW} / \mathrm{cm}^{2}$ ) porque a intensidade de saturação é determinada pelo tempo de decaimento do estado meta-estável. 
0 diagrama de níveis de energia do $\mathrm{Cr}^{3+}$ nos três materiais aqui estudados são similares e apresentamos na figura 5.1 o referente ao rubi segundo a referência [45]. A alexandrita e o $\mathrm{GdAlO}_{3}: \mathrm{Cr}^{3+}$ apresentam algumas particularidades, além de diferentes posições dos níveis de energia. No $\mathrm{GdAlO}_{3}: \mathrm{Cr}^{3+}$ o estado fundamental não é degenerado mas sim desdobrado em quatro níveis [46]. Na alexandrita os íons de cromo podem ocupar dois tipos de sítios de simetria: o de inversão e o de espelho ("mirror site"), em contraste

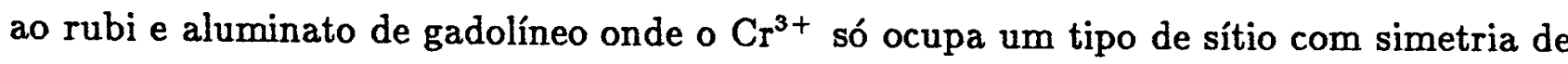
inversão.

A transição entre estados de uma mesma configuração é proibida por dipolo elétrico se o ín está num centro de simetria de inversão e é, digamos, "mais permitida" quando o ín ocupa um centro sem tal simetria. É porque neste último caso os termos ímpares do campo cristalino permite a mistura de estados de outra configuração com paridade oposta aos estados originais (veja por exemplo ref. [47]). Em consequência disto o tempo de decaimento dos íons no sítio de simetria de espelho é muito menor do que o daqueles íons no centro de simetria de inversão [56].

Nas figuras 5.2 a 5.4 são mostrados os espectros de absorção não polarizados e à temperatura ambiente para as três amostras aqui estudadas. O eixo vertical registra absorbância (Abs) ou Densidade Óptica. Esses espectros foram obtidos com um espectrômetro Cary 2315. Neles podem ser vistas as bandas ${ }^{4} T_{2}(550 \mathrm{~nm}),{ }^{4} T_{1 a}(400 \mathrm{~nm})$ e ${ }^{4} \mathrm{~T}_{1 b}(250 \mathrm{~nm})$. Também pode-se ver a absorção para o nível ${ }^{2} \mathrm{E}$ em $694 \mathrm{~nm}$ no rubi e em $680 \mathrm{~nm}$ na alexandrita. No aluminato de gadolíneo esta transição situa-se em $726 \mathrm{~nm}$ e é por isso que não aparece na figura 5.4.

Notamos ainda que o aluminato apresenta uma diferença muito grande com relação aos outros dois compostos na região de $200-300 \mathrm{~nm}$. Isto é porque, além da banda ${ }^{4} \mathrm{~T}_{1 b}$ e da banda de transferência de carga do $\mathrm{Cr}^{3+}$, existe também uma superposição da banda 
de exciton do Gd e ainda a banda de centros de cor que se formam quando do crescimento do cristal de $\mathrm{GdAlO}_{3}$ [48].

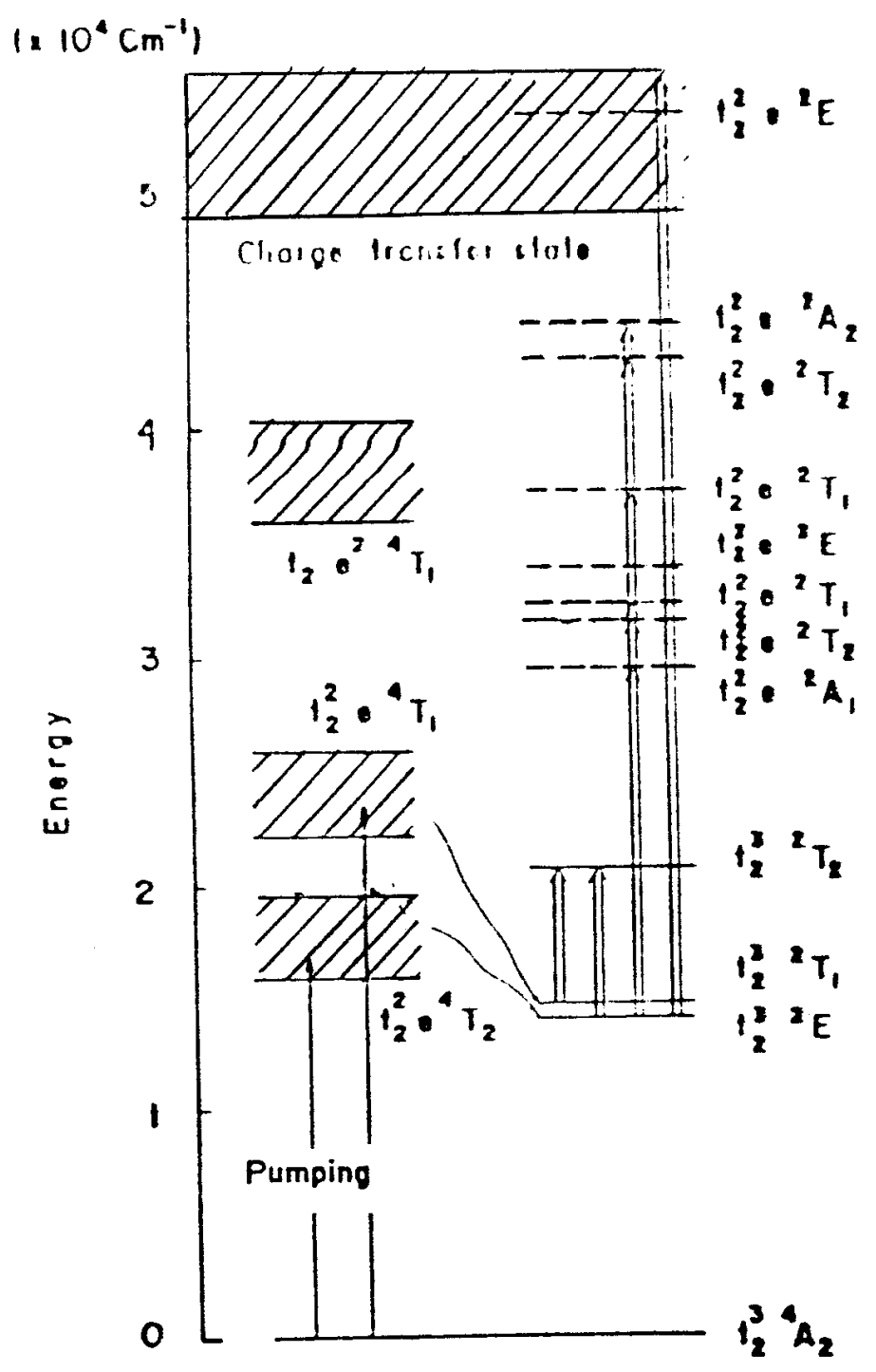

Figura 5.1. Diagrama dos níveis de energia do rubi, segundo Kushida[45]. 


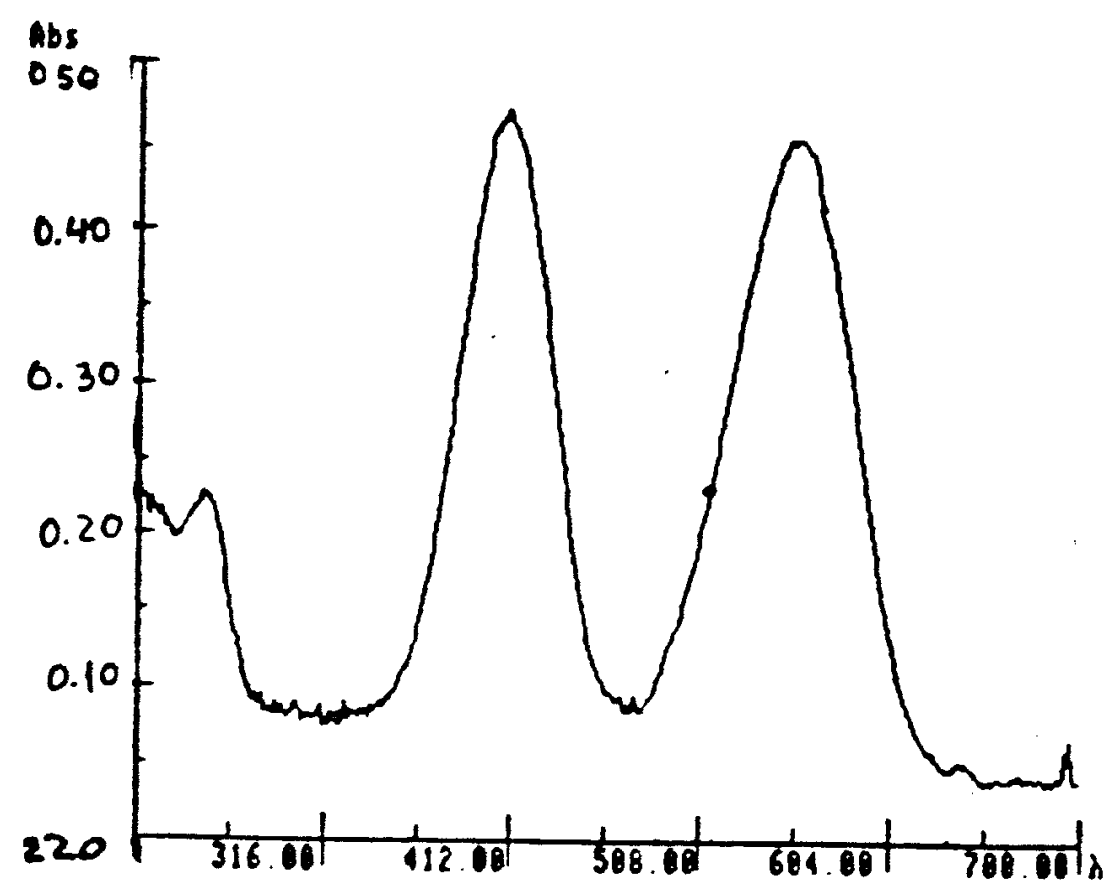

Figura 5.2. Espectro de absorção em rubi a temperatura ambiente.

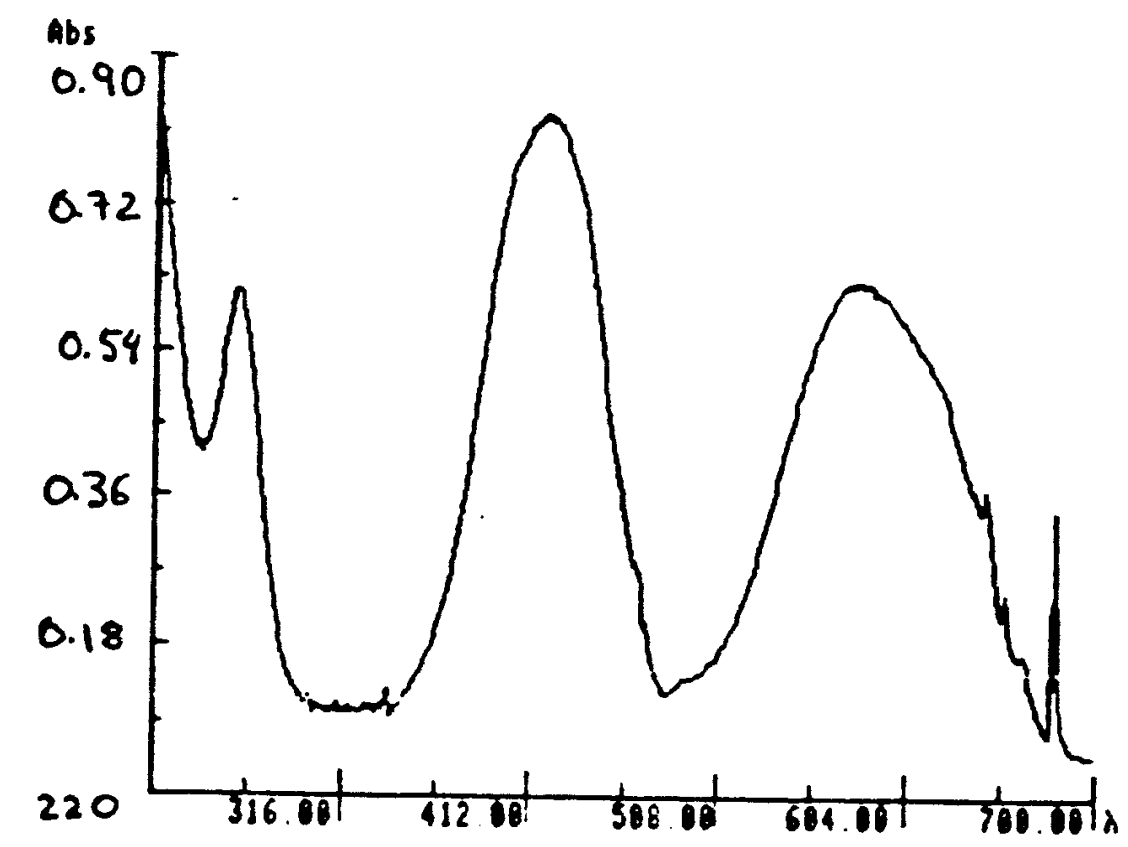

Figura 5.3. Espectro de absorção em alexandrita a temperatura ambiente. 


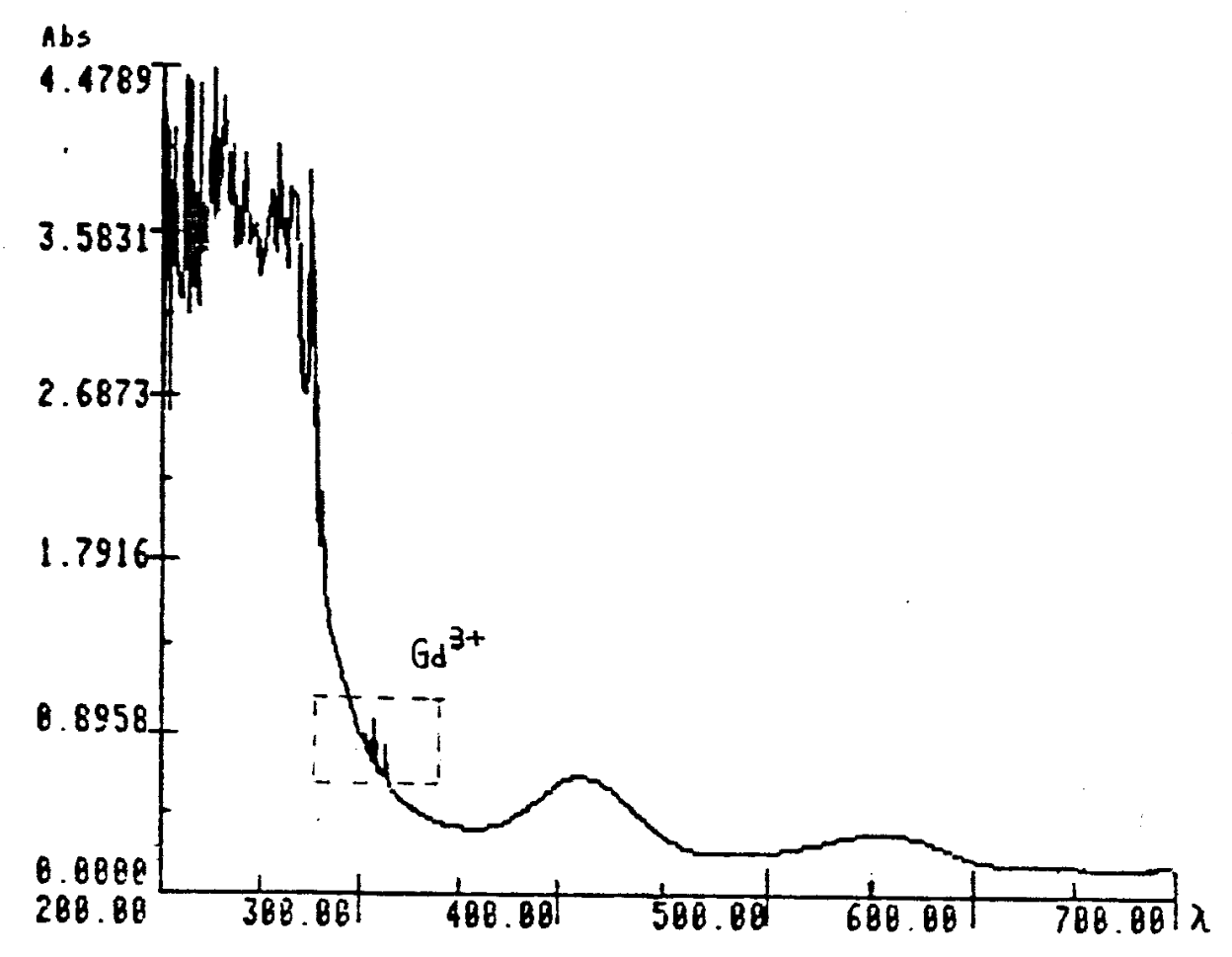

Figura 5.4. Espectro de absorção em $\mathrm{GdAlO}_{3}: \mathrm{Cr}^{3+}$ a temperatura ambiente.

\subsection{DESCRIÇÃO DO EXPERIMENTO DE MISTURA DE ONDAS}

A montagem experimental para a medida do ganho de energia por um feixe fraco $I_{2}$, cedida pelo feixe forte $I_{1}$, através da mistura de duas ondas, está esquematizada na figura 5.5. O feixe de um laser de argônio com potência travada - Coherent Innova 200 - é separado em dois através de uma lâmina de vidro LV. O feixe forte $I_{1}$ chega na amostra $\mathrm{A}$ após reflexão nos espelhos dielétricos $\mathrm{M}$ que refletem $100 \%$ à $45^{\circ} \mathrm{em} 5145 \AA$. A intensidade do feixe de prova $I_{2}$ é cerca de $1 \%$ de $I_{1}$. Este feixe atinge a amostra depois de passar por um filtro neutro $\mathrm{F}$ e ser refletido por um espelho $\mathrm{M}$ o qual está montado em conjunto com uma cerâmica piezo-elétrica PZT Jodon modelo MD-44. A lente $\mathrm{L}_{f}$ tem distância 


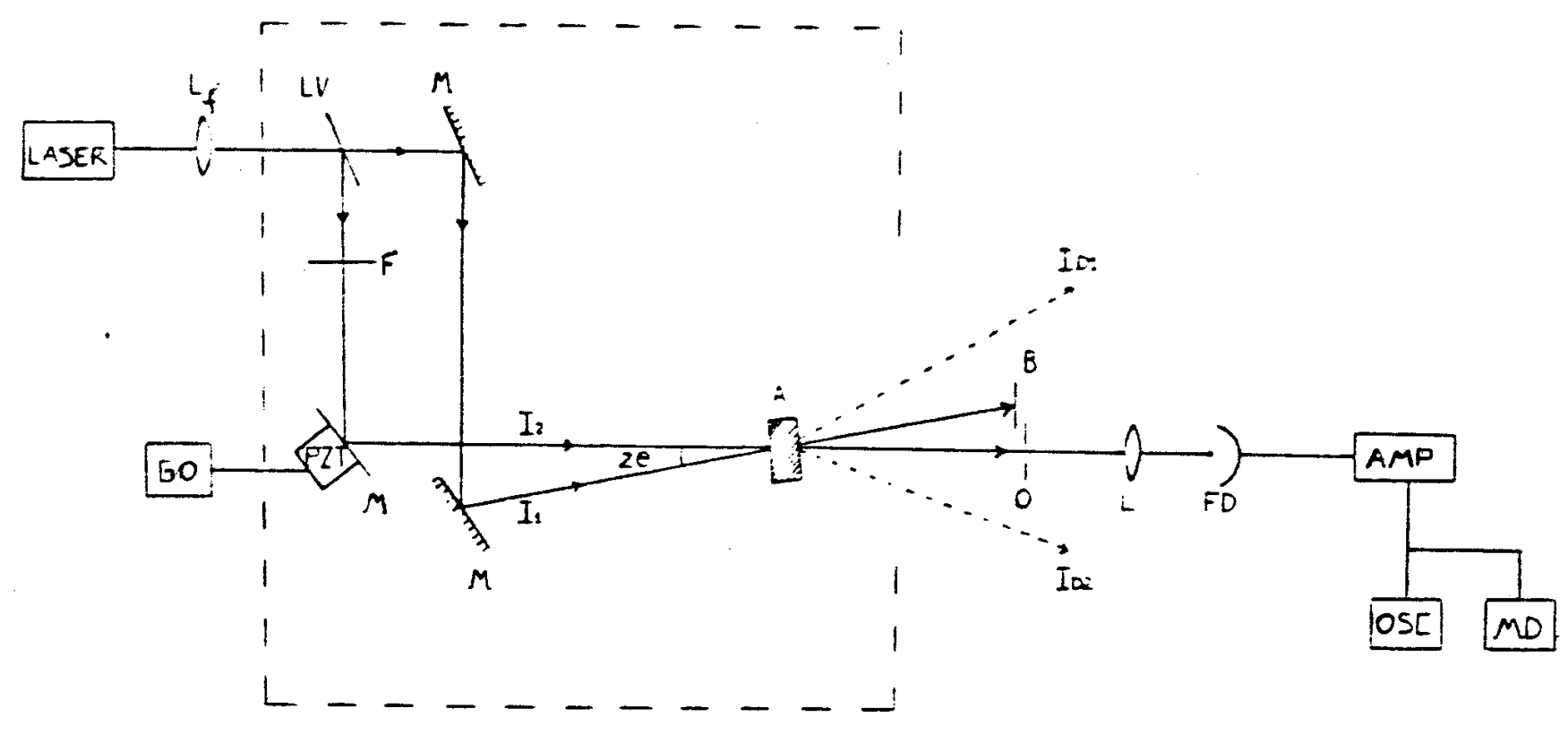

Fig. 5.5. Montagem experimental para observação de NDTWM. 
focal de $60 \mathrm{~cm}$ e a amostra é colocada no foco dessa lente. Nenhum dos feixes incide perpendicularmente à superfície da amostra. Cada um deles forma um ângulo de $1^{\circ} \mathrm{com}$ a normal à superfície ( $2^{\circ}$ entre $\left.\mathrm{si}\right)$.

Após a amostra o feixe forte é bloqueado por um anteparo B. O feixe fraco passa através de uma íris $O$ sendo finalmente coletado por uma lente $L$ que focaliza-o num fotodiodo MRD-300. O sinal desse fotodiodo é amplificado por um amplificador linear AMP e a seguir pode ser monitorado por um osciloscópio OSC ou medido por um multímetro digital $\mathrm{MD}$.

A parte da figura que está delimitada por linhas pontilhadas representa uma pequena mesa de alumínio espesso coberta com acrílico transparente. Isto evita circulação de ar ou poeira que pode causar distúrbios no padrão de interferência quando o laser estiver em potências mais altas. Esta mesa e os demais componentes ópticos (laser, $\mathrm{L}_{f}, \mathrm{~B}, \mathrm{O}, \mathrm{L}, \mathrm{FD}$ ) estão sobre uma mesa de mármore com banco de areia e entre ambas as mesas existe uma espuma espessa. Tudo isto concorreu para uma excelente estabilidade de todo o sistema.

Os feixes difratados em primeira ordem estão representados por linhas pontilhadas e identificados como $I_{D_{1}}$ e $I_{D_{2}}$ correpondendo às difrações do feixe forte e do fraco, respectivamente. GO é um gerador de onda digital de $0-10 \mathrm{~V}$ em conjunto com um amplificador chaveado o que permite uma saída controlada de 0 - 3000 V. Este gerador pode fornecer três tipos de onda: rampa ascendente, rampa descendente e triangular. Os tempos de subida e de descida da onda triangular foram calibrados com o uso de um frequencímetro de modo a serem exatamente iguais.

A aplicação de uma rampa com frequência $f_{\mathrm{r}}$ faz o PZT mover-se com velecidade constante e isto causa uma mudança na frequência do feixe $I_{2}$ por efeito "doppler". Ajustamos a tensão máxima da rampa de modo que o feixe se desloque um comprimento 
de onda o que corresponde a uma diferença $f_{r}$ em sua frequência linear. Dessa forma, a relação entre o parâmetro de dessintonia $\Omega^{\prime}$ e a frequência da rampa é simplesmente:

$$
\Omega^{\prime}= \pm 2 \pi f_{r} \tau
$$

Polarizamos o PZT de modo que com a rampa ascendente ele se retrai, diminuindo a frequência do feixe de prova e originando $\Omega^{\prime}>0$ (veja equação (4.12d)).

A superposição dos feixes $I_{1}$ e $I_{2}$ na amostra pode ser monitorada pelo osciloscópio colocando-se uma onda triangular no PZT com uma certa frequência de modo a satisfazer (aproximadamente) a condição de máximo $\Gamma_{2}\left(\Omega^{\prime}\right)$, equação (4.19), e alinhando-se um dos espelhos até que se tenha uma onda quadrada com máxima amplitude possível. Feito isto, ao se colocar uma rampa o sinal é praticamente constante e pode ser lido diretamente num multímetro digital, o que simplifica sobremaneira a detecção!

A diferença de caminho entre os dois feixes foi de aproximadamente $1 \mathrm{~cm}$, que é muito menor do que o comprimento de coerência do laser de argônio. O raio do feixe foi determinado colocando-se uma fenda de $10 \mu \mathrm{m}$ no lugar da amostra e fazendo-a deslocar-se de maneira que o perfil do feixe pudesse ser detectado. Este perfil foi aproximadamente gaussiano e obtivemos o valor de $\mathrm{w}=130 \mu \mathrm{m}$ que é o raio do feixe quando a intensidade cai de $e^{-2}$ do seu valor máximo. A polarização do campo elétrico de ambos os feixes é linear e perpendicular ao plano da figura 5.5.

\subsection{MISTURA DE ONDAS EM RUBI}

Medidas de TWM em rubi já haviam sido feitas anteriormente [30, 49] e por isso esse cristal serve como referência para a verificação do bom funcionamento do sistema 
experimental. Nossa amostra tem a forma cilíndrica com o eixo c paralelo ao eixo do cilindro. Isto é conhecido na literatura como $0^{\circ}$-rubi. $O$ comprimento da amostra é de $0,55 \mathrm{~cm}$ e os feixes incidiram ao longo do eixo c com o campo elétrico perpendicular ao mesmo (polarização $\sigma$ ).

A seção de choque do estado fundamental em $5145 \AA$ é $\sigma_{g}=6,5 \times 10^{-20} \mathrm{~cm}^{2}[45]$ e o tempo de vida é $3,4 \mathrm{~ms}$ [50], ambos à temperatura ambiente. A intensidade de saturação prevista pela eq. (III.5) é de $1,75 \mathrm{~kW} / \mathrm{cm}^{2}$ e nós observamos o máximo $\Gamma_{2}\left(\Omega^{\prime}\right)$ em $1,47 \mathrm{~kW} / \mathrm{cm}^{2}$ que através de (5.1), com o coeficiente de absorção $\alpha_{g}=0,70 \mathrm{~cm}^{-1}$ medido por nós, nos dá $I_{\delta}=1,76 \mathrm{~kW} / \mathrm{cm}^{2}$ em perfeito acordo. Os tempos de resposta $T_{1}^{\prime}$ por nós observados através da TWM em duas intensidades bem distintas, 0,1 e 1,47 $\mathrm{kW} / \mathrm{cm}^{2}$, foram de 3,3 e $2,1 \mathrm{~ms}$, respectivamente [25]. Através da equação (4.12c) obtémse o tempo médio $T_{1} \simeq 3,5 \mathrm{~ms}$ o que mostra um excelente acordo entre nossos resultados e os das refs. [50] e [30].

Na figura 5.6 é mostrada a curva do ganho $\Gamma_{1}\left(\Omega^{\prime}\right)$ em função da dessintonia $\Omega^{\prime}$ em $5145 \AA$ com a intensidade do feixe forte $I_{o}^{+}(0)=0,1 \mathrm{~kW} / \mathrm{cm}^{2}$. Os resultados experimentais são mostrados com quadrados e a linha sólida é obtida por (4.13) e (4.41b) com $n_{2}^{\prime}=$ $1,8 \times 10^{-8} \mathrm{~cm}^{2} / \mathrm{W}$ e $\mathrm{r}=0,03$. O mesmo valor de $\mathrm{r}$ foi obtido por Boothroyd et al $[49,51]$, entretanto nosso $n_{2}^{\prime}$ é cerca de duas vezes maior. Contudo acreditamos que nossos resultados são melhores, conforme discutiremos adiante.

A máxima transferência de energia foi de $67 \%$, obtida da expressão de $\Gamma_{1}\left(\Omega^{\prime}\right) \operatorname{com} \Omega^{\prime}$ e $S_{o}$ iguais a 1. Isto mostra uma maior potencialidade do rubi para aplicação em osciladores em $\lambda=5145 \AA$ ao invés de $4880 \AA$, visto que neste último caso a transferência de energia é menor [30].

Nenhuma difração de primeira ordem pode ser observada mesmo com intensidades 
próximas da intensidade de saturação. Dois fatores concorrem para isto:

a) o índice de refração não-linear é muito pequeno.

b) o fator $Q$ que expressa a condição de grade fina $(Q<<1)$ ou espessa $(Q>>1)$ e definido por (pág. 100 ref. [19])

$$
Q=\frac{2 \pi L \lambda}{\Lambda^{2} \eta}
$$

é igual a 45 na nossa amostra, ou seja, a grade é muito espessa.

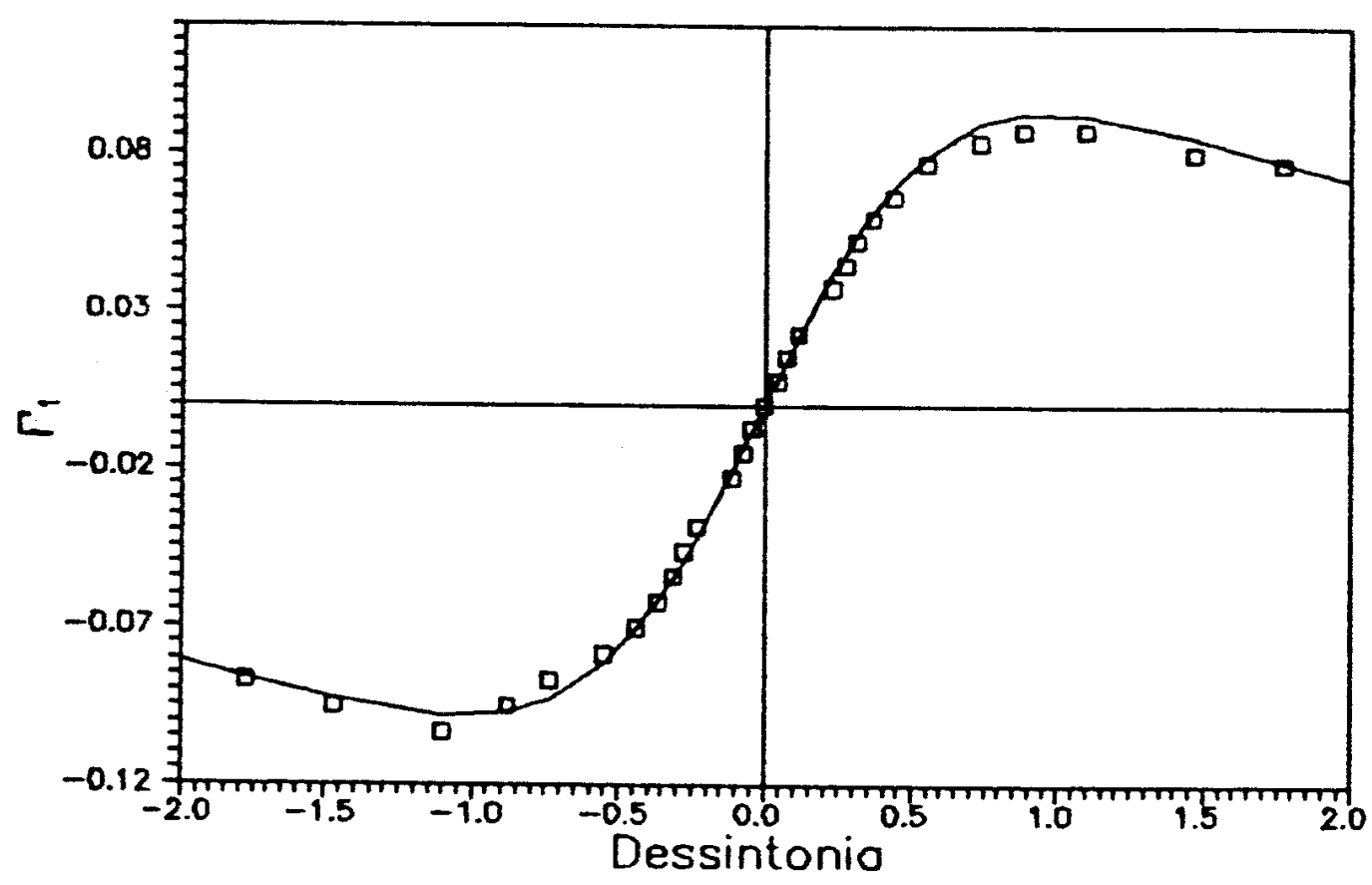

Figura 5.6. Ganho em função da dessintonia no rubi.

$$
I_{o}^{+}(0)=0,1 \mathrm{~kW} / \mathrm{cm}^{2} \quad T_{1}^{\prime}=3,3 \mathrm{~ms} \quad n_{2}^{\prime}=1,8 \times 10^{-8} \mathrm{~cm}^{2} / W \quad r=0,03
$$




\section{4-1. Absorção do Estado Excitado}

O sistema de três níveis que utilizamos para desenvolver nosso modelo teórico sobre mistura de ondas não considera a absorção do estado excitado $\alpha_{e}$ porque, assim, precisaríamos de mais níveis para descrever o sistema. Entretanto, nos cristais dopados com $\mathrm{Cr}^{3+}$ a absorção do estado excitado pode ser até maior do que a do estado fundamental $[45,52]$. Mas a população que sai do nível ${ }^{2} \mathrm{E}$ para níveis superiores volta para esse nível novamente, através de decaimento não-radiativo num tempo muito mais curto do que o tempo de decaimento do nível ${ }^{2} \mathrm{E}[52,57]$. Portanto, no estado estacionário o $\mathrm{Cr}^{3+}$ se comporta como um sistema de três níveis e a absorção do estado excitado precisa ser levada em conta apenas na parte imaginária da susceptibilidade (eq. (4.38)) e o nosso modelo pode ser aplicado. Os resultados experimentais do ganho $\Gamma_{1}\left(\Omega^{\prime}\right)$ comprovam isso!

A seção de choque do estado excitado em $5145 \AA$ é $\sigma_{e}=3,7 \times 10^{-20} \mathrm{~cm}^{2}$ (pol. $\sigma$ ) medida por Kushida [45] à temperatura ambiente. Medimos a absorção do estado excitado observando-se diretamente a transmissão do laser em intensidades baixas e a seguir em intensidades muito maiores do que $I_{\delta}$ como foi feito anteriormente por A. Szabo [53]. O coeficiente de absorção total $\alpha$ para incidência normal é:

$$
\alpha=\frac{\alpha_{g}+\alpha_{e} S_{o}}{1+S_{o}}
$$

então quando $S_{o} \rightarrow 0$ só obtemos $\alpha_{g}$ e à intensidades muito altas a absorção é toda do estado excitado. Mostramos na figura 5.7 a transmissão (= Ps / Pi) em função da potência incidente $\mathrm{Pi}$ (corrigida com as reflexões na superfície da amostra) quando o feixe do laser não foi focalizado (asteriscos) e quando focalizado com uma lente de $7,5 \mathrm{~cm}$ de distância focal (quadrados). Esses dados fornecem $\sigma_{e} / \sigma_{g}=0,60$ em excelente acordo com o valor de 0,57 obtido por Kushida [45] e de 0,54 obtido por Szabo [53]. 


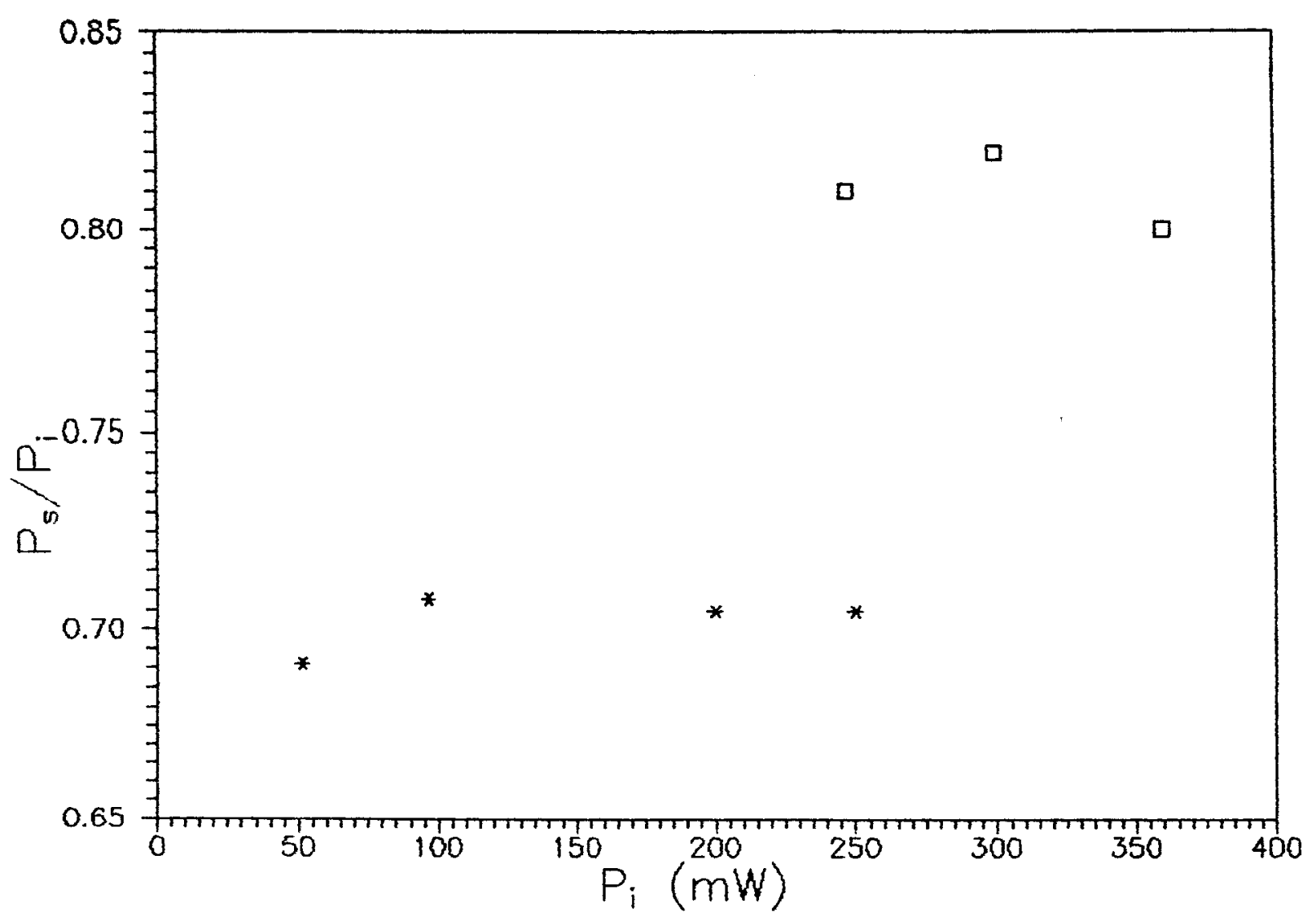

Figura 5.7 Transmissõo do Rubi em intensidades baixas (*) e muito altas (o). ¿ temperatura ambiente, como funcão da potêncio incidente $P_{i}$ em $5145 \AA$. $P_{s}$ é a potência após o cristal.

A concordância nos valores obtidos pelo método de Kushida (lâmpada com flashs rápidos) e pelo método de Szabo (laser contínuo com $I>10 I_{\delta}$ ) revelam que a produção de calor no cristal, devida às altas intensidades, não afeta as características do cristal de rubi. Resultados similares foram observados na alexandrita [52]. 


\section{4-2. Índice Não-Linear}

A parte imaginária do índice de refração não-linear por (III.7) pode ser escrita:

$$
n_{2}^{\prime \prime}=\frac{\alpha_{g} \lambda}{4 \pi I_{6}}\left(1-\sigma_{e} / \sigma_{g}\right)
$$

e com nossos valores experimentais dos coeficientes de absorção e da intensidade de saturação chegamos ao valor de $6,5 \times 10^{-10} \mathrm{~cm}^{2} / \mathrm{W}$, enquanto que nossa medida da mistura de duas ondas nos dá $n_{2}^{\prime \prime}=5,4 \times 10^{-10} \mathrm{~cm}^{2} / \mathrm{W}$ que é $17 \%$ menor. Esta diferença é completamente aceitável e está dentro do erro experimental e principalmente na incerteza no valor de r que é uma grandeza muito pequena.

Também por (III.7), supondo alargamento homogêneo e que apenas a banda ${ }^{4} \mathrm{~T}_{2}$ contribui para a susceptibilidade do estado fundamental, a substituição das expressões para as susceptibilidades [58] fornece a seguinte expressão para a parte real $n_{2}^{\prime}$ :

$$
\begin{gathered}
n_{2}^{\prime}=\frac{\lambda}{4 \pi I_{\delta}}\left(\sum_{j>e} \frac{N_{o} \sigma_{e j}^{(o)} \Delta_{e j}}{1+\Delta_{e j}^{2}}-\alpha_{g} \Delta_{g i}\right) \\
\Delta_{e j}=\left[\left(\nu_{j}-\nu_{e}\right)^{2}-\nu^{2}\right] / \nu \gamma_{j e} \\
\Delta_{g i}=2\left(\nu_{i}-\nu\right) / \gamma_{g i}
\end{gathered}
$$

onde $N_{o}$ é a concentração de íons de cromo, $\sigma_{e j}^{(0)}$ é a seção de choque no centro da transição entre o estado excitado (e) e um estado acima deste $(j), \gamma_{j e}$ é a largura de linha da transição, $\nu_{\ell}$ é a energia do $\ell$-ésimo nível, $\nu$ é a energia da excitação e o índice (i) corresponde à banda ${ }^{4} \mathrm{~T}_{2}$. Todas as energias são $\mathrm{em} \mathrm{cm}^{-1}$. 
Pelo espectro de absorção do estado excitado da referência [45] e aqui reproduzido na figura 5.8, vê-se que em $5145 \AA$ a absorção se dá para os níveis ${ }^{2} \mathrm{~T}_{1}+{ }^{2} \mathrm{~T}_{2}$ cujo centro está a $17.900 \mathrm{~cm}^{-1}$ acima do nível ${ }^{2} \mathrm{E}$, com $\sigma_{e j}^{(o)}=7,8 \times 10^{-20} \mathrm{~cm}^{2}$, e a largura desta transição é aproximadamente $2870 \mathrm{~cm}^{-1}$. Na nossa amostra medimos uma largura de linha $\gamma_{g i}$ de $2600 \mathrm{~cm}^{-1}$. Com estes dados em (5.6) obtém-se $n_{2}^{\prime} \simeq 8 \times 10^{-10} \mathrm{~cm}^{2} / \mathrm{W}$ que é uma ordem de grandeza menor do que o valor observado pela TWM. Comparando as figuras 5.8a e $\mathrm{b}$ nota-se que as transições na região de $15000-30000 \mathrm{~cm}^{-1}$ possuem seções de choque da mesma ordem $\left(10^{-19} \mathrm{~cm}^{2}\right)$ e por isso a contribuição desses níveis não é suficiente para explicar a diferença. Mas o estado de transferência de carga, embora mais afastado, possui uma seção de choque $\sigma_{C T}^{(o)} \simeq 1,0 \times 10^{-17} \mathrm{~cm}^{2}$. Esta banda está $40000 \mathrm{~cm}^{-1}$ acima do nível ${ }^{2} \mathrm{E}$ e tem largura $\gamma_{j e} \simeq 5000 \mathrm{~cm}^{-1}[45]$ e com $N_{o}=\alpha_{g} / \sigma_{g}=1,0810^{19} \mathrm{~cm}^{-3}$, na nossa amostra, obtemos o valor de $n_{2}^{\prime} \simeq 2 \times 10^{-8} \mathrm{~cm}^{2} / \mathrm{W}$ correspondente à contribuição desta banda sozinha.

Isto parece confirmar que a banda de transferência de carga é a que mais contribui para a parte real do índice não-linear no rubi. A primeira suspeita deste fato surgiu anos atrás para explicar a observação de bi-estabilidade à temperatura ambiente quando o rubi foi excitado entre as linhas $R$ e por isso deveria haver um cancelamento das contribuições dessas linhas, o que resultaria num $n_{2}^{\prime}$ extremamente pequeno e nenhuma bi-estabilidade deveria ocorrer $[54,17]$. Recentemente Adler e Lawandy [55] mediram a dependência de $n_{2}^{\prime}$ com o comprimento de onda na região de $5650-6050 \AA$ e concluiram que o estado de transferência de carga é o responsável pelo valor de $n_{2}^{\prime}$ no rubi entre 77 e $300 \mathrm{~K}$.

Um importante aspecto destas observações merece destaque: como $\Delta_{C T}$ é muito grande, $n_{2}^{\prime}$ segue aproximadamente a forma de linha da banda ${ }^{4} \mathrm{~T}_{2}$ (através de $I_{6}$ ) e deve ter um valor máximo no centro desta banda $(\sim 5555 \AA)$. Ou seja, tem-se um alto valor de $n_{2}^{\prime}$ numa transição ressonante o que é impossível num sistema de apenas dois níveis. 

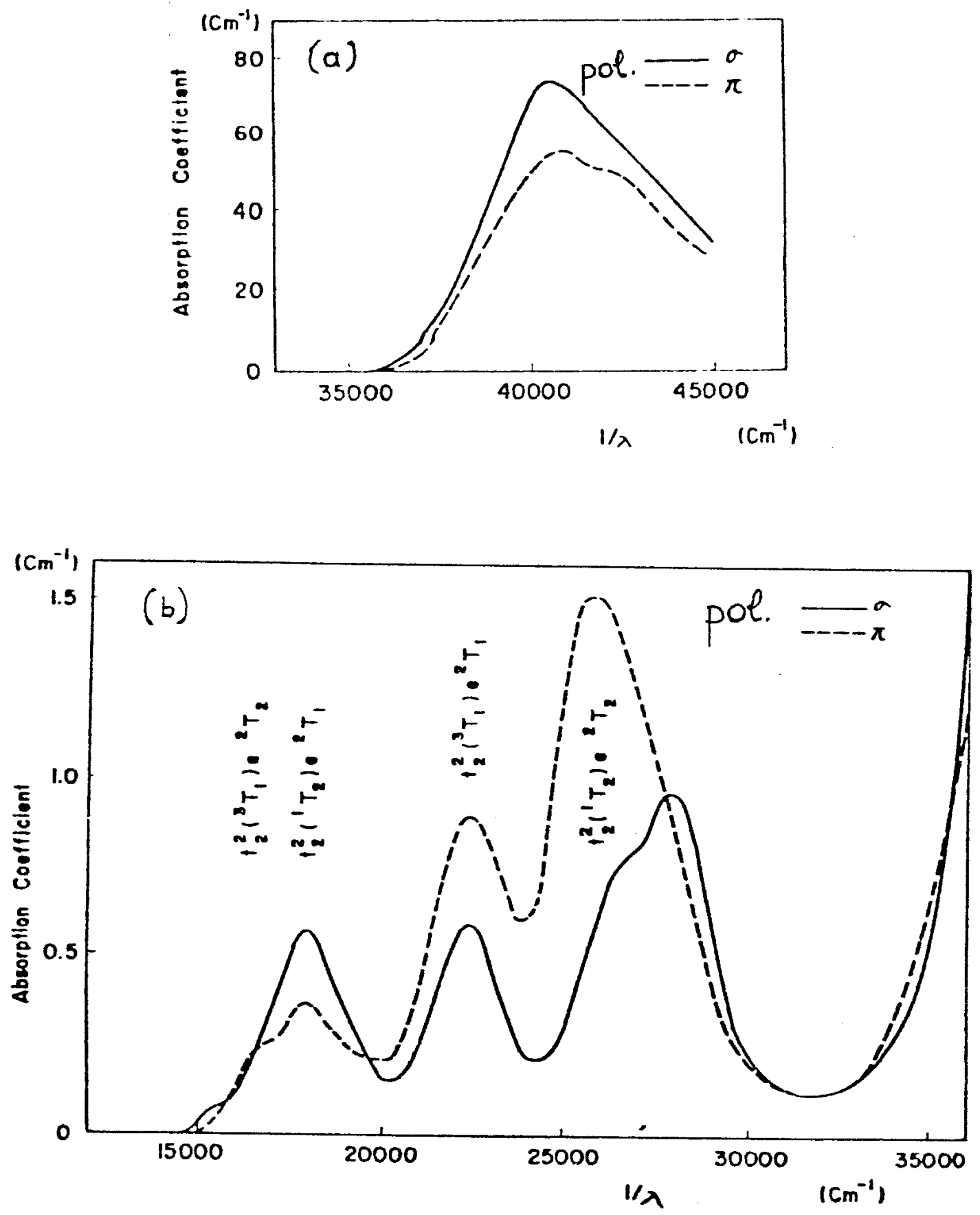

Figura 5.8. Espectro de absorção do estado excitado no rubi a temperatura ambiente, segundo Kushida[45]. (a)- região do visível e ultra-violeta próximo, (b)- região do ultravioleta. A concentração de cromo é de $7,3 \times 10^{18} \mathrm{~cm}^{-3}$. 
Na tabela 5.1 mostramos os valores experimentais obtidos neste trabalho para o rubi através da mistura de duas ondas. Os dados são para $5145 \AA$ e com polarização $\sigma$. E na tabela 5.2 apresentamos os valores de $n_{2}^{\prime}$ e $\mathrm{r}$ devidos somente à contribuição do estado de transferência de carga previstos pela equação (5.6) em comprimentos de onda que foram utilizados na referência [30] para medir $n_{2}$ em rubi. Os valores aqui previstos estão em pleno acordo com os publicados naquela referência.

Tabela 5.1. Valores experimentais em rubi para

$$
\lambda=5145 \AA \text { e com polarização } E \perp c .
$$

\begin{tabular}{|cccccccc|}
\hline $\mathrm{L}(\mathrm{cm})$ & $\mathrm{N}_{o}\left(\mathrm{~cm}^{-3}\right)$ & $\alpha_{g}\left(\mathrm{~cm}^{-1}\right)$ & $\alpha_{e}\left(\mathrm{~cm}^{-1}\right)$ & $\mathrm{T}_{1}(\mathrm{~ms})$ & $I_{\delta}\left(\mathrm{kW} / \mathrm{cm}^{2}\right)$ & $n_{2}^{\prime}\left(\mathrm{cm}^{2} / \mathrm{W}\right)$ & $\mathrm{r}$ \\
\hline 0,55 & $1,08 \times 10^{19}$ & 0,70 & 0,42 & 3,5 & 1,76 & $1,8 \times 10^{-8}$ & 0,03 \\
\hline
\end{tabular}

Tabela 5.2. Valores estimados da contribuição do estado de transferência de carga para $n_{2}$ em rubi

\begin{tabular}{|ccc|}
\hline$\lambda(\AA)$ & $n_{2}^{\prime}\left(10^{-8} \mathrm{~cm}^{2} / \mathrm{W}\right)$ & $\mathrm{r}$ \\
\hline 4880 & 0,70 & 0 \\
\hline 5800 & 3,20 & 0,07 \\
\hline 6060 & 0,76 & $-0,02$ \\
\hline
\end{tabular}




\subsection{MISTURA DE ONDAS EM ALEXANDUITA}

Medidas das propriedades não-lineares da alexandrita têm sido feitas através da mistura degenerada (ou não) de quatro ondas $[56,59]$ com excitação na banda ${ }^{4} \mathrm{~T}_{2}$ e mais recentemente através da auto-difração de primeira ordem por mistura degenerada de duas ondas (DTWM) com excitação direta nas linhas R [20]. Entretanto não é de nosso conhecimento de que transferência de energia por mistura quase degenerada de duas ondas (NDTWM) tenha sido observada anteriormente.

A alexandrita é um material laser que opera à ternperatura ambiente na região de 701 - $818 \mathrm{~nm}$, através de bombeamento com lâmpada de "flash" cuja radiação é absorvida pelas bandas ${ }^{4} \mathrm{~T}_{2} \mathrm{e}^{4} \mathrm{~T}_{1 a}[44]$. O cristal tem simetria ortorômbica e por isso suas propriedades espectroscópicas dependem da polarização da luz com relação aos três eixos cristalinos, em contraste ao rubi onde os eixos a e b são equivalentes. O laser de alexandrita opera com o campo elétrico paralelo ao eixo b porque a seção de choque no centro da banda ${ }^{4} \mathrm{~T}_{2}$ é cerca de 4 vezes maior nesta polarização do que com $\mathrm{E} \|$ a. Isto pode ser visto na figura 5.9 onde é mostrado os espectros polarizados a temperatura ambiente, retirados. da referência [52]. Os pontos representam a seção de choque do estado fundamental $\sigma_{g}$ e a linha sólida é a seção de choque do estado excitado $\sigma_{e}$. Obtivemos exatamente os mesmos espectros em nossa amostra para o estado fundamental e a medida do coeficiente de absorção em $5145 \AA$ mostrou-se independente da intensidade, ou seja, não conseguimos observar uma variação significativa (maior do que 10\%) na transmissão da amostra quando esta foi focalizada. Isto significa que a absorção do estado excitado é aproximadamente igual à do estado fundamental (veja eq. (5.4)) mas não pudemos detectar o valor absoluto de $\alpha_{e}$. É por isso que reproduzimos aqui apenas os resultados de Shand et al para que possamos fazer uma discussão semelhante à que fizerros no caso do rubi. 


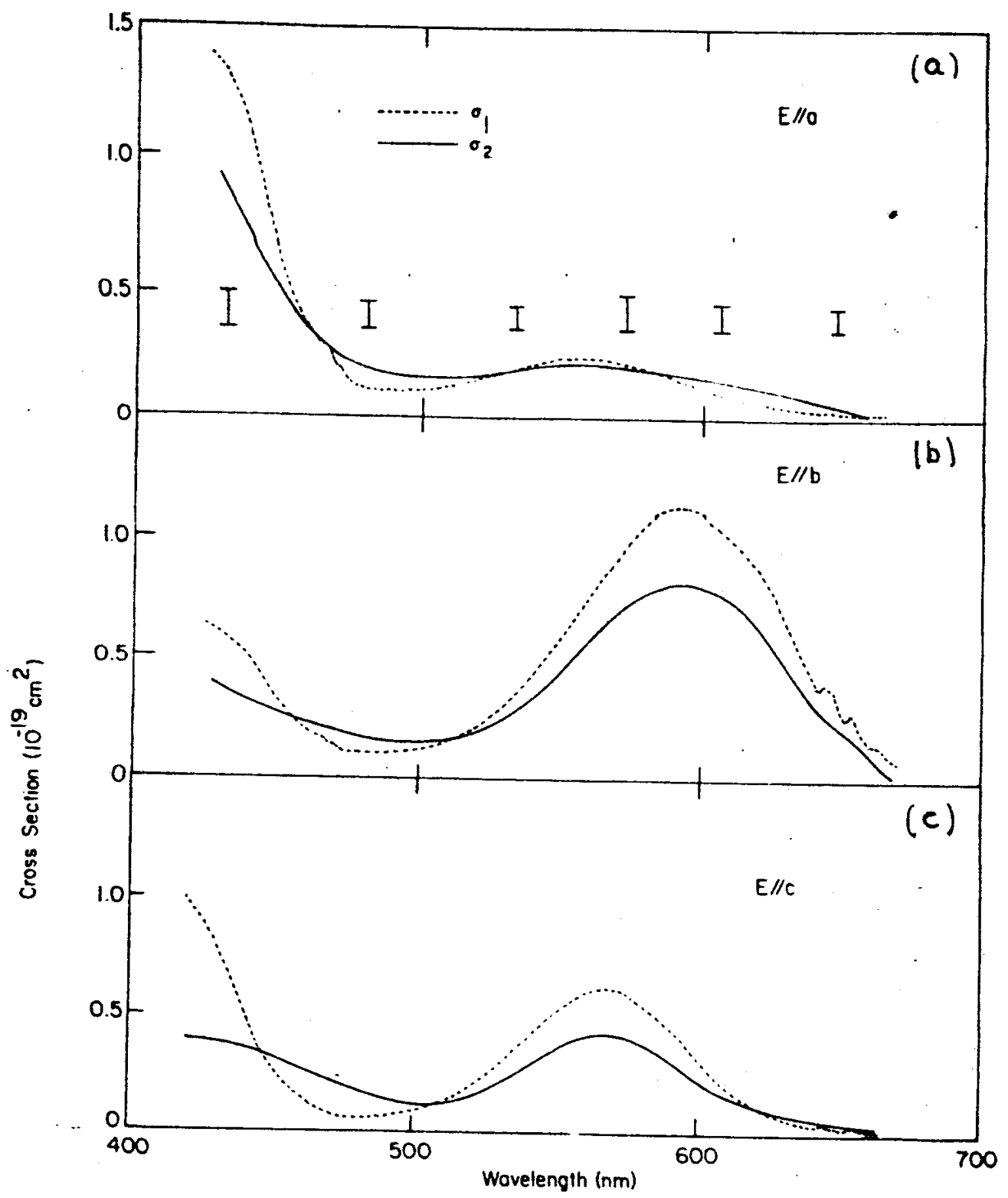

Figura 5.9. Seção de choque de absorção em alexandrita a temperatura ambiente, para luz polarizada ao longo dos eixos a, b e c, segundo Shand et al[52]. $\sigma_{1}$ e $\sigma_{2}$ são referentes aos estados fundamental e excitado, respectivamente. As barras verticais representam o erro experimental em $\sigma_{2}$. 
Aproximadamente $78 \%$ dos íons $\mathrm{Cr}^{3+}$ ocupam os sítios com simetria de espelho (SE) e os restantes $22 \%$ estão em centros de simetria com inversão (SI). Quando o cristal é bombeado em $5145 \AA$ são excitados preferencialmente aquels íons $\mathrm{Cr}^{3+}$ que ocupam os centros SI (veja figura 9 da ref. [56]) e portanto a grade de população formada por TWM deverá ter o tempo de decaimento associado à emissão do nível meta-estável ${ }^{2} \mathrm{E}(\mathrm{ms})$. Por outro lado, o bombeamento direto no nível ${ }^{2} \mathrm{E}(\lambda=680 \mathrm{~nm})$ ou na banda ${ }^{4} \mathrm{~T}_{2}$ excita preferencialmente os íons em sítios SE que decaem com um tempo da ordem de $240 \mu$ s à temperatura ambiente [56].

\section{5 - 1. Curva de Ganho}

Nós fizemos as medidas de NDTWM com os feixes incidindo ao longo do eixo c e com os campos polarizados paralelos ao eixo a. Nessa situação o vetor q da grade induzida é paralelo ao eixo b. O comprimento da amostra é $0,25 \mathrm{~cm}$ e o coeficiente de absorção em $5145 \AA$ é de $1,16 \mathrm{~cm}^{-1}$ nessa polarização.

Na figura 5.10 mostramos a curva de ganho $\Gamma_{1}\left(\Omega^{\prime}\right)$ em função da dessintonia $\Omega^{\prime} \mathrm{em}$ $5145 \AA$ com a intensidade do feixe forte de $0,1 \mathrm{~kW} / \mathrm{cm}^{2}$. A linha sólida representa o melhor ajuste da nossa teoria com: $n_{2}^{\prime}=4 \times 10^{-8} \mathrm{~cm}^{2} / \mathrm{W}, \mathrm{r}=0,03$ e o tempo de resposta $T_{1}^{\prime}=$ $28,5 \mathrm{~ms}$. Os quadrados são os resultados experimentais. $O$ máximo $\Gamma_{2}\left(\Omega^{\prime}\right)$ foi observado em $0,65 \mathrm{~kW} / \mathrm{cm}^{2}$ com a frequência da rampa fixada em $\Omega^{\prime}=1$ quando a intensidade do feixe forte era de $0,1 \mathrm{~kW} / \mathrm{cm}^{2}$. Então, por (5.1), obtém-se $I_{\delta}=0,79 \mathrm{~kW} / \mathrm{cm}^{2}$ e por (4.12c) $\mathrm{T}_{1}=32 \mathrm{~ms}$. Este valor do tempo de vida do nível ${ }^{2} \mathrm{E}$ está em excelente acordo com os 35 ms obtidos por Weaver e Payne através de DFWM [56] e mostra que os íons em centros SI é quem mais contribuem neste comprimento de onda. Com a seção de choque $\sigma_{g}=1,5 \times$ $10^{-20} \mathrm{~cm}^{2}$, obtida da figura 5.9, a intensidade de saturação prevista por (III.5) é de 0,80 
$\mathrm{kW} / \mathrm{cm}^{2}$, o que mais uma vez revela um excelente acordo entre teoria e experimento.

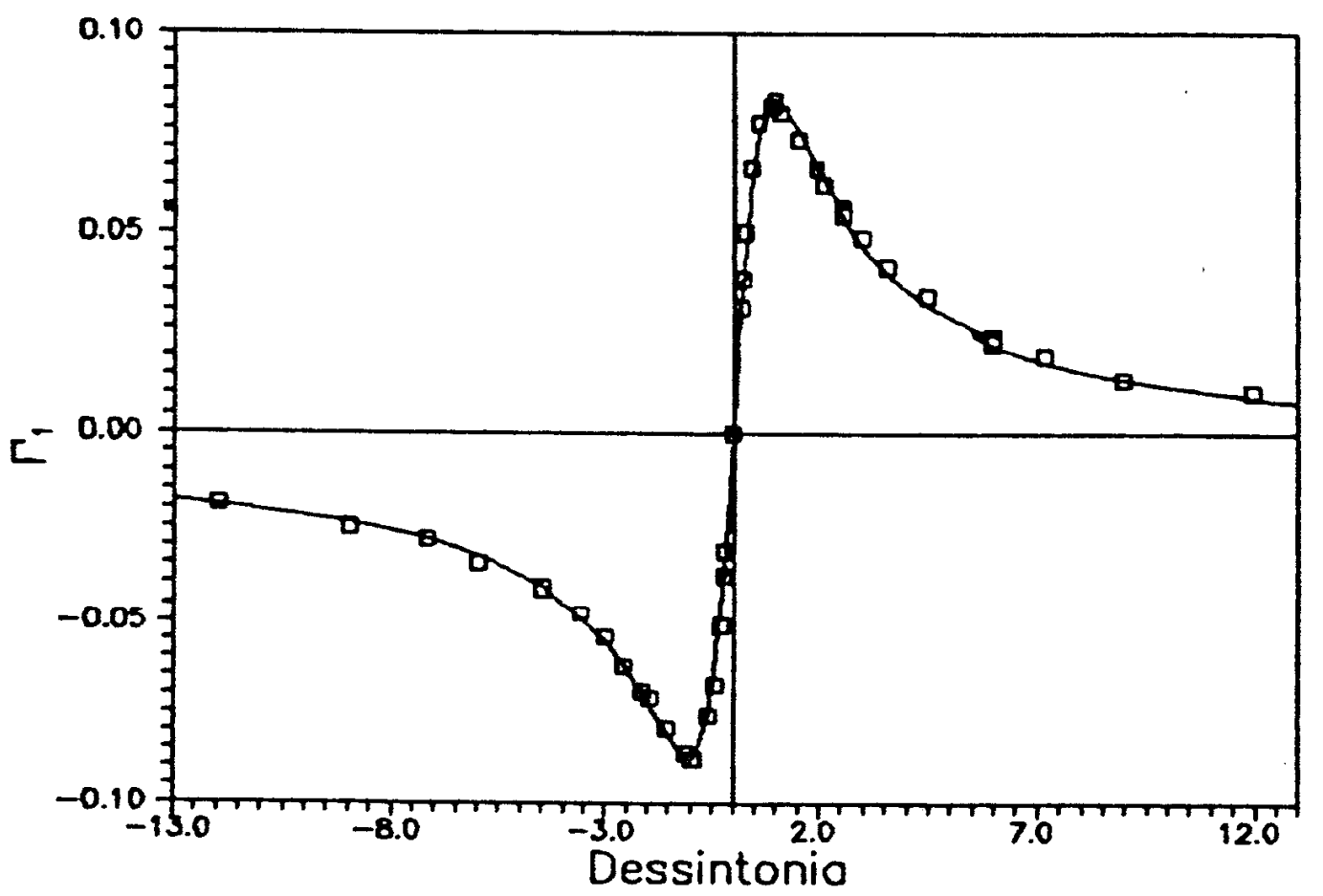

Figura 5.10. Ganho em função da dessintonia na alexandrita.

$$
I_{o}^{+}(0)=0,1 \mathrm{~kW} / \mathrm{cm}^{2} \quad T_{1}^{\prime}=28.5 \mathrm{~ms} \quad n_{2}^{\prime}=4,0 \times 10^{-8} \mathrm{~cm}^{2} / W \quad r=0,03
$$

A máxima transferência de energia foi de $26 \%$. É fácil ver que a transferência de energia depende do produto $n_{2}^{\prime} I_{6} L$ e que se a amostra de alexandrita tivesse o mesmo comprimento do rubi a transferência máxima também seria aproximadamente $67 \%$. Entretanto nosso cristal de alexandrita possui uma concentração $N_{o}=7,73 \times 10^{19} \mathrm{~cm}^{-3}$ que é 7 vezes maior do que a do cristal de rubi e, uma vez que $n_{2}^{\prime}$ depende linearmente da concentração, podemos concluir que a transferência de energia por NDTWM em alexandrita é muito menor do que em rubi para $5145 \AA$. 


\section{5 - 2. Outras Ordens de Difração e Índice Não-Linear}

Foi possivel observar a difração de primeira ordem do feixe forte para intensidades próximas da saturação mas a intensidade desta ordem foi muito baixa e por isso não conseguimos detectar qualquer variação de intensidade como função da dessintonia $\Omega^{\prime}$. Note que a observação dessa ordem nessa amostra, com baixa intensidade, é consistente com o fato de que a rede formada é menos espessa $(Q=21)$ do que no caso da amostra de rubi ( $n_{2}^{\prime} I_{6}$ é aproximadamente igual).

A parte imaginária do índice de refração não-linear $n_{2}^{\prime \prime}=1,2 \times 10^{-9} \mathrm{~cm}^{2} / \mathrm{W}$ prevê por (5.5) uma seção de choque do estado excitado igual a $1,2 \times 10^{-20} \mathrm{~cm}^{2}$, que é menor do que o valor medido por Shand et al [52] de $1,7 \times 10^{-20} \mathrm{~cm}^{2}$. Porém o erro experimental na determinação de $\sigma_{e}$ é cerca de $50 \%$, como pode ser visto pelas barras verticais na figura 5.9, o que nos leva a concluir que nossos resultados prevêem $\sigma_{e}$ de acordo com o que foi observado por eles. Além disso nota-se que $\sigma_{e} \simeq \sigma_{g}$ o que explica porque não conseguimos observar variação do coeficiente de absorção com a intensidade.

Através do diagrama de níveis (figura 5.1) e também da figura 5.9 vê-se que a contribuição dos níveis ${ }^{2} \mathrm{~T}_{1}+{ }^{2} \mathrm{~T}_{2}\left(\simeq 18000 \mathrm{~cm}^{-1}\right.$ acima de $\left.{ }^{2} \mathrm{E}\right)$ cancela àquela do estado fundamental na equação (5.6a) e que, portanto, as contribuições dos níveis situados mais acima é que são importantes. Não encontramos na literatura valores da seção de choque do estado excitado para energias acima de $25.000 \mathrm{~cm}^{-1}$ e por isso não podemos estimar a contribuição da banda de transferência de carga para $n_{2}^{\prime}$. Contudo com $\sigma_{e}=1,0 \mathrm{x}$ $10^{-10} \mathrm{~cm}^{2}$ e supondo $\gamma_{j e} \simeq 2500 \mathrm{~cm}^{-1}$ para a transição entre o estado excitado e o nível ${ }^{2} \mathrm{~T}_{1}$ situado $25000 \mathrm{~cm}^{-1}$ acima do ${ }^{2} \mathrm{E}$ obtém-se $n_{2}^{\prime} \simeq 1 \times 10^{-8} \mathrm{~cm}^{2} / \mathrm{W}$. É possível que a contribuição deste nível e a dos imediatamente superiores sejam suficientes para explicar o nosso valor experimental de $n_{2}^{\prime}$. Note que $n_{2}^{\prime} I_{\delta} / N_{0} \lambda$, que só depende das seções de choque, 
é quase uma ordem de grandeza menor na alexandrita do que no rubi. Por outro lado, em nossa amostra este fator é igual a $0,81 \times 10^{-20} \mathrm{~cm}^{2} \mathrm{em}$ concordância com o valor que se obtém com os dados da referência [ $E$ ], que é $0,86 \times 10^{-20} \mathrm{~cm}^{2}$ em $4880 \AA$. Tudo isto pode ser um indicativo de que a banda e transferência de carga não é importante para a polarizabilidade do estado excitado ${ }^{2} \mathrm{E}$ em centros de simetria de inversão.

Na tabela 5.3 agrupamos os nossos resultados experimentais em alexandrita e que foram discutidos acima.

Tabela 5.3. Valores experimentais em alexandrita para

$$
\lambda=5145 \AA \text { e com polarização E || a. }
$$

\begin{tabular}{|ccccccc|}
\hline $\mathrm{L}(\mathrm{cm})$ & $\mathrm{N}_{o}\left(\mathrm{~cm}^{-3}\right)$ & $\alpha_{g}\left(\mathrm{~cm}^{-1}\right)$ & $\mathrm{T}_{1}(\mathrm{~ms})$ & $I_{6}\left(\mathrm{~kW} / \mathrm{cm}^{2}\right)$ & $n_{2}^{\prime}\left(\mathrm{cm}^{2} / \mathrm{W}\right)$ & $\mathrm{r}$ \\
\hline 0,25 & $7,73 \times 10^{10}$ & 1,16 & 32 & 0,79 & $4,0 \times 10^{-8}$ & 0,03 \\
\hline
\end{tabular}

\subsection{MISTURA DE ONDAS EM GdAlO ${ }_{3}: \mathrm{Cr}^{3+}$}

O aluminato de gadolíneo faz parte de um grupo de compostos do tipo $\mathrm{TMO}_{3}$, onde T é um terra rara e $M$ um metal de transição. Tais compostos são iso-estruturais, sua célula unitária é ortorrômbica e pertencem ao grupo espacial $\mathrm{D}_{2 h}^{16}$-Pbnm. Quatro pseudocélulas do tipo perovskita-distorcida estão no interior da célula ortorrômbica $[60,61]$. No aluminato de gadolíneo o desvio de uma estrutura perovskita ideal (cúbica) é muito pequeno e se pode construir uma pseudo-célula com dimensões 3,731 x 3,731 x 3,734 $\AA$ e um ângulo de $90,6^{\circ}$ [46]. Podemos visualizar esta pseudo-célula como um cubo ligeiramente distorcido, onde $8 \mathrm{Gd}^{3+}$ estão nos vértices e $6 \mathrm{O}^{2-}$ estão nos centros das faces, e o $\mathrm{Al}^{3+}$ 
no centro do cubo. Quando o $\mathrm{Cr}^{3+}$ é inserido como dopante, ele ocupa os sítios do $\mathrm{Al}^{3+}$ devido aos seus raios iônicos serem próximos. Então o $\mathrm{Cr}^{3+}$ está num sítio de simetria octaédrica, formada pelos seis oxigênios, com ligeira distorção. Essa distorção, por sua vez, tem-se mostrado menor do que a ocorrida no rubi [62], o que explica o maior tempo de vida do nível ${ }^{2} \mathrm{E}$ conforme veremos adiante.

A potencialidade do aluminato de gadolíneo como material hospedeiro para meio laser foi verificada há cerca de vinte anos, mas a grande dificuldade de se obter cristais com boa qualidade óptica, devida à presença de defeitos durante a fabricação desses cristais [48], e também o surgimento de materiais mais promissores tais como: o laser de alexandrita [44] em 1976 e o de titânio e safira [63] em 1982, desviaram a atenção dos pesquisadores para esses novos compostos. Contudo, novas técnicas de crescimento tem sido desenvolvidas e recentemente Merkle et al [64] investigaram as propriedades do $\mathrm{Ti}^{3+}$ em $\mathrm{EuAlO}_{3}$ e $\mathrm{GdAlO}_{3}$ que, segundo eles, obtiveram cristais de boa qualidade e sugeriram a possibilidade de ação laser no $\mathrm{GdAlO}_{3}: \mathrm{Ti}^{3+}$.

Por outro lado, grande parte das pesquisas experimentais no IFQSC/USP têm sido direcionadas no $\mathrm{GdAlO}_{3}: \mathrm{Cr}^{3+}$ por causa da facilidade da obtenção desses cristais com boa qualidade óptica, crescidos pelo Dr. J.P. Andreeta [65] e pelo Prof. H. Scheel [66]. Algumas dessas pesquisas revelam a interação entre pares de cromo [62], um forte acoplamento entre os $\mathrm{Gd}^{3+}$ mais próximos e $\circ \mathrm{Cr}^{3+}[67]$ e a transferência cooperativa de energia com a absorção de um fóton entre o $\mathrm{Cr}^{3+}$ e $\circ \mathrm{Gd}^{3+}$ [68]. Também observou-se absorção de dois fótons em $\mathrm{GdAlO}_{3}$ puro [69], conjugação de fase por mistura degenerada de quatro ondas no $\mathrm{GdAlO}_{3}: \mathrm{Cr}^{3+}[70]$ e mediu-se pela primeira vez a parte real do índice não-linear [70].

Descreveremos a seguir o que acreditamos ser a primeira observação de: transferência de energia por NDTWM no $\mathrm{GdAlO}_{3}: \mathrm{Cr}^{3+}$ e também difração de primeira ordem [36]. 


\section{6 - 1. Curvas de Ganho e de Saturação}

A amostra utilizada tinha a forma de uma pastilha retangular com as faces maiores paralelas entre si e perpendicular ao eixo c. Os eixos a e b não foram determinados. Contudo, nossos espectros de absorção polarizados não indicaram diferenças significativas entre várias polarizações diferentes, quando a luz se propagou ao longo do eixo c. 0 mesmo fato foi observado por Basso [62] numa amostra orientada. Portanto consideraremos apenas que usamos luz polarizada perpendicular ao eixo c. O comprimento da amostra foi de 0,14 cm e o coeficiente de absorção $4,2 \mathrm{~cm}^{-1}$. A dopagem de cromo foi de $1 \%$ nominal.

Na figura 5.11 está mostrada a curva de ganho $\Gamma_{1}\left(\Omega^{\prime}\right)$ em função da dessintonia $\Omega^{\prime}$ em $5145 \AA$ para $I_{o}^{+}(0)=0,1 \mathrm{~kW} / \mathrm{cm}^{2}$. Os quadrados são os nossos resultados experimentais e a linha sólida é o melhor ajuste de nosso modelo teórico com $n_{2}^{\prime}=16 \times 10^{-8} \mathrm{~cm}^{2} / \mathrm{W}$, $\mathrm{r}=0,08$ e $\mathrm{T}_{1}^{\prime}=11,2 \mathrm{~ms}$. Uma diferença marcante entre o $\mathrm{GdAlO}_{3}: \mathrm{Cr}^{3+}$ e os outros dois cristais (rubi e alexandrita) foi detectada quando aumentamos a intensidade do feixe forte: as curvas de ganho $\Gamma_{1}$ experimentais foram muito bem ajustadas com o mesmo valor de $n_{2}^{\prime}$ mas diferentes valores de $\mathrm{r}$, indicando uma dependência da parte imaginária $n_{2}^{\prime \prime}$ com a intensidade [36]. Esta variação de r é mostrada na figura 5.12 (quadrados) e a linha sólida será discutdia na seção 5.6-4. O decréscimo de $\mathrm{r}$ é surpreendente e inexplicável à luz do modelo de três níveis (veja eq. (5.5)). Adiaremos a discussão deste fato até a seção 5.6-4. 


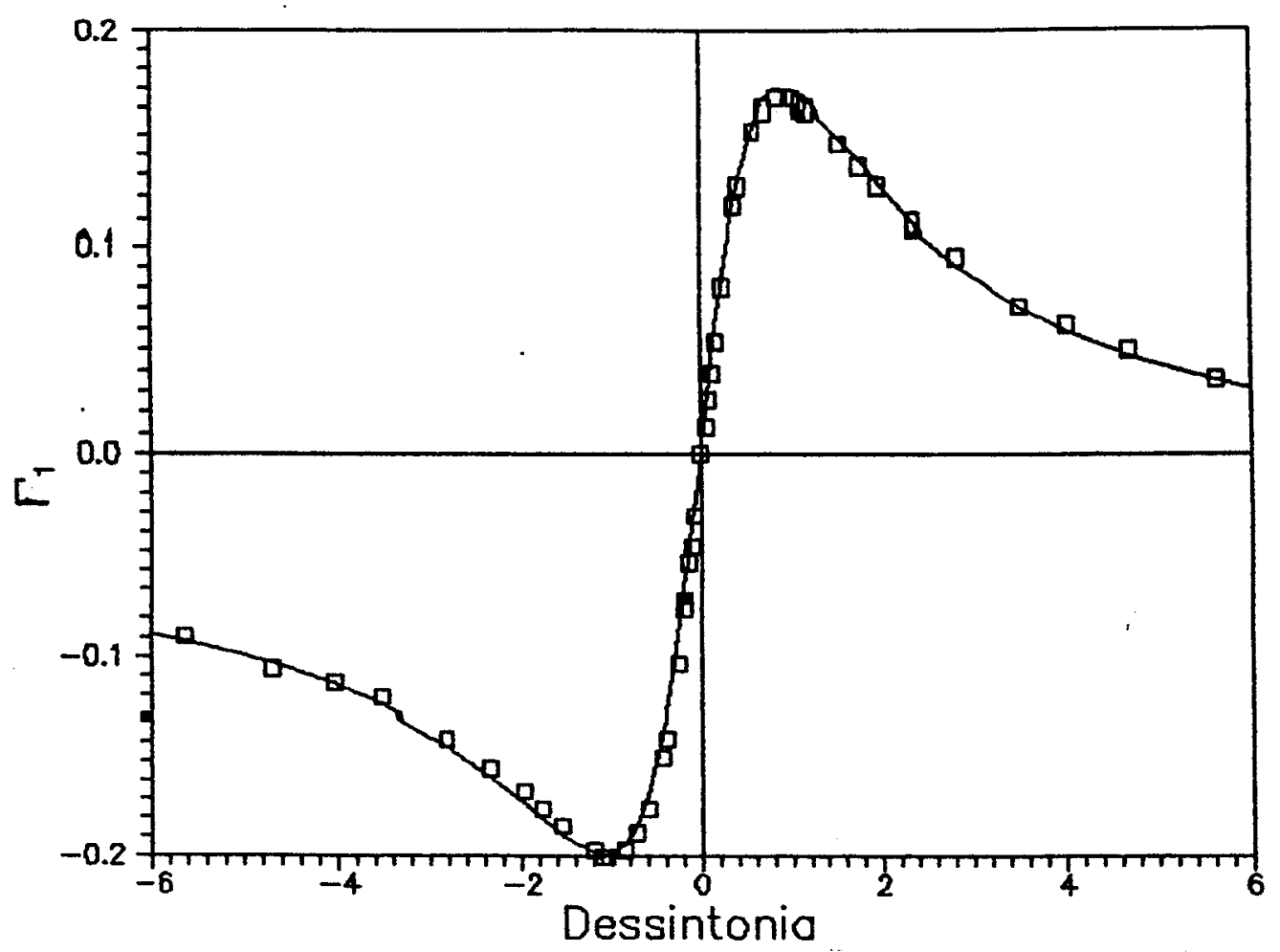

Figura 5.11. Ganho em função da dessintonia no $\mathrm{GdAlO}_{3}: \mathrm{Cr}^{3+}$. $I_{o}^{+}(0)=0,1 \mathrm{~kW} / \mathrm{cm}^{2} \quad T_{1}^{\prime}=11,2 \mathrm{~ms} \quad n_{2}^{\prime}=16 \times 10^{-8} \mathrm{~cm}^{2} / W \quad r=0,08$

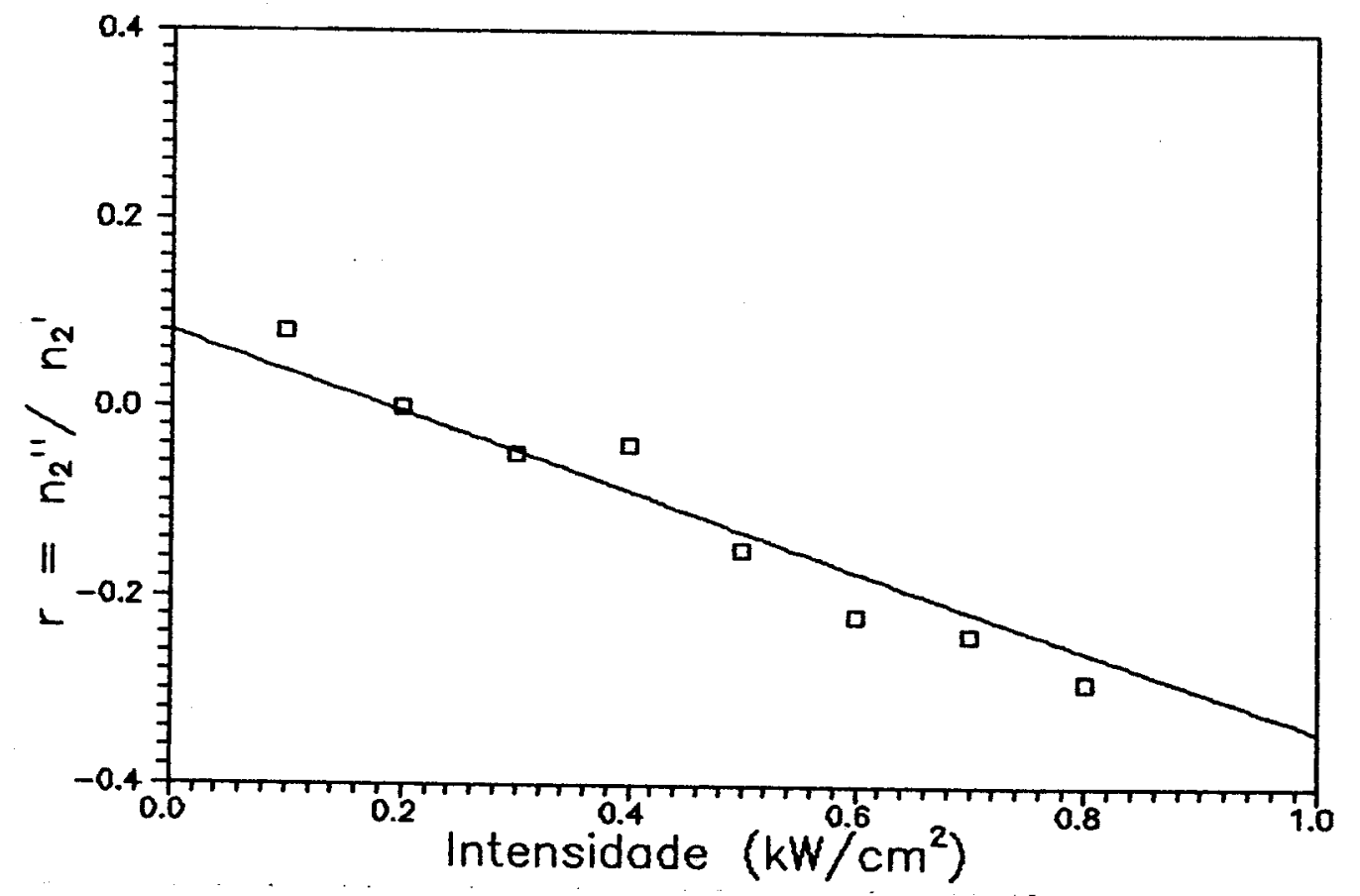

Figura 5.12. Mudança de $r$ com a intensidade no $\mathrm{GdAlO}_{3}: \mathrm{Cr}^{3+}$. 
Na figura 5.13 mostramos a saturação do ganho $\Gamma_{2}\left(\Omega^{\prime}\right)$. Note que os pontos experimentais estão em bom acordo com o previsto pela nossa teoria e com 0 valor de $n_{2}^{\prime}$ que fora determinado na curva de $\Gamma_{1}$ à intensidade de apenas $0,1 \mathrm{~kW} / \mathrm{cm}^{2}$. Então a variação de $\mathrm{r}$ se deve exclusivamente à mudança de $n_{2}^{\prime \prime}$ com a intensidade pois $\Gamma_{2}$ é independente de $n_{2}^{\prime \prime}$. A intensidade de saturação é de $1,2 \mathrm{~kW} / \mathrm{cm}^{2}$ e o tempo de decaimento é $T_{1}=12 \mathrm{~ms}$. Um valor de $13,2 \pm 0,5 \mathrm{~ms}$ foi observado por Olhman et al [46], o que mostra um bom acordo com o nosso resultado.

Com nossos valores de $I_{\delta}, \mathrm{T}_{1}$ e $\alpha_{\theta}$ obtemos a seção de choque $\sigma_{\boldsymbol{q}}=2,68 \times 10^{-20} \mathrm{~cm}^{2}$ e a concentração de $\mathrm{Cr}^{3+} N_{o}=1,57 \times 10^{20} \mathrm{~cm}^{-3}$. Não encontramos na literatura valores de $\sigma_{g}$ para o $\mathrm{GdAlO}_{3}: \mathrm{Cr}^{3+}$ mas o nosso valor é cerca de duas vezes maior do que o obtido em $\mathrm{YAlO}_{3}: \mathrm{Cr}^{3+}$ [71]. Uma maneira de verificarmos se o nosso $\sigma_{g}$ é confiável é calcularmos a porcentagem $\mathrm{p}$ de $\mathrm{Cr}^{3+}$ através da expressão [47]:

$$
p=100 N_{o} V / n
$$

onde $n=4$ é o número de íons $\mathrm{Al}^{3+}$ por célula unitária e $V=207,25 \times 10^{-24} \mathrm{~cm}^{3}[62,68]$ é o volume da célula unitária. Isto nos dá $p=0,8 \%$, em pleno acordo com a concentração nominal de $1 \%$ do $\mathrm{Cr}^{3+}$.

A transferência de energia máxima foi cerca de $100 \%$. Mas fazendo-se uma análise idêntica àquela entre rubi e alexandrita (seção 5.5-1) percebe-se que também no $\mathrm{GdAlO}_{3}: \mathrm{Cr}^{3+}$ a transferência de energia é menos eficiente do que no rubi, para $5145 \AA$. O alto valor de $n_{2}^{\prime}$ observado na amostra de $\mathrm{GdAlO}_{3}: \mathrm{Cr}^{3+}$ também se deve à alta concentração de $\mathrm{Cr}^{3+}$, a qual é uma ordem de grandeza maior do que na amostra de rubi. 


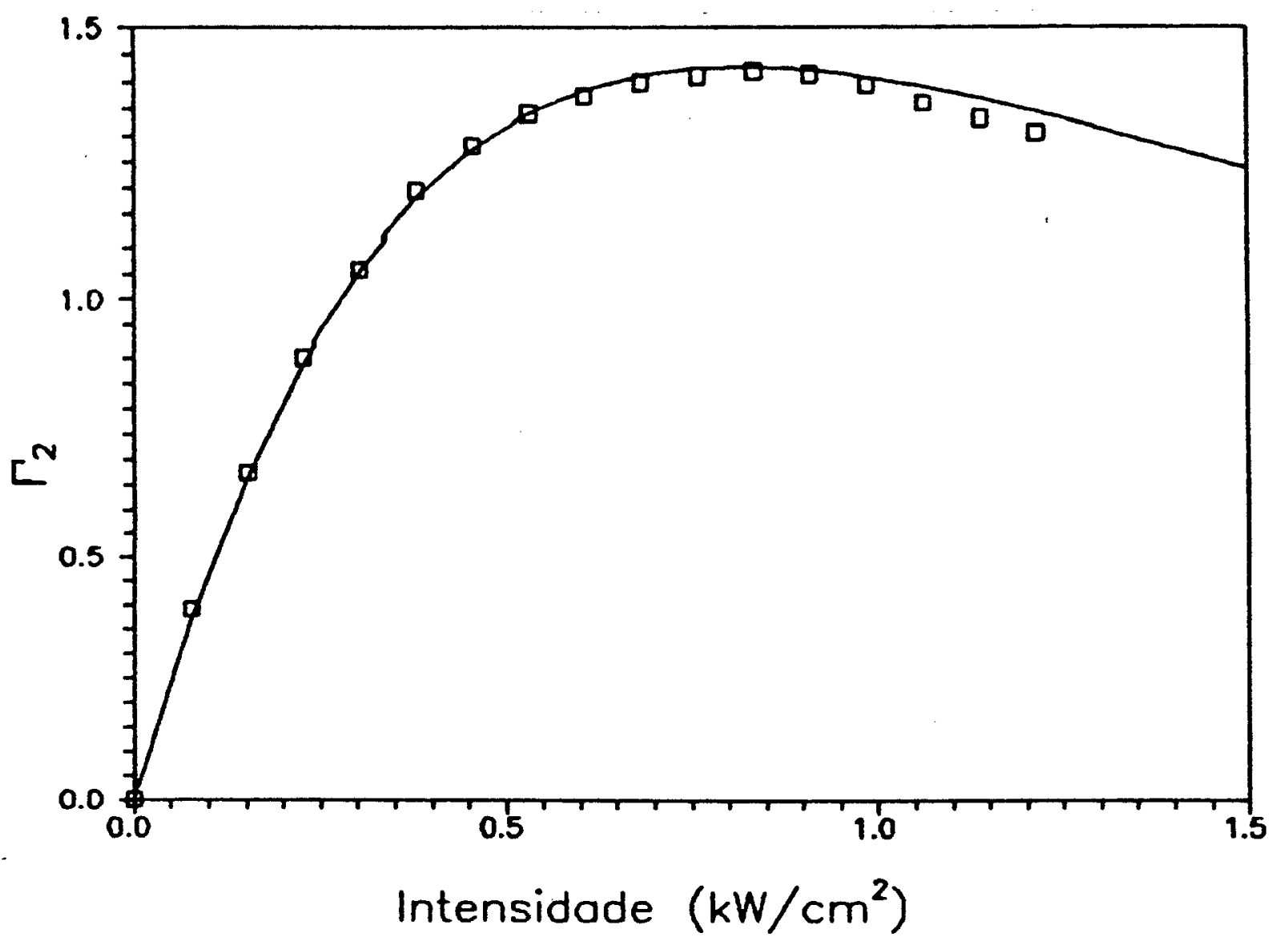

Figura 5.13. Saturação do ganho $\Gamma_{2}$ em $\mathrm{GdAlO}_{3}: \mathrm{Cr}^{3+}$ a temperatura ambiente.

$$
I_{\delta}=1,2 \mathrm{~kW} / \mathrm{cm}^{2} \quad n_{2}^{\prime}=16 \times 10^{-8} \mathrm{~cm}^{2} / W
$$




\section{6-2. Difração de Primeira Ordem}

Nessa amostra foi possível observar os feixes difratados em primeira ordem com intensidades $I_{o}^{+}(0)$ bem abaixo da saturação. Isto é compreensível porque temos um alto valor de $n_{2}^{\prime}$ e a rede é ainda menos espessa do que aquela formada na alexandrita. $O Q$ é aproximadamente igual a 10. Este valor tem sido considerado como um limite inferior para uma boa performance da teoria de ondas acopladas em grades espessas [24]. A intensidade do feixe fraco difratado em primeira ordem foi muito pequena mas a do feixe forte difratado $\mathrm{I}_{1}^{+}$em primeira ordem pode ser medida como função da dessintonia. $\mathrm{Na}$ figura 5.14 apresentamos o que definimos como ganho do feixe forte difratado $\Gamma_{d}^{+}\left(\Omega^{\prime}\right)$, em analogia ao ganho $\Gamma_{1}\left(\Omega^{\prime}\right)$ :

$$
\Gamma_{d}^{+}\left(\Omega^{\prime}\right) \equiv \ln \left[\frac{I_{1}^{+}\left(L, \Omega^{\prime}\right)}{I_{1}^{+}(L, 0)}\right]
$$

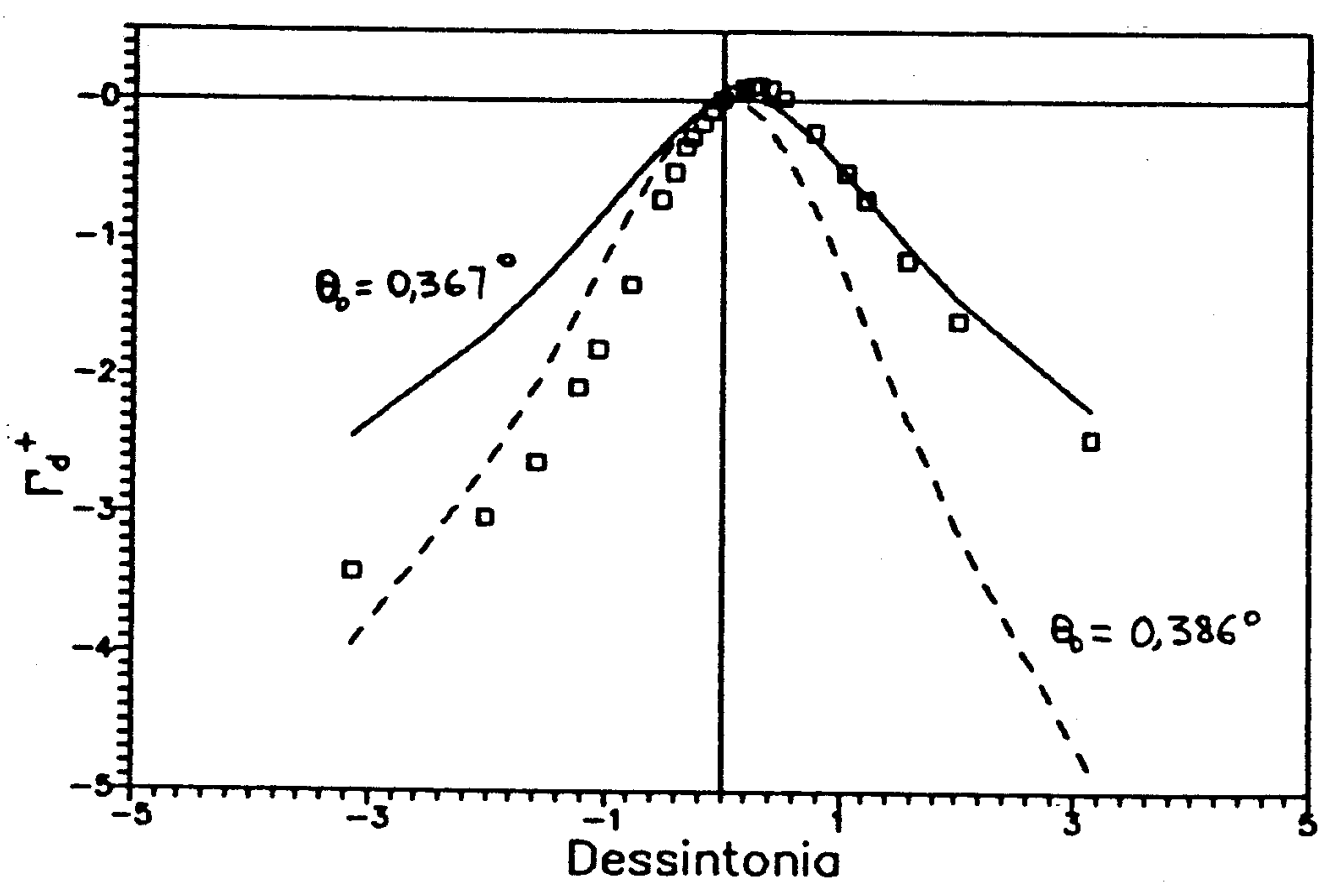

Figura 5.14. Ganho da difração de primeira ordem do feixe forte $\Gamma_{d}^{+}$em função da dessintonia em $\mathrm{GdAlO}_{3}: \mathrm{Cr}^{3+} \operatorname{com} \mathrm{I}_{o}^{+}(0)=0,2 \mathrm{~kW} / \mathrm{cm}^{2}$. Veja esclarecimentos no texto. 
com $I_{1}^{+}\left(L, \Omega^{\prime}\right)$ a intensidade do feixe difratado em função da dessintonia $\Omega^{\prime}$. Os quadrados representam os resultados experimentais para $I_{0}^{+}(0)=0,2 \mathrm{~kW} / \mathrm{cm}^{2}$. Uma solução analítica exata não é possível também neste caso. Por outro lado a solução numérica das equações (4.36) não nos permitiria perceber certas minúcias que podem ser de extrema valia. Conseguimos uma solução analítica aproximada supondo as seguintes condições:

a) $\mathrm{O}$ campo elétrico $\mathrm{A}_{0}^{+}$do feixe forte não muda ao longo do meio tanto em fase quanto em amplitude.

b) A diferença de fase inicial entre os dois feixes que produzem a grade é nula.

c) $\mathrm{O}$ feixe difratado $\mathrm{A}_{1}^{+}$se origina em $z=0$.

Apenas a primeira destas condições é que pesa nos resultados. A expressão para $I_{1}^{+}$é:

$$
\begin{gathered}
I_{1}^{+}\left(L, \Omega^{\prime}\right)=\left[\frac{2 \pi\left|n_{2}\right| I_{o}^{+}(0) L}{\lambda \cos \theta_{o}\left(1+S_{o}\right)^{2}}\right]^{2} \frac{I_{o}^{-}(0)\left(1+\Omega^{\prime 2}\right)^{-1}}{\left[\left(\Gamma_{1} / 4\right)^{2}+(P / 2)^{2}\right]}\left[\operatorname{sen}^{2}(P / 2)+\operatorname{senh}^{2}\left(\Gamma_{1} / 4\right)\right] \\
\times \quad \exp \left[\Gamma_{1} / 2-\alpha L\left(1+S_{o}\right)^{-1}\right] \\
P\left(\Omega^{\prime}\right)=-8 \pi \eta \operatorname{sen}^{2} \theta_{o}(L / \lambda)-\left(\frac{d \phi_{0}^{-}}{d z}\right)_{z=0} L
\end{gathered}
$$

todos os símbolos referem-se às definições do capítulo 4 e a dependência de $P$ em $\Omega^{\prime}$ está no segundo termo de $(5.9 \mathrm{~b})$, o qual omitimos por simplicidade. Com os valores experimentais do $n_{2}$ e demais grandezas obtivemos as duas curvas (sólida e tracejada) desenhadas também na figura 5.14. A diferença entre elas é apenas no valor de $\theta_{0}$ do primeiro termo em (5.9b). Para a curva sólida $\theta_{0}=0,367^{\circ}\left(\theta=1,46^{\circ}\right)$ e para a tracejada $\theta_{o}=0,386^{\circ}\left(\theta=1,54^{\circ}\right)$. 0 índice de refração $\eta=2$ foi obtido na referência [46].

Estes resultados revelam uma extrema dependência da solução não no valor de $\theta_{o} \mathrm{em}$ si mas sim com $P\left(\Omega^{\prime}\right)$. Esta grandeza se origina das fases dos campos e o primeiro termo 
é exatamente a diferença entre as componentes $z$ dos vetores de onda $\left(\beta_{p}\right.$ em (4.33)) da primeira ordem difratada e da ordem zero, na aproximação $\theta_{0}<<1$ e é igual a Q. Como nossa expressão não leva em conta a variação de fase do feixe forte é muito provável que as diferenças observadas na figura 5.14 sejam por causa disto. De maneira geral podemos dizer que (5.9) prevê de forma razoável o comportamento experimental !

A dependência acentuada na fase dos feixes difratados em primeira ordem é um comportamento esperado pois, como vimos na capítulo 3 , apenas os feixes de ordem zero satisfazem automaticamente a condição de Bragg enquanto a primeira ordem de difração depende criticamente na diferença de fase experimentada ao longo da grade espessa. Isto está claro em (5.9), pois se a grade estiver estacionária $\left(\Omega^{\prime}=0\right)$ a intensidade da luz difratada $I_{1}^{+}$é proporcional à $\operatorname{sen}^{2}(P / 2) /(P / 2)^{2}$, lembre-se que $\Gamma_{1}(0)=0$, e esta é a mesma dependência encontrada na geração de harmônicos, eq. (3.4), o que revela a semelhança entre tais processos. Por outro lado a intensidade $I_{1}^{+}$será máxima quando $P / 2<<1$ ou $Q<<1$ que é a condição de grade fina. Vemos assim que a condição de grade fina (ou não) é o fator determinante para observação (ou não) da primeira ordem de difração.

Concluimos que a difração em primeira ordem poderá ser detectada em nossas amostras de rubi e alexandrita reduzindo o ângulo entre os feixes incidentes. Estudos nessa direção estão sendo conduzidos no momento em nosso grupo de óptica.

\section{6-3. Parte Real do Índice Não-Linear}

Não encontramos na literatura espectros de absorção do estado excitado ${ }^{2} \mathrm{E}$ em $\mathrm{GdAlO}_{3}: \mathrm{Cr}^{3+}$, mas o valor de $n_{2}^{\prime} I_{\delta} / N_{o} \lambda=2,38 \times 10^{-20} \mathrm{~cm}^{2}$ é comparável ao de rubi $\left(5,70 \times 10^{-20} \mathrm{~cm}^{2}\right)$ e três vezes maior do que na alexandrita. Isto parece indicar que também no $\mathrm{GdAlO}_{3}: \mathrm{Cr}^{3+}$ é o estado de transferência de carga quem mais contribui para a 
polarizabilidade do nível ${ }^{2} \mathrm{E}$. Realizamos um experimento de modo a obter mais subsídios para tal conclusão. De fato o que fizemos foi medir $n_{2}^{\prime}$ em função do comprimento de onda dos feixes, por meio de NDTWM, ou seja, o espectro de $n_{2}^{\prime}$. Uma experiência idêntica foi realizada recentemente por Adler e Lawandy em rubi [55] conforme relatamos na seção 5.4 .

A montagem experimental é a mesma que aquela descrita na seção 5.3 mas com pequenas modificações: o laser de argônio foi usado para bombear um laser de corante - Innova CR-699/21 - operando com rodamina 6G na região de 560-620 nm e a saída deste laser é que foi usada para formar a grade induzida na amostra. 0 comprimento de onda foi medido com um "wavemeter" comercial - Burleigh - que opera através de um interferômetro de Michelson. Uma parte da luz do laser de corante foi desviada antes da lente $L_{f}$ (figura 5.5) por uma lâmina de vidro e esta luz entra no "wavemeter" por intermédio de uma fibra óptica.

A potência do laser de corante ficou limitada pelo baixo rendimento na região do vermelho, o pico de emissão da rodamina é em $570 \mathrm{~nm}$, de modo que a mínima potência obtida em 6150 A foi usada para todos os comprimentos de onda. Em cada comprimento de onda medimos a potência do feixe forte no lugar da amostra, para compensar as prováveis diferenças impostas pelos componentes ópticos. Nosso interesse era medir a variação de $n_{2}^{\prime}(\lambda)$ e não seu valor absoluto, por isso não medimos o raio do feixe e sim estimamos seu valor através das relações de propagação de um feixe gaussiano por uma lente [18]. A amostra foi transladada de modo a compensar o deslocamento do foco da lente $\mathrm{L}_{f}$ com o comprimento de onda.

A frequência da rampa foi ajustada em cada comprimento de onda de modo que $\Omega^{\prime}=1$ em todas as medidas. A intensidade do feixe forte foi de $0,5 \mathrm{~kW} / \mathrm{cm}^{2}$ e as intensidades de saturação foram estimadas pela equação (III.5) através da medida do coeficiente de 
absorção e comparando com o valor obtido em 5145 A. O experimento foi realizado à temperatura ambiente e os resultados são mostrados na figura 5.15 para o $\mathrm{GdAlO}_{3}: \mathrm{Cr}^{3+}$. Na figura 5.16 reproduzimos os resultados de Adler e Lawandy para o rubi [55]. O nosso valor de $n_{2}^{\prime}$ em $5720 \AA$ foi cerca de $40 \times 10^{-8} \mathrm{~cm}^{2} / \mathrm{W}$ e os dados estão normalizados a este valor. O espectro de $n_{2}^{\prime}$ revela o seguinte: Mr ostor entencien 6

i) O sinal de $n_{2}^{\prime}$ (positivo) é o mesmo dos dois lados da banda ${ }^{4} \mathrm{~T}_{2}$, cujo centro está em $5550 \AA$. Isto não ocorre num sistema de dois níveis, conforme discutimos no Capítulo 3.

ii) O espectro é suave e largo, ou seja, não há linhas estreitas e é praticamente independente da temperatura (pelo menos no rubi).

A primeira observação nos diz que o primeiro termo em (5.6a) é dominante. E para que este termo seja positivo é preciso que a diferença de energia $\nu_{j}-\nu_{e}$ seja maior do que a energia da radiação $\sim 20.000 \mathrm{~cm}^{-1}$, implicando níveis com energia $\nu_{j}$ acima de $34.000 \mathrm{~cm}^{-1}$ já que $\nu_{e}=13.750 \mathrm{~cm}^{-1}$. Uma rápida inspeção na figura 5.1 nos mostra que em tal região existe uma série de níveis estreitos e também uma banda larga ${ }^{4} T_{1 b}$ em torno de $37.000 \mathrm{~cm}^{-1}$, além da banda de transferência de carga (CT). A contribuição dos níveis estreitos teria um espectro composto de linhas finas e alargadas por fônons, sendo fortemente dependente da temperatura. Por outro lado, a contribuição da banda ${ }^{4} \mathrm{~T}_{1 b}, 23.000 \mathrm{~cm}^{-1}$ acima do ${ }^{2} \mathrm{E}$, não é suficiente para explicar o valor de $n_{2}^{\prime}$ no rubi. $\mathrm{E}$ fácil concluir que a banda CT é quem contribui efetivamente no rubi e, mesmo que não conheçamos a seção de choque da transição ${ }^{2} \mathrm{E} \rightarrow{ }^{4} \mathrm{~T}_{1 b}$ e nem tenhamos feito medidas à baixa temperatura no $\mathrm{GdAlO}_{3}: \mathrm{Cr}^{3+}$, existe uma marcante semelhança nos espectros de $n_{2}^{\prime}$ desses dois cristais, além do fato de que os parâmetros do campo cristalino no $\mathrm{GdAlO}_{3}: \mathrm{Cr}^{3+}$ [46] são muito próximos aos do rubi [72]. Por isso não hesitamos em afirmar de que a banda $\mathrm{CT}$ também é a responsável pelo $n_{2}^{\prime}$ do $\mathrm{GdAlO}_{3}: \mathrm{Cr}^{3+}$. 


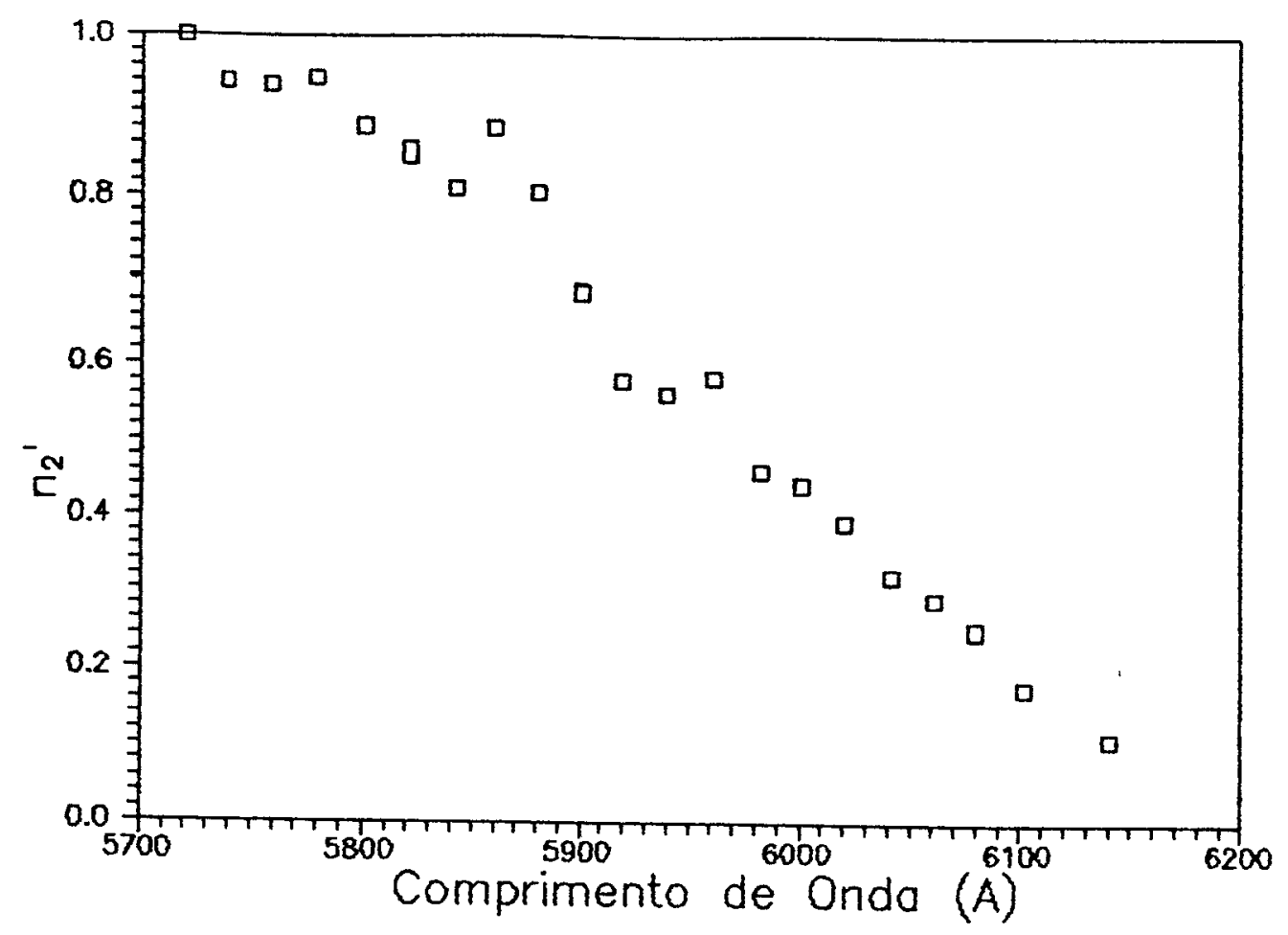

Figura 5.15 Parte real do índice de refracõo nõo-lineor $n_{2}^{\prime}$ em fyuncão do comprimento de onda no $\mathrm{GdAlO}_{3}: \mathrm{Cr}^{3+}$ a temperatura ambiente por NDTWM. Os dados foram normalizados oo valor de $n_{2}^{\prime}$ em $5720 R$.

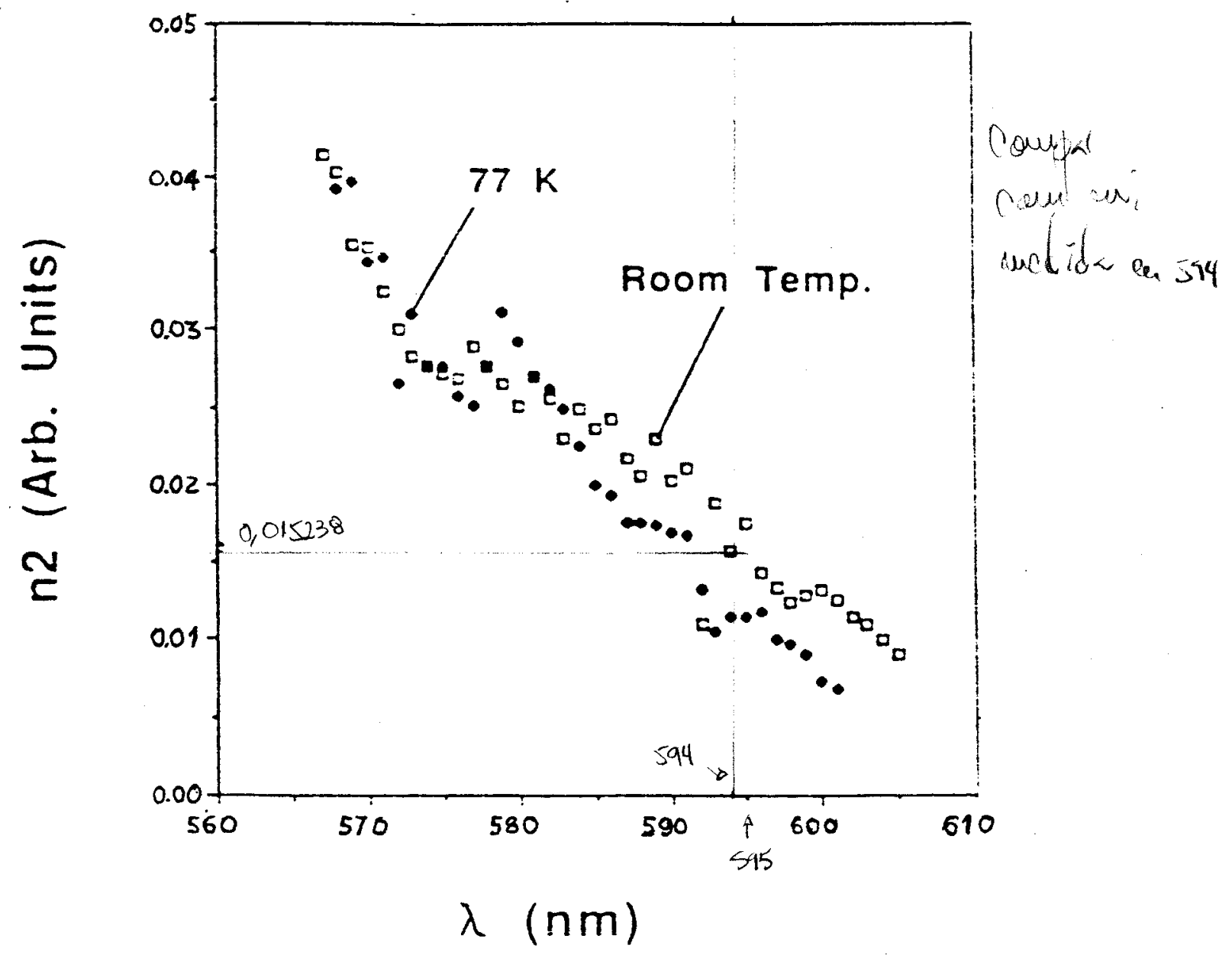

Figura 5.16. $\mathrm{n}_{2}$ para rubi a temperatura ambiente e à $77 \mathrm{~K}$, segundo Adler e Lawandy [55]. 
Com os dados do rubi para a largura da banda CT e a posição da mesma, e os valores de $n_{2}^{\prime}$ e $I_{\delta}$ experimentais estimamos a seção de choque no centro da transição ${ }^{2} \mathrm{E} \rightarrow \mathrm{CT}$ como sendo $0,4 \times 10^{-17} \mathrm{~cm}^{2}$ que é cerca de duas vezes menor do que no rubi. Uma consequência desse nosso experimento é que em $6150 \AA n_{2}^{\prime}$ é dez vezes menor do que em $5720 \AA$, portanto $n_{2}^{\prime} \simeq 4 \times 10^{-8} \mathrm{~cm}^{2} / \mathrm{W}$ no $\mathrm{GdAlO}_{3}: \mathrm{Cr}^{3+}$ e será ainda menor em 6300 A. A mesma relação ocorre no rubi (compare as figuras 5.15 e 5.16) e isto mostra que houve um equívoco quanto à atribuição dos valores de $n_{2}^{\prime}$ medidos anteriormente por um método interferométrico [70] como sendo em $6328 \AA$. No referido experimento a amostra foi colocada num dos braços de um interferômetro de Michelson, sintonizado na frequência de um laser de He-Ne e um laser de argônio com alta potência era focalizado na amostra para modificar o índice de refração da mesma, através da parte não-linear. A mudança de índice provoca o corrimento das franjas de interferência e a variação de fase observada é proporcional a $n_{2}^{\prime} I L / \lambda$. Aqui o comprimento de onda é do laser de He-Ne mas quem mudou o índice foi o laser de argônio. Portanto, de fato, os resultados são para $\lambda=5145 \AA$ e não $\lambda=6328 \AA$. As amostras de rubi e $\mathrm{GdAlO}_{3}: \mathrm{Cr}^{3+}$ são as mesmas que nós usamos em nosso trabalho e os valores de $n_{2}^{\prime}$ medidos por tal método foram [70]: $1,3 \times 10^{-8} \mathrm{~cm}^{2} / \mathrm{W}$ para o rubi e $18,6 \times 10^{-8} \mathrm{~cm}^{2} / \mathrm{W}$ para o $\mathrm{GdAlO}_{3}: \mathrm{Cr}^{3+}$, revelando um bom acordo com as nossas medidas de NDTWM.

\section{6-4. Parte Imaginária $n_{2}^{\prime \prime}$ e Absorção do Estado Excitado}

Mostramos na seção 5.6-1 que a razão r variou com a intensidade e que esta variação está associada à parte imaginária $n_{2}^{\prime \prime}$. Deixemos isto de lado por enquanto e vamos analisar o valor de $r=r_{o}$ em $I_{o}^{+}(0)=0$. Com $r_{0}=0,1$ tem-se $n_{2}^{\prime \prime}=1,6 \times 10^{-8} \mathrm{~cm}^{2} / \mathrm{W}$ mas isto implica em $\sigma_{e}<0$, o que não é possível. Uma possibilidade para esta discrepância seria a necessidade de incluir no modelo teórico contribuições da susceptibilidade de terceira 
ordem $\chi^{(3)}$ que não envolvem saturação da absorção por um fóton. Ou seja, contribuições dos outros níveis presentes no sistema, não-ressonantes com a frequência do laser, como por exemplo a contribuição da banda de transferência de carga. É certo que o sistema de três níveis é uma aproximação mas os resultados para o rubi e alexandrita estão em bom acordo com o modelo de três níveis e mesmo a parte real de $n_{2}^{\prime}$, bem como a curva de saturação de $\Gamma_{2}\left(\Omega^{\prime}\right)$, no $\mathrm{GdAlO}_{3}: \mathrm{Cr}^{3+}$ indicam que o modelo é bem razoável. Por isso, e também com base em algumas observações experimentais que iremos discutir adiante, proporemos uma outra possibilidade que pode explicar a variação de r.

Antes porém é preciso observar que o erro cometido na determinação de I pode ser da ordem de $50 \%$ pois se trata de um parâmetro determinado pelo ajuste de pontos experimentais através de um logarítimo, $\Gamma_{1}\left(\Omega^{\prime}\right)$, e possui um valor muito pequeno. Por exemplo: numa medida anterior de $\mathrm{r} \operatorname{com} I_{o}^{+}(0)=0,1 \mathrm{~kW} / \mathrm{cm}^{2}$ obtivemos 0,13 [36] e noutra 0,08 . De qualquer modo a variação de $\mathrm{r}$ com a intensidade foi observada sistematicamente no $\mathrm{GdAlO}_{3}: \mathrm{Cr}^{3+}$, enquanto nada foi detectado nos outros dois compostos. Uma estimativa para $r_{o}$ pode ser feita através de (5.5) e (5.6a), considerando apenas a contribuição da banda CT para $n_{2}^{\prime}$, que é:

$$
\mathrm{r}_{0} \simeq\left(\sigma_{g} / \sigma_{C T}^{(o)}\right) \Delta_{C T}\left(1-\sigma_{\varepsilon} / \sigma_{g}\right)
$$

com $\Delta_{C T}$ definido em (5.6b) e considerado muito maior do que um para a transição ${ }^{2} \mathrm{E}$ $\rightarrow C T$. Com o valor estimado para $\sigma_{C T}^{(o)}$ no $\mathrm{GdAlO}_{3}: \mathrm{Cr}^{3+}$ e com $\Delta_{C T}$ igual ao do rubi deveríamos esperar $\mathrm{r}_{o} \simeq 0,1\left(1-\sigma_{e} / \sigma_{a}\right)$. Portanto o valor de 0,1 implica que $\sigma_{e}$ é muito menor do que $\sigma_{\sigma}$ e, adimitindo um erro de $50 \%$, no máximo $\sigma_{e}$ será metade de $\sigma_{g}$.

Usando o mesmo método descrito na seção 5.4-1, medimos a absorção do estado excitado no $\mathrm{GdAlO}_{3}: \mathrm{Cr}^{3+}$ numa outra amostra, com $0,3 \%$ de $\mathrm{Cr}^{3+}\left(\mathrm{N}_{0}=5,61 \times 10^{19}\right.$ $\mathrm{cm}^{-3}$ ), em quatro linhas do laser de argônio e em várias linhas do laser de corante. A 


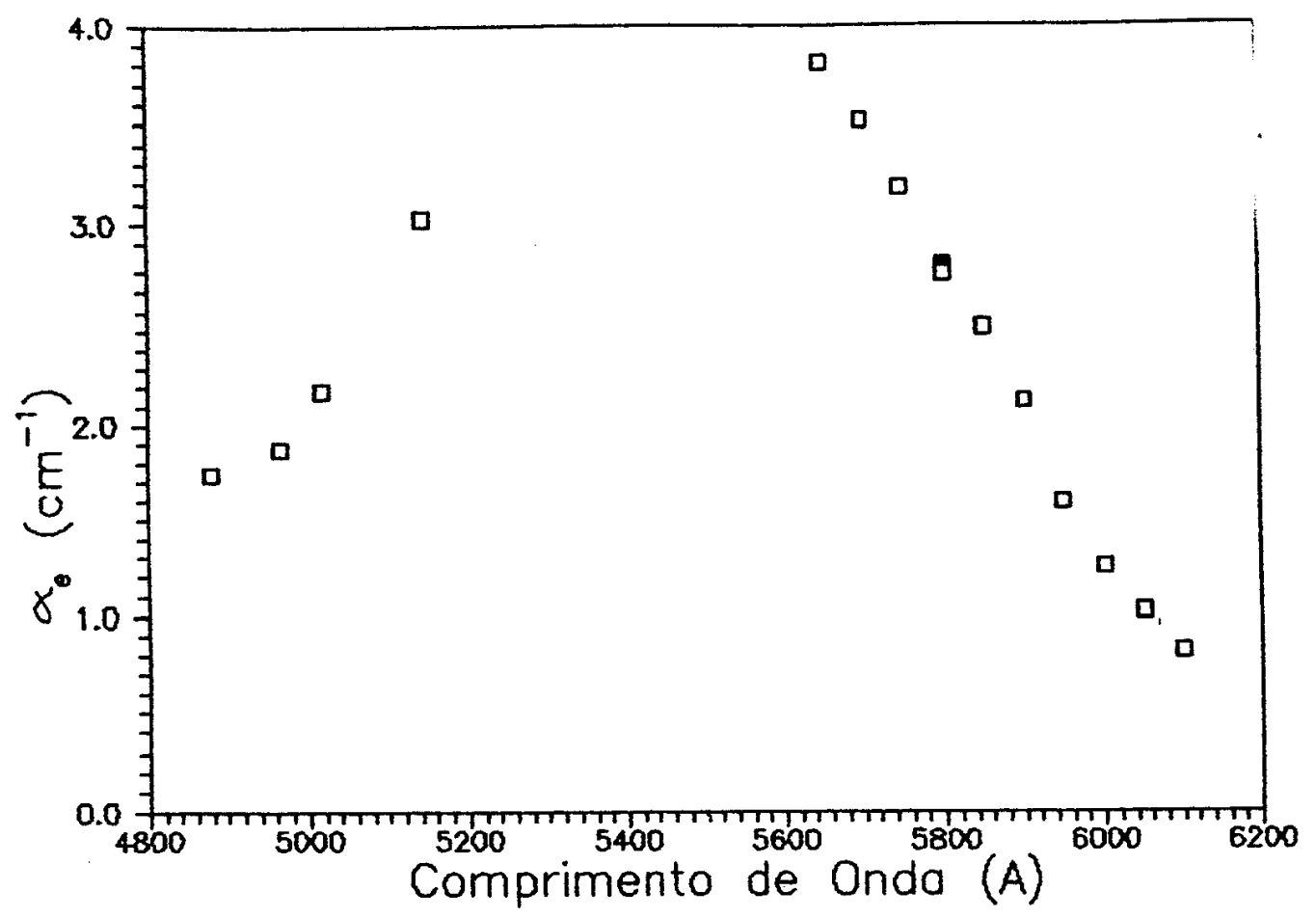

Figura 5.17 Coeficiente de absorcão do estado exçitada a temperatura ambiente no $\mathrm{GdANO}_{3}: \mathrm{Cr}^{3} \mathrm{em}$ funçõo do comprimento de anda.

$N_{0}=5.61 \times 10^{19} \mathrm{~cm}^{-3}$.

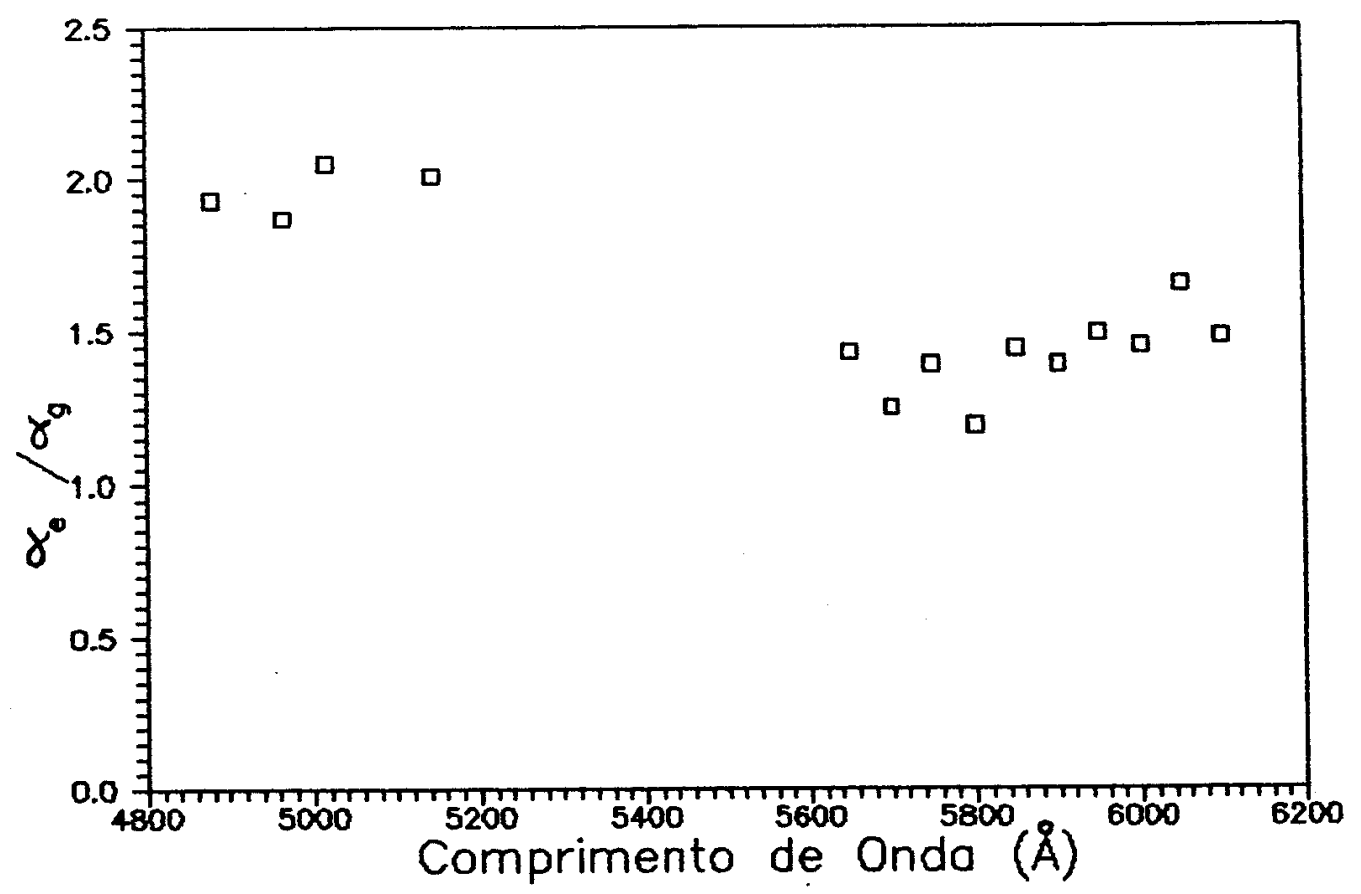

Figura 5.18 Razão entre os coeficientes de absorçăo em altos e baixas intensidades, a temperatura ambiente, no $\mathrm{GdAlO}_{3}: \mathrm{Cr}^{3+}, \mathrm{em}_{19}$ funcốp do comprimento de onda.

$N_{0}=5.61 \times 10^{19} \mathrm{~cm}^{-3}$. 
razão para termos utilizado uma amostra diferente foi simplesmente porque a primeira $(0,8 \%)$ extraviou-se! Os resultados estão nas figuras 5.17 - 18. A região de $5200-5600 \AA$ é inacessível com nossos lasers mas é evidente que existe um máximo (pelo menos) em $\alpha_{e}$ na referida região. Note que o pico da absorção ${ }^{4} A_{2} \rightarrow^{4} T_{2}$ também se situa nessa mesma região. De fato se colocarmos juntas as curvas de $\alpha_{e}$ e $\alpha_{g}$ obteremos o mesmo tipo de comportamento da figura $5.9 \mathrm{~b}$ para a alexandrita, porém com a parte pontilhada naquela figura representando a absorção do estado excitado ${ }^{2} \mathrm{E}$.

Um detalhe muito importante é revelado na figura 5.18: a seção de choque do estado excitado é aproximadamente um fator de 2 maior do que a do estado fundamental nas quatro linhas do laser de argônio e cerca de 1,5 na região 5600 - $6100 \AA$. A princípio essas constatações indicariam que no modelo de três níveis o $r_{o}$ seria negativo em toda a região estudada, incluindo $\lambda=5145 \AA$, e isto não é o que observamos $\left(r_{o}>0\right)$. Seríamos imediatamente tentados a afirmar que o modelo não parece adequado no caso do $\mathrm{GdAlO}_{3}: \mathrm{Cr}^{3+}$. Porém não nos esqueçamos de que nossa determinação de $\sigma_{e}$ é feita com o uso de altas intensidades e por isso pode conter contribuições de algum mecanismo de transferência de energia entre pares de íons no estado excitado! Tal mecanismo daria uma contribuição nula à intensidade zero e nossas observações ainda não invalidam as previsões da equação (5.10).

No $\mathrm{GdAlO}_{3}: \mathrm{Cr}^{3+}$ observou-se a interação entre pares de íons $\mathrm{Cr}^{3+}$ à $77 \mathrm{~K}$, através do espectro de emissão, em concentrações de 0,1\% [46]. Essa emissão foi observada em $7355 \AA$. Basso [62] estudou os espectros de excitação, emissão e absorção dos pares no $\mathrm{GdAlO}_{3}: \mathrm{Cr}^{3+}$ em baixas temperaturas e verificou a absorção pelos pares em torno de $3600 \AA\left(27285 \mathrm{~cm}^{-1}\right)$. Diante dessas observações resolvemos fazer um espectro de emissão na região das linhas $R$ nessa nova amostra de $0,3 \%$ à temperatura ambiente. Isto está mostrado na figura 5.19, onde indicamos a energia dos picos abaixo da identificação das 


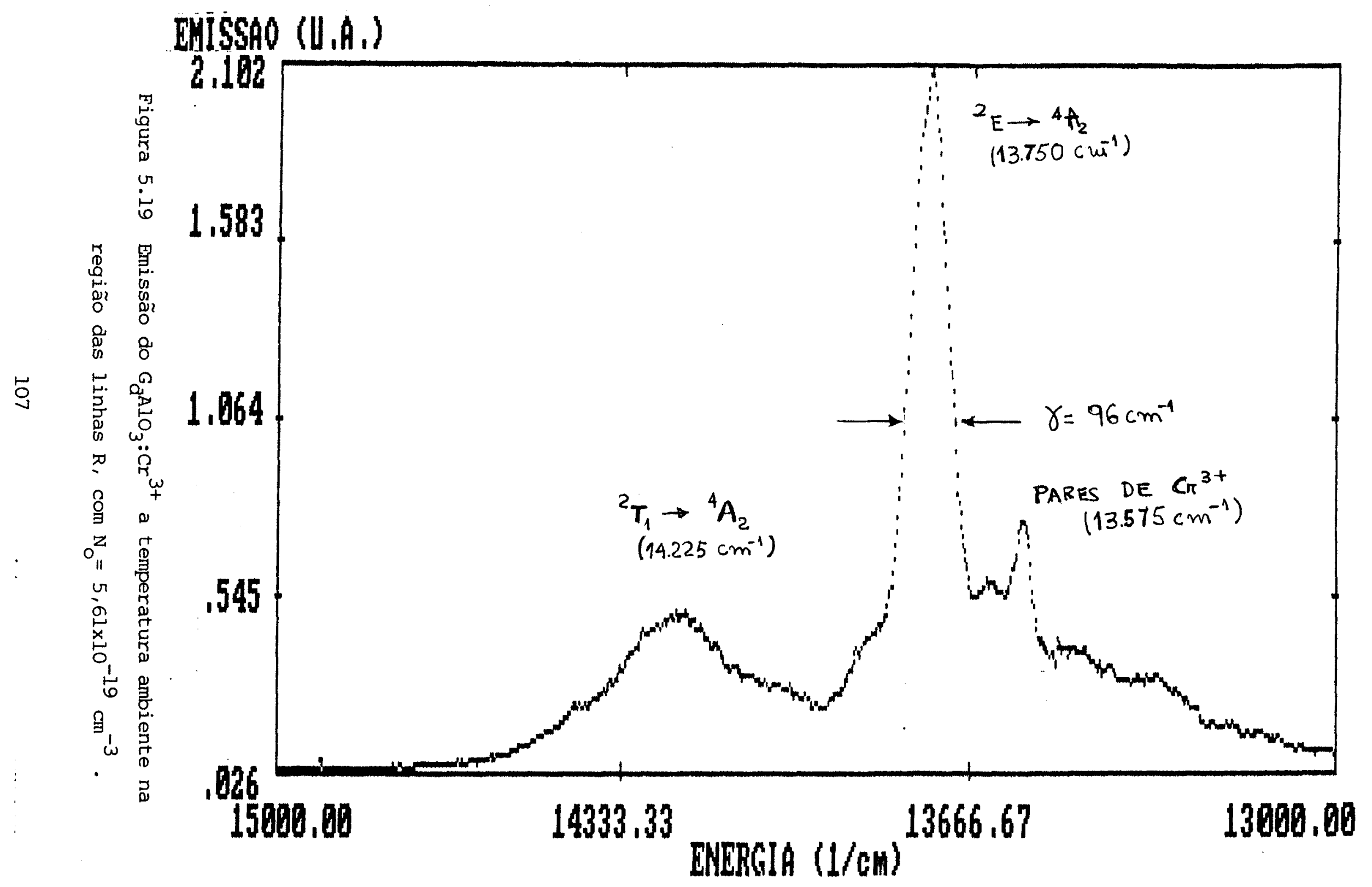


transições. $\mathrm{O}$ aparecimento da transição ${ }^{2} \mathrm{~T}_{1} \rightarrow{ }^{4} \mathrm{~A}_{2}$ em $14.225 \mathrm{~cm}^{-1}$ se deve à população térmica do nível ${ }^{2} \mathrm{~T}_{1}$ a partir do nível ${ }^{2} \mathrm{E}$. Esta emissão não é detectada em baixas temperaturas pois já a $77 \mathrm{~K}$ a população do ${ }^{2} \mathrm{~T}_{1}$ é menor cerca de 1000 vezes.

A identificação da emissão em $13.575 \mathrm{~cm}^{-1}$ (7366 $\AA$ ) como sendo devida aos pares de $\mathrm{Cr}^{3+}$ é reforçada quando comparamos nosso espectro com o que fora obtido por Duarte [68] numa outra amostra com $0,2 \%$ nominal. Na nossa amostra $(0,3 \%)$ a intensidade relativa dos picos entre a emissão do ${ }^{2} \mathrm{E}$ e dos pares é de 2,8 e entre ${ }^{2} \mathrm{E}$ e ${ }^{2} \mathrm{~T}_{1}$ é de 4,4. No espectro de Duarte (veja pág. 91 de [68]) esses números são respectivamente : 5,4 e 2,7. Portanto, com um aumento na concentração de 1,5 vezes a intensidade da emissão dos pares aumentou de 1,93 enquanto a emissão do ${ }^{2} \mathrm{~T}_{1}$ diminuiu de 0,61 . Isto está de acordo com o aumento esperado de 2,25 na emissão dos pares, uma vez que a intensidade desta emissão depende do quadrado da concentração. Conclui-se daqui que: com o aumento da concentração de $\mathrm{Cr}^{3+}$ a interação entre os pares é muito efetiva, chegando a inibir a emissão do nível ${ }^{2} \mathrm{~T}_{1}$.

Uma outra observação experimental no $\mathrm{GdAlO}_{3}: \mathrm{Cr}^{3+}$ completa a base do mecanismo que iremos propor adiante. Duarte verificou a ocorrência de "Transferência de Energia Cooperativa e Absorção de um Fóton" (TECAF) entre um íon $\mathrm{Cr}^{3+}$ no estado excitado ${ }^{2} \mathrm{E}$ e um íon $\mathrm{Gd}^{9+}$ no estado fundamental ${ }^{8} \mathrm{~S}_{7 / 2}$ [68]. O TECAF foi proposto por Altarelli e Dexter [75] em 1970. O coeficiente de absorção $\alpha_{T E}$ para este processo pode ser escrito como [73-75]:

$$
\alpha_{T E}(\nu)=C_{T E} N_{A} N_{B} \sigma_{A o}^{e m} \sigma_{B o}^{a b} \int_{0}^{\infty} g_{A}^{e m}\left(\nu^{\prime}\right) g_{B}^{a b}\left(\nu^{\prime}+\nu\right) d \nu^{\prime}
$$

onde $C_{T E}$ depende do tipo de interação entre os íons $A$ e $B$ (dipolar, quadripolar, etc), $N_{j}$ é a concentração do j-ésimo íon, $\sigma_{j o}$ é a seção de choque integrada na frequência, $g_{j}(\nu$ ") é a forma de linha normalizada para a transição do j-ésimo íon e os super-escritos em 
e $a b$ denotam a emissão e absorção, respectivamente. Este processo pode ser $10^{4}-10^{5}$ vezes mais eficiente do que o processo de absorção de dois fótons quando o íon $B$ é olhado sozinho [75].

Considerando o produto $P_{B}=N_{B} \sigma_{B 0}^{a b}=\pi N_{B} \sigma_{B}^{(o)} \gamma_{B} / 2$ (Cap. 3 da ref. [58]), com $\gamma_{B}$ a largura de linha e $\sigma_{B}^{(o)}$ a seção de choque no centro da linha da transição ocorrida em $B$, vê-se que no gadolíneo: $N_{B} \simeq 10^{22} \mathrm{~cm}^{-3}, \sigma_{B}^{(0)} \simeq 10^{-22} \mathrm{~cm}^{2}$ e $\gamma_{B} \simeq 10 \mathrm{~cm}^{-1}$ [69] o que dá $P_{G d} \simeq 20 \mathrm{~cm}^{-2}$. Note que o gadolíneo é um constituinte da rede e que o coeficiente de absorção do $\mathrm{Gd}^{3+}$ é da mesma ordem do $\mathrm{Cr}^{3+}\left(\sim 1 \mathrm{~cm}^{-1}\right)$, como pode ser visto na figura 5.4 no destaque pontilhado. Se, por outro lado, o íon $B$ for $\mathrm{um}_{\mathrm{Cr}^{3+}}$ no estado excitado ${ }^{2} \mathrm{E}$, a troca de energia com a absorção de um fóton $\left(\sim 20.000 \mathrm{~cm}^{-1}\right)$ levaria este íon para a regiáo de energia em $47.000 \mathrm{~cm}^{-1}(213 \mathrm{~nm}$ ) que é a região da banda CT (veja figura 5.4). Como a seção de choque para a transição ${ }^{2} \mathrm{E} \rightarrow \mathrm{CT}$ é cerca de $10^{-18} \mathrm{~cm}^{2}$, a largura de linha é $\gamma_{C T} \simeq 10^{3} \mathrm{~cm}^{-1}$ e $N_{o} \simeq 10^{20} \mathrm{~cm}^{-3}$, tem-se neste caso $P_{C r} \simeq 10^{5} \mathrm{~S}_{o}\left(1+\mathrm{S}_{o}\right)^{-1}$ $\mathrm{cm}^{-2}$. Vê-se que este processo pode ser muito mais eficiente do que o primeiro que fora observado por Duarte [68], mesmo à intensidades baixas.

Nossa proposta é que este tipo de transferência está ocorrendo, ou seja, TECAF entre pares de $\mathrm{Cr}^{3+}(A$ e $B)$ no estado excitado e que após a transferência o íon $A$ vai para o estado fundamental, enquanto o $B$ vai para a banda CT de onde ele decai nãoradiativamente de volta para o ${ }^{2} \mathrm{E}$ e daí ele emite. O esquema desse processo é ilustrado na figura 5.20. Tal processo explica porque observamos variação de $\mathrm{r}$ com a intensidade e também a forma e a posição do pico da absorção do estado excitado, conforme figura 5.17. Vejamos: 

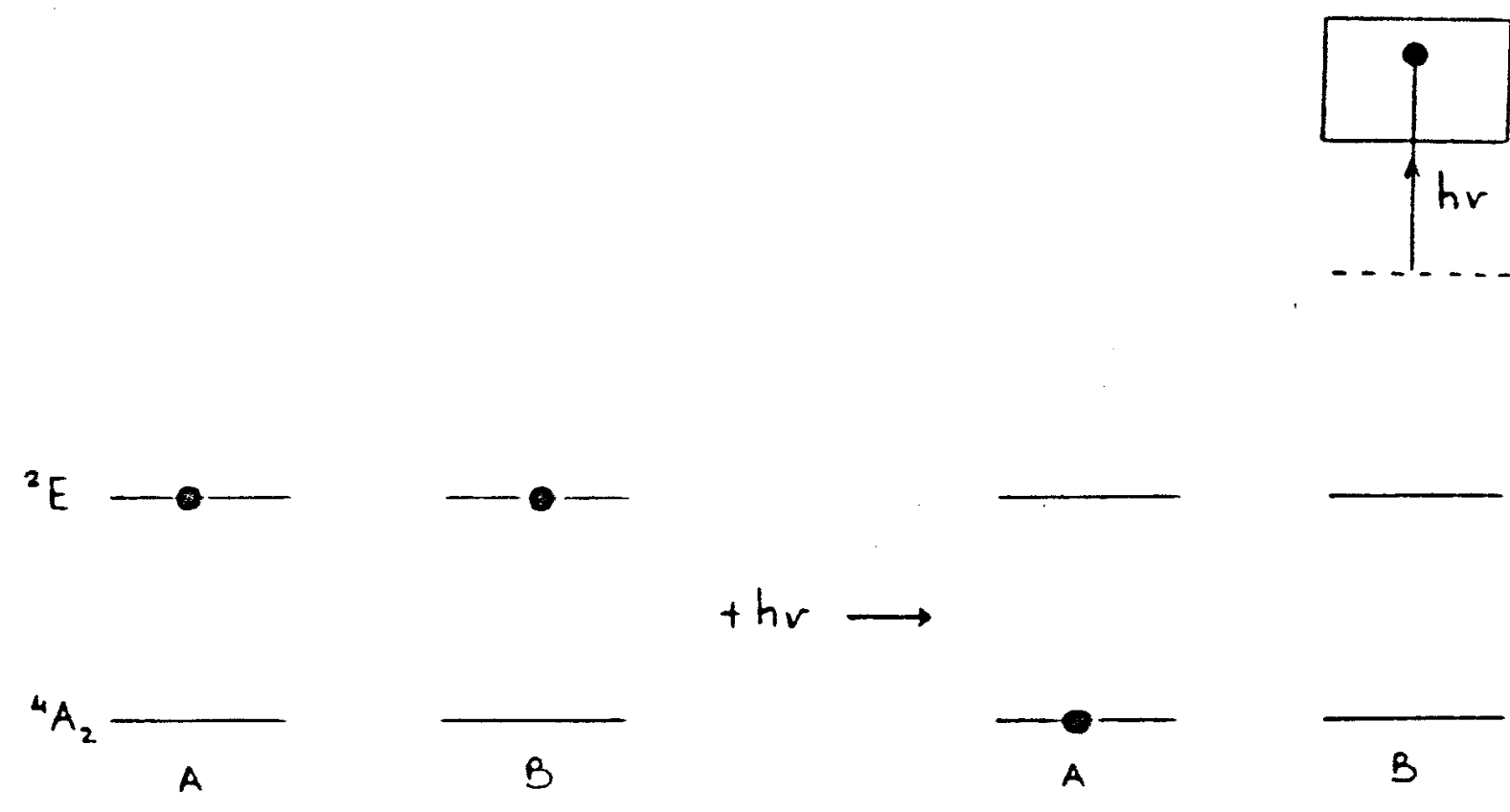

Figura 5.20. Processo de transferência de energia cooperativa entre pares de $\mathrm{Cr}^{3+}$ no estado excitado com a absorção de um fóton $h \nu$ (TECAF).

1) A forma de linha da transição em $B$ é a forma de linha da absorção do estado excitado para a banda CT e por isso é muito mais larga do que a forma de linha da emissão do nível ${ }^{2} \mathrm{E}$. Devida à grande separação em energia entre ${ }^{2} \mathrm{E}$ e CT, na região de superposição da emissão ${ }^{2} \mathrm{E} \rightarrow{ }^{4} \mathrm{~A}_{2}$ com a absorção ${ }^{2} \mathrm{E} \rightarrow \mathrm{CT}$ a forma de linha $g_{B}^{a b}\left(\nu^{\prime}+\nu\right)$ é praticamente constante $\left(g_{A}^{e m}\left(\nu^{\prime}\right) \sim \delta\left(\nu^{\prime}-\nu_{e}\right)\right)$ e podemos aproximá-la por $g_{B}^{a b}\left(\nu_{e}+\nu\right)$, onde $\nu_{e}$ é a energia do nível ${ }^{2} \mathrm{E}$. E a equação (5.11) se escreve:

$$
\begin{aligned}
\alpha_{T E}(\nu) & \simeq C_{T E} N_{A}^{2} \sigma_{A 0}^{e m} \sigma_{B 0}^{a b} g_{B}^{a b}\left(\nu_{e}+\nu\right) \\
& =C_{T E} N_{A}^{2} \sigma_{A 0}^{e m} \sigma_{B 0}^{a b}\left[1+4\left(\nu_{o}-\nu\right)^{2} / \gamma_{C T}^{2}\right]^{-1}
\end{aligned}
$$


com $\nu_{o}=\nu_{C T}-2 \nu_{e}$. Pelo espectro de absorção do estado excitado (figura 5.17) tem-se $\gamma_{C T} \simeq 3000 \mathrm{~cm}^{-1}$ e supondo um máximo em $5550 \AA$ (o pico da banda ${ }^{4} \mathrm{~T}_{2}$ ), correspondendo a $\nu_{o} \simeq 18.000 \mathrm{~cm}^{-1}$, a energia da banda $\nu_{C T}$ seria de $45.500 \mathrm{~cm}^{-1}$. Isto corresponde a observação da absorção do estado fundamental para a banda CT em 220 $\mathrm{nm}$ no $\mathrm{GdAlO}_{3}: \mathrm{Cr}^{3+}$ e está em perfeito acordo com o espectro da figura 5.4. Com estes valores de $\nu_{C T}$ e $\gamma_{C T}$ e o valor de $n_{2}^{\prime}$ em $5145 \AA$, obtém-se uma seção de choque $\sigma_{C T}^{(0)}=$ $0,33 \times 10^{-17} \mathrm{~cm}^{2}$ que é três vezes menor do que no rubi.

2) Por (5.12) verifica-se que a seção de choque $\sigma_{T E}(\nu)$ para este processo é função da intensidade e da concentração de $\mathrm{Cr}^{3+} N_{o}$ :

$$
\begin{gathered}
\sigma_{T E}(\nu) \equiv \frac{\alpha_{T E}(\nu)}{N_{A}}=N_{o} \frac{S_{o}}{1+S_{o}} F(\nu) \\
F(\nu) \equiv C_{T E} \sigma_{A 0}^{e m} \sigma_{B 0}^{a b} g_{B}^{a b}\left(\nu_{e}+\nu\right)
\end{gathered}
$$

onde $S_{o}$ é o parâmetro de saturação. Seguindo os apêndices II e III pode-se mostrar facilmente que a inclusão da contribuição (5.13) na parte imaginária da susceptibilidade do estado excitado implica numa correção da parte imaginária do índice não-linear, em primeira ordem na intensidade, que agora se escreve:

$$
n_{2}^{\prime \prime}=n_{20}^{\prime \prime}\left[1-\frac{F(\nu) N_{o}}{\sigma_{g}\left(1-\sigma_{e} / \sigma_{g}\right) I_{\delta}} I\right]
$$

onde $n_{20}^{\prime \prime}$ é a parte imaginária na ausência do processo TECAF. Portanto, em primeira aproximação, $r$ decresce linearmente com a intensidade a partir do seu valor inicial em $I=0$.

Nosso $\alpha_{e}$ experimental seria composto da contribuição normal de um íon isolado, $N_{o} \sigma_{e}$, mais a contribuição $\alpha_{T E}=N_{o}^{2} F(\nu)$. Com o valor medido de $\alpha_{e}=3,02 \mathrm{~cm}^{-1} \mathrm{em} 5145 \AA$ 
e considerando $\sigma_{e}=0,2 \sigma_{o}$, obtém-se $F(\nu)=8,64 \times 10^{-40} \mathrm{~cm}^{5}$. Quando substituimos os demais valores experimentais em (5.14), para o caso da amostra com $0,8 \%$, obtemos:

$$
\mathbf{r}=\mathbf{r}_{\mathrm{o}}(1-5,27 I)
$$

e para manter coerência com (5.10) usamos $r_{0}=0,08$ e traçamos a linha sólida na figura 5.12. O bom acordo entre os valores de $r$ experimentais e a curva (5.15) parece-nos um forte indicativo de que o TECAF entre pares de $\mathrm{Cr}^{3+}$ no estado excitado é a causa da variação da parte imaginária do índice de refração não-linear.

Na tabela 5.4 fazemos um resumo dos valores experimentais para o $\mathrm{GdAlO}_{3}: \mathrm{Cr}^{3+}$ à temperatura ambiente, no comprimento de onda $5145 \AA$ e com polarização perpendicular ao eixo $c$.

Tabela 5.4. Valores experimentais em $\mathrm{GdAlO}_{3}: \mathrm{Cr}^{3+}$ para $\lambda=5145 \AA$ e com polarização $\mathrm{E} \perp \mathrm{c}$.

\begin{tabular}{|cccccccc|}
\hline $\mathrm{L}(\mathrm{cm})$ & $\mathrm{N}_{o}\left(\mathrm{~cm}^{-3}\right)$ & $\alpha_{g}\left(\mathrm{~cm}^{-1}\right)$ & $\sigma_{C T}^{(0)}\left(\mathrm{cm}^{2}\right)$ & $\mathrm{T}_{1}(\mathrm{~ms})$ & $I_{\delta}\left(\mathrm{kW} / \mathrm{cm}^{2}\right)$ & $n_{2}^{\prime}\left(\mathrm{cm}^{2} / \mathrm{W}\right)$ & $\mathrm{r}$ \\
\hline 0,14 & $1,57 \times 10^{20}$ & 4,2 & $3,3 \times 10^{-18}$ & 12 & 1,2 & $16 \times 10^{-8}$ & 0,08 \\
\hline
\end{tabular}




\section{BI-ESTABILIDADE ÓPTICA EM FILMES DE $\mathrm{ZrO}_{2} \mathrm{E}$ INCONEL}

\subsection{INTRODUÇÃO}

Neste Capítulo iremos descrever em linhas gerais o fenômeno da bi-estabilidade óptica (BO) e em particular trataremos os chamados sistemas passivos puramente ópticos (SPPO). Por sistema passivo entende-se meio sem inversão de população ou meio sem exibir ganho. Nosso propósito é discutir o efeito produzido quando uma cavidade Fabry-Perot (FP) é composta de espelhos que, por si só, podem introduzir propriedades não-lineares e gerar bi-estabilidade óptica. Isto foi observado por nós quando nosso interesse era observar a $\mathrm{BO}$ no $\mathrm{GdAlO}_{3}: \mathrm{Cr}^{3+}$. O aluminato de gadolíneo dopado com cromo apresentava-se como um grande promissor para a observação de BO, em vista do alto índice de refração nãolinear $n_{2}^{\prime}$ relativo ao rubi, onde a bi-estabilidade óptica fora observada [54]. Entretanto não conseguimos observar $\mathrm{BO}$ no $\mathrm{GdAlO}_{3}: \mathrm{Cr}^{3+}$ e no final desse capítulo discutiremos as possíveis causas que concorreram para isto.

Apresentaremos alguns resultados experimentais de $\mathrm{BO}$ em filmes de $\mathrm{ZrO}_{2}$ e inconel (liga de níquel, cromo e ferro). Esses resultados são apenas qualitativos porque, como dissemos acima, nosso objetivo era identificar um filme que não apresentasse propriedades não-lineares para que pudessemos utilizá-lo na confecção dos espelhos da cavidade FP que seria empregada na observação da $\mathrm{BO}$ no $\mathrm{GdAlO}_{3}: \mathrm{Cr}^{3+}$. Por outro lado, as propriedades não-lineares de filmes dielétricos, tais como o $\mathrm{ZrO}_{2}$, ainda são pouco conhecidas e só recentemente é que tem-se discutido teoricamente a possibilidade dos filmes apresentarem BO [76] e observou-se a bi-estabilidade óptica em filmes de $\mathrm{TiO}_{2}$ [77], quase ao mesmo tempo em que nós verificamos o efeito no $\mathrm{ZrO}_{2}$ [78]. 


\subsection{O QUE É BI-ESTABILIDADE ÓPTICA?}

Um sistema é denominado opticamente bi-estável se ele apresenta dois estados de saída $I$, para um único valor da intensidade de entrada $I_{i}$ em alguma região dos valores de entrada. Por exemplo um sistema representado pela curva $I$, x $I_{i}$ na figura 6.1 é bi-estável entre $I_{d}$ e $I_{u}$. Tal sistema é não-linear, pois a intensidade de saída $I$, não é igual a uma constante vezes a intensidade de entrada $I_{i}$. Para que um sistema apresente

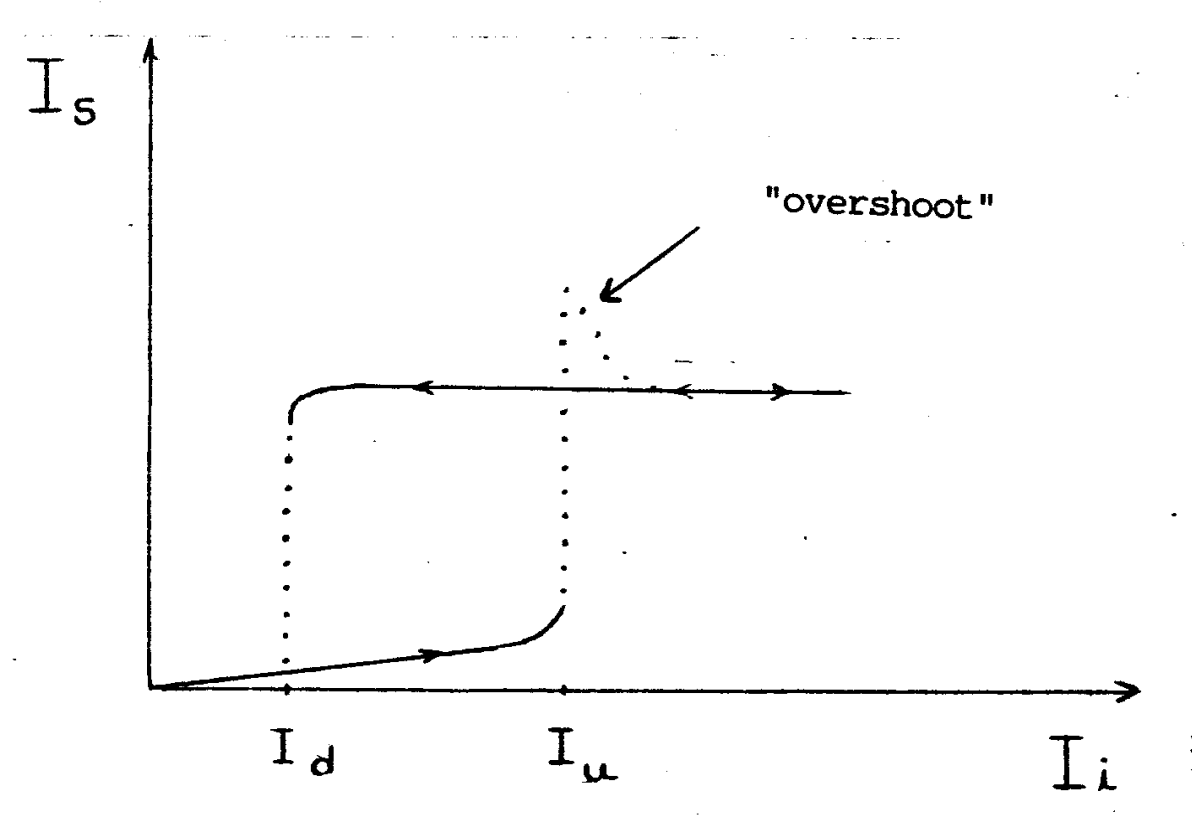

Figura 6.1. Curva característica de um sistema bi-estável.

bi-estabilidade óptica não basta que o mesmo seja não-linear é preciso também que exista algum mecanismo de realimentação. De uma maneira geral os sistemas bi-estáveis apresentam a seguinte relação:

$$
I_{\bullet}=\mathrm{T}\left(I_{\bullet}\right) I_{i}
$$


onde $\mathrm{T}\left(I_{0}\right)$ é a transmissão do sistema, a qual é função da própria intensidade de saída, configurando uma realimentação.

Os sistemas opticamente bi-estáveis são classificados de duas formas: intrínsicos ou híbridos. Num sistema intrínsico (ou puramente óptico (SPO)) a realimentação surge através da interação da luz com a matéria. Um exemplo é uma cavidade FP contendo um meio Kerr onde a dependência da transmissão do FP com a intensidade $I_{a}$ se deve à mudança da fase (sintonia) do FP, ocasionada pelo índice não-linear. Já num sistema híbrido, normalmente a realimentação é gerada por intermédio de um sinal elétrico (originado por um detector que monitora a intensidade transmitida) que é aplicado em algum mecanismo capaz de modificar a fase da cavidade. Tal mecanismo pode ser, por exemplo, um PZT acoplado a um dos espelhos da cavidade [79] ou um cristal eletro-óptico no interior da cavidade [80].

Os sistemas híbridos apresentam uma grande vantagem sobre os SPO que é a possibilidade da observação de bi-estabilidade óptica com intensidades muito baixas, já que o sinal elétrico usado para excitar o mecanismo de realimentação pode ser amplificado eletronicamente ao nível requerido pelo tipo de mecanismo (PZT por exemplo).

\subsection{MATERIAIS E MECANISMOS DE REALIMENTAÇ̃̃O EM SISTEMAS PASSIVOS PURAMENTE ÓPTICOS (SPPO)}

Diversos sistemas ópticos que apresentam bi-estabilidade e outros efeitos relacionados com esta última, tais como: ganho diferencial, chaveamento óptico, limitador, etc. têm sido investigados na última década.

A primeira observação de bi-estabilidade em SPPO foi feita num FP contendo vapor de 
sódio [81]. A grande importância deste trabalho é que o mesmo revelou o caráter dispersivo da bi-estabilidade, que até então era investigada com base em modelos de absorção saturada. Neste último caso, bi-estabilidade absorptiva, o mecanismo de realimentação é obtido pelo branqueamento ("bleaching") do meio absorvedor, devido a alta intensidade dentro da cavidade FP [82], e nenhuma mudança de fase é envolvida. Contrário à BO dispersiva onde a realimentação é devida à mudança de fase do FP por meio do índice Kerr.

A segunda observação de BO dispersiva em SPPO foi feita em rubi [54]. A sua importância está no fato de que foi: a) o primeiro sólido e b) o primeiro sólido à temperatura ambiente a exibir bi-estabilidade óptica. Também observou-se pela primeira vez o que é denominado de "overshoot" (ver fig. 6.1), o qual ocorre quando a intensidade de entrada é variada rapidamente com relação ao tempo de resposta do sistema não-linear (FP + meio) $[17,83]$.

Os líquidos $\mathrm{CS}_{2}$, nitrobenzeno e os cristais líquidos foram os materiais seguintes a apresentarem bi-estabilidade óptica intrínsica em cavidades FP [83]. Como vimos no Capítulo 2, nestes materiais o mecanismo não-linear dominante é a reorientação molecular introduzida pela luz. Nos cristais líquidos o aquecimento do material devido ao laser, origina uma contribuição adicional ao índice não-linear, mas de sinal contrário. Segundo McCall [79], um sistema não-linear com estas características pode exibir auto-oscilações e isto foi observado em filmes de cristais líquidos por Cheung et al [84].

O semicondutor GaAs foi o primeiro deste tipo de material em que observou-se biestabilidade óptica e também auto-oscilação em SPPO $[85,86]$. O mecanismo não-linear foi obtido usando-se uma frequência de excitação ligeiramente abaixo da banda de absorção de excitons, o que produz uma mudança na polarizabilidade associada à ressonância de excitons e origina um índice de refração dependente da intensidade [85]. 
Todos os tipos de bi-estabilidade descritos acima são baseados num meio não-linear dentro de uma cavidade Fabry-Perot e são de caráter dispersivo. Entretanto, não é necessária a utilização de uma cavidade óptica para observar BO. Kaplan [87] propôs a possibilidade de ter-se BO utilizando-se um meio não-linear e dois feixes incidentes contra-propagando-se no meio. O mecanismo de realimentação é originado da interação mútua entre os feixes, através de auto-focalização (ou auto-desfocalização) dos mesmos, quando atravessam o meio não-linear. Isto foi observado pela primeira vez em vapor de sódio onde o segundo feixe foi obtido através de um espelho [88]. Mais tarde Tai et al [89] observaram pela primeira vez a BO sem espelho algum num meio dispersivo, o sódio, seguindo a proposta inicial de Kaplan [87]. Também conseguiram observar bi-estabilidade óptica num feixe conjugado fazendo-se incidir um feixe de prova ao sistema inicial.

A eliminação da cavidade óptica apresenta principalmente duas grandes vantagens: a) inexistência de tempos de elevação e decaimento, inerentes às cavidades; b) a possibilidade de se usar fontes de luz com banda larga.

O número de trabalhos na área de bi-estabilidade óptica de uma maneira geral (intrínsica ou híbrida) é muito extenso e nós nos limitaremos aos exemplos citados acima. Uma visão geral sobre o assunto pode ser obtida no livro de H.M. Gibbs [17].

\subsection{BI-ESTABILIDADE ÓPTICA NUMA CAVIDADE FABRY-PEROT}

\section{4-1. Teoria}

Vamos considerar o caso mais geral de uma cavidade Fabry-Perot formada por espelhos absorvedores e com um meio não-linear de comprimento $L$ (índice $\hat{n}$ e coeficiente de 
absorção $\alpha$ ) em seu interior. Na figura 6.2. está esquematizada este tipo de cavidade. O espelho de entrada é caracterizado por sua transmissão $T$ e reflexões $R$ (externa) e $R^{\prime}$ (interna) que são diferentes no caso de espelho absorvedor [16]. O espelho de saída caracteriza-se por sua transmissão $T_{M}$ e reflexão interna $R_{M}$. Denotando por T a transmissão da cavidade, $\mathrm{R}$ a reflexão, $A$ a absorção total do sistema e usando o tratamento para interferência de multi-ondas [16] chega-se às seguintes expressões [90]:

$$
\begin{gathered}
\mathrm{T}=T_{M} e^{-\alpha L} T_{F} \\
\mathrm{R}=R+T_{F}\left\{T R_{M} e^{-2 \alpha L}+2 R_{\alpha}\left[\cos (\psi+\phi)-R_{\alpha}^{\prime} \cos \phi\right]\right\} \\
T_{F} \equiv T /\left\{\left(1-R_{\alpha}^{\prime}\right)^{2}\left[1+F \operatorname{sen}^{2}(\psi / 2)\right]\right\} \\
\phi \equiv 2 \delta_{T}-\delta_{R}-\delta_{R^{\prime}} \\
\psi \equiv \delta_{R^{\prime}}-\delta_{R_{M}}+4 \pi \hat{n} L / \lambda \\
R_{\alpha}^{\prime} \equiv\left(R^{\prime} R_{M}\right)^{\frac{1}{2}} e^{-\alpha L} \\
F \equiv 4 R_{\alpha}^{\prime} /\left(1-R_{\alpha}^{\prime}\right)^{2} \\
R_{\alpha} \equiv\left(R R_{M}\right)^{\frac{1}{2}} e^{-\alpha L} \\
\therefore
\end{gathered}
$$




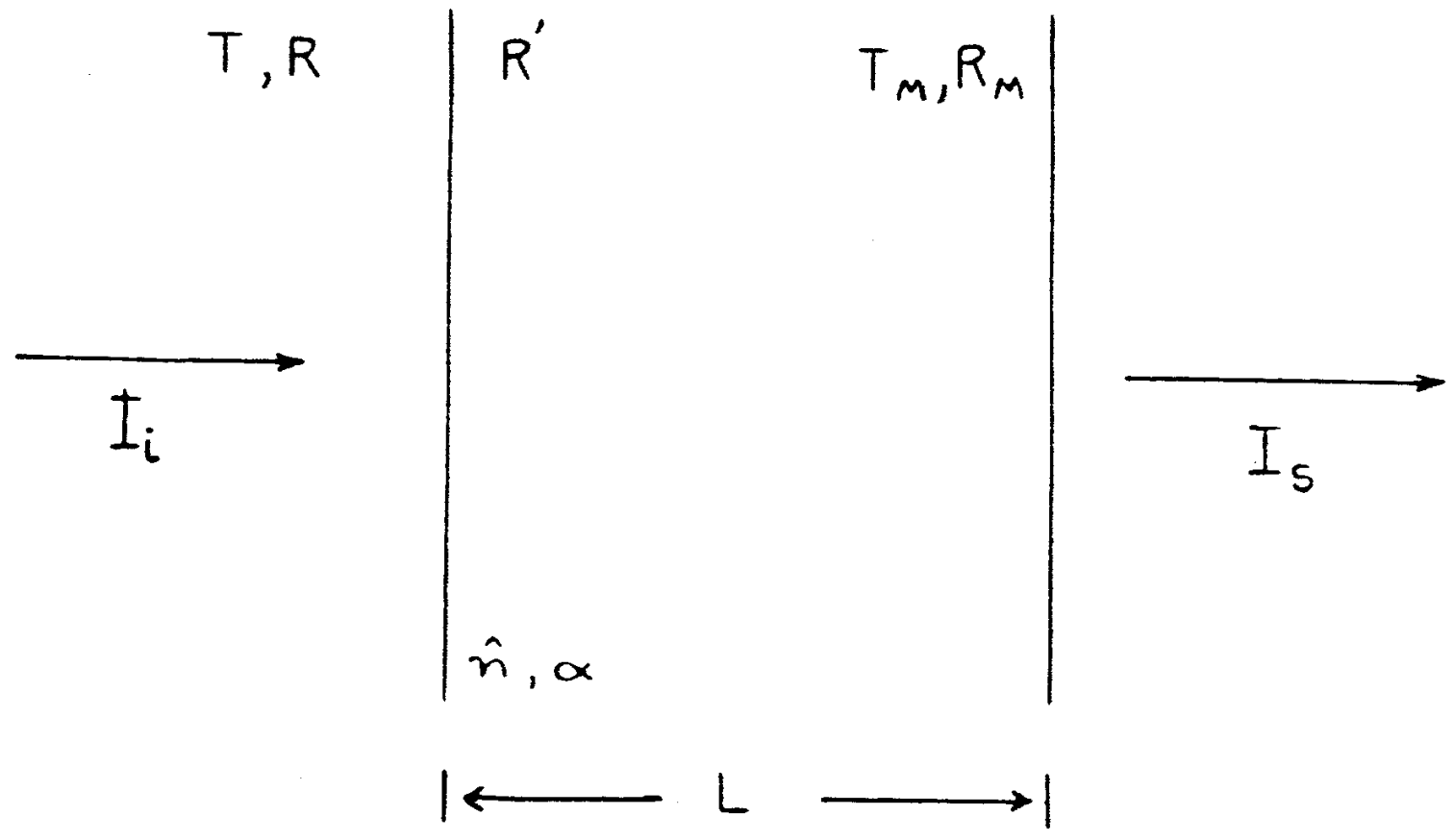

Figura 6.2. Cavidade Fabry-Perot contendo um meio não-linear.

onde $\delta_{i}$ representa a mudança de fase introduzida por cada espelho durante transmissão $(T)$ ou reflexão $\left(R, R^{\prime}\right.$ e $\left.R_{M}\right)$. A absorção total do sistema $A$ é obtida pela conservação de energia $\mathrm{R}+\mathrm{T}+A=1$. A "finess" (fator de qualidade) da cavidade $\mathrm{F}$ é dada pela relação:

$$
F=\pi \sqrt{F} / 2
$$

e as equações (6.2) mostram claramente que o fator de qualidade é seriamente diminuído à medida que a absorção do meio aumenta. Estas expressões (6.2) tornam-se simples no caso de espelhos não absorvedores. Nesta situação tem-se: $\phi=\pi$ e $R^{\prime}=R$ e o tratamento está descrito no trabalho de Miller [91]. 
A optimização de uma cavidade descrita por (6.2) é uma tarefa complexa em vista do número de parâmetros envolvidos. Entretanto, pode-se formar etalons bi-estáveis com ótimo contraste, operando em baixas intensidades, utilizando-se meios sensíveis à mudança de temperatura, mesmo com pobre fator de qualidade [90]. Nestes sistemas o parâmetro importante não é a transmissão da cavidade T e sim a absorção $A$. Aqui a fase da cavidade $\psi$ é função da mudança de temperatura, a qual pode mudar o comprimento da cavidade (através do coeficiente de expansão linear do meio) ou o índice de refração $\hat{n}$ (através do coeficiente termo-óptico) ou ambos. Portanto a absorção $A$ é função da intensidade através da intensidade absorvida $I_{A}$ pela cavidade ou:

$$
I_{A}=A\left(I_{A}\right) I_{i}
$$

o que caracteriza uma realimentação. Este tipo de bi-estabilidade é denominado de termoóptica e agora passaremos a discutir a observação desta $\mathrm{BO}$ no $\mathrm{ZrO}_{2}$ e inconel.

\section{4-2. Experimentos em $\mathrm{ZrO}_{2}$ e Inconel.}

É uma prática comum utilizarmos espelhos onde na maioria das vezes o que nos interessa é saber a reflexão (ou transmissão) dos mesmos na região de comprimento de onda em que iremos usá-los. Isto pode ser um tanto frustrante quando os espelhos forem empregados em aplicações que necessitem de altas potências, pois os materiais utilizados na confecção dos espelhos podem apresentar propriedades não-lineares tanto de origem eletrônica (pouco estudado) quanto de origem térmica (caso mais comum). A situação é mais crítica quando os espelhos são empregados em experimentos interferométricos pois a dilatação térmica do substrato (normalmente em contato com um suporte) fará com que o sistema sofra alterações. 
Tal fato aconteceu conosco quando montamos uma cavidade FP com espelhos de $\mathrm{ZrO}_{2}$ para observarmos a $\mathrm{BO}$ no $\mathrm{GdAlO}_{3}: \mathrm{Cr}^{3+}$. A cavidade foi do tipo confocal com raio igual a $1,5 \mathrm{~cm}$. A intensidade na entrada da cavidade FP foi variada através de um modulador eletro-óptico (MO) em conjunto com um prisma Glan (P). O eixo de polarização desse prisma formou um ângulo de $45^{\circ}$ com a vertical para que, juntamente com um prisma romboédrico de Fresnel (PR), pudessemos isolar o laser da luz que retorna da cavidade FP. Na figura 6.3 está o esquema da montagem experimental. A lente $L_{f}$ serve para acoplar os modos do FP e do laser. FD são foto-diodos e GO é o gerador de ondas que descrevemos no Capítulo 5. MC é um micro-computador que controla a tensão aplicada no modulador eletro-óptico e ao mesmo tempo aquisiciona os dados de entrada e saída.

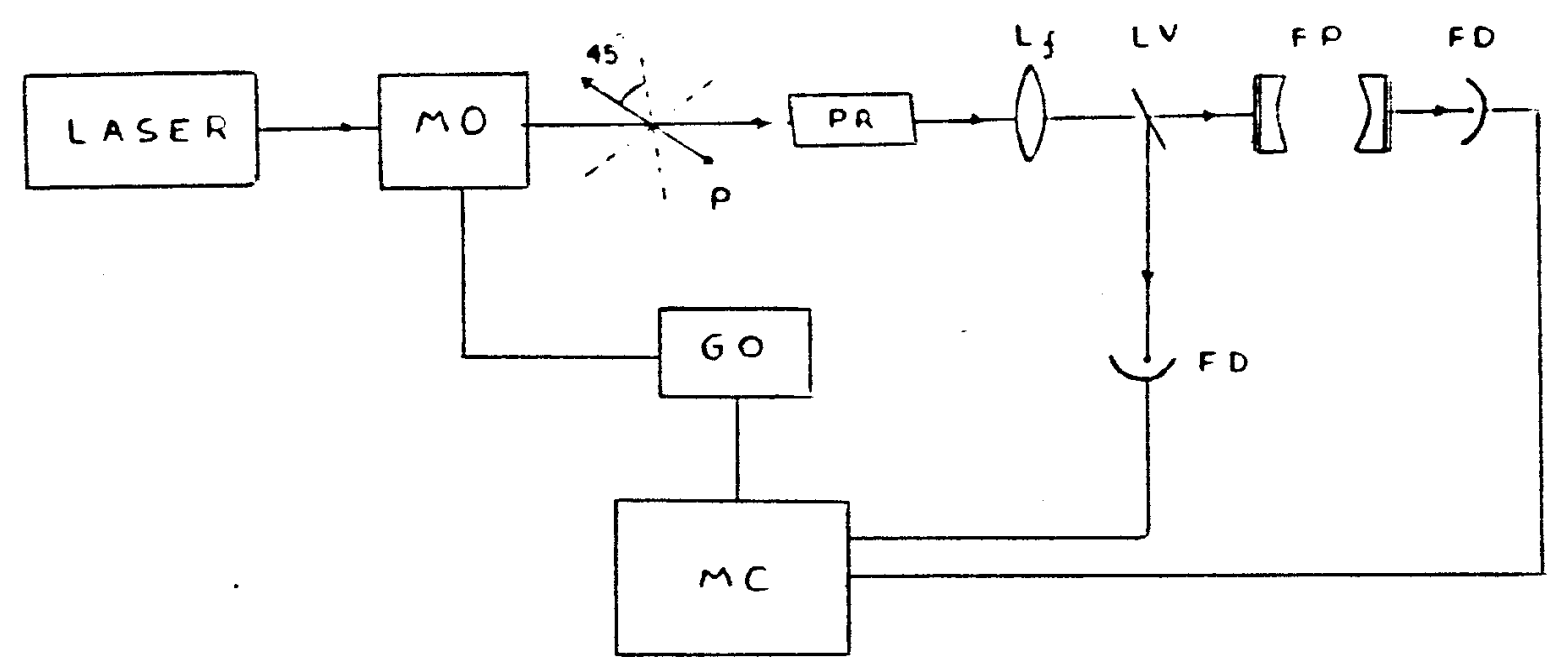

Figura 6.3. Montagem experimental para observação de bi-estabilidade óptica.

Nós fizemos várias modificações no programa de aquisição originalmente desenvolvido por Tonissi Jr. et al [92]. A aquisição é feita da seguinte maneira: 
a) a interface do micro-computador transforma os sinais analógicos dos foto-diodos em sinais digitais, os quais são captados pelo "software" e armazenados em variáveis do programa. Essa leitura pode ser repetida tantas vezes se queira, com a finalidade de se fazer uma média dos valores medidos em cada potência do laser.

b) o "software" incrementa uma variável inteira $J$ (0 a 255) e uma rotina em "assembler" transforma o valor dessa variável num nível de tensão digital (0 a $5 \mathrm{~V}$ ) que está disponível num conector BNC da interface. Este sinal digital é amplificado pela fonte chaveada do gerador de ondas GO a um nível de tensão apropriado para excitar o modulador MO. O fator de amplificação é cerca de 300 e com aproximadamente $1500 \mathrm{~V}$ a luz que sai de MO está polarizada a $90^{\circ}$ com relação ao polarizador $P$.

c) no novo valor da intensidade incidente é feita uma nova leitura e o ciclo $a-b$ se repete até o valor máximo de intensidade $I_{i}$ desejada.

d) o retorno à intensidade nula é feito segundo os passos a-b-c, mas decrescendo a variável $J$ até zero.

O tempo de aquisição entre dois pontos pode ser controlado através de uma outra variável, a qual gera um atraso entre os incrementos (decrementos) da variável $J$. 0 ciclo de aquisição pode ser interrompido em qualquer ponto simplesmente pressionando-se uma tecla. E, uma vez interrompido, poderá continuar do mesmo ponto também com o pressionamento de uma tecla.

Na figura 6.4 mostramos a transmissão do sistema sem a presença da cavidade FP. Nessa figura e nas seguintes, $P_{\text {ent }}$ representa a potência do laser e não a potência efetiva medida após a lente $\mathrm{L}_{f}$. Esta última é cerca de $60 \%$ de $P_{\text {ent }}$. $P_{a i}$ está em unidades arbitrárias. Nota-se que a transmissão do sistema é linear. 


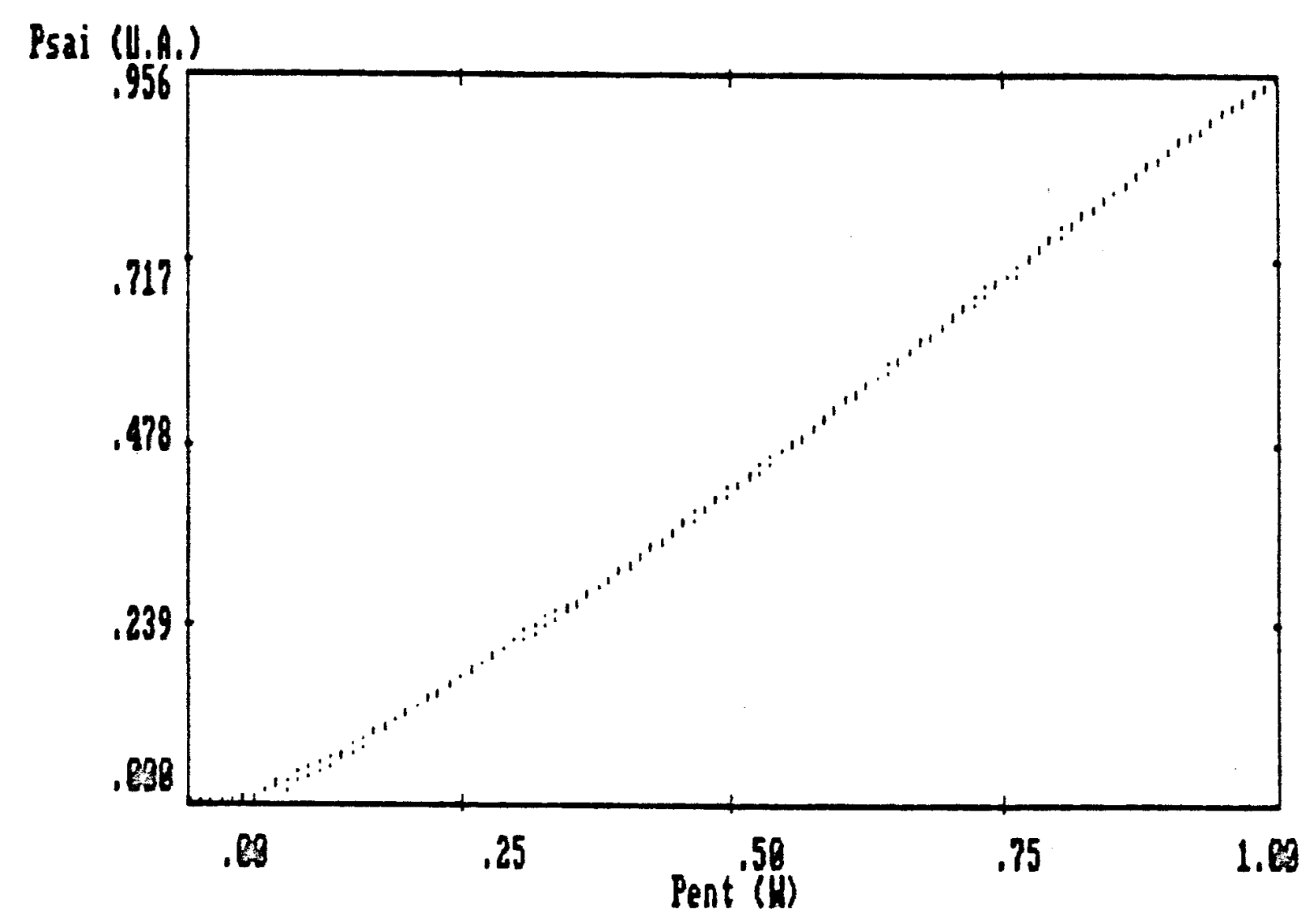

Figura 6.4. Transmissão do sistema óptico sem cavidade FP.

Nas figuras 6.5a,b mostramos a transmissão quando a cavidade FP confocal está presente. As setas indicam o sentido da variação da potência de entrada. Abaixo de $250 \mathrm{~mW}$ a transmissão é linear e por isso não registramos esta parte da curva. Vêse claramente os ciclos de histerese, característicos de multi-estabilidade óptica (mais de um ciclo). Também nota-se os "overshoot", tanto na subida quanto na descida dos estados de baixa transmissão (cavidade desligada) e de alta transmissão (cavidade ligada), respectivamente. 

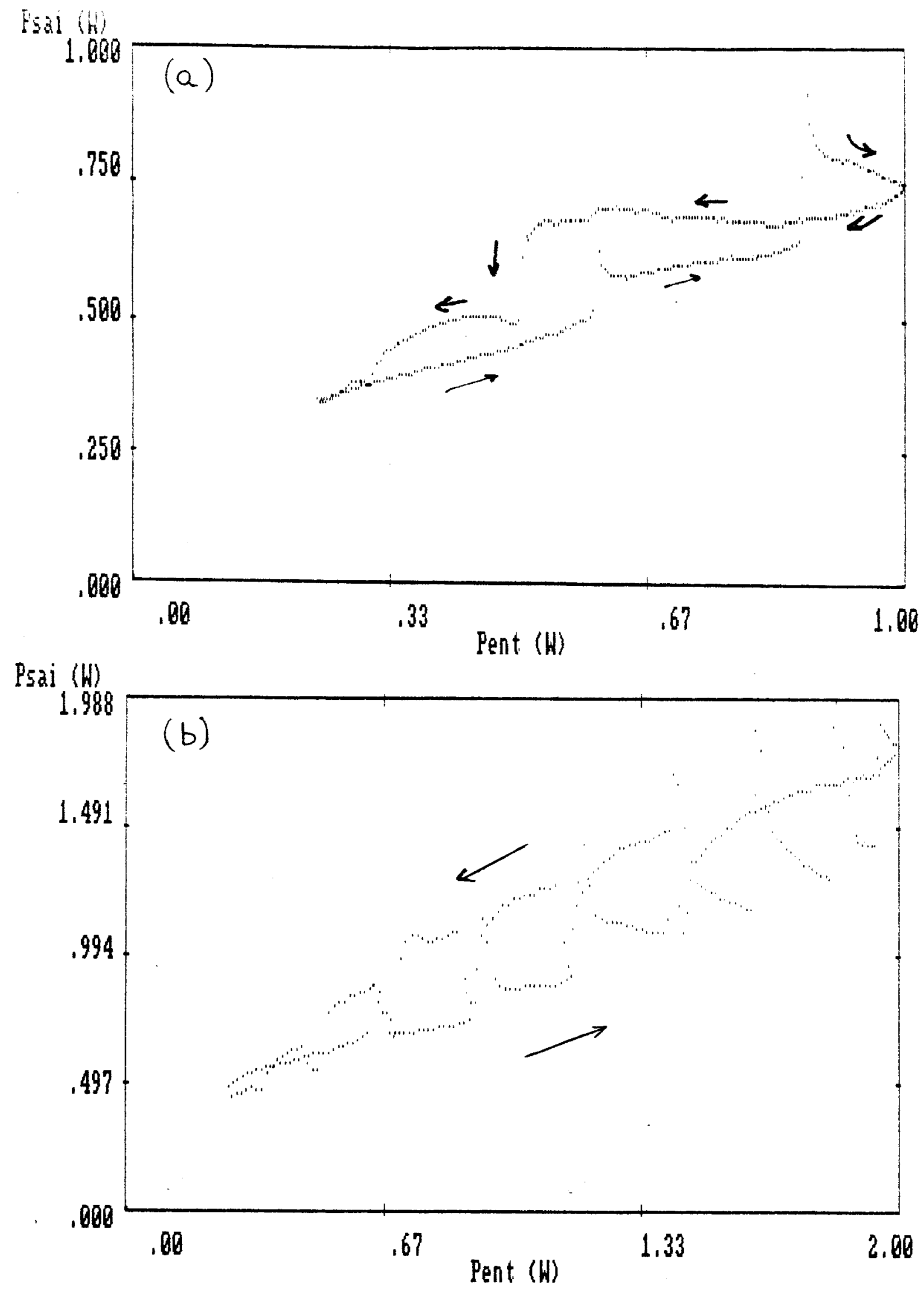

Figura 6.5. Transmissão de uma cavidade FP confocal com espelhos de $\mathrm{ZrO}_{2}$ 
Na figura 6.6a mostramos a bi-estabilidade óptica observada com uma cavidade FP plana. Os espelhos também são de $\mathrm{ZrO}_{2}$. Na parte b o ciclo foi interrompido quando o sistema estava "ligado", mas numa potência $0,7 \mathrm{~W}$ que é inferior à necessária para ligá-lo $(0,8 \mathrm{~W})$ e o laser foi bloqueado por alguns segundos. Daí o laser foi desbloqueado mas a cavidade permaneceu desligada porque a potência não é suficiente para ligá-lo novamente.

Na figura 6.7 mostramos a potência de saída em função do tempo quando a potência de entrada foi repentinamente variada de 0,25 para $1 \mathrm{~W}$ e mantida neste valor. Nota-se um caráter oscilatório da transmissão, que é indicativo da competição entre dois mecanismos não-lineares com diferentes constantes de tempo e de sinais contrários $[79,93]$. Acreditamos que a maior contribuição seja a de efeitos térmicos pois não observamos comportamento não-linear em filmes de $\mathrm{Ta}_{2} \mathrm{O}_{5}$, os quais possuem coeficiente de extinção $10^{-6}$ que é dez vezes menor do que o $\mathrm{ZrO}_{2}$ [94].

O inconel é uma liga com uma composição básica de $75 \%$ de níquel, $15 \%$ de cromo e $8 \%$ de ferro e possui um alto coeficiente de extinção $(\sim 1)$ [95]. Esse material é usado principalmente na fabricação de filtros ópticos de banda larga para operação na região do visível do espectro de frequência. Devido ao seu alto poder de absorção, pudemos observar bi-estabilidade termo-óptica num filme de inconel depositado sobre um substrato de vidro com $5 \mathrm{~mm}$ de espessura. Neste caso o filtro foi usado como um etalon, onde o espelho de entrada é o filme de inconel e o espelho de saída é a interface vidro-ar. O vidro é o meio sensor de temperatura. O calor transferido do inconel para o vidro faz com que este último se dilate e também mude o seu índice de refração. A fase $\psi$ do etalon pode ser escrita como [90]:

$$
\psi=\psi_{\circ}+(4 \pi n / \lambda)(\gamma+\beta) C P_{A}
$$




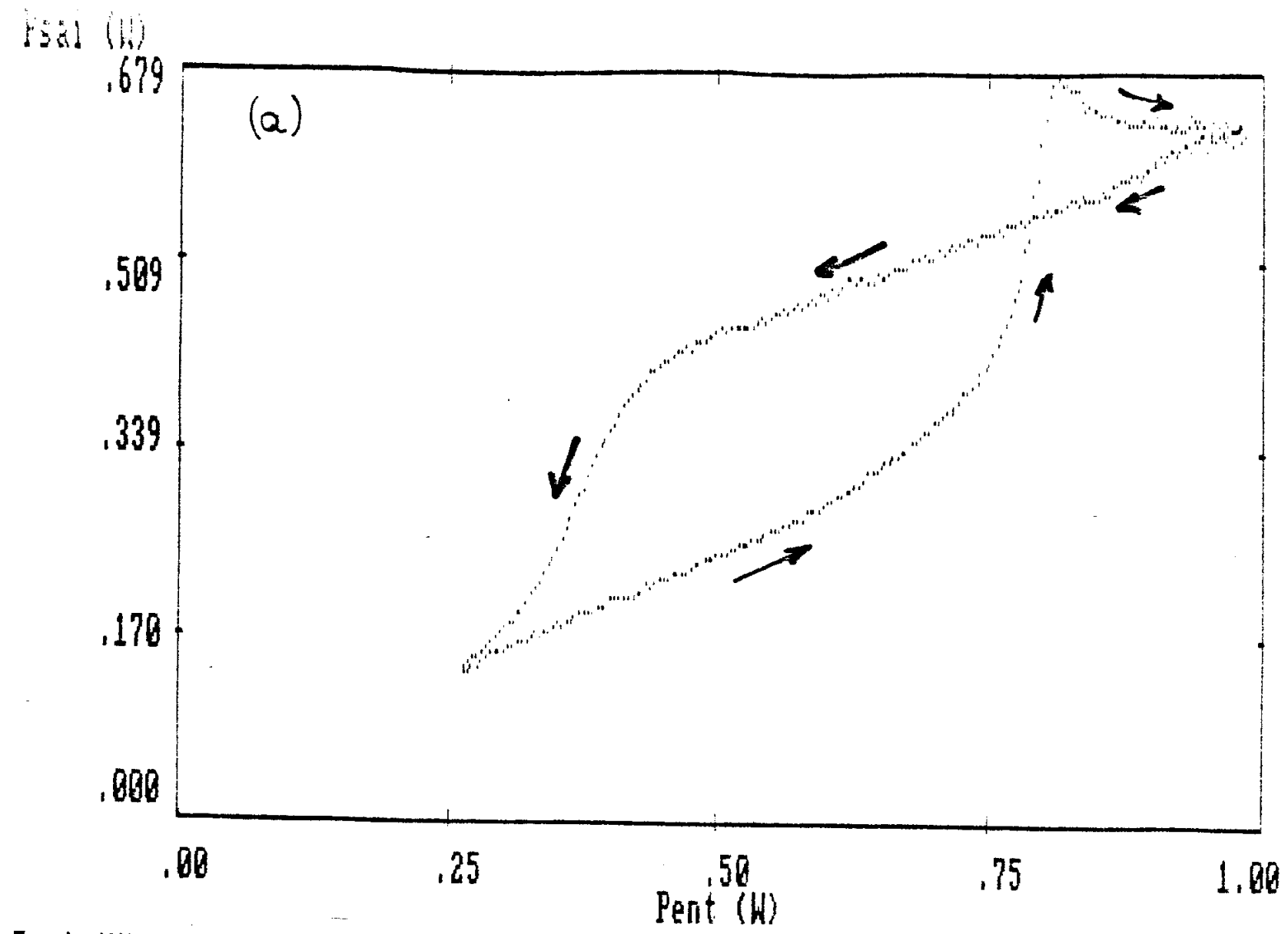

Psai (H)

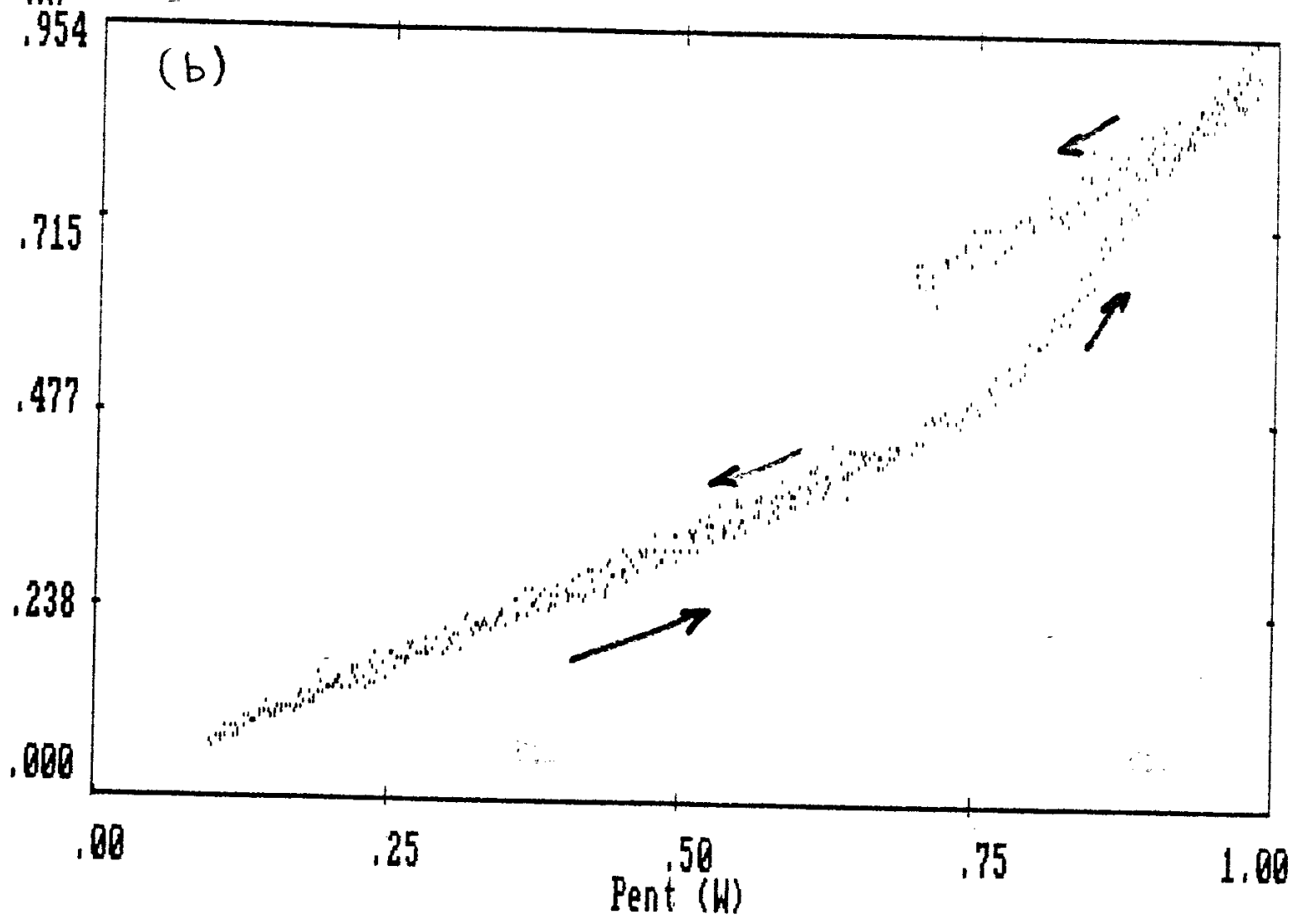

Figura 6.6. Transmissão de uma cavidade FP plana com espelhos de $\mathrm{ZrO}_{2}$ 


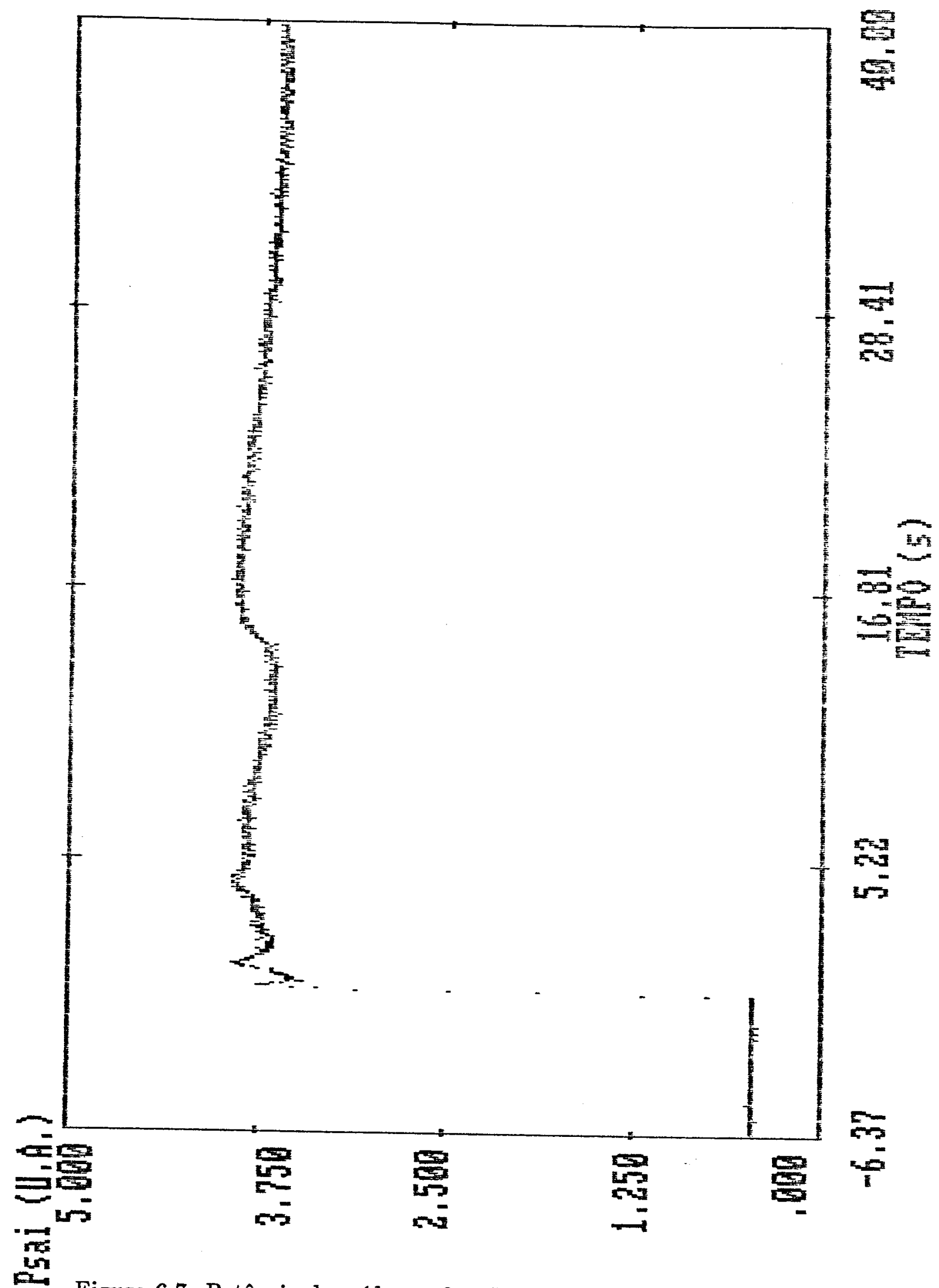

Figura 6.7. Potência de saída em função do tempo para uma cavidade FP plana com espelhos de $\mathrm{ZrO}_{2}$ 
onde $\psi_{o}$ é a fase inicial do etalon na ausência de luz, $\gamma \equiv n^{-1}(d n / d T)$ é o coeficiente termo-óptico do vidro $\left(10^{-6}\right), \beta$ é o coeficiente de expansão térmica $\left(10^{-5}\right)$ e $C$ é uma constante que relaciona o aumento de temperatura do vidro com a potência absorvida pelo inconel $\mathrm{P}_{A}$ e depende essencialmente da forma do etalon e da vizinhança do sistema.

Na figura 6.8 mostramos a multi-estabilidade que nós observamos num filtro de inconel com $R=0,21, R^{\prime}=0,05$ e $T=0,38 \mathrm{em} 5145 \AA$. Os pontos são os resultados experimentais e a curva sólida não representa qualquer ajuste teórico e é apenas uma ajuda visual para identificação dos ciclos de histerese. Os ciclos são muito estreitos em consequência do baixo fator de qualidade $F \simeq 0,3$. Mas esses resultados revelam a viabilidade de se construir etalons compactos com filmes em ambos os lados do vidro (inconel e $\mathrm{Ta}_{2} \mathrm{O}_{5}$ por exemplo) de modo que se tenha alto fator de qualidade. Isto permitiria a observação de bi-estabilidade óptica em baixas potências e com maior definição dos estados ligado e desligado. 


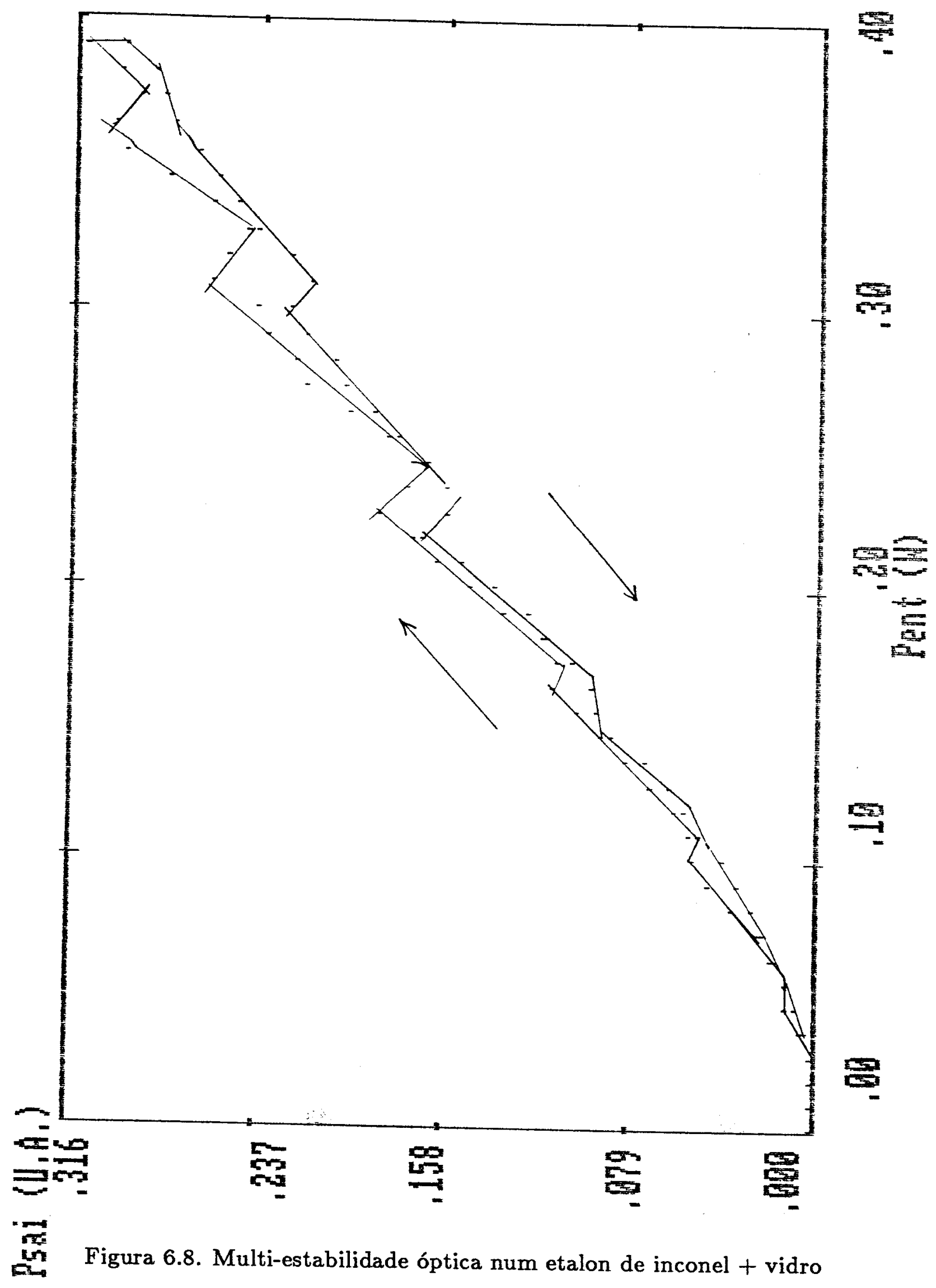




\subsection{TENTATIVAS DE OBSERVAR BI-ESTABILIDADE ÓPTICA EM GdAlO ${ }_{s}$ :r $^{3+}$}

Uma vez que o $\mathrm{Ta}_{2} \mathrm{O}_{5}$ não apresentou comportamento não-linear, usamos este material para confeccionar os espelhos de uma cavidade FP confocal com raio de $4 \mathrm{~cm}$ para tentar observar BO no aluminato de gadolíneo dopado com cromo. A transmissão dos epelhos foi de $12 \%$ em $5145 \AA$, satisfazendo a condição de optimização [91]:

$$
T=1-e^{-\alpha L}
$$

para uma amostra de $0,1 \mathrm{~cm}$ de espessura e com coeficiente de absorção $\alpha=1,5 \mathrm{~cm}^{-1} \mathrm{em}$

$5145 \AA$. Um dos espelhos foi colado num PZT e o conjunto foi fixado num suporte mecânico de boa qualidade. Por sua vez, o suporte foi preso por parafusos de teflon à extemidade de um tubo de zerodur, o que permitira o alinhamento da cavidade através dos controles $\mathrm{x}-\mathrm{y}$ do suporte. Na outra extremidade do tubo foi colado o espelho de saída. Com a cavidade vazia medimos uma "finess" da ordem de 10, monitorando num osciloscópio a transmissão do FP em função da mudança de fase, devida à aplicação de uma rampa no PZT. Medimos a potência de saída do FP em função da potência de entrada para vários valores da fase inicial e constatamos a linearidade do sistema.

O cristal de $\mathrm{GdAlO}_{3}: \mathrm{Cr}^{3+}$ foi então colocado no centro da cavidade através de um orifício no tubo de zerodur. Com o cristal no interior do FP não conseguimos operação no modo fundamental da cavidade. A presença de modos de ơdem superior resultou num contraste muito pobre o que inviabilizou a observação da bi-estabilidade óptica.

Acreditamos que a principal causa é a deformação espacial dos feixes no interior da cavidade devida à auto-focalização e auto-modulação de fase [20]. Pois, com os valores experimentais do $\mathrm{GdAlO}_{3}: \mathrm{Cr}^{3+}$, a potência crítica para auto-focalização nessa amostra é 
de apenas $3 \mathrm{~mW}$ (conforme a equação (3.10b)). E a potência mínima para observarmos biestabilidade em nossa cavidade seria de $15 \mathrm{~mW}$, correspondente à uma intensidade mínima de $75 \mathrm{~W} / \mathrm{cm}^{2}$ (ver eq. $13 \mathrm{da}$ ref. 91 ).

Tentamos observar a bi-estabilidade transversal sem cavidade, tal como Tai et al [89] observaram no sódio, mas a amostra era muito fina e apenas conseguimos verificar a variação do diâmetro do feixe transmitido (um deles) em função da intensidade. É possível que uma amostra com cerca de $1 \mathrm{~cm}$ permita esse tipo de bi-estabilidade. Também tentamos o tipo de auto-aprisionamento, onde o feixe auto-focalizado é transmitido através de um "pinhole" e refletido por um espelho imediatamente após esse "pinhole" [88]. Basicamente esta configuração é idêntica à anterior e por isso os resultados foram os mesmos, ou seja, nenhuma constatação de BO.

A intensidade mínima para se observar BO numa cavidade FP é inversamente proporcional à $n_{2}^{\prime} / \alpha$ [91] e a potência crítica para auto-focalização é inversamente proporcional à $n_{2}^{\prime}$, por isso é provável que se possa observar $\mathrm{BO}$ no $\mathrm{GdAlO}_{3}: \mathrm{Cr}^{3+}$ na região do vermelho $(\sim 6200 \AA)$, pois teríamos aproximadamente o mesmo $n_{2}^{\prime} / \alpha$ de $5145 \AA$ mas a potência crítica para auto-focalização é pelo menos dez vezes maior por causa da diminuição do índice $n_{2}^{\prime}$, conforme vimos no Capítulo 5 . 


\section{CONCLUSÕES}

Neste trabalho tivemos a oportunidade de mostrar que o tratamento teórico de Zhou et al [37] sobre NDTWM, em sistemas absorvedores de dois níveis, está incompleto. Ou seja, o termo desprezado no cálculo da susceptibilidade [38] é o que origina a razão r entre as partes imaginária e real do índice de refração não-linear $n_{2}$. Demonstramos que a presença deste termo é que explica o branqueamento ("bleaching") de um feixe sobre o outro, no caso degenerado $\left(\Omega^{\prime}=0\right)$, quer num sistema de dois ou três níveis.

O nosso modelo é mais geral e apresenta as seguintes características:

- pode ser utilizado em sistemas de dois ou três níveis.

- pode ser empregado no tratamento da mistura de várias ondas e não apenas no caso de duas, este último é derivado como um caso particular do modelo.

- podemos usá-lo mesmo quando as intensidades das duas ondas incidentes não guardam qualquer relação entre si, ou seja, não há a obrigatoriedade de que um feixe seja muito mais intenso do que o outro.

O nosso modelo teórico foi testado com sucesso nos três cristais diferentes aqui estudados: rubi, alexandrita e $\mathrm{GdAlO}_{3}: \mathrm{Cr}^{3+}$. Os valores experimentais da intensidade de saturação, do tempo de vida do nível ${ }^{2} \mathrm{E}$ e do índice de refração não-linear, obtidos pela técnica de NDTWM, estão em muito bom acordo com os determinados por outras técnicas, tais como DFWM e o método interferométrico (MI). Isto mostra uma grande vantagem da NDTWM sobre as duas últimas, já que na DFWM só é possível determinar o módulo de $n_{2}$, enquanto no MI as dificuldades experimentais são acentuadas e só a parte real $n_{2}^{\prime}$ é que pode ser detectada. Note que na NDTWM $n_{2}^{\prime}$ e $n_{2}^{\prime \prime}$ são determinados separadamente. 
Pela primeira vez foi demonstrada a transferência de energia por NDTWM em alexandrita e também no $\mathrm{GdAlO}_{3}: \mathrm{Cr}^{3+}$. Nós verificamos que $n_{2}^{\prime} I_{\delta} / N_{0}$ é o parâmetro importante para se fazer comparação entre os materiais, num determinado comprimento de onda, e vimos que a eficiência em $5145 \AA$ é maior no rubi, seguido do aluminato e por último vem a alexandrita. Isto claramente desfaz a afirmação de Catunda [20] de que o $\mathrm{GdAlO}_{3}: \mathrm{Cr}^{3+}$ teria o $n_{2}$ "mais alto de todos os cristais com $\mathrm{Cr}^{3+}$ para a linha $5145 \AA$ do Ar". Seu engano foi devido à incorreta atribuição do parâmetro comparativo como sendo $n_{2}^{\prime} / \alpha_{g}$

Usando uma expressão para a parte real de $n_{2}$, eq. (5.6a), e os valores experimentais do espectro de absorção do estado excitado, verificamos que a contribuição da banda CT é dominante no rubi, mas há poucos indícios de que o mesmo ocorra na alexandrita, pelo menos nos sítios de inversão. E devido à semelhança entre o rubi e o aluminato no que diz respeito a:

- o alto valor de $n_{2}^{\prime}$

- o espectro de $n_{2}^{\prime}$

- os parâmetros do campo cristalino

concluimos que também no $\mathrm{GdAlO}_{3}: \mathrm{Cr}^{3+}$ é a banda $\mathrm{CT}$ quem efetivamente contribui para $n_{2}^{\prime}$

O espectro de $n_{2}^{\prime}$, tanto no aluminato quanto no rubi, revela que os valores anteriormente medidos pelo método interferométrico foram inadequadamente atribuídos ao comprimento de onda do laser de He-Ne [70] quando de fato aqueles valores se referem à 5145 Å.

Quanto à dependência da razão r com a intensidade, considerando que: 
a) os resultados experimentais da parte imaginária $n_{2}^{\prime \prime}$ estão em muito bom acordo com o que é previsto pela equação (5.5), no caso do rubi e da alexandrita;

b) a dependência de r com a intensidade no $\mathrm{GdAlO}_{3}: \mathrm{Cr}^{3+}$ acontece através de $n_{2}^{\prime \prime}$;

c) no aluminato, o espectro de absorção do estado excitado previa um $r$ negativo em $I=0$, o contrário do que fora observado.

d) observamos emissão dos pares de cromo numa amostra de $\mathrm{GdAlO}_{3}: \mathrm{Cr}^{3+}$ com uma concentração muito menor do que a amostra utilizada na determinação de $r$,

Concluimos que o mecanismo TECAF entre pares de cromo no nível ${ }^{2} \mathrm{E}$ deve ser o responsável pela mudança de $\mathrm{r}$ no $\mathrm{GdAlO}_{3}: \mathrm{Cr}^{3+}$. Devemos enfatizar que os valores de $\mathrm{r}$ previstos por tal mecanismo, eq. (5.15), se adaptam muito bem aos resultados experimentais e que o nosso proposto TECAF seria muito mais efetivo do que o observado por Duarte [68] entre cromo e gadolíneo.

Quanto aos filmes depositados em espelhos ou filtros, verificamos que o $\mathrm{Ta}_{2} \mathrm{O}_{5}$ não apresenta comportamento não-linear para intensidades de até $5 \mathrm{~kW} / \mathrm{cm}^{2} . \mathrm{O} \mathrm{ZrO}_{2}$, por sua vez, é um filme que apresenta característica não-linear correspondente à dois mecanismos diferentes e de sinais contrários. Devido ao alto poder de absorção do inconel, discutimos a viabilidade da construçâo de um sistema bi-estável compacto consistindo de um etalon de vidro com deposição de inconel e $\mathrm{Ta}_{2} \mathrm{O}_{5}$ em ambos os lados.

Por último, relatamos nosso insucesso em não conseguir observar $\mathrm{BO}$ em $\mathrm{GdAlO}_{3}: \mathrm{Cr}^{3+}$. Mas nossas tentativas de observação de $\mathrm{BO}$ transversal, embora frustradas, revelam que a interação entre os feixes contra-propagantes é muito efetiva e de fato observamos a mudança do diâmetro do feixe quando a intensidade era variada. Fizemos um experimento idêntico no rubi e não conseguimos detectar tal efeito. Isso está coerente 
com as observações de Catunda [20] sobre os efeitos de auto-modulação transversal de fase nesses cristais. Se considerarmos ainda que o TECAF provoca um aumento da absorção do $\mathrm{GdAlO}_{3}: \mathrm{Cr}^{3+}$, que em baixas intensidades é proporcional ao quadrado da intensidade, teremos um conjunto de efeitos (transversal e TECAF) favoráveis à destruição do contraste ou do fator de qualidade de uma cavidade FP, inviabilizando a operação bi-estável. 


\section{REFERÊNCIAS BIBLIOGRÁFICAS}

1. T.H. Maiman - Nature 187, 493 (1960).

2. E. Hecht and A. Zajac, "Optics", ed. Addison-Wesley Publishing Co., Inc., $4^{\underline{a}}$ edição, (1979).

3. M. Goeppert-Mayer - Ann. Phys. (Leipzig), 9, 273 (1931).

4. P.A. Franken, A.E. Hill, C.W. Peters and G. Weinreich - Phys. Rev. Lett. 7, 118 (1961).

5. W. Kaiser and C.G.B. Garrett - Phys. Rev. Lett. 7, 229 (1961).

6. M. Bass, P.A. Franken, A.E. Hill, C.W. Peters, G. Weinreich - Phys. Rev. Lett. 8, 18 (1962).

7. D.M. Bloom, J.T. Yardley, J.F. Young, S.E. Harris - Appl. Phys. Lett. 24, 427 (1974).

8. R.A. Fischer, "Optical Phase Conjugation”, ed. Academic Press, Inc. (1979).

9. J.F. Reintjes, "Nonlinear Optical Parametric Processes in Liquids and Gases", ed. Academic Press, Inc. (1984).

10. J.D. Jackson, "Classical Eletrodynamics", ed. Wiley, Inc. (1963) (expansão da polarização - ver pág. 101).

11. D.C. Hanna, M.A. Yuratich, D. Cotter, "Nonlinear Optics of Free Atoms and Molecules", ed. Springer-Verlag (1979).

12. Y.R. Shen, "The Principles of Nonlinear Optics", ed. John Wiley \& Sons, Inc. (1984).

13. J.A. Armstrong, N. Bloembergen, J. Ducuing and P.S. Pershan - Phys. Rev. 127, 1918 (1962).

14. P.N. Butcher, "Nonlinear Optical Phenomena", Bull. no 200, Eng. Expt. Station, Ohio State University (1965).

15. J. Ducuing, "Quantum Optics", ed. Academic Press, Inc. (1965).

16. "Progress in Optics", ed. E. Wolf, North-Holand Publishing Co., vol. XII (1974). , 
17. H.M. Gibbs, "Optical Bistability: Controlling Light With Light", ed. Academic Press, Inc. (1985).

18. A. Yariv, "Quantum Electronics", ed. John Wiley \& Sons, Inc. (1975).

19. H.J. Eichler, P. Günter, D.W. Pohl, "Laser-Induced Dynamic Gratings", ed. SpringerVerlag, vol. 50 (1986).

20. T. Catunda, "Conjugação de Fase e Modulação Transversal de Fase em Cristais

Dopados com $\mathrm{Cr}^{3+}$, Tese de Doutoramento, IFQSC/USP, São Paulo (1989).

ou T. Catunda and J.C. Castro - Opt. Comm. 63, 185 (1987).

21. G.C. Bjorklund - IEEE J. Quantum Elect. QE-11, 287 (1975).

22. E.L. Dawes and J.H. Marburger - Phys. Rev. 179, 862 (1969).

23. H.M. Smith, "Holographic Recording Materials", Topics Appl. Phys. 20, ed. Springer (1977).

24. H. Kogelnik, "Coupled Wave Theory for Thick Hologram Gratings", Bell. Syst. Tech. Journal 48, 2909 (1969).

25. S.C. Zilio, J.C. Penaforte, E.A. Gouveia and M.J. Bell - Opt. Comm. 86, 81 (1991).

26. D.B. Brayton - Appl. Opt. 13, 2346 (1974).

27. D.L. Staebler and J.J. Amodei - J. Appl. Phys. 34, 1042 (1972).

28. Y. Silberberg and I. Bar-Joseph - J. Opt. Soc. Am. B1, 662 (1984).

29. P. Yeh - J. Opt. Soc. Am. B3, 747 (1986).

30. I. McMichael, P. Yeh and P. Beckwith - Opt. Lett. 13, 500 (1988).

31. M.A. Kramer, W.R. Tompkin and R.W. Boyd - Phys. Rev. A34, 2026 (1986).

32. G. Grynberg, E. Le Bihan and M. Pinard - J. Physique 47, 1321 (1986).

33. T.H. Liu and I.C. Khoo - IEEE J. Q. Elect. QE-23, 2020 (1987).

34. W.R. Tompkin, R.W. Boyd, D.W. Hall, P.A. Tick - J. Opt. Soc. Am. B4, 1030 (1987).

35. I.C. Khoo and R. Normandin - Appl. Phys. Lett. 52, 525 (1988).

36. J.C. Penaforte, E.A. Gouveia and S.C. Zilio - Opt. Lett. 16, 452 (1991). 
37. H. Zhou, X. Mi, Q. Jiang, R. Zhang, P. Ye - Opt. Comm. 78, 382 (1990).

38. M. Pinard and G. Grynberg - J. Physique 49, 2027 (1988).

39. N. Bloembergen and Y.R. Shen - Phys. Rev. A133, A37 (1964).

40. A diferença no sinal de $\mathrm{r}$ é porque usamos $n_{2}=n_{2}^{\prime}+i n_{2}^{\prime \prime}$ e o fator de 2 que (4.15) difere da eq. (4) da ref. [30] é provavelmente devido à relação entre $n_{2}$ e $\Delta \chi$ ou $\chi^{(3)}$. Aqui nós usamos $2 n_{0} n_{2}=\Delta \chi$ no MKS ou $n_{o} n_{2}=2 \pi \Delta \chi$ no CGS.

41. J.C. Penaforte, "Mistura de Duas Ondas Quase Degeneradas em Absorvedores Saturáveis", Tese de Doutoramento, IFQSC/USP - São Paulo (1991).

42. H. Fujiwara, K. Shio and S. Miyanaga - J. Opt. Soc. Am. B 8, 1740 (1991).

43. H.L. Fragnito, S.F. Pereira and A. Kiel - J. Opt. Soc. Am. B 4, 1309 (1987).

44. R.C. Morris and C.F. Cline - U.S. Patent No. 3997853 (1976).

45. T. Kushida - IEEE J. Q. Elect. QE-2, 524 (1966).

46. R.C. Ohlmann, R. Mazelzsky and J. Murphy, "High Energy Cristalline Laser Materials", Technical Report of Westinghouse Labs, dez. (1967).

47. E.A. Gouveia, "Estudo Espectroscópico do Íon $\mathrm{Pr}^{3+}$ na Matriz $\mathrm{YAlO}_{3} \cdot$ Campo Cristalino, Níveis de Energia e Forças de Oscilador",Tese de Mestrado, DF/UFPE, Pernambuco (1985).

48. V.A. Antonov, P.A. Arsenev, I.G. Linda and V.L. Farshtendiker - Phys. Stat. Sol. A 15, K63 (1973).

49. S.A. Boothroyd, J. Chrostowski and M.S. O'Sullivan - J. Opt. Soc. Am. B 6, 766 (1989).

50. D.F. Nelson and M.D. Sturge - Phys. Rev. A 137, 1117 (1965).

51. S.A. Boothroyd, J. Chrostowski and M.S. O'Sullivan - Opts. Letts. 14, 946 (1989).

52. M.L. Shand, J.C. Walling and R.C. Morris - J. Appl. Phys. 52, 953 (1981).

53. A. Szabo - Opt. Comm. 12, 366 (1974).

54. T.N.C. Venkatesan and S.L. McCall - Appl. Phys. Letts. 30, 282 (1977).

55. C.L. Adler, N.M. Lawandy - Opts. Comm. 81, 33 (1991). 
56. S.C. Weaver, S.A. Payne - Phys. Rev. B 40, 10727 (1989).

57. L.J. Andrews, S.M. Hitelman, M. Kokta, D. Gabbe - J. Chem. Phys. 84, 5229 (1986).

58. "Laser Spectroscopy - Basic Concepts and Instrumentation", W. Demtröder, ed. Springer-Verlag, New York (1982).

59. A. Suchocki, G.D. Gilliland and R.C. Powell - Phys. Rev. B 35, 5830 (1987).

60. S. Geller and E.A. Wood - Acta. Cryst. 9, 563 (1956).

61. S. Geller and V.B. Bala - Acta. Cryst. 9, 1019 (1956).

62. H.C. Basso, "Propriedades Óticas dos fons Isolados e dos Pares de $\mathrm{Cr}^{3+}$ em $\mathrm{GdAlO}_{3}: \mathrm{Cr}^{3+}$,Dissertação de Mestrado, IFQSC/USP, São Paulo (1980).

63. P.F. Moulton - Opts. News, nov./dez., 9 (1982).

64. L. Merkle, H.R. Verdun, U. Brauch, G.F. de la Fuente, E. Behrens and L.M. Thomas - J. Opt. Soc. Am. B 6, 2342 (1989).

65. J.P. Andreeta, A.C. Hernandes and N.J.H. Gallo - Mat. Res. Bull. 24 (1989).

66. M.A. Aegerter, H.C. Basso and H.J. Scheel - Proceedings of International Conference on Lasers, 80, 383 (1980).

67. M. Matsuoka, M.A. Aegerter, M.C. Terrile, H. Panepucci, J.S. Helman, H.J. Scheel Phys. Rev. Lett. 50, 204 (1983).

68. J.L. Duarte, "Transferência de Energia Induzida por Luz entre o $\mathrm{Cr}^{+3}$ e o $\mathrm{Gd}^{+3}$ no $\mathrm{GdAlO}_{3}: \mathrm{Cr}^{+3} "$, Tese de Doutorado, IFQSC/USP, São Paulo (1990).

69. L.A.O. Nunes, "Espectroscopia de Dois Fótons do Íon $\mathrm{Gd}^{+3}$ em Estruturas Perovskitas", Tese de Doutorado, IFQSC/USP, São Paulo (1988).

70. T. Catunda, "Conjugação de Fase por Mistura Degenerada de Quatro Ondas em Rubi e $\mathrm{GdAlO}_{3}: \mathrm{Cr}^{3+}$ ", Dissertação de Mestrado, IFQSC/USP, São Paulo (1984).

ou T. Catunda, J.P. Andreeta and J.C. Castro - Appl. Opts. 25, 2391 (1986).

71. D.G. Steel, S.C. Rand and J. Liu - J. Opt. Soc. Am. B 4, 1794 (1987). 
72. "Spectroscopy of Solid-State Laser-Type Materials", ed. Baldassare Di Bartolo, Plenum Press, New York and London (1987).

73. F. Auzel, "Materials and Devices Using Double-Pumped Phosphors with Energy Transfer", Proceedings of the IEEE 61, jun. (1973).

74. D.L. Dexter - J. Chem. Phys. 21, 836 (1953).

75. M. Altarelli and D.L. Dexter - Opts. Comm. 2, 36 (1970).

76. B.G. Bovard and H.A. Macleod - J. Mod. Opt. 35, 1151 (1988).

77. F. Mitschke, G. Ankerhold and W. Lange - Proc. SPIE - Int. Soc. Opt. Eng. 1017, 217 (1989).

78. E.A. Gouveia e J.C. Castro, "Multi-Estabilidade Óptica em Filmes de $\mathrm{ZrO}_{2}$ ", XII Encontro Nacional de Física da Matéria Condensada, Caxambu, MG (1989).

79. S.L. McCall - Appl. Phys. Lett. 32,284 (1978).

80. P.W. Smith, E.H. Turner and P.J. Maloney - IEEE J. Q. Elect. QE-14, 207 (1978).

81. H.M. Gibbs, S.L. McCall and T.N.C. Venkatesan - Phys. Rev. Lett. 36, 1135 (1976).

82. G.F. Agrawal and H.J. Carmichael - Phys. Rev. A 19, 2074 (1979).

83. T. Bischofberger and Y.R. Shen - Phys. Rev. A 19, 1169 (1979).

84. Mi-Mee Cheung, S.D. Durbin and Y.R. Shen - Opts. Lett. 8, 39 (1983).

85. H.M. Gibbs, S.L. McCall, T.N.C. Venkatesan, A.C. Gossard, A. Passner and

W. Wiegmann - Appl. Phys. Lett. 35, 451 (1979).

86. J.L. Jewell, H.M. Gibbs, S.S. Tarng, A.C. Gossard, W. Wiegmann - Appl. Phys. Lett. 40, 291 (1982).

87. A.E. Kaplan - Opts. Lett. 6, 360 (1981).

88. J.E. Bjorkholm, P.W. Smith, W.J. Tomlinson, A.E. Kaplan - Opts. Lett. 6, 345 (1981).

89. K. Tai, H.M. Gibbs, N. Peyghambarian, A. Mysyrowicz - Opts. Lett. 10, 220 (1985).

90. G. Orriols and C. Schmidt-Iglesias - Opts. Comm. 63, 66 (1987).

91. D.A.B. Miller - IEEE J. Q. Electr. QE-17, 306 (1981). 
92. S.A. Tonissi Jr., F.M.M. Yasuoka, L.A.O. Nunes e J.C. Castro - Rev. Fís. Aplic. e Instrum., 5, 412 (1990).

93. M. Okada and K. Takizawa - IEEE J. Quant. Electr. QE-17, 517 (1981).

94. H.K. Pulker, "Coatings on Glass", ed. Elsevier Science Publishers B.V. (1984).

95. W.V. Goodell, J.K. Coulter, P.B. Johnson - J. Opt. Soc. Am. 63, 185 (1973). 


\section{APÊNDICE I}

\section{CÁlCULO DA MATRIZ DENSIDADE}

Vamos considerar que o termo de relaxação em (2.22) corresponde à emissão espontânea e então podemos representá-lo através de um operador $\gamma$ na forma:

$$
\left(\frac{\partial \rho^{(\mathbf{n})}}{\partial t}\right)_{\text {rel }}=-\frac{1}{2}\left(\gamma \rho^{(\mathbf{n})}+\rho^{(\mathbf{n})} \rho\right)
$$

e a matriz deste operador é diagonal [39]. Seus elementos de matriz $\gamma_{i j}$ estão relacionados às taxas de decaimento $\Gamma_{a}$ e $\Gamma_{a b}$ por:

$$
\begin{gathered}
\delta_{i j} \Gamma_{a}=\gamma_{i j} \\
\Gamma_{a b}=\frac{1}{2}\left(\gamma_{a a}+\gamma_{b b}\right)
\end{gathered}
$$

$\delta_{i j}$ é o delta de Kronecker. A substituição de (I.2) em (4.6) nos dá:

$$
\begin{gathered}
\frac{\partial \rho_{a a}^{(o)}}{\partial t}=\left[i \frac{\Omega_{1}}{2}\left(\rho_{a b}^{(o)}-\rho_{b a}^{(o)}\right) e^{i\left(\omega_{1} t-k_{1} \cdot \mathbf{r}\right)}+c . c .\right]-\Gamma_{a} \rho_{a a}^{(o)} \\
\frac{\partial \rho_{a b}^{(o)}}{\partial t}=\left[i \frac{\Omega_{1}}{2}\left(\rho_{a a}^{(o)}-\rho_{b b}^{(o)}\right) e^{i\left(\omega_{1} t-k_{1} \cdot \mathbf{r}\right)}+c . c .\right]+\left(i \omega_{o}-\Gamma_{a b}\right) \rho_{a b}^{(o)} \\
\Gamma_{a} \rho_{a a}^{(1)}+\frac{\partial \rho_{a a}^{(1)}}{\partial t}=\frac{1}{2}\left[i \Omega_{2}\left(\rho_{a b}^{(o)}-\rho_{b a}^{(o)}\right) e^{i\left(\omega_{2} t-\mathbf{k}_{\mathbf{a}} \cdot \mathbf{r}\right)}+i \Omega_{1}\left(\rho_{a b}^{(1)}-\rho_{b a}^{(1)}\right) e^{i\left(\omega_{1} t-\mathbf{k}_{1} \cdot \mathbf{r}\right)}+\text { c.c. }\right]
\end{gathered}
$$




$$
\left(\Gamma_{a b}-i \omega_{0}\right) \rho_{a b}^{(1)}+\frac{\partial \rho_{a b}^{(1)}}{\partial t}=\frac{1}{2}\left[i \Omega_{2}\left(\rho_{a b}^{(0)}-\rho_{b b}^{(0)}\right) e^{i\left(\omega_{3} t-k_{2} \cdot r\right)}+i \Omega_{1}\left(\rho_{a a}^{(1)}-\rho_{b b}^{(1)}\right) e^{i\left(\omega_{1} t-k_{1} . r\right)}+c . c .\right]
$$

onde consideramos o fato de que na ausência dos campos $\left(A_{1}=A_{2}=0\right)$ o sistema se encontra em equilíbrio com $\rho_{a a}^{(o)}(\infty)=\rho_{a a}^{(1)}(\infty)=0$ e $\rho_{b b}^{(o)}(\infty)=1$. Infinito $(\infty)$ denota antes da aplicação dos campos.

Utilizando a aproximação de onda girante e assumindo as condições de estado estacionário,

$$
\begin{gathered}
\rho_{a b}^{(o)}=\rho_{b a}^{(o) *}=\bar{\rho}_{a b}^{(o)} e^{i\left(\omega_{1} t-k_{1} \cdot \mathbf{r}\right)} \\
\rho_{a a}^{(o)}=\text { constante } \\
\rho_{a a}^{(o)}+\rho_{b b}^{(o)}=1
\end{gathered}
$$

onde $\bar{\rho}_{a b}^{(o)}$ independe do tempo, as equações (I.3) fornecem:

$$
\begin{gathered}
\bar{\rho}_{a b}^{(o)}=-\frac{i \Omega_{1}}{2}\left(\Gamma_{a b}-i \delta_{1}\right)^{-1}\left(\rho_{b b}^{(o)}-\rho_{a a}^{(\rho)}\right) \\
\rho_{b b}^{(o)}-\rho_{a a}^{(o)}=\left[1+\frac{\Gamma_{a b}\left|\Omega_{1}\right|^{2}}{\Gamma_{a} \delta_{j}^{2}\left(1+r^{2}\right)}\right]^{-1}
\end{gathered}
$$

De maneira similar, para achar as soluções na primeira ordem, substituimos (4.9) em (I.4) e, lembrando que $\rho_{a a}^{(1)}+\rho_{b b}^{(1)}=0$ (sistema fechado de dois níveis), obtém-se o seguinte sistema de equações em $B, C$ e $D$ :

$$
2 e^{-i \mathbf{k}_{1} \cdot \mathbf{r}}\left(\Gamma_{a}-i \Delta\right) B=-i \Omega_{1} C^{*} e^{-i 2 \mathbf{k}_{1} \cdot \mathbf{r}}+i \Omega_{1}^{*} D-i \Omega_{2} \bar{\rho}_{b a}^{(o)} e^{-i \mathbf{k}_{2} \cdot \mathbf{r}}
$$




$$
\begin{gathered}
{\left[\Gamma_{a b}+i\left(\Delta-\delta_{1}\right)\right] C=i \Omega_{1} e^{-i k_{1} \cdot r} B^{*}} \\
2\left(\Gamma_{a b}-i \delta_{2}\right) D=-i \Omega_{2} e^{-i k_{2} \cdot r}\left(\rho_{b b}^{(o)}-\rho_{a a}^{(o)}\right)+i 2 \Omega_{1} e^{-i k_{1} \cdot r} B \\
\Delta \equiv \delta_{2}-\delta_{1}=\omega_{1}-\omega_{2}
\end{gathered}
$$

Note que este sistema é o mesmo obtido por Bloembergen e Shen (pág. A43 da ref. [39]) mas em sua equação (3.8) falta um termo que é aquele contendo $\bar{\rho}_{b a}^{(o)}$ em (I.8a). Em consequência disto, sua solução para $\rho_{b a}^{\left(\omega_{2}\right)}$ (que equivale ao nosso $D$ ) não está completa. A resolução do sistema (I.8) é:

$$
2 B=e^{i\left(k_{1}-k_{2}\right) \cdot \mathbf{r}} \Omega_{1}^{*} \Omega_{2}\left(\rho_{b b}^{(o)}-\rho_{a a}^{(o)}\right) G\left[H+\left(\Gamma_{a b}-i \Delta\right)\left|\Omega_{1}\right|^{2}\right]^{-1}
$$

$$
2 C=-e^{i\left(k_{2}-2 k_{1}\right) \cdot r} \Omega_{1} \Omega_{2}^{*} \bar{\rho}_{a b}^{(o)}\left(2 \Gamma_{a b}+i \Delta\right)\left[H^{*}+\left(\Gamma_{a b}+i \Delta\right)\left|\Omega_{1}\right|^{2}\right]^{-1}
$$

$$
2 D=-e^{-i \mathbf{k}_{2} \cdot r} i \Omega_{2}\left(\rho_{b b}^{(o)}-\rho_{a a}^{(o)}\right)\left(\Gamma_{a b}-i \delta_{2}\right)^{-1}\left\{1-G\left|\Omega_{1}\right|^{2}\left[H+\left(\Gamma_{a b}-i \Delta\right)\left|\Omega_{1}\right|^{2}\right]^{-1}\right\}
$$

e introduzimos $G$ e $H$ por simplicidade. Estes são identificados por:

$$
\begin{gathered}
G=\frac{1}{2}\left(2 \Gamma_{a b}-i \Delta\right)\left[\Gamma_{a b}+i\left(\delta_{1}-\Delta\right)\right]\left(\Gamma_{a b}+i \delta_{1}\right)^{-1} \\
H=\left(\Gamma_{a}-i \Delta\right)\left(\Gamma_{a b}-i \delta_{2}\right)\left[\Gamma_{a b}+i\left(\delta_{1}-\Delta\right)\right]
\end{gathered}
$$


Comparando (I.12) com (I.7a) vemos que o primeiro termo representa a susceptibilidade do sistema de dois níveis, vista pelo campo $A_{2}$, na ausência do outro campo $A_{1}\left(\Omega_{1}=\right.$ $0)$. O segundo termo está relacionado à interação entre os dois campos e é este que origina a transferência de energia entre ambos. A susceptibilidade $\chi_{3}=\chi_{2}^{\prime}-i \chi_{2}^{\prime \prime}$ é determinada pela relação:

$$
\chi_{2}=\frac{2 N}{\epsilon_{o} \hbar}\left|\mu_{a b}\right|^{2}\left(\frac{D e^{i \mathbf{k}_{\mathbf{2}} \cdot \mathbf{r}}}{\Omega_{2}}\right)
$$

e sua parte imaginária é

$$
\begin{gathered}
\chi_{2}^{\prime \prime}=\frac{\chi_{o}^{\prime}}{\left(\Gamma_{a}+x \Gamma_{a b}\right)} \Gamma_{a}\left\{\frac{\Gamma_{a b}}{\delta_{2}}+\frac{x}{2} \frac{\left[\Delta\left(2 \Gamma_{a b}-\Gamma_{a}+\Gamma_{a b} x\right)+2 \Gamma_{a b}\left(\Gamma_{a}+x \Gamma_{a b}\right) r\right]}{\left(\Gamma_{a}+x \Gamma_{a b}\right)^{2}+\Delta^{2}(1+x)^{2}}\right\} \\
x \equiv \frac{\left|\Omega_{1}\right|^{2}}{\delta_{1}^{2}\left(1+r^{2}\right)}
\end{gathered}
$$

onde $\chi_{o}^{\prime}=N\left|\mu_{a b}\right|^{2} / \epsilon_{o} \hbar \delta_{2}\left(1+r^{2}\right)$ é a parte real da susceptibilidade linear e consideramos que $\Delta<<\delta_{1}, \delta_{2}$.

Note que nossa expressão para $\chi_{2}^{\prime \prime}$ difere daquela obtida por Pinard e Grynberg [38] (ou Zhou et al [37]) pela presença do termo proporcional a $r$. É este termo que prevê a diminuição da absorção $\alpha_{2}$ quando as frequências sâo iguais $(\Delta=0)$. A partir de (I.16) obtém-se a expressão (4.11b) para o coeficiente de absorção $\alpha_{2}$ após as aproximações $\Gamma_{a b}>>\Gamma_{a}$ e $x<<1$. 


\section{APÊNDICE II}

\section{ÍNDICE KERR EM SISTEMAS DE DOIS NÍVEIS}

No sistema de dois níveis a susceptibilidade pode ser escrita como (ver pág. 153 da ref. [33]):

$$
\chi(I)=\frac{n_{o} c \alpha_{o}}{\left[1+\left(\delta T_{2}\right)^{2}\right] \omega_{o}} \frac{\delta T_{2}-i}{1+I / I_{\delta}}
$$

onde $\alpha_{o}$ é o coeficiente de absorção linear (intensidade) no centro da linha e $\delta=\omega_{o}-\omega$ é a dessintonia com relação à frequência central $\omega_{o}$. A equação (II.1) pode ser re-escrita na forma:

$$
\chi(I)=\chi(o)-\chi(o) \frac{I}{I_{\delta}}\left(1+I / I_{\delta}\right)^{-1}
$$

com $\chi(o)$ a susceptibilidade linear. Portanto, até a primeira ordem na intensidade (II.2) se reduz a

$$
\chi(I)=\chi(o)-\chi(o) \frac{I}{I_{\delta}}
$$

de maneira que o índice Kerr $n_{2}$ é identificado como

$$
n_{2}=-\frac{\chi(o)}{2 n_{o} I_{\delta}}
$$

que, através de (II.1), separa-se em partes real $n_{2}^{\prime}$ e imaginária $n_{2}^{\prime \prime}\left(n_{2}=n_{2}^{\prime}+i n_{2}^{\prime \prime}\right)$ :

$$
n_{2}^{\prime}=-\frac{c \alpha_{o}}{\left[1+\left(\delta T_{2}\right)^{2}\right] \omega_{o}} \frac{\delta T_{2}}{2 I_{\delta}}
$$




$$
n_{2}^{\prime \prime}=\frac{c \alpha_{o}}{\left[1+\left(\delta T_{2}\right)^{2}\right] \omega_{o}} \frac{1}{2 I_{\delta}}
$$

e a razão $r=-\left(\delta T_{2}\right)^{-1}$ é

$$
r=\frac{n_{2}^{\prime \prime}}{n_{2}^{\prime}}=-\frac{\chi^{\prime \prime}(0)}{\chi^{\prime}(0)}
$$

com a susceptibilidade linear $\chi(0)=\chi(0)^{\prime}-i \chi(0)^{\prime \prime}$. Essa escolha do sinal positivo para o termo complexo de $n_{2}$ define o sinal de $r$ através do sinal da parte real $n_{2}^{\prime}$. 


\section{APÊNDICE III}

\section{SISTEMA DE TRÊS NÍVEIS}

Considere um sistema de três níveis como o que está esquematizado abaixo, onde $W_{p} e$ $\mathrm{W}_{d}$ são as taxas de bombeamento e de decaimento induzido, respectivamente, $\mathrm{T}_{1}$ e $\mathrm{T}_{\boldsymbol{i}}$ são os tempos de decaimento espontâneo e $\gamma$ é a taxa de decaimento entre o nível intermediário $i$ e o nível final $e$.

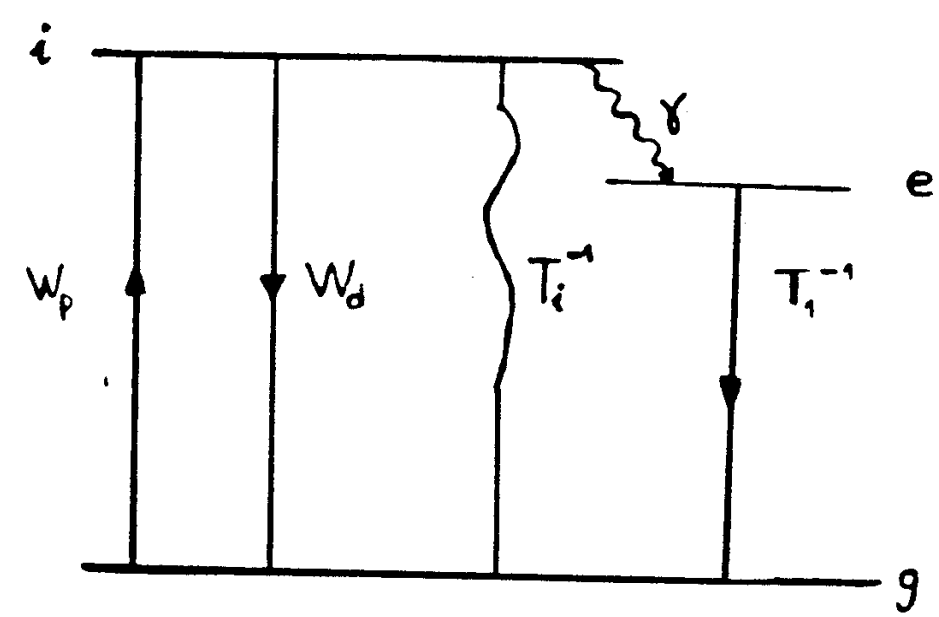

As equações de taxa pará as probabilidades de ocupaçâo dos estados são:

$$
\begin{gathered}
\frac{d n_{g}}{d t}=-n_{g} \mathrm{~W}_{p}+n_{i}\left(\mathrm{~W}_{d}+\mathrm{T}_{i}^{-1}\right)+n_{e} \mathrm{~T}_{1}^{-1} \\
\frac{d n_{\epsilon}}{d t}=-n_{e} \mathrm{~T}_{1}^{-1}+n_{i} \gamma \\
1=n_{g}+n_{i}+n_{e}
\end{gathered}
$$

Para bombeamento com intensidade constante $\mathrm{I}, \mathrm{W}_{p}=\sigma_{g} I / \hbar \omega$ onde $\sigma_{g}$ é a seção de choque de absorção do estado fundamental e a solução no estado estacionário é: 


$$
n_{e}=\gamma \mathrm{T}_{1} n_{i}=\gamma \mathrm{T}_{1}\left(1+\gamma \mathrm{T}_{1}+\sigma_{i} / \sigma_{\sigma}\right)^{-1} I / I_{\delta}\left(1+I / I_{\delta}\right)^{-1}
$$

com $\sigma_{i}$ a seção de choque de emissão estimulada do nível intermediário e, como $\sigma_{\mathfrak{g}}$, depende da frequência do laser $\omega . I_{\delta}$ é a intensidade de saturação, definida por:

$$
I_{\delta}=\frac{\hbar \omega}{\sigma_{g} \mathrm{~T}_{i}}\left(1+\gamma \mathrm{T}_{i}\right)\left(1+\gamma \mathrm{T}_{1}+\sigma_{i} / \sigma_{\vartheta}\right)^{-1}
$$

A susceptibilidade do sistema é:

$$
\begin{aligned}
\chi & \equiv n_{g} \chi_{g}+n_{i} \chi_{i}+n_{e} \chi_{e} \\
& =\chi_{g}+n_{i}\left(\chi_{i}-\chi_{g}\right)+n_{e}\left(\chi_{e}-\chi_{g}\right)
\end{aligned}
$$

que, juntamente com (III.4) e analogia com o Apêndice II, se relaciona ao índice de refração não-linear $n_{2}$ através de:

$$
n_{2}=\frac{\gamma \mathrm{T}_{1}}{2 n_{o} I_{\delta}}\left(1+\gamma \mathrm{T}_{1}+\sigma_{i} / \sigma_{g}\right)^{-1}\left[\left(\chi_{e}-\chi_{g}\right)+\left(\gamma \mathrm{T}_{1}\right)^{-1}\left(\chi_{i}-\chi_{g}\right)\right]
$$

Esse sistema pode ser reduzido ao sistema de dois níveis fazendo-se:

$$
\begin{aligned}
\gamma & =0 \\
o_{i} & =\sigma_{g} \\
\chi_{i} & =-\chi_{g} \\
n_{e} & =0
\end{aligned}
$$

Outra situação interessante é quando $\gamma>\mathrm{T}_{1}^{-1}, \mathrm{~T}_{i}^{-1}$ e $\sigma_{i}=0$, a qual corresponde ao bombeamento exclusivo do nível final $e$. Neste caso tem-se 


$$
\begin{aligned}
& n_{i} \simeq 0 \\
& n_{2}=\frac{\left(\chi_{e}-\chi_{o}\right)}{2 n_{o} I_{\sigma}}
\end{aligned}
$$

Em ambos os casos a parte linear da mudança de susceptibilidade (e o índice $n_{2}$ ) possui a mesma forma e pode ser re-escrita como:

$$
\Delta \chi=f\left(\chi_{e}-\chi_{g}\right)
$$

onde $f=\frac{1}{2}$ no sistema de dois níveis e igual a 1 no último caso. De modo semelhante, a equação para a taxa de ocupação do estado final $\left(n_{i}\right.$ ou $\left.n_{e}\right)$ é única:

$$
\mathrm{T} \frac{d n_{j}}{d t}+\left(1+I / I_{\delta}\right) n_{j}=f I / I_{\delta}
$$

com $T$ substituído por $T_{i}$ ou $T_{1}$ conforme o caso. 


\section{APÊNDICE IV}

\section{ORIGEM DOS TERMOS $\mathrm{D}_{\mathrm{p} \mathrm{m}}^{ \pm}(\mathrm{E})$}

$\mathrm{Na}$ equação (4.23) usamos um supra-índice zero em $S^{(\circ)}(x, z, t)$ porque consideramos a interferência apenas entre os feixes de ordem zero na formação da grade de população. A rigor, a interferência de todas as ordens contribuem para o parâmetro de saturação, o que modifica a forma dessa grade [43]. Em primeira aproximação, considerando-se que as amplitudes das ondas geradas são muito menores do que as de ordem zero, essa contribuição pode ser obtida fazendo-se

$$
\begin{gathered}
S(x, z, t)=S^{(o)}(x, z, t)+\Delta S \\
n_{e}=n_{e}^{(o)}+\Delta n_{e}
\end{gathered}
$$

onde $n_{e}^{(o)}$ é a densidade de população que foi obtida em $(4.26,29)$. Substituindo estas equações em (4.23) chega-se à:

$$
\Delta n_{e}=\frac{\Delta S}{\left(1+S^{(0)}\right)^{2}}=2 \frac{<E^{(0)} \Delta E>}{I_{\delta}\left(1+S^{(0)}\right)^{2}}
$$

com $<>$ representando a média temporal, $E^{(0)}$ o campo elétrico de ordem zero e $\Delta E$ o campo de todas as outras ordens. Então, até a primeira ordem em $\Delta E$ a equação de onda (4.31) se escreve:

$$
\left\{\nabla^{2} E+\left(\frac{\omega}{c}\right)^{2}\left(\eta^{2}+\chi_{o}+n_{e}^{(o)} \chi_{N L}\right) E\right\}+\left[\left(\frac{\omega}{c}\right)^{2} \chi_{N L} \Delta n_{e} E^{(o)}\right]=0
$$


Os termos até os coeficientes $C$ 's em (4.36) são provenientes da parte entre chaves na equação acima e os termos em $D_{p m}^{ \pm}(E)$ são originados da parte em colchetes. Quando as intensidades de ordem zero $\left(I_{o}^{+}\right.$e $\left.I_{o}^{-}\right)$são diferentes cada $D_{p m}^{ \pm}$é uma expressão relativamente grande incluindo algumas somas nos coeficientes $C$. Por outro lado, se uma das intensidades for muito menor do que a outra os $D_{p m}^{ \pm}(E)$ simplificarm bastante e sua contribuição mais importante só afeta os termos de ordem superior $(p \geq 1)$. Isto é devido ao fato de que nesta aproximação $\left(S_{1}<<S_{o}\right)$ os termos de ordem zero $A_{o}^{+}$e $A_{o}^{-}$ não se misturam com os de ordem superior porque estes últimos são muito menores. Sendo este o caso, para $I_{o}^{-}<<I_{o}^{+}$tem-se:

$$
\begin{aligned}
& D_{p m}^{+}(E) \simeq \frac{S_{o}}{1+S_{o}} B_{m-p} A_{m}^{+} e^{i(p-m) \Delta \phi} ; \quad \ell \geq 1 \\
& D_{p m}^{-}(E) \simeq \frac{S_{o}}{1+S_{o}} B_{p-m} A_{m}^{-} e^{i(m-p) \Delta \phi} ; \quad \ell \geq 1
\end{aligned}
$$

com os $B$ 's dados por (4.27) que são:

$$
B_{n}=(-1)^{n}\left(1+S_{0}\right)^{-1}\left[\frac{S_{1}}{2\left(1+S_{0}\right)}\right]^{|n|}
$$

